\title{
Determination of fungal gene expression in planta by qRT-PCR and characterization of putative pathogenicity related genes of Verticillium longisporum
}

\author{
Dissertation \\ zur Erlangung des Doktorgrades \\ der Fakultät für Agrarwissenschaften \\ der Georg-August Universität Göttingen
}

vorgelegt von Hai Quan Xu

geboren in Jiangsu

Göttingen im September 2010 
1. Referent:

Prof. Dr. Petr Karlovsky

2. Korreferent:

Prof. Dr. Andreas von Tiedemann

Tag der mündlichen Prüfung: 16. 02. 2011 


\section{Contents}

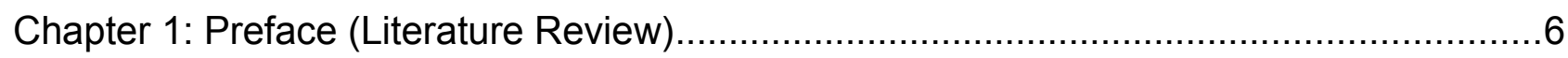

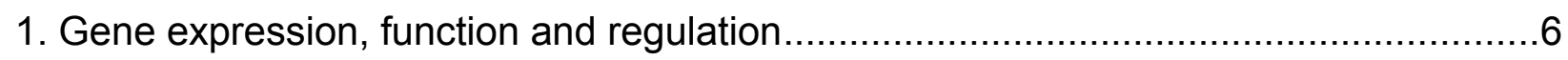

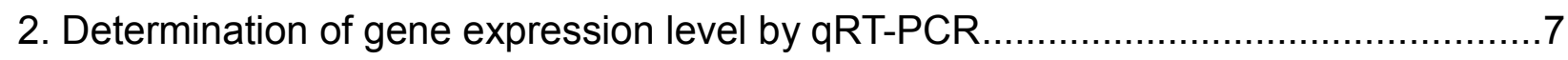

3. Transcriptome profiling after Verticillium infection.................................................

3.1. Transcriptome profiling by cDNA-AFLP .......................................................

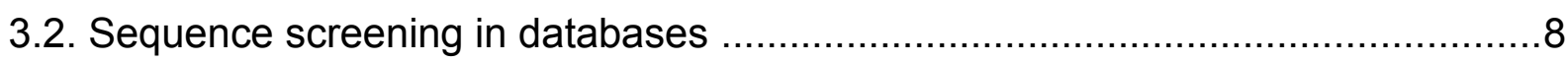

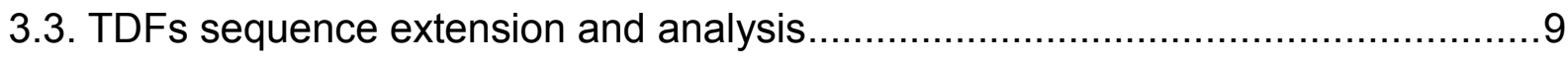

4. Antisense RNA and RNAi mediated gene silencing..........................................10

5. Green fluorescent protein (GFP) as reporter gene.............................................11

6. The oilseed rape phytopathogen $V$. longisporum .................................................12

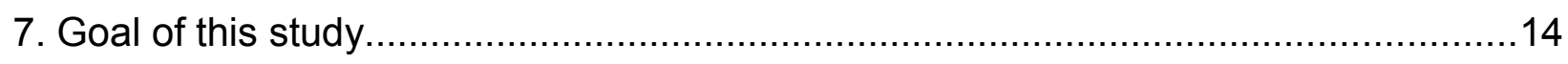

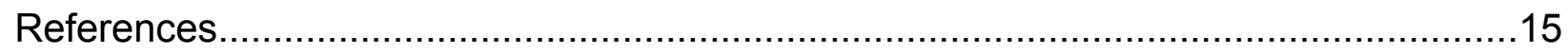

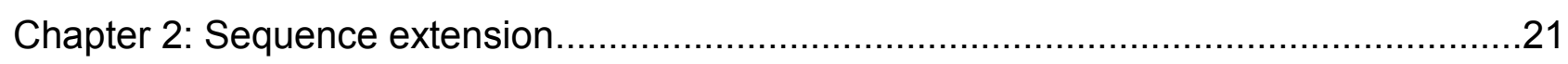

2.1. PCR based methods for sequence extension of TDFs after CDNA-AFLP screening

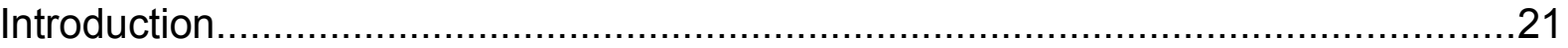

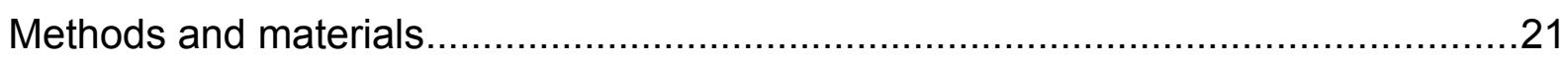

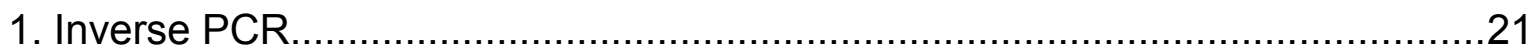

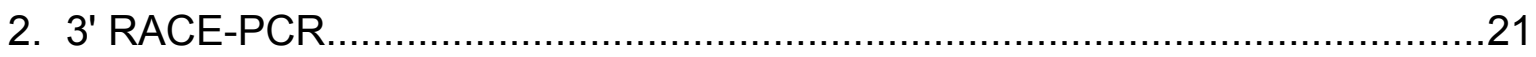

3. PCR-amplicons using primers based on sequences of related species...........23

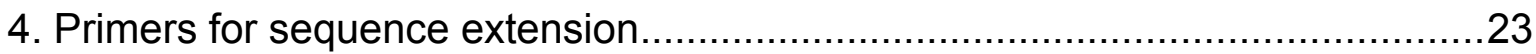

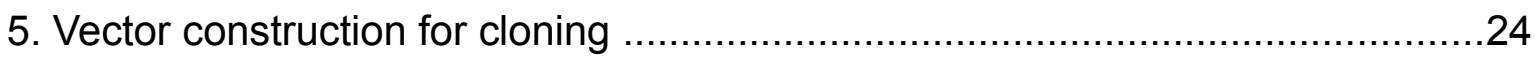

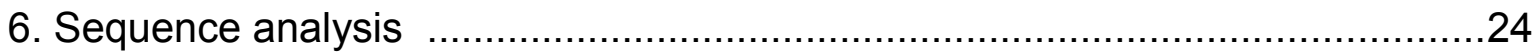

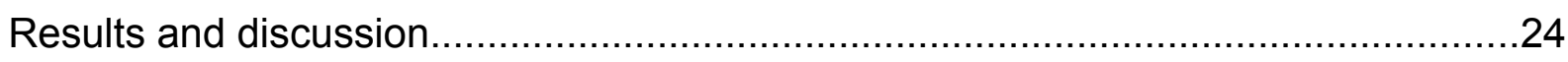

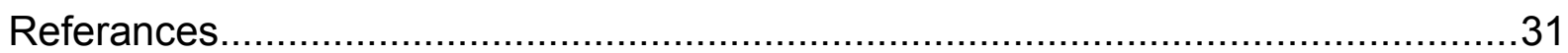

2.2. Generating a genomic DNA library with microtiter plate monitoring for sequence

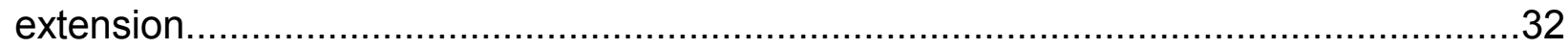

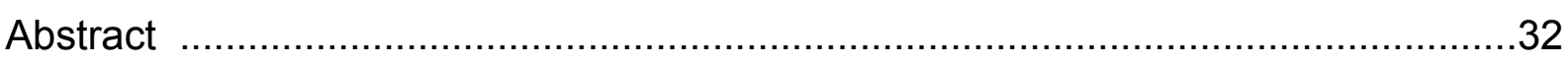




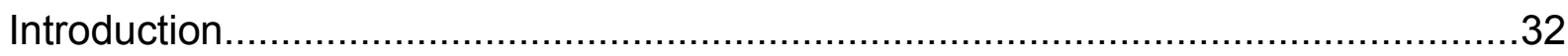

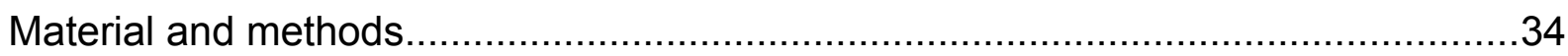

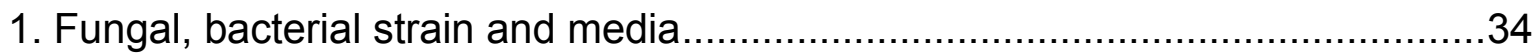

2. Preparation of the electroporation competent cells..........................................34

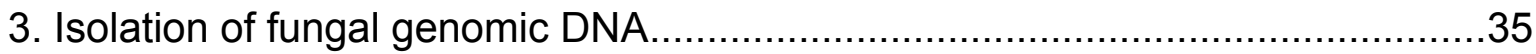

4. Partial digestion of gDNA with Sau3Al and isolation of target fragments ..........36

5. Preparation of standard plasmid pUC57 as vector .........................................37

6. Transformation and monitoring in 96-well microtiter plate.................................37

7. Polymerase chain reaction and designed primers for target genes....................37

8. Procedure of screening and identification..........................................................39

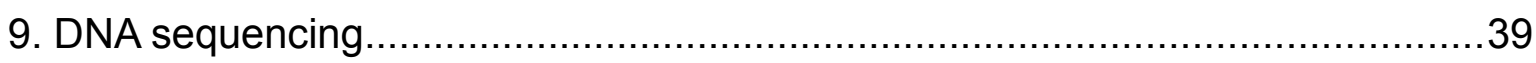

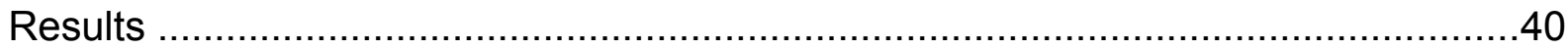

1. Plate monitoring and a rapid procedure for colony identification .......................40

2. Detection of target genes from the genomic library .........................................40

3. Analysis and characterisation of VI_6.2 gene ……………………...............40

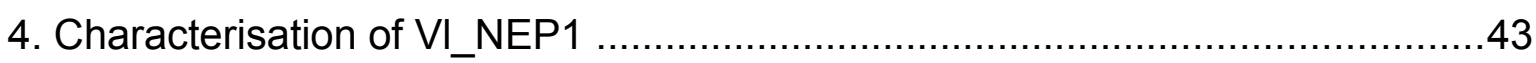

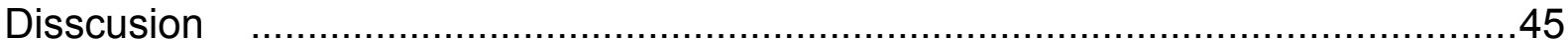

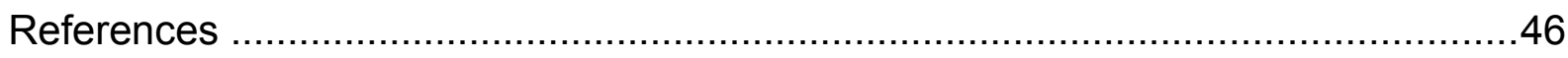

Chapter 3: Determination of in planta gene expression by qRT-PCR .............................49

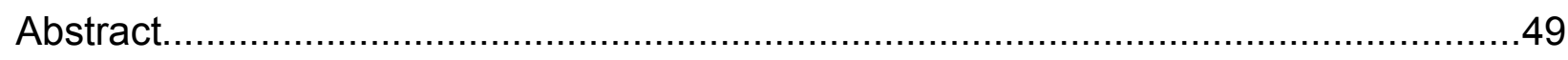

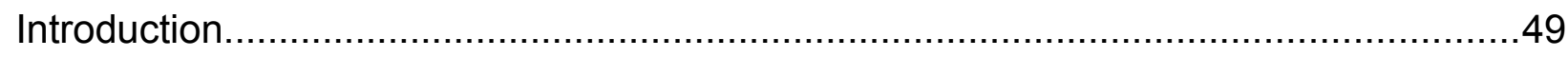

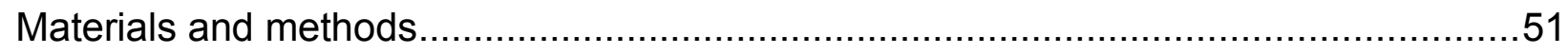

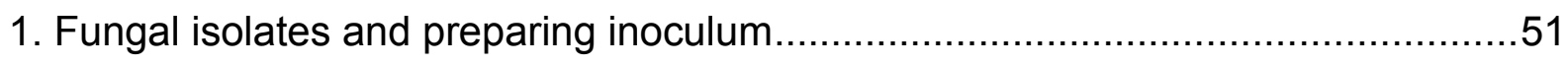

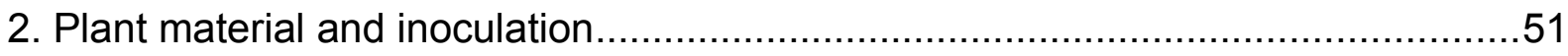

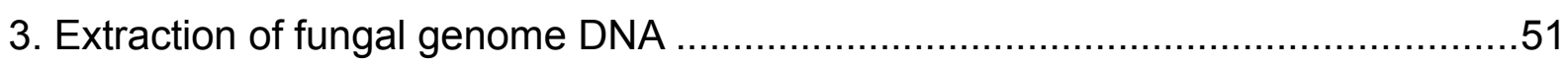

4. Quantification of fungal DNA in planta tissue by qRT-PCR ...............................52

5. Total RNA extraction, mRNA purification and synthase of cDNA ….....................52

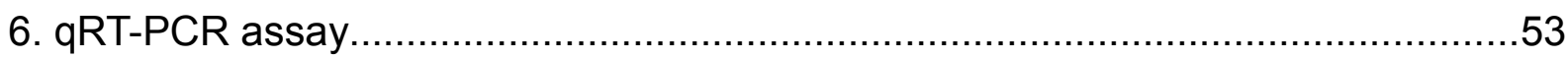

7. Primers used in qRT-PCR

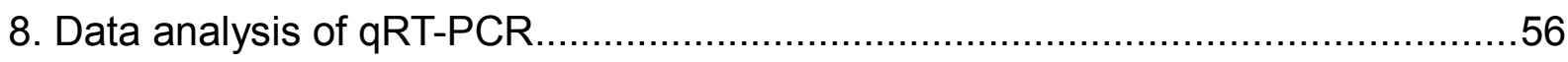


Results and discussion.

1. Relative gene expression of putative pathogenicity related genes in planta.........57

2. Establishment of in planta qRT-PCR and selection of primers .59

References.

Chapter 4: A potential pathogenicity related gene VI_6.2 from Verticillium longisporum and its role in cell-wall integrity 65

Abstract. .65

Introduction. 66

Materials and Methods. 67

1. Bacterial strains. 67

2. Fungal isolates and Preparation of fungal inoculum for plant infection. 67

3. Plant material, inoculation, cultivation and assessment of disease development. .68

4. Genomic DNA extraction and checking the quality and quantity of DNA. 69

5. Total RNA extraction, measurement and mRNA purification. 69

6. Primers of VI_6.2 gene for quantitative RT-PCR. 70

7. Determination of in planta gene expression by qRT-PCR for $V$. longisporum.......70

8. Generation of a genomic library .71

9. Construction of binary Vector with antisense fragment in vitro. 71

10. Agrobaterium-mediated fungal transformation of $V$. longisporum. .73

11. In vitro gene expression using qRT-PCR .74

12. In vitro test with detergents 74

Results .75

1. Isolation and characterisation of VI_6.2 gene containing putative WSC domains..75

2. Differential silencing effect of VI_6.2 gene in vitro mediated by antisense RNA ...77

3. Pathogenicity test of VI_6.2 gene silenced mutants in planta. .77

4. Growth inhibition assay with VI_6.2 gene silenced mutants with detergents. .80

5. Growth inhibition assay with VI_6.2 gene silenced mutants with different pH-value

6. Growth assay of VI_6.2 gene silenced mutants with Trichoderma species .82

Discussion. 83 
References

Chapter 5: Identification and characterisation of a ACE1-like gene VI_12.1 of Verticillium

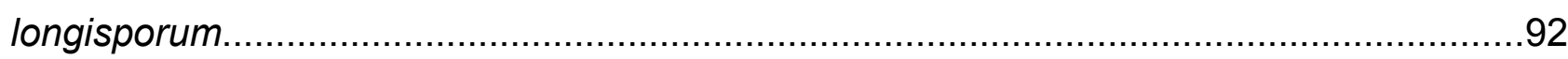

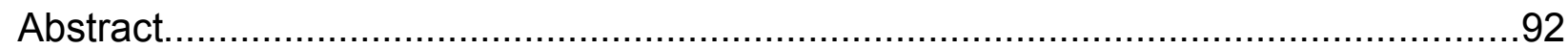

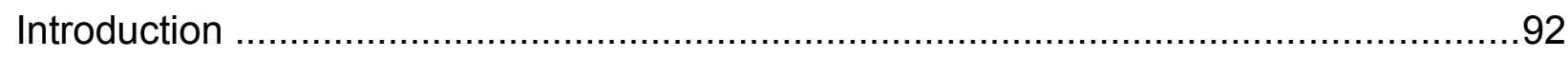

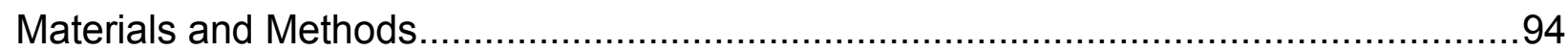

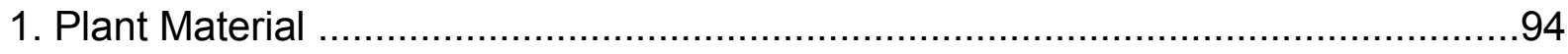

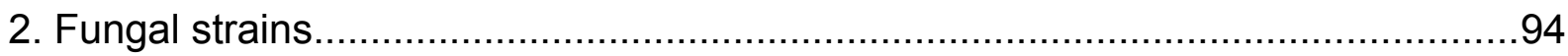

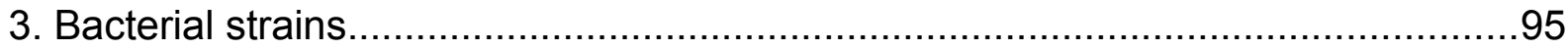

4. Determination of gene expression in vitro and in planta by qRT-PCR .................95

5. Construction of the binary vector pPK2-RNAi-Hairpin-VI_12.1 .........................96

6. Agrobacterium-mediated transformation for knock-down of ACE1-like VI_12.1....97

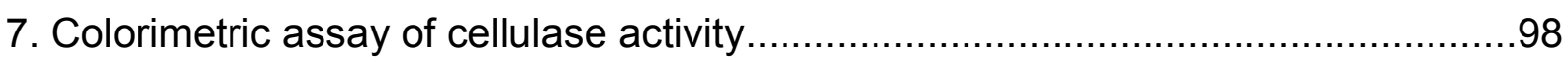

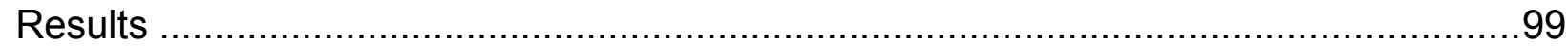

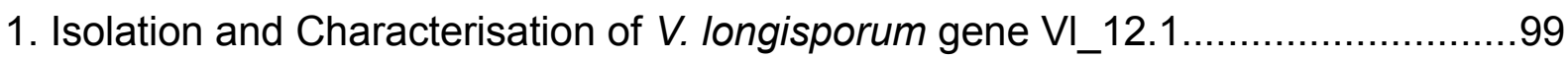

2. Generation and characterisation of VI_12.1 silenced mutants.......................102

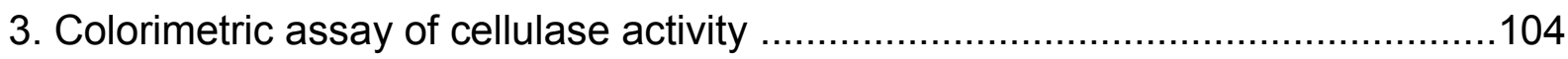

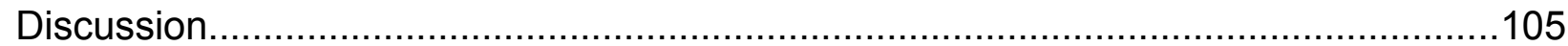

1. $\mathrm{C} 2 \mathrm{H} 2$-Zinc finger as a interaction modular for ACE1 and its homologue in VL....105

2. ACE1-like gene VI_12.1 related with pathogenesis ..................................106

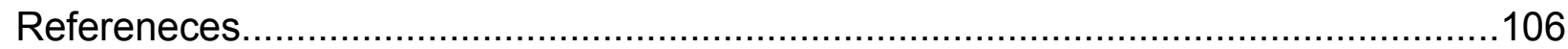

Chapter 6: A putative VI_PKS1 gene involved in melanistic process.........................113

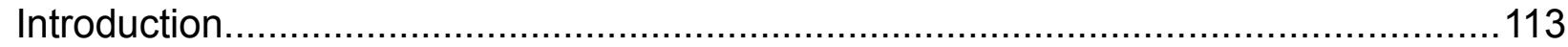

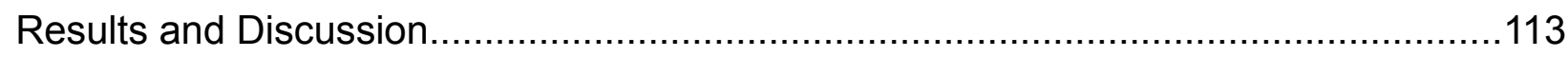

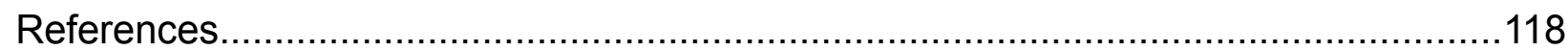

Chapter 7: Labeling V. Iongisporum with GFP and its derivatives.............................120

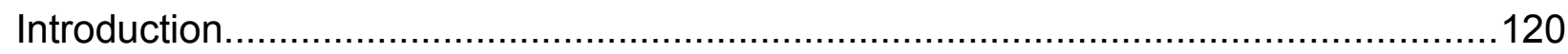

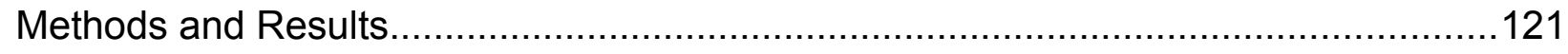

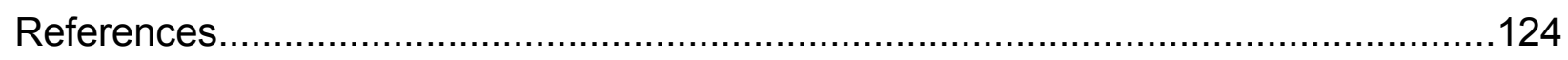

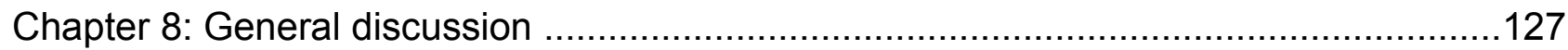




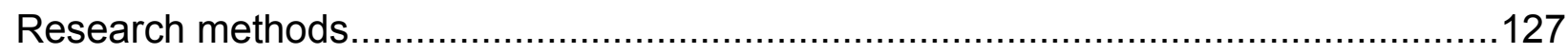

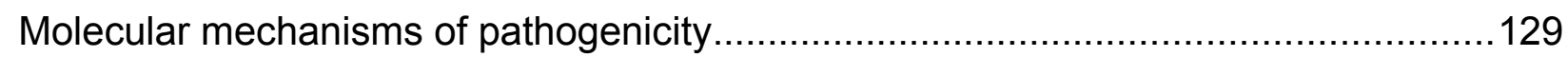

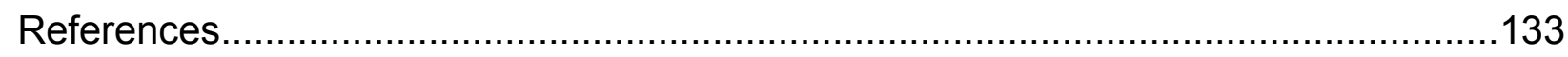

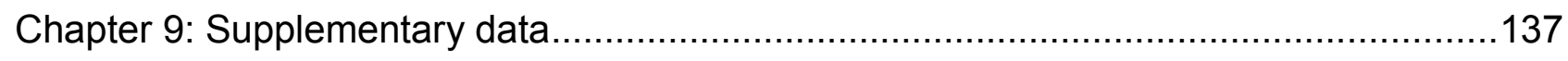

Extended DNA and amino acid sequences of genes and proteins of $V$. longisporum .137

1). VI_6.2 gene (Hypothetical protein including 4 WSC binding domains)..........137

2). VI_2.1 gene (Isochorismate hydrolase) ....................................................139

3). VI_11.1 gene (Peroxidase/Catalase).....................................................139

4). VI_12.1 (VI_10.2) gene (Zinc-finger transcription factor ace1) ......................140

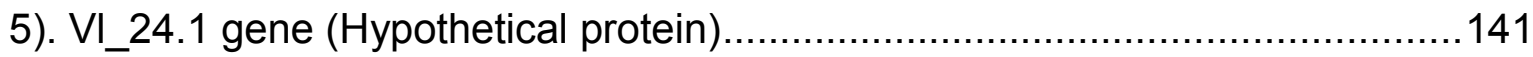

6). VI_25.8 gene (IBR finger domain- containing protein)...............................141

7). VI_33.3 gene (DOA4-independent degradation protein)..............................142

8). VI_34.2 gene (NADH:ubiquinone oxidoreductase 14kD subunit) .................142

9). VI_NEP1 (Necrosis- and ethylene-inducing protein).....................................142

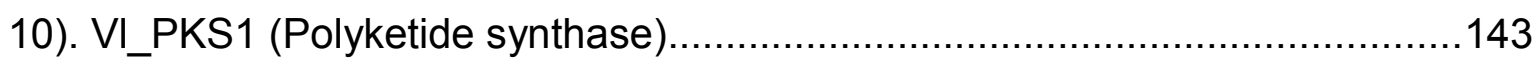

11). VI_12.2 gene (Hypothetical protein) ....................................................... 144

Presentations at national and international conferences...........................................145

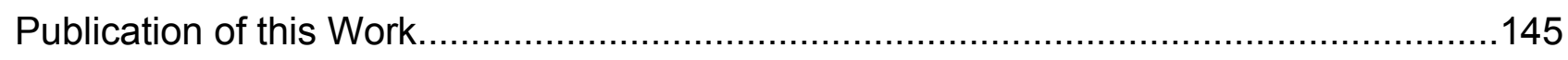

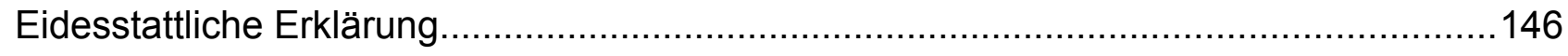

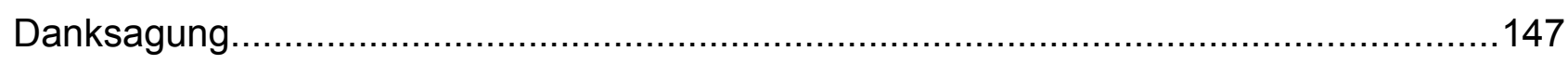

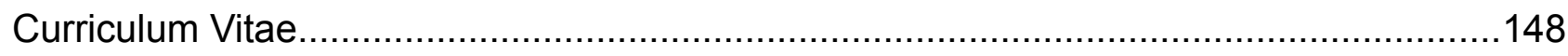




\section{Chapter 1: Preface (Literature Review)}

\section{Gene expression, function and regulation}

"Understanding gene function is the key to understanding disease" (Oxford Centre for Gene Function). Analysis of gene expression, function and regulation presently are essential for the phytopathogical research, and is of increasing significance in the development of possible treatments. Gene expression (Figure 1) involves the synthesis of functional gene products like RNA and protein which is responsible for the development and function of all organisms and give rise to its phenotype.

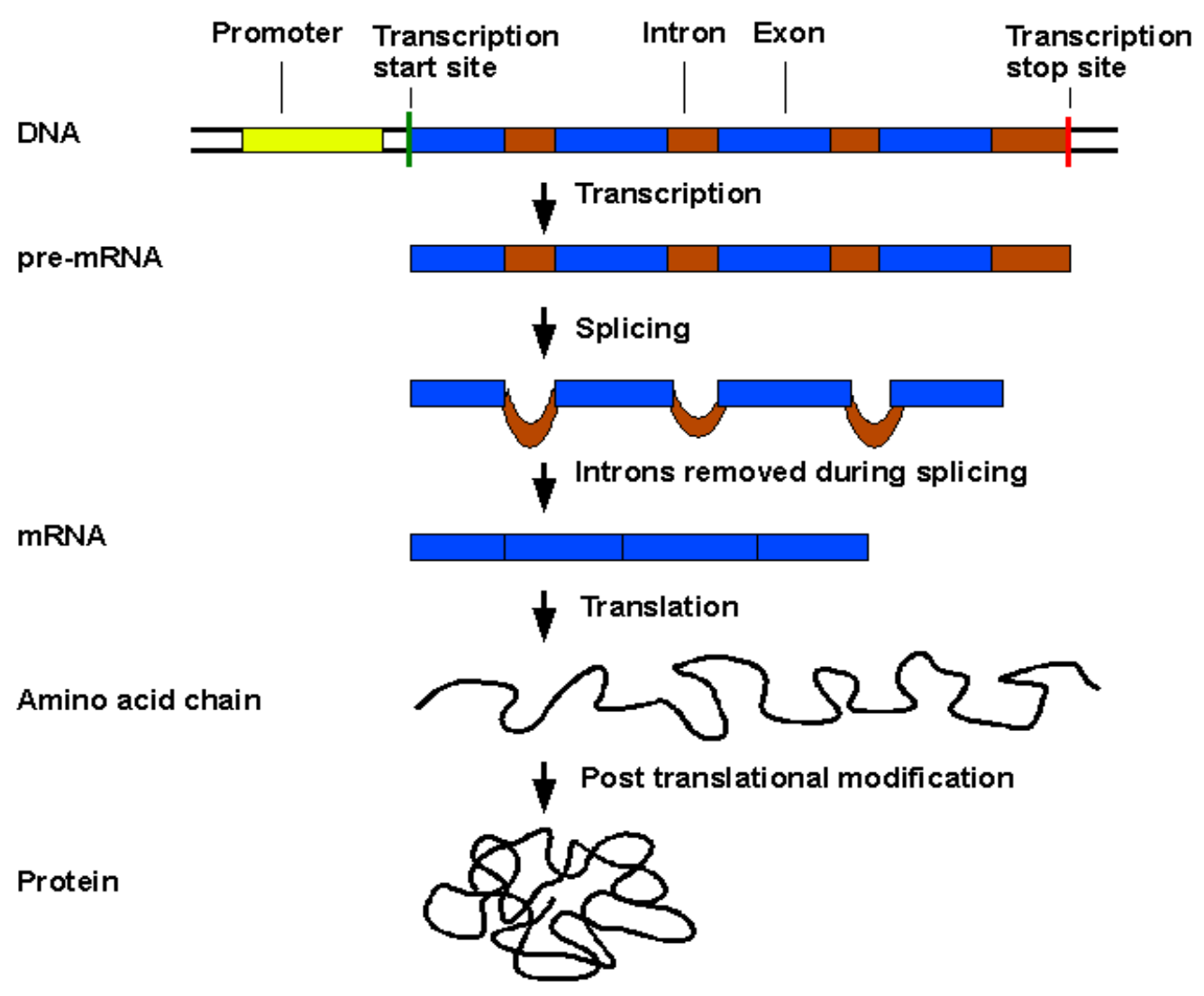

Figure 1: Gene expression Process in higher organisms (http://www.newsmedical.net/health/What-is-Gene-Expression.aspx). The gene expression process modulates possible in several steps, including the transcription, RNA splicing, translation, and post-translational modification of a protein.

Gene regulation may control the cellular differentiation, cell growth, timing, location, and amount of gene expression etc. In this work, we demonstrated RNA based antisense and 
interference gene knock-down, and GFP (Green Fluorescent Protein) based report gene fusion to determinate the expression, function and regulation of some putative pathogenicity related genes of Verticillium longisporum.

\section{Determination of gene expression level by qRT-PCR}

The polymerase reaction first described by Kleppe and co-workers in 1971 (1) and developed by Kary Mullis into the polymerase chain reaction (PCR) 1983 (2) allows a short DNA sequence to be amplified many times by enzymatic replication therefore the name chain reaction". Today, PCR is thanks to its simplicity widely practised in many organism related areas and for many different applications (3, 4), Which include cloning, sequencing, gene functional analysis and the diseases diagnosis (5). However, the exponential nature of DNA amplification is prone to change the experimental data with significant standard errors because of variable amplification efficiently in the different tubes (6).

The Quantitative Real-Time Reverse Transkriptase PCR (qRT-PCR) was therefore developed to measure the amount of PCR products using fluorescent dye, such as SYBR Green (7), EvaGreen (8) in real time. Then the starting cDNA or RNA of gene expression can be calculated quantitatively in regression. We optimised a procedure in this study for determination in planta fungal gene expression and to characterise the gene silenced mutant strains by qRT-PCR.

\section{Transcriptome profiling after Verticillium infection}

\subsection{Transcriptome profiling by cDNA-AFLP}

The transcriptome screening reflects gene expression variation due to external environmental conditions, it includes all mRNA transcripts which are being actively expressed at any given condition. Recently DNA microarrays have become the standard tool for genome expression analysis with full-sequence information. A cDNA-AFLP based transcript screening method can allow the same analysis without prior sequence knowledge. The metabolites in xylem vessels of host plant rapes were used as elicitor for fungel cultivation in vitro for CDNA-AFLP technique based, pathogenicity related transcriptome monitoring (Arne Weiberg 2008). A comparison between treatment with xylem sap from healthy plants and from infected plant gave us a map of a difference of 
transcript-derived fragments (TDFs) (Figure 2). An analysis of those TDFs, which were changed especially under induction treatment with xylem sap of Brassica napus, was planned as next step.

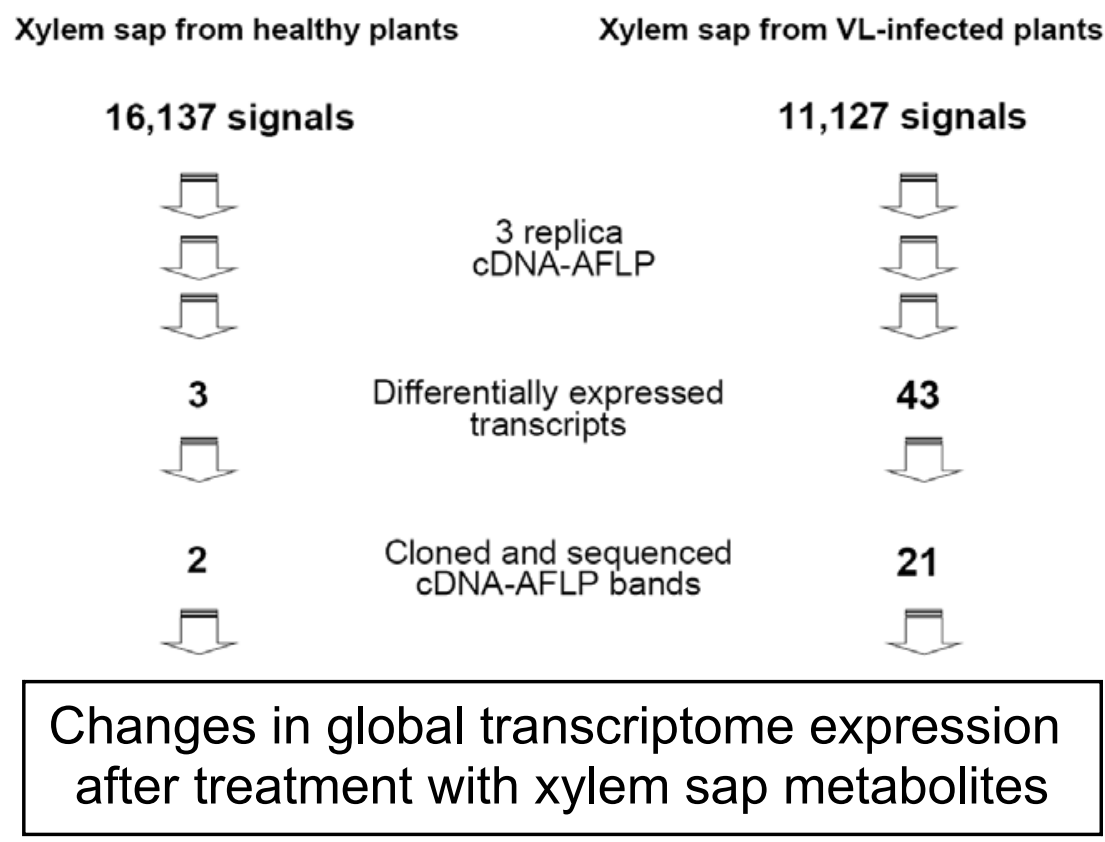

Figure 2: Verticillium transcriptome profiling (modified after A. Weiberg 2008). The left line is treated with xylem sap of healthy plants, and the right line is treated with xylem sap of V.longisporum-infected plants. The general profiling procedure separated in three steps: 1. cDNA-AFLP (3 replica); 2. Differentially expressed transcripts; 3. Cloned and sequenced cDNA-AFLP bands.

\subsection{Sequence screening in databases}

Recent electronic databases proliferate the huge amount of cDNA and genomic sequences of the biological organisms. One way to obtain full-length cDNA sequences, which contain the profiled hit TDFs, is to screen the short TDF sequences (with average length $82 \mathrm{bp}$ ) using databases correlated with blast search tools. In this case we used Verticillium group database (Broad Institute, Massachusetts, United States) and NCBI (National Centre for Biotechnology Information) Genbank databases. As a result, it was only possible in some cases to obtain the several similar cDNA sequences from the related species. For an improvement of the reliability of blast search in databases and a further characterisation of the TDFs related genes, the sequence extension of the short TDFs was necessary. 


\subsection{TDFs sequence extension and analysis}

Rapid amplification of cDNA-ends with Polymerase Chain Reaction (RACE-PCR) is a modification of reverse transcription PCR (RT-PCR) and a practical technique to obtain full-length cDNA sequences. It is used to amplify sequences between a characterized region in the mRNA (cDNA) for example by cDNA-AFLP screening and anchor or adapter sequence that is paired to the $5^{\prime}$ or $3^{\prime}$ end (9). Inverse Polymerase Chain Reaction (IPCR) (10) is another method for amplifying unknown cDNA or genomic DNA regions (11). This method can amplify DNA sequences of a flanking regions rapidly near the known sequence. These PCR based methods are quite variable from one transcript hit to another and do not always produce successful results. An another method is to generate a genomic library for sequence extension but this is time-consuming and then is used as a second alternative .

There are two types of DNA libraries for an organism, genomic library and cDNA library. A genomic library is a collection of clones constructed of randomly generated overlapping DNA fragments which represent the complete genome of an organism, and the cDNA library contains only complementary DNA molecules synthesized from all mRNA molecules. To generate a cDNA library, the total mRNA is isolated from the organism of interest. For eukaryotes, whose mRNAs bind a poly-A tail, their cDNAs can be synthesized easily with the enzyme reverse transcriptase and changed into double-stranded DNA molecules by DNA polymerase. Then they are completely inserted into standard vectors and cloned. For generation of a genomic DNA library, the genomic DNA is fragmented, for example digested with a "four cutter" restriction enzyme, and then it is inserted into a plasmid or phage vector. The number of clones that are generated to form a genomic library depends on the size of the genome and the size of insert. More than 50 fungi have been sequenced including human and plant pathogens. With the recent genomic information we know a fungal genome is about $1 \sim 4 \times 10^{7} \mathrm{bp}$ long, if a plasmid or a phage vector can carry up to $10 \mathrm{~kb}$ fragment, this would require $1 \sim 4 \times 10^{3}$ recombinant plasmids or phages. However a bacterial phage has been described, which can take a fragment with a relative large size as insert. Generally the work with RNA is more sensitive and expensive than DNA.

Bioinformatic databases and tools (12) are an essential component of molecular biology nowadays. The first bioinformatic/biological databases were constructed during the first 
protein sequencing, which was bovine insulin consisting of 51 residues and reported in 1956. A few years later, the first nucleic acid sequence of yeast alanine tRNA with 77 bases was published. Dayhoff collected all the available sequence data and created the first bioinformatic database a year later. The Phage $\Phi-X 174$ was sequenced in 1977, since then many genome sequences have been decoded and saved in databases. The Protein Data_Bank followed in 1972 and the Swiss-Prot protein sequence database began in 1987. These development allows scientists to face a growing challenge for sequence analysis, such as genome annotation, gene expression, gene regulation, protein expression, genomics etc. We applied different methods to screen hits of TDFs in databases, to extent DNA sequence of TDFs and used the analysed results as basis for further characterisation.

\section{Antisense RNA and RNAi mediated gene silencing}

Gene regulation in the cell is controlled at either the transcriptional or post-transcriptional level which achieves respectively via histone modification to inhibit transcriptional machinery such transcription factor, RNA polymerase etc. or via construction of doublestranded RNA to destruct target messenger RNA. Within a cell the single-strand sequence messenger RNA can be translated into a polypeptide, therefore it names "sense-strand" and its complementary strand names "antisense strand". Gene regulation at posttranscriptional level depends on two important aspects of RNA function, antisense-RNA regulation and RNA interference (RNAi).

The natural antisense-RNAs were found independently by Tomizawas and Nordströms research groups in 1981, they reported that small plasmid-encoded RNA regulators respectively control the copy numbers of the Escherichia coli plasmids ColE1 and R1 (13, 14). The phenomenon of clear antisense-RNA regulation was first discovered by scientists in the Netherlands (15). they found some diluted deep color flowers in plant pegunia after intergration in pegunia genome with a chalcone synthase gene in antisense direction. The chalcone synthase gene plays a key roll for flower pigmentation. This discovery was used for producing the first genetically engineered food tomato "Flavr Savr", which was intergrated a tomato gene in tomato genome in antisense direction by the company Calgene in Californian, and submitted to the U.S. Food and Drug Administration (FDA) in 1992 (16). The used tomato gene is polygalacturonase which can degrade cell wall component pectin to make tomato more susceptible to be infected by fungal pathogen, 
when the antisense gene is expressed in tomato cell, the tomato's susceptible process can be postphoned (17). The antisense-RNA regulation was fund in all three biological kingdoms later $(18,19)$.

A revolutionary observation of gene silencing in plant attracted many scientists around the world especially in the area of Caenorhabditis elegans research (20). In 1998, Craig C. Mello and Andrew Fire reported that double stranded RNA has a catalytic or amplification component in the gene expression interference process. They injected a few molecules of double stranded RNA into $C$. elegans and found a powerful gene silencing effect, neither mRNA nor antisense RNA injections had a similar effect on protein production (21). They were awarded the Nobel Prize in Physiology or Medicine in 2006 for their research (22).

Mechanism of RNAi basis on an immune-like system in an organism. only single-strand RNA molecules exist in the cytoplasm of the cell. They are cut by a Dicer enzyme into small fragments of 21-23 base pairs called small interfering RNAs (siRNAs). One of the RNA pair strands is the antisense strand, which can bind to a complementary sense sequence on mRNA and silence the function of the related gene. The complex of siRNA and protein is called the "RNA-induced silencing complex" (RISC) (23). There is a growing indication that siRNAs can also inhibit the transcription of genes (24).

RNAi is a potential tool in molecular biology which can be used in many areas. In plants, Nature reported that RNAi was used as a tool for producing decaffeinated coffee plants (25). Nature Biotechnology carried a report that a transgenic corn plant expressed a insect "western corn rootworm" inhibiting dsRNA when the plant was eaten by its pest, the dsRNA could inhibit the synthesis of an enzyme from the pest and control it (26). RNAi's target so specifically, it may be possible to use in human therapy. Currently there are trials using siRNA molecules in the clinical treatment to many different diseases (27). We used both methods, antisense-RNA regulation and RNAi, to generate target gene silenced strains for $V$. longisporum gene function analysis.

\section{Green fluorescent protein (GFP) as reporter gene}

The GFP from the jellyfish Aequorea victoria, is a protein composed of 238 amino acid residues $(26.9 \mathrm{kDa})$, which exhibits green fluorescence under excitation by blue light (28, 29). Shimomura researched Aequorea victoria successfully in 1962 (30), Chalfie and his co-workers published their results in 1994 about Green fluorescent protein used as a 
marker for gene expression in Escherichia coli (31). together with Roger Y. Tsien (32) they awarded the 2008 Nobel Prize in chemistry for their discovery and development of the green fluorescent protein. The idea to use GFP as a tracer molecule was got first by Douglas Prasher in 1987, he envisioned that it would be possible to use biomolecular techniques to insert the GFP gene at the end of the hemoglobin gene, right before the stop codon (33). As a result, the cell would produce a hemoglobin molecule with a GFP attached to it (Figure 3). Today the GFP is often introduced into organisms and integrated in their genome by transformation as a reporter gene in molecular biology $(34,35)$. Heterologous expression of GFP was first accomplished in Escherichia coli and Caenorhabditis elegans (36), and then also in many fungi (37), although GFP constructs were not always stable expression, Different forms of GFP controlled by constitutive or inducible fungal promoters or Neurospora-GFP fusion proteins were tried but not found to be expressed at levels required for imaging (38). Two new binary vectors each for promoter and gene fusion were constructed in this study.
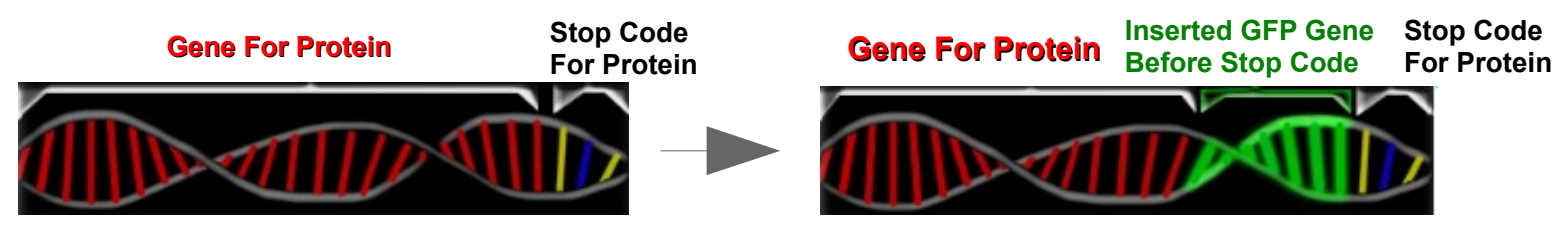

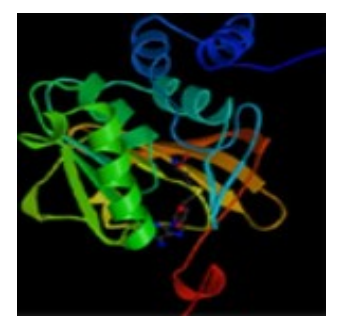

Protein

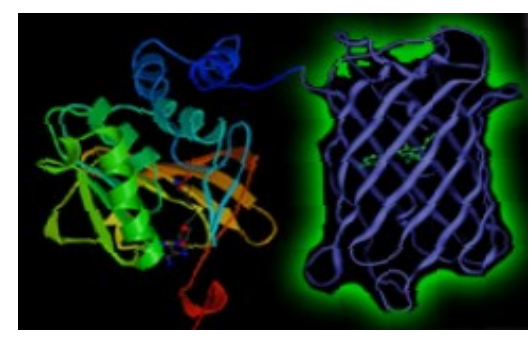

Protein with GFP

Figure 3: Model for GFP expression after Douglas Prasher's Idea [Pictures modified according to Marc Zimmer (39)]

\section{The oilseed rape phytopathogen $V$. longisporum}

Verticillium wilt is one of the most important disease causing economic losses in oilseed rape (Brassica napus spp. Oleifera). The occurrence is increasing in northern Europe (40, $41,42,43)$. This pathogenic disease is caused by the soil-borne, host-specific, vascular, and "near-diploid" fungal phytopathogen V. longisporum comb. Nov (44, 45), which was first reported by Isaac in 1957 and Stark in 1961. The morphology of $V$. longisporum is 
very similar to two other important phytopathogen $V$. dahliae and $V$. albo-atrum with a small difference in the length of spores (46). These findings lead to the suggestion of a new subspecies $V$. dahliae f. sp.longisporum.

$V$. longisporum enters through the roots by direct penetration of the epidermal cells or through open wounds (47). The conidia enter the vascular system, move upwards in to the xylem vessels, Typical symptoms on oilseed rape are premature ripening and stunting under greenhouse conditions (Figure 4). Because of its systemically infection, fungicides for direct control of the disease have little effect on host plants infected by the pathogen, and micro-sclerotia can survive 10-15 years in the soil. Control of Verticillium wilt is particularly difficult. The knowledge of the pathogenicity related genes involved in the V.longisporum may benefit for the development of resistant plant varieties.

Molecular mechanisms through all stages of Verticillium differentiation are still unclear. It is not known how the fungus expresses its pathogenicity and which virulence factors are involved specifically during the parasitic phase. Investigation of the parasitic phase of Verticillium via functional and comparative genomics, transcriptomics, proteomics and metabolomics can bring an useful output to explain the pathogen-host interaction, and may provide helpful informations for developing resistant plants or new control strategies. Recently Verticillium has become a model-system for phytopathology research. In Verticillium genus species such as V. dahliae, V. albo-atrum, V. longisporum and $V$. tricorpus etc. are economic very important. Among them a comparative genome project of V. dahliae and V. albo-atrum was started by the NSF/USDA Microbial Genome Sequencing Program under collaboration with the Broad Institute in 2004 and V. dahliae's complete mitochondrial genome was sequenced in 2006 (48), Genomic DNA and complementary DNA (cDNA) free accessible growing sequence informations allowed the scientists to progress their research in Alignment, Taxonomy, Phylogeny and Motif finding etc. within Verticillium and its related species $(45,49,50,51,52,53)$. Verticillium Gene functional analysis improved to understand the biological development and pathogenesis. Meantime some individual genes of Verticillium have been studied, such as a necrosis and ethylene inducing peptide (Vd_NEP) (54), a trypsin protease (50), a mitogen-activated MAP kinase (55), a hydrophobin (56) etc.. 


\section{Goal of this study}

In this study, we try to get to know more about function of some candidate genes of V.longisporum. With different methods RACE-PCR (rapid amplification of CDNA-ends with polymerase chain reaction), inverse PCR on self circularized genomic DNA, creating a genomic library and direct cloning with primers on the basis of $V$. dahliae to produce fulllength sequences of candidate Transcript-derived Fragments (TDFs) after cDNA-AFLP screening.

A genome library of $V$. longisporum was constructed and hierarchical pools of clones was prepared for fast PCR-based screening. These resource allowed us to identify library clones carrying full-length genomic copy of candidate genes (58). In addition to candidate genes identified by cDNA-AFLP further genes of potential interest were selected based on published reports on a related species $V$. dahlie and other pathogenic fungi for transcription analysis in planta and other investigations (54). The real-time RT-PCR procedure on the basis of RNA from roots and shoots of Brassica napus was established and optimized. Genes found by cDNA-AFLP to be affected by xylem sap in vitro were investigated in planta using the quantitative real-time RT-PCR. To resolve the pattern of gene expression in space and time, selected candidate genes were fused with reporter genes $(59,60,61)$. Some of them were overexpressed and inactivated to learn more about the role of the genes in pathogenicity (62).

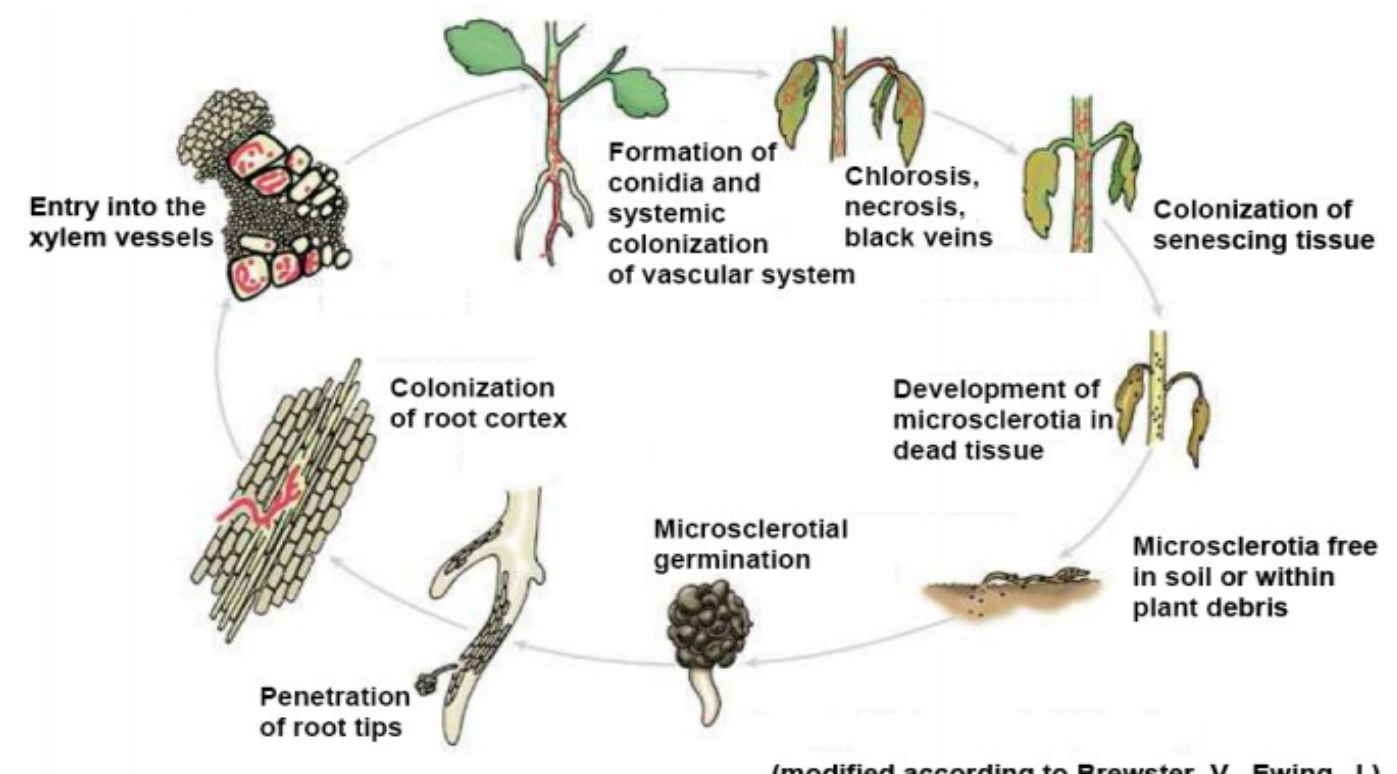

Figure 4: Monocyclic Verticillium wilt disease and microsclertia-producing Modified according to Rowe and Powelson (55). 


\section{References}

1. Kleppe, K., Ohtsuka, E., Kleppe, R., Molineux, I. \& Khorana, H.G. (1971). Studies on polynucleotides. XCVI. Repair replications of short synthetic DNA's as catalysed by DNA polymerases. J. Mol. Biol. 56 (2): 341-361.

2. Bartlett, J.M. \& Stirling, D. (2003). A Short History of the Polymerase Chain Reaction. Methods Mol Biol. 226: 3-6

3. Saiki, R.K., Gelfand, D. H., Stoffel, S, Scharf, S. J., Higuchi, R., Horn, G. T., Mullis, K.B. \& Erlich, H. A. (1988). Primer-directed enzymatic amplification of DNA with a thermostable DNA polymerase. Science. 239 (4839): 487-491.

4. Mackay, I. M., Arden, K. E., \& Nitsche, A. (2002). Real-time PCR in virology. Nucleic Acids Res. 30 (6): 1292-1305.

5. Cheng, S., Fockler, C., Barnes, W. M., \& Higuchi, R. (1994). Effective amplification of long targets from cloned inserts and human genomic DNA. Proc Natl Acad Sci. 91(12): 5695-5699.

6. Zachar, V., Thomas, R. A., \& Goustin, A. S. (1993). Absolute quantification of target DNA: a simple competitive PCR for efficient analysis of multiple samples. Nucleic Acids Research. 21(8): 2017-2018.

7. Zipper, H., Brunner, H., Bernhagen, J. \& Vitzthum, F. (2004). Investigations on DNA intercalation and surface binding by SYBR Green I, its structure determination and methodological implications. Nucleic acids research 32 (12): e103.

8. Wang, W. J., Chen, K. S. \& Xu, C. J. (2006). DNA quantification using Eva-Green and a real-time PCR instrument. Analytical Biochemistry. 356(2): 303-305.

9. Frohman, M. A., Dush, M. K. \& Martin, G. R. (1988). Rapid production of full length cDNAs from rare transcripts: amplification using a single gene-specific oligonucleotide primer Proc. Natl Acad. Sci. USA. 85: 8998-9002.

10. Ochman, H., Gerber, A. S. \& Hartl, D. L. (1988). Genetic Application of an Inverse Polymerase Chain Reaction. Genetics. 120: 621-623.

11. Jong, A. Y., T'ang, A., Liu, D. P. \& Huang, S. H. (2002). Inverse PCR. Genomic DNA 
cloning. PCR Cloning Protocols, Second Edition.

12. Hogeweg, P. and Hesper, B. (1978). Interactive instruction on population interactions. Compute Biol Med. 8: 319-327.

13. Tomizawa, J., Itoh, T., Selzer, G., Som, T. (1981). Inhibition of ColE1 RNA primer formation by a plasmid-specified small RNA. Proc. Natl. Acad. Sci. U.S.A. 78: 14211425.

14. Stougaard, P., Molin, S. \& Nordström, K. (1981). RNAs involved in copy-number control and incompatibility of plasmid R1. Proc. Natl. Acad. Sci. U.S.A. 78: 60086012.

15. Van der Krol, A. R., Lenting, P. J., Veenstra, J. G., van der Meer, I. M., Koes, R. E., Gerats, A. G. M., Mol, J. N. M., \& Stuitje, A. R. (1988). An antisense chalcone synthase gene in transgenic plants inhibits flower pigmentation. Nature. 333, 866869.

16. Keith, R., Hiatt, B., Martineau, B., Kramer, M., Sheehy, R., Sanders, R., Houck, C. \& Emlay, D. (1992). Safety Assessment of Genetically Engineered Fruits and Vegetables: A Case Study of the Flavr Savr Tomato. CRC Press. p. 288.

17.Sanders, R.A. \& Hiatt, W. (2005). Tomato transgene structure and silencing. Nat. Biotechnol. Bd. 23: 287-289.

18. Brantl, S. (2002). Antisense-RNA regulation and RNA interference. Biochimica et Biophysica Acta 1575: 15-25.

19. Martens, H. \& Nellen W. Epigenetisches Genesilencing: RNA Interferenz und Antisense RNA. BIOspektrum 4: 351-355.

20. Guo, S. \& Kemphues, K. (1995). par-1, a gene required for establishing polarity in C. elegans embryos, encodes a putative Ser/Thr kinase that is asymmetrically distributed. Cell. 81 (4): 611-620.

21.Fire, A., Xu, S., Montgomery, M., Kostas, S., Driver, S. \& Mello, C. (1998). Potent and specific genetic interference by double-stranded RNA in Caenorhabditis elegans. Nature. 391(6669): 806-811. 
22. Bertil, D. (2007). Advanced Information: RNA interference. The Nobel Prize in Physiology or Medicine 2006.

23. Meister, G. \& Tuschl, T. (2004). Mechanisms of gene silencing by double-stranded RNA, Nature, 431: 343-349

24.Rossi, J.J. (2007). Trancriptional activation by small RNA duplexes. Nature chemical biology. 3: 136-137.

25. Ogita, S., Uefuji, H., Yamaguchi, Y., Koizumi, N.,\& Sano, H. (2003). Producing decaffeinated Coffee Plants. Nature. 423: 823.

26.Pal-Bhadra, M., Bhadra, U. \& Birchler, J. (1997). Cosuppression in Drosophila: gene silencing of Alcohol dehydrogenase by white-Adh transgenes is Polycomb dependent. Cell. 90(3): 479-490.

27. Brower, V. (2010). RNA Interference Advances to Early-Stage Clinical Trials. JNCIJ Natl Cancer Inst. 102(19): 1459-1461.

28. Prendergast, F. \& Mann, K. (1978). Chemical and physical properties of aequorin and the green fluorescent protein isolated from Aequorea forskålea. Biochemistry. 17 (17): 3448-3453.

29. Tsien, R. (1998). The green fluorescent protein (PDF). Annu Rev Biochem. 67: 509-544.

30. Shimomura, O., Johnson, F. \& Saiga, Y. (1962). Extraction, purification and properties of aequorin, a bioluminescent protein from the luminous hydromedusan, Aequorea. J Cell Comp Physiol. 59: 223-239.

31. Chalfie, M., Tu, Y., Euskirchen, G., Ward, W. W. \& Prasher, D. C. (1994). Green fluorescent protein as a marker for gene expression. Science. 263: 802-05.

32. Heim, R., Cubitt, A. \& Tsien, R. Y. (1995). Improved green fluorescence. Nature. 373: 663-664.

33. Phillips, G. (2001). Green fluorescent protein--a bright idea for the study of bacterial protein localization. FEMS Microbiol Lett. 204 (1): 9-18. 
34. Chudakov, D., Lukyanov, S. \& Lukyanov, K. (2005). Fluorescent proteins as a toolkit for in vivo imaging. Trends Biotechnol. 23(12): 605-613.

35. Chalfie, M., Tu, Y., Euskirchen, G., Ward, W. \& Prasher, D. (1994). Green fluorescent protein as a marker for gene expression. Science. 263 (5148): 802-805.

36. Lorang, J.M. et al. (2001). Transformation of other filamentous fungi with pCT74 resulted in GFP expression. Appl. Env. Microbiol. 67:1987.

37.Freitag, M., Ciuffetti, L. M. \& Selker, E. U. (2001). Expression and visualization of Green Fluorescent Protein (GFP) in Neurospora crassa. Fungal Genetics Newsletter. 48: 15-19.

38. Kroeker, G. (1976). Verticillium dahliae on Brassica oil seed crops in Sweden, $2^{\text {nd }}$ International Verticillium Symposium, Berkeley, U.S.A., Abstract, 28-29.

39. http://www.conncoll.edu/ccacad/zimmer/GFP-ww/prasher.html

40.Svenson, C. H. \& Lerenius, C. (1987). An investigation on the effect of Verticillium wilt (Verticillium dahliae Kleb.) on oilseed rape. Working group integrated control in oilseed rap. IOBC/WPRS Bulletin, X/4: 30-34.

41.Krüger, W. (1989). Untersuchungen zur Verbreitung von Verticillium dahliae Kleb. Und anderen Krankheits- und Schaderregern bei Raps in der Bundesrepublik Deutschland. Nachrichtenblatt des Deutschen Pflanzenschutzdienstes, 41: 49-56.

42. Steventon, L. A., Fahleson, J., Hu, Q. \& Dixelius, C. (2002). Identification of the causal agent of Verticillium wilt of winter oilseed rape in Sweden, V. Iongisporum Mycological Research. 106: 5570-5578.

43.Dixelius, C., Happstadius, I., \& Berg, G. (2005). Verticillium wilt on Brassica oil crops- a Swedish perspective. Journal of the Swedish Seed Association. 115: 3648.

44. Karapapa, V. K., Bainbridge, B. W. \& Heale, J. B. (1997). Morphological and molecular haracterization of Verticillium longisporum comb, nov., pathogenic to oilseed rape Mycol. Res. 101 (11): 1281-1294.

45.Zeise, K. \& von Tiedermann, A. (2001). Morphological and physiological 
differentiation among vegetative compatibility groups of Verticillium dahliae and $V$. longisporum. J. Phytopathology. 149: 469-475.

46. Stark, C. (1961). Das Auftreten der Verticillium-Tracheomykosen in Hamburger Gartenbau-Kulturen. Gartenbauwissenschaft. 26: 493-528.

47. Schnathorst, W. C. (1981). Life cycle and epidemiology of Verticillium. In M. E. Mace, A. A. Bell, \& C. H. Beckmann(Eds.), Fungal wilt diseases of plants. 81-111. New York, Academic Press.

48. Pantou M. P., Kouvelis V. N., \& Typas M. A. (2006). The complete mitochondrial genome of the vascular wilt fungus Verticillium dahliae: a novel gene order for Verticillium and a diagnostic tool for species identification. Curr. Genet. 50:125-136.

49. Fahleson J., Lagercrantz U., Hu Q., Steventon L.A. \& Dixelius C. (2003). Estimation of genetic variation among Verticillium isolates using AFLP analysis. Eur. J. Plant Pathol. 109:361-371.

50. Karapapa V. K. \& Typas M. A. (2001). Molecular characterization of the hostadapted pathogen Verticillium longisporum on the basis of a group-I intron found in the nuclear SSU-rRNA gene. Curr. Microbiol. 42:217-224.

51. Kouvelis V. N., Sialakouma A. \& Typas M. A. (2008). Mitochondrial gene sequences alone or combined with ITS region sequences provide firm molecular criteria for the classification of Lecanillium species. Mycol. Res. 112:829-844.

52. http://www.broad.mit.edu/annotation/genome/verticilliumdahliael (visited on September 2010).

53. Neumann M. J. \& Dobinson K. F. (2003). Sequence tag analysis of gene expression during pathogenic growth and microsclerotia development in the vascular wilt pathogen Verticillium dahliae. Fung. Genet. Biol. 38:54-62.

54. Wang J., Cai Y., Gou J., Mao Y., Xu Y., Jiang W., Chen X. (2004). VdNEP, an elicitor from Verticillium dahliae, induces cotton plant wilting. Appl. Environ. Microbiol. 70:4989-4995.

55. Rowe, R. C. \& Powelson, M. L. (2002). Potato Early Dying: Management Challenges in a Changing Production Enviroment. Plant Disease. 86(11): 11841193. 
56. Rauyaree, P., Ospina-Giraldo, M. D., Kang, S., Bhat, R. G., Subbarao, K. V., Grant, S. J. \& Dobinson, K. J. (2005). Mutations in VMK1, a mitogen-activated protein kinase gene, affect microsclerotia formation and pathogenicity in Verticillium dahliae. Curr. Genet. 48:109-116.

57. Klimes, A., Dobinson, K. F. (2006). A hydrophobin gene, VDH1, is involved in microsclerotial development and spore viability in the plant pathogen Verticillium dahliae. Fung. Genet. Biol. 43:283-294.

58. Weiberg, A. (2008). Identifizierung von Xylemsaft-induzierten Genen im vaskulären Pathogen Verticillium longisporum mittels einer verbesserten cDNA-AFLP Methode für transkriptomweite Expressionsstudien. Online Dissertation.

59. Farfsing, J. W. (2004). Regulation des Mais-induzierten mig2-Genclusters in Ustilago maydis. Online Dissertation.

60. Utermark, J. \& Karlovsky, P. (2006). Quantification of green fluorescent protein fluorescence using real-time PCR thermal cycler. Biotechniques 41: 150-154.

61.Eynck, C., Koopmann, B., Grunewaldt, G., Karlovsky, P. \& von Tiedermann, A. (2007). Differential interaction of Verticillium longisporum and $V$. dahliae with Brassica napus detected with molecular and histological techniques. Europ. J. Plant Path. 118: 259-274.

62. Nakayashiki, H., Hanada, S., Nguyen, B. Q., Kadotani, N., Tosa, Y. \& Mayama, S. (2005). RNA silencing as a tool for exploring gene function in ascomycete fungi. Fungal Genet Biol 42: 274-283. 


\section{Chapter 2: Sequence extension}

\subsection{PCR based methods for sequence extension of TDFs after cDNA-AFLP screening}

\section{Introduction}

cDNA-AFLP is a PCR-based genome-wide expression analysis technology which does not require any gene sequence information, after identification of differential expressionscreening to obtain full sequence of a target gene will be expected (1). Some PCR-based methods, Inverse PCR $(2,3,4)$, RACE-PCR (rapid amplification of cDNA-ends with polymerase chain reaction) $(5,6)$, cloning with amplificons using primers designed with DNA sequences from related species and direct sequencing can be used to extend short TDF (Transcript derived Fragment) DNA sequence. Even they were limited in some cases because of technique limitations.

\section{Methods and materials}

\section{Inverse PCR}

Inverse PCR is a variant of polymerase chain reaction method which uses one known DNA sequence to amplify the flanking unknown DNA fragment and described first by Ochman et al in 1988 (2). The template for IPCR is a with restriction fragment self-formed sequence circle after ligation (Figure 1). The primers for IPCR oriented in the reverse direction of the regular orientation. Fungal gemonic DNA of $V$. longisporum was extracted, digested with endo-restriction enzymes EcoRI, BamHI, Xbal, Pstl, Hindlll and Sacl (Fermentas, St. Leon-Rot, Germany), self-ligated with T4 ligase (Fermentas, St. Leon-Rot, Germany) and provided as template for PCR. Inverse gene specific primers were deduced from cDNAAFLP fragment sequences. PCR products were separated on a $1 \%$ agarose gel, extracted from gel with QIAquick Gel Extraction Kit (Qiagen, Germany), sequenced directly or after cloning in standard vector pBluescript KS(+) (Fermentas, St. Leon-Rot, Germany).

\section{3' RACE-PCR}

RACE-PCR (Rapid Amplification of cDNA Ends) sometimes called one-sided PCR, was used to win the full length sequence of an RNA transcript from a small known sequence to 
3' end (3' RACE-PCR) or the 5' end (5' RACE-PCR) (6) (Figure 2). The same protocol was used for CDNA synthesis with RNA as template. Total RNA was extracted and purified with mRMA extraction kit. The polyA tail that exists at the 3 ' end of all eukaryotic mRNAs was applied for designing a reverse Oligo (dT) anchor prime here using (dT) ${ }_{18}$. which was paired with gene specific forward primer from a known sequence within the transcript for amplification. PCR products were separated on a $1.2 \%$ agarose gel, extracted from gel with Qiagen-kit and sequenced.

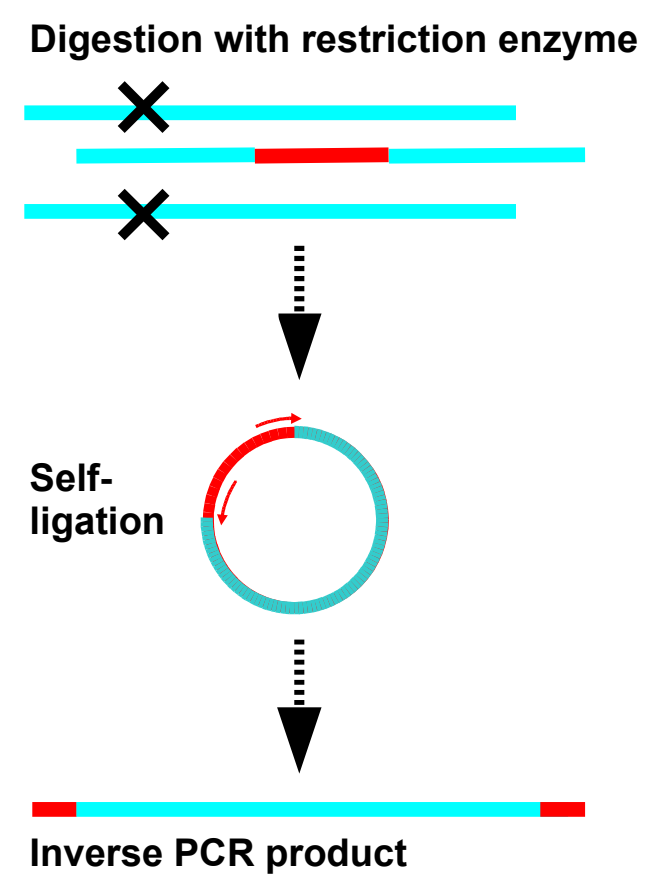

Figure 1: Scheme of IPCR Process. IPCR includes the digestion of genomic DNA, circulation of restricted fragments and using primers designed from the characterized region to amplify unknown flanking sequence by PCR (2).

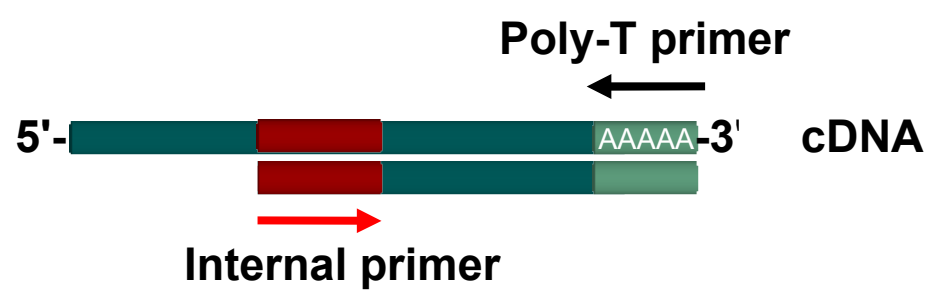

Figure 2: scheme of 3' RACE-PCR Process. All eukaryotic mRNAs exist a polyA tail at the $3^{\prime}$ end. For generating cDNA reverse transcription PCR uses a $3^{\prime}$ end starting Oligo-dTanchor primer which is complementary to $3^{\prime}$ end natural polyA tail. The $3^{\prime}$ end starting Oligo-dT-anchor primer is used then with an characterised $5^{\prime}$ internal sense primer for amplification of a unknown DNA region by PCR that is called 3' RACE-PCR (6). 


\section{PCR-amplicons using primers based on sequences of related species}

V. dahliae and Verticillium albo-altrum are closely related with V. longisporum on genome sequence level (7). Sequences of TDFs were blasted in Verticillium group Database (Broad institute), some target genes with high identity to TDFs were investigated and their gene specific primers deduced through the full-length gene sequences. A direct sequencing without cloning for some sequence regions of target genes VI_6.2, VI_12.1, VI_12.2 and VI_34.2 was applied.

\section{Primers for sequence extension}

Table 1: Primers for cloning and sequencing of target genes after TDFs.

\begin{tabular}{|c|c|c|}
\hline Nr. & Name of primer & Sequence of primer \\
\hline \multirow[t]{2}{*}{1} & TDF2.1_Sdal-F & 5'-ATCGATCCTGCAGGGACTCCTGTTCATCAAATAA-3' \\
\hline & TDF2.1_Notl-R & 5'-ATCGATGCGGCCGCATTGATCATAACGGTAGCAT-3' \\
\hline \multirow[t]{2}{*}{2} & TDF11.1-I_Sdal- & 5'-ATCGATCCTGCAGGTCGCCATACCTCGTCCTGCC-3' \\
\hline & TDF11.1-I_Notl-R & 5'-ATCGATGCGGCCGCGCAAACTGGTCTGGGTTCTC-3' \\
\hline \multirow[t]{2}{*}{3} & TDF11.1-II_Sdal-F & 5'-ATCGATCCTGCAGGTACCTCTTCAAGTACGAGTG-3' \\
\hline & TDF11.1-II_Notl-R & 5'-ATCGATGCGGCCGCGAATACTGGTCCAGTGAAGT-3' \\
\hline \multirow[t]{2}{*}{4} & TDF12.1-I_Sdal-F & 5'-ATCGATCCTGCAGGAATTTGTTCCGCCCACTTCC-3' \\
\hline & TDF12.1-I_NotI-R & 5'-ATCGATGCGGCCGCATCCGTTAGTGTATGGTCGG-3' \\
\hline \multirow[t]{2}{*}{5} & TDF12.1-II_Sdal-F & 5'-ATCGATCCTGCAGGGGCACCGGTAAGTCAACTCT-3' \\
\hline & TDF12.1-II_Notl-R & 5'-ATCGATGCGGCCGCATCCGTTAGTGTATGGTCGG-3' \\
\hline \multirow[t]{2}{*}{6} & TDF24.1-I_Sdal-F & 5'-ATCGATCCTGCAGGCGATTCGTCCTGGCCCCTCC-3' \\
\hline & TDF24.1-I_Notl-R & 5'-ATCGATGCGGCCGCTGCCTGACCTGGCAGTACTG-3' \\
\hline \multirow[t]{2}{*}{7} & TDF25.8-I_Sdal-F & 5'-ATCGATCCTGCAGGCAACATTGCCTGACCGCTGC-3' \\
\hline & TDF25.8-I_NotI-R & 5'-ATCGATGCGGCCGCCGTTCGAGCAGCTCTTCCAT-3' \\
\hline \multirow[t]{2}{*}{8} & TDF25.8-II_Sdal-F & 5'-ATCGATCCTGCAGGTACAATTTACGAGATGGCAT-3' \\
\hline & TDF25.8-II_Notl-R & 5'-ATCGATGCGGCCGCTCGGCGCTCATCCGTGGTAT-3' \\
\hline \multirow[t]{2}{*}{9} & TDF33.3_Sdal-F & 5'-ATCGATCCTGCAGGTCCTAGTTCCATCGCCAGGC-3' \\
\hline & TDF33.3_Notl-R & 5'-ATCGATGCGGCCGCCTCAAGGCGCAATTCAGGCG-3' \\
\hline \multirow[t]{2}{*}{10} & TDF34.2_Sdal-F & 5'-ATCGATCCTGCAGGAGCAAGCTCAACCTCCATCA-3' \\
\hline & TDF34.2_Notl-R & 5'-ATCGATGCGGCCGCCCAACACAGTGAAGCACAGT-3' \\
\hline
\end{tabular}




\section{Vector construction for cloning}

The primers (Table 1), the were for sequence extension of target-TDFs using cloning strategy, were designed on bases of sequences of the related species and synthesized by company invitrogen. The target fragments were amplified by PCR and inserted into standard vector pBluescript SK(-) for sequencing by cloning (Figure 3).

\section{Sequence analysis}

NCBI (National Centre for Biotechnology Information) GenBank and Verticillium group database were used for genes hits (TDFs) blast. The DNA sequences isolated from $V$. longisporum was translated using the "Transeq" software in EMBL-EBI. The "ClustalW2" program in EMBL-EBI (European Molecular Biology Laboratory-European Bioinformatics Institute) was used for construction of the multiple sequences alignment and phylogenetic trees.

A phylogram is a branching diagram exhibiting the inferred evolutionary relationships among various biological species based upon similarities and changes their DNA or protein sequences.

\section{Results and discussion}

The sequence extensions brought more sequence information for candidate transcrit derived fragments (genes) such as TDF2.1, TDF6.2, TDF10.2, TDF11.1, TDF12.1, TDF12.2, TDF24.1, TDF25.8, TDF30.2, TDF33.3, and TDF34.2 etc. (Table 2 and supplementary data). $V$. longisporum may be near-diploidy and hybrid origin, its isolates were estimated to keep double amount of DNA per nucleus as compared with per haploid nucleus in $V$. dahliae. It was suggested that $V$. longisporum may be fused by two different parental Verticillium species (8). Under field conditions parasexuality was observed $(9,10)$. The performance of $V$. longisporum at sequence level may be an additional evidence of the exist of parasexual systems. According to the taxonomic analysis using RAPD etc. methods both $V$. dahliae and $V$. albo-atrum were suggested as $V$. longisporum's parents. Our phylogenic results confirm this estimation, however the relationship between $V$. longisporum to $V$. dahliae is close than $V$. longisporum to $V$. albo-atrum.

Comparison with the GRIM19 cell death regulator-like gene sequence from these three species, we found that $V$. longisporum presented higher similarity to $V$. dahliae than to $V$. 
albo-atrum in alignment score and sequence identities (Table 3 ) The further investigation demonstrated that $V$. longisporum in 44 nucleotides change positions including 6 gap penalties at 4 positions and 44 mismatches at 40 positions. V. longisporum kept absolute similarity to $V$. dahliae than to $V$. albo-atrum with a change ratio in 8.25 times $(33: 4)$ for mismatch positions. Both $V$. longisporum and $V$. dahliae had 2 same gap penalties, but $V$. albo-atrum monopolized other 4 gap penalties (Figure 4). Table 5 shown phylograms and relationship scales of 8 candidate genes among these three species, 6 of them demonstrated that the evolutionary relationship of $V$. longisporum were close to $V$. dahliae than to V. albo-atrum. An another phylogenetic analysis of the candidate genes VI_2.1, VI_11.1, VI_12.1, VI_33.3 and VI_34.2 was carried out and compared with sequences of 28 related species classified in appropriate groups at aminoacid sequence levels (Figure 5). The sequences were blasted from NCBI GenBank and Verticillium group database (Table 4). The Phylograms showed that V. Iongisporum, V. dahliae and V. albo-atrum were closely related than all other species at amino acid levels using five VI_genes, and VI_33.3 and VI_34.2 are absolute identical at amino acid level among three Verticillium species. We suggested that these two genes may play the basic roles in fungal biological development during the evolutionary process.

Table 2: Analysis of TDFs and extended sequences using NCBI-Blast.

\begin{tabular}{|c|c|c|c|c|}
\hline $\begin{array}{l}\text { Name of } \\
\text { Candidates }\end{array}$ & $\begin{array}{l}\text { TDFs } \\
\text { (bp) }\end{array}$ & $\begin{array}{l}\text { Extended } \\
\text { sequences (bp) }\end{array}$ & $\begin{array}{l}\text { Sequence extension used } \\
\text { Methods }\end{array}$ & NCBI-BLAST hits \\
\hline VI_2.1 & 71 & 724 & Cloning & Isochorismate hydrolase \\
\hline VI_6.2 & 78 & 7873 & $\begin{array}{l}\text { Genome library and direct } \\
\text { sequencing }\end{array}$ & $\begin{array}{l}\text { Hypothetical protein incloding } 4 \text { WSC binding } \\
\text { domains }\end{array}$ \\
\hline VI_11.1 & 72 & 2473 & Cloning & Peroxidase/Catalyse \\
\hline VI_10.2 & 68 & \multirow[t]{2}{*}{2437} & \multirow{2}{*}{$\begin{array}{l}\text { RACE-PCR, Cloning and } \\
\text { direct sequencing }\end{array}$} & \multirow[t]{2}{*}{ Zinc-finger transcription factor ace 1} \\
\hline VI_12.1 & 204 & & & \\
\hline VI_12.2 & 172 & 681 (UTR) & Direct sequencing & hypothetical protein \\
\hline VI_24.1 & 56 & 1493 & Cloning & hypothetical protein \\
\hline VI_25.8 & 135 & 565 & Cloning & $\begin{array}{l}\text { IBR (In between Ring) finger domain- } \\
\text { containing protein (indirect TF) }\end{array}$ \\
\hline VI_33.3 & 97 & 1430 & Cloning & $\begin{array}{l}\text { DOA4-independent degradation protein (Snf7 } \\
\text { super-family) }\end{array}$ \\
\hline VI_34.2 & 76 & 925 & Inverse PCR and Cloning & $\begin{array}{l}\text { NADH:ubiquinone oxidoreductase 14kD } \\
\text { subunit) GRIM19 cell death regulator }\end{array}$ \\
\hline
\end{tabular}


Table 3: Alignment scores and identities of GRIM19 cell death regulator-like (VI_34.2) gene sequences among $V$. longisporum, $V$. dahliae VdLs.17 and $V$. albo-atrum VaMs.10.

\begin{tabular}{|l|l|l|l|l|l|l|l|}
\hline Nr. & DNA sequence & Length & Nr. & DNA sequence & Length & Score & Identity \\
\hline 1 & VI_TDF_34.2 & 684 & 2 & Vd_VDAG_09543.1 & 683 & 98,0 & 98.8 \\
\hline 2 & VI_TDF_34.2 & 684 & 3 & Vaa_VDBG_09810.1 & 682 & 94.0 & 94.3 \\
\hline 3 & Vd_VDAG_09543.1 & 683 & 3 & Vaa_VDBG_09810.1 & 682 & 94.0 & 94.1 \\
\hline $\begin{array}{l}\text { Score } \\
\text { Identity }=\Sigma \text { (identities, mismatches) }-\Sigma \text { (identities) }-\Sigma \text { (map penalties) }\end{array}$ \\
\hline
\end{tabular}

Table 4: The related species for phylogenetic analysis of the candidate genes VI_2.1, VI_11.1, VI_12.1, VI_33.3 and VI_34.2 at aminoacid sequence levels *.

\begin{tabular}{|c|c|c|c|}
\hline Code & Name of species & Code & Name of species \\
\hline Ac & Aspergillus clavatus NRRL 1 & $\mathrm{Nf}$ & Neosartorya fischeri NRRL 181; \\
\hline Ad & Ajellomyces dermatitidis SLH14081 & $\mathrm{Nh}$ & Nectria haematococca mpVI 77-13-4; \\
\hline Af & Aspergillus fumigatus Af293 & $\mathrm{Pb}$ & Paracoccidioides brasiliensis $\mathrm{Pb} 01$ \\
\hline An & Aspergillus niger & $\mathrm{Pc}$ & Penicillium chrysogenum Wisconsin 54-1255 \\
\hline Ao & Aspergillus oryzae RIB40 & $\mathrm{Pd}$ & Penicillium decumbens \\
\hline $\mathrm{Bf}$ & Botryotinia fuckeliana B05.10 & $\mathrm{Pg}$ & Puccinia graminis f. sp. tritici CRL 75-36-700-3; \\
\hline $\mathrm{Bt}$ & Burkholderia thailandensis MSMB43 & $\mathrm{Pm}$ & Penicillium marneffei ATCC 18224 \\
\hline $\mathrm{Cg}$ & Chaetomium globosum CBS 148.51 & Ss & Sclerotinia sclerotiorum 1980 \\
\hline $\mathrm{Gg}$ & Glomerella graminicola M1.001 & $\operatorname{Tr}$ & Trichoderma reesei \\
\hline $\mathrm{Gm}$ & Gibberella moniliformis & Ts & Talaromyces stipitatus ATCC 10500 \\
\hline Gz & Gibberella zeae $\mathrm{PH}-1$ & Um & Ustilago maydis 521 \\
\hline Lm & Leptosphaeria maculans & Vaa & Verticillium albo-atrum VaMs.10 \\
\hline Mo & Magnaporthe oryzae 70-15 & Vd & Verticillium dahliae VdLs.17 \\
\hline Nc & Neurospora crassa OR74A & VI & Verticillium longisporum VL43 \\
\hline
\end{tabular}



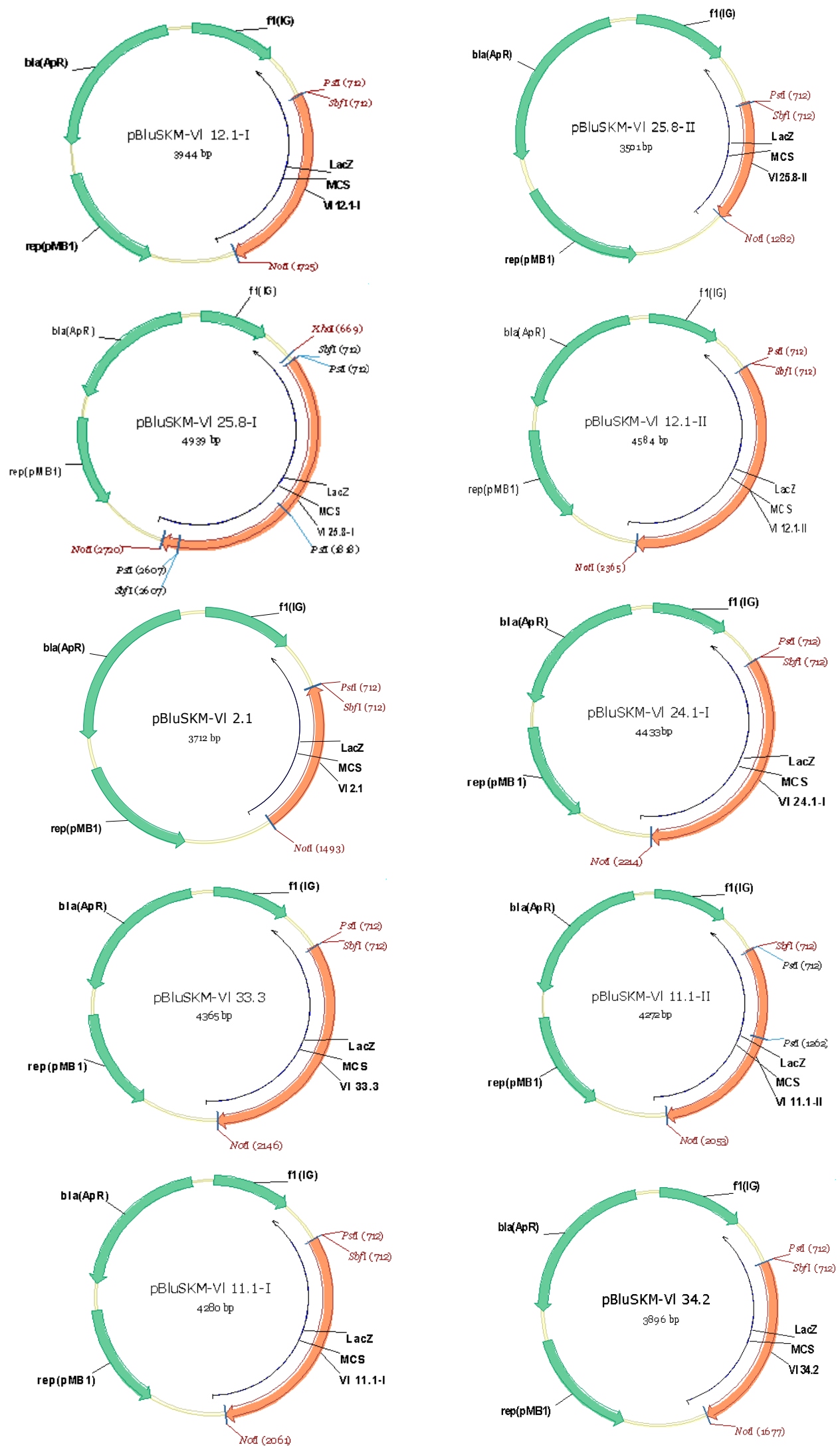

Figure 3: Construction maps of vector pBluSK(-) containing target fragments of VI_2.1; VI_11.1; VI_12.1; VI_24.1; VI_25.8; VI_33.3 and VI_34.2. The primers were listed in Table 1. 
VI TDF 34.2 $\mathrm{Vd}{ }^{-} \mathrm{VDA} \overline{\mathrm{G}} \quad 09543.1$

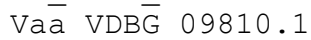

VI TDF 34.2 $\mathrm{Vd}^{-} \mathrm{VDA} \overline{\mathrm{G}} \quad 09543.1$

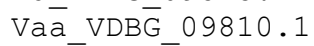

VI TDF 34.2 $\mathrm{Vd}^{-} \mathrm{VDA} \overline{\mathrm{G}} \quad 09543.1$

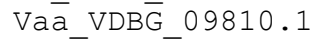

VI TDF 34.2 Vd ${ }^{-} \operatorname{VDA} \bar{G} \quad 09543.1$ Vaà_VDBG__09810.1

VI TDF 34.2 $\mathrm{Vd}{ }^{-} \mathrm{VDA} \overline{\mathrm{G}} \quad 09543.1$

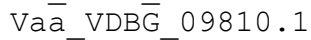

VI TDF 34.2 $\mathrm{Vd}^{-} \mathrm{VDA} \overline{\mathrm{G}} \quad 09543.1$ Vaà_VDBG 09810.1

VI_TDF 34.2 $\mathrm{Vd}{ }^{-} \operatorname{VDA} \bar{G} \quad 09543.1$

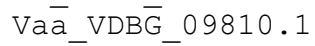

VI TDF 34.2 Vd ${ }^{-} \mathrm{VDA} \overline{\mathrm{G}} \quad 09543.1$ Vaà_VDBG__09810.1

VI TDF 34.2 $\mathrm{Vd}{ }^{-} \mathrm{VDA} \overline{\mathrm{G}} \quad 09543.1$

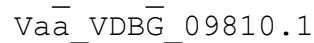

VI TDF 34.2 $\mathrm{Vd}^{-} \mathrm{VDA} \overline{\mathrm{G}} \quad 09543.1$ Vaà_VDBG__09810.1

VI_TDF 34.2 $\mathrm{Vd}{ }^{-} \mathrm{VDA} \overline{\mathrm{G}} \quad 09543.1$

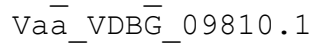

VI TDF 34.2 $\mathrm{Vd}{ }^{-}{ }^{-} \mathrm{VDA} \bar{G} \quad 09543.1$ Vaā_VDBG__09810.1
ATGCCCCAGGACATGCCGCCCGTGGGCGGCTATAATGCCGTTCAATACAAGGTGGGTTTA 60 ATGCCCCAGGACATGCCGCCCGTGGGCGGCTATAATGCCGTTCAATACAAGGTGGGTTTA 60 ATGCCCCAGGACATGCCGCCCGTGGGCGGCTACAATGCCGTTCAATACAAGGTGGGTTTA 60

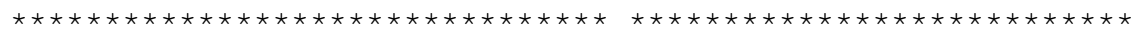

CCGATCGATCCCGTCGTGGCCGACAGCTAGGCCAATTGGGCTCAATACAGTGCATCAATG 120 CCGATCGATCCCATCGTGGCCGACAGCCAGGCCAATTGGGCTCAATACAGTGCATCAATG 120 CCGATCGATCTCGTCGTGGCCGACAGCGATGCCAATCGGGCTCAATATAG-GCGTCAATG 119

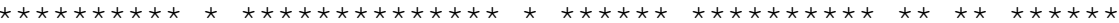

CCTCTTCAGCACCGATAAACTTCAACGAGACTCCGCATCAGGCCCCAGGCGCCCATACAG 180 CCTCTTCAGCACCGATAAACTTCAACGAGACTCCGCATCAGGCCCCAGGCGCCCATACAG 180 CCTCTTGAGCACCAATGAACTTCTACGAGACTCCGCATCAAGCCCCAGGCGCCCATACAG 179

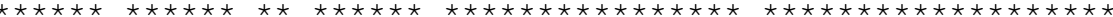

ACTTCTCCCCGAGCAACGCCGGCTAACGCTTCTCCTAGCGTAACCTCCCCGCCCGCGGCT 240 ACTTCTCCCCGAGCAACGCCGGCTAACGCTTCTCCTAGCGCAACCTCCCCGCCCGCGGCT 240 ACTTCTCCCCGAGCAACGCCGGCTAACGCTTCCCCTAGCGCAACCTCCCCGCCCGCGGCT 239

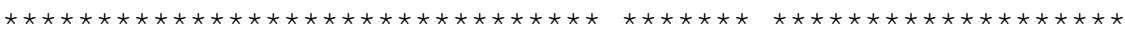

TCCGCCCTGGAATCCTCCTTCTCGGAATGGGCGCCGTCATGGGCTACGGCTGGTACAAAC 300 TCCGCCCTGGAATCCTCCTTCTCGGAATGGGCGCCGTCATGGGCTACGGCTGGTACAAAC 300 TCCGCCCTGGAATCCTCCTCCTCGGAATGGGCGCCGTCATGGGCTACGGCTGGTACAAGC 299

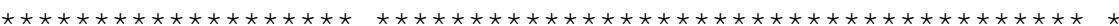

TGATCAAGGGCATCCGCGAGGCCAAGTACGTCCTCGTTCCCCCCTC-CCGCTTTGTCTCG 359 TGATCAAGGGCATCCGCGAGGCCAAGTACGTCCTCGTTCCCCCCTC-CCGCTTTGCCTCG 359 TGATCAAGGGCATCCGCGAGGCCAAGTGCGTCCTCGTTTCCCCCTCGCTGCTTTGTCTCG 359

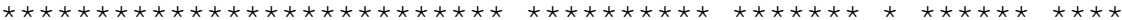

TCTTGCTTCGGCTGCGTAGCTTGGAGCCGTTGACCAATCCTCCCTCGAACAAAGAACTGA 419 TCTTGCTTCGGCTGCGTAGCTTGGAGCCGTTGACCAATCCTCCCTCGAACAAAGAACTGA 419 TCTTGCTTCGGCTGCGTAGCTTGGAGTCGTTGACCAATCCTCCCTCGAACGAAAAGCTAA 419

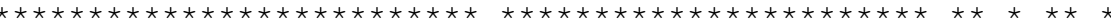

CCACCATGCCAGCGAGCTTGCCCGTGAGAAGATGTGGGCGCGCATCCACCTCATTCCTCT 479 CCACCGTGCCAGCGAGCTCGCCCGTGAGAAGATGTGGGCGCGCATCCACCTCATTCCTCT 479 CCACCATGCCAGCGAGCTCGCCCGTGAGAAGATGTGGGCGCGCATTCACCTCATTCCTCT 479

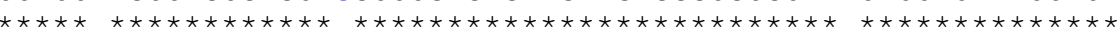

CCTCCAGGCCGAGGAGGACCGCGACCAGATCCGCCGATGGTACGCCGATCAGGCGCGCGA 539 CCTCCAGGCCGAGGAGGACCGCGACCAGATCCGCCGATGGTACGCCGACCAGGCGCGCGA 539 CCTCCAGGCCGAGGAGGACCGTGACCAGATCCGCCGATGGTACGCCGACCAGGCGCGCGA 539

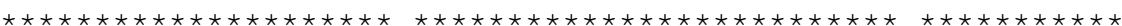

GAAGGAGCTGCTGGGCGAGAACACGCGTGTGTACCACACGGACAGGTAGGACTGACTGGA 599 GAAGGAGCTGCTGGGCGAGAACACGCGTGTGTACCACACGGACAGGTAGGACTGACTGGA 599 GAAGGAGCTGCTGGGCGAGAACACGCGTGTGTACCACACGGACAGGTAGGACTGATAGGG 599

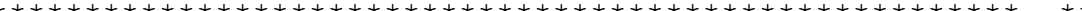

CGGCTTGCTGTAGAGGGCCGTTTGCTAACGAGGTGCAGGGTTTGTCCGACCCACGTTCGC 659 CGGCTTGCTGTAGAGGGCCGTTTGCTAACGAGGCGCAGG-TTTGTCCGACCTACGTTCGC 658 CGGCTGGCTGTAGAGG-TTTTGTGCTAACGAGGCGCAGG-TTTGTCCGACCCACGTTCGC 657

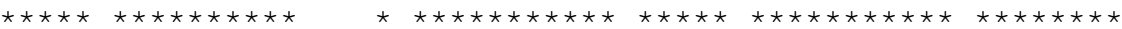

TGTTGCGCCGGAGAAGACGAAATAG 684 TGTTGCGCCGGAGAAGACGAAATAG 683 TGTTGCGCCGGAGAAGACGAAATAG 682

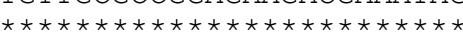

Figure 4: Alignment of the GRIM19 cell death regulator-like (VI_34.2) gene sequences among V. longisporum (VI_TDF_34.2), V. dahliae VdLs.17 (Vd_VDAG_09543.1) and V. albo-atrum VaMs.10 (Vaa_VDBG_09810.1). red colour: V. longisporum = V. dahliae; green colour: $V$. longisporum $=$ V. albo-atrum; blue colour: $V$. dahliae $=$ V. albo-atrum . 
lolic colour: $V$. longisporum $\neq V$. dahliae $\neq V$. albo-atrum.

(a) VI_2.1 and related species

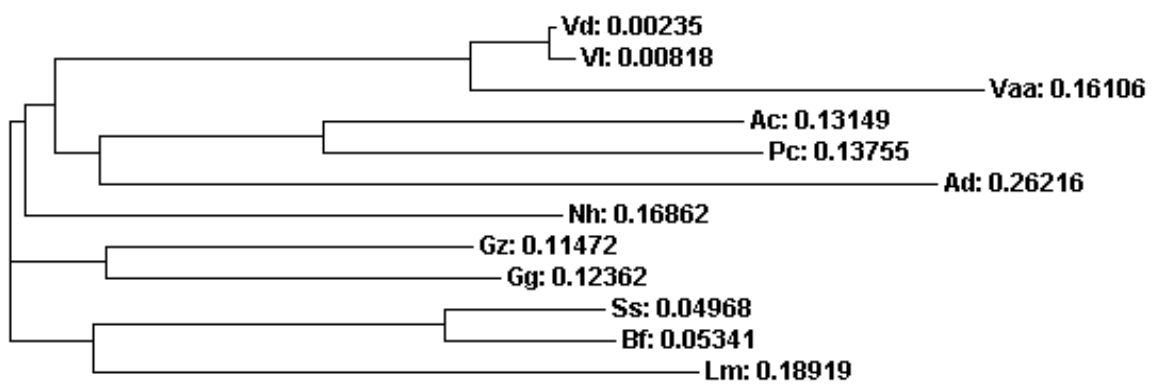

(b) VI_11.1 and related species

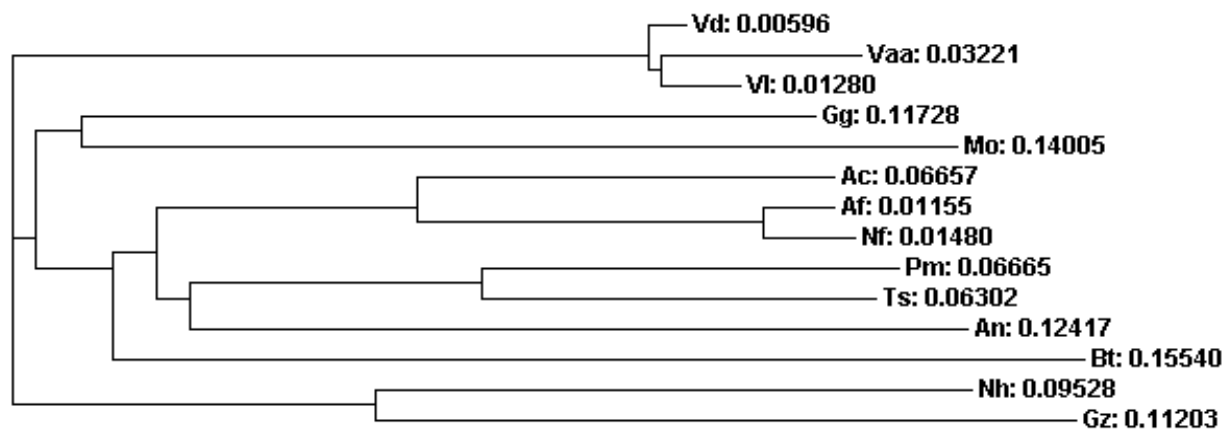

(c) VI_12.1 and related species

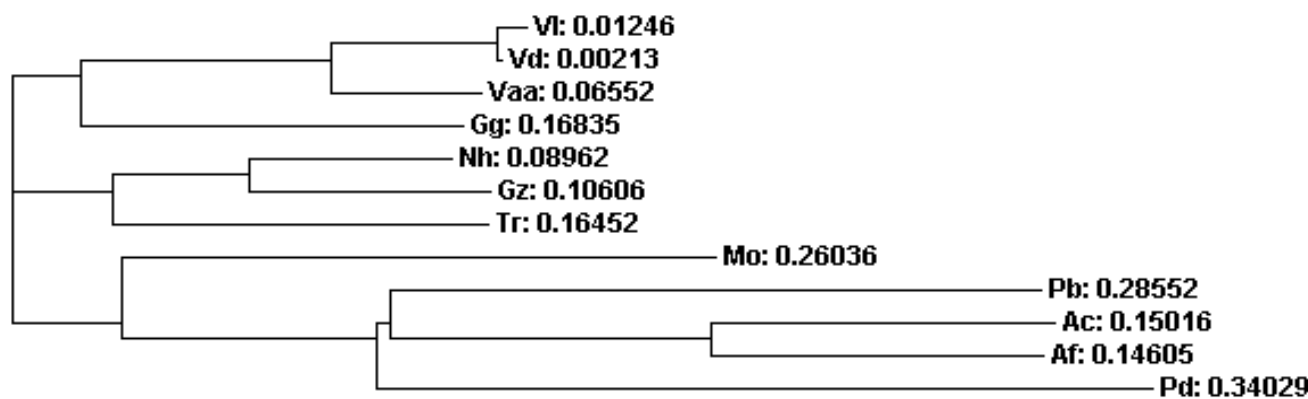

(d) VI_33.3 and related species

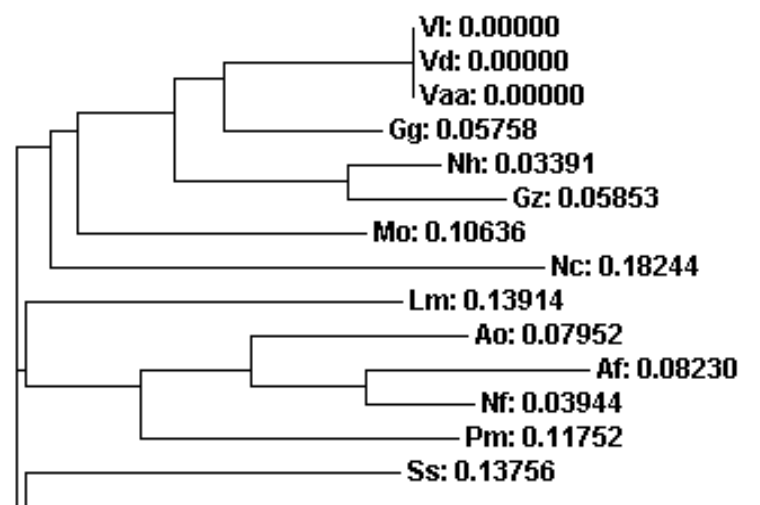


(e) VI_34.2 and related species

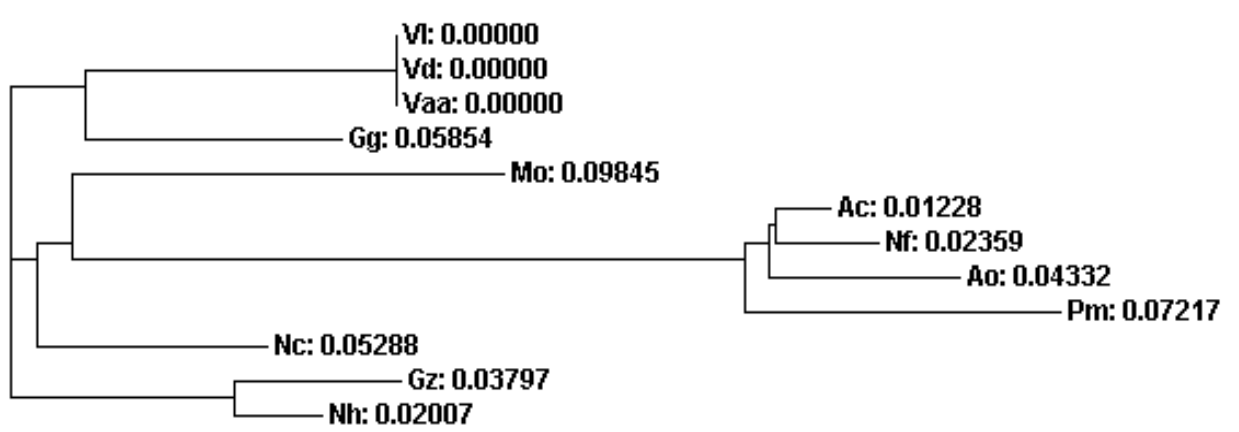

Figure 5: Phylogenetic analysis of candidate genes based on amino acid sequences. The candidate five genes were, (a) VI_2.1, (b) VI_11.1, (c) VI_12.1 (d) VI_33.3, and (e) VI_34.2. Phylograms were derived using software ClustalW2. Names of selected species found in Table 4 after the letter-codes in each phylogram. The numbers behind codes indicated the evolutionary relationship scales under a node.

Table 5: Phylograms show genetic distances of 8 candidate genes at DNA level among the species V. longisporum, V. dahliae VdLs.17 and V. albo-atrum VaMs.10.

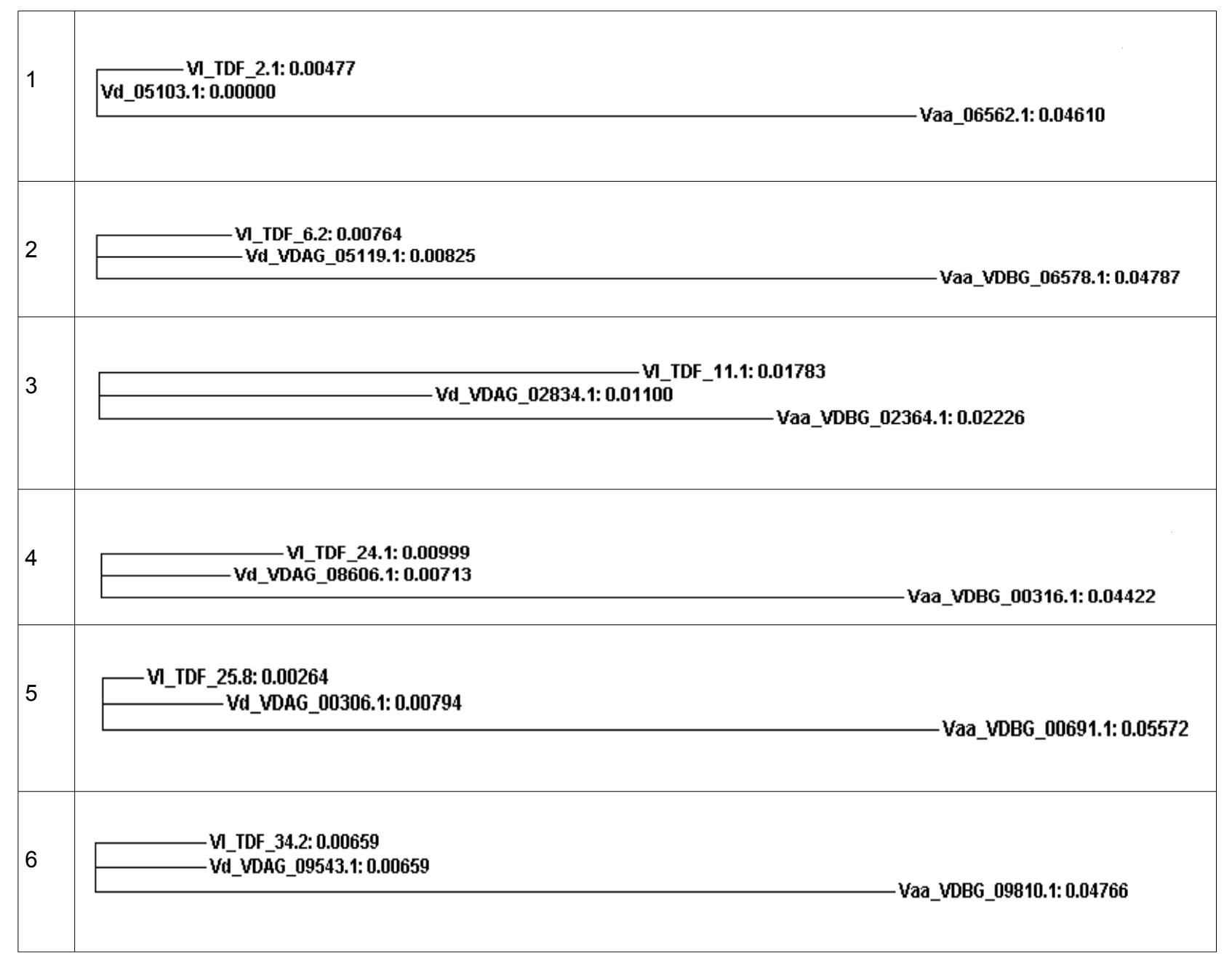




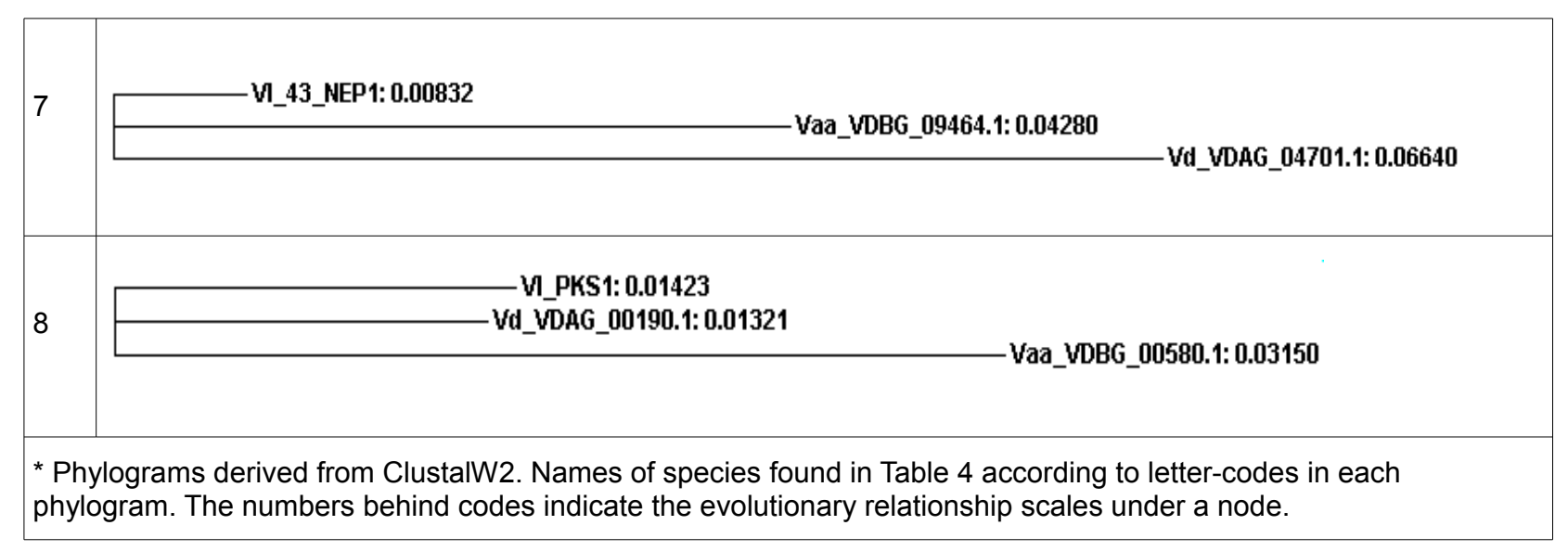

\section{Referances}

1. Reijans, M. et al., (2003). Quantitative comparison of cDNA-AFLP, microarrays, and GeneChip expression data in Saccharomyces cerevisiae. Gemomics. 82: 606-618.

2. Ochman, H., Gerber, A. S. \& Hartl, D. L. (1988). Genetic application of an inverse polymerase chain reaction. Genetics. 120(3): 621-3.

3. Jong, A. Y., T'ang, A., Liu, D. P. \& Huang, S. H. (2002). Inverse PCR. Genomic DNA cloning. PCR Cloning Protocols, Second Edition.

4. Garcés, J. A. and Gavin, R. H. (2001). Using an Inverse PCR Strategy to Clone Large, Contiguous Genomic DNA Fragments. Cytoskeleton Methods and Protocols 161(I), 3-8.

5. Frohman M. A. (1994) On beyond classic RACE (rapid amplification of cDNA ends). PCR Methods Appl. 4: 40-48.

6. Ohara, O.. Dorit, R. L. \& Gilbert, W. (1989). One-sided polymerase chain reaction: The amplification of cDNA. Proc.Natl. Acad. Sci. USA. 86: 5673-5677.

7. Fahleson, J., Hu, Q. \& Dixelius, C. (2004). Phylogenetic analysis of Verticillium species based on nulear and mitochondrial sequences. Arch Microbiol. 181: 435442.

8. Karapapa, V. K., Bainbridge, B. W., Heale, J. B. (1997). Morphological and molecular characterisation of Verticillium longisporum comb. nov., pathogenic to oilseed rape. Mycol. Res. 101:1281-1294. 
9. Clakson, J. M. \& Heale, J. B. (1985c). A preliminary investigation of the genetics of pathogenicity in hop wilt isolates of Verticillium albo-atrum. Transactions of the Britisch Mycological Society. 85: 345-350.

10. Heal, J. B. (1988). Verticillium spp.: the cause of vascular wilts in many species. advances in Plant Pathology. 6: 291-312.

\title{
2.2. Generating a genomic DNA library with microtiter plate monitoring for sequence extension
}

\author{
Haiquan Xu, Christian Löfke, Arne Weiberg and Petr Karlovsky
}

\begin{abstract}
A genomic library of Verticillium longisporum was constructed with a purpose of extension gene sequence of target TDFs after a cDNA-AFLP-based transcript screening in $V$. longisporum. This microtiter plate monitored library contains 9986 clones with an average insert size of 8-12 kb, representing approximately $50 \%$ diploid genome equivalents. It was constructed from the wild type isolate VL43 of $V$. longisporum. A selection procedure was improved for identifying a clone with target genes from the library by PCR in three steps. From this library we got VI_6.2 gene and three VI_NEP genes with full length sequences of ORF(Open Reading Frame) and UTR (Untranslated Region).
\end{abstract}

\section{Introduction}

Total genomic DNA of filamentous fungi can be fragmented with partially digestion using a restriction endonulease or other methods. The appropriate fragments are fractionated and ligated into a standard cloning vector forming various recombinants. The collection of recombinants can be transferred into Escherichia coli or another proper species to build a genomic library which is used to screen the interesting target genes. To generate a genomic library is a conventional method both for genome sequence assembling (1) and extending TDFs (Transcriptome derived Fragments) sequences (2). However, This method is time-consuming (3). Here we present a improved procedure that we have rapidly got the target genes in large size from a genomic library. 
The genome of an organism is a complete set of genes. The diploid organisms (like ourselves) contain two genomes. The table 1 presents a list of representative genome sizes from the organisms where the genomes have been sequenced. The table 2 presents a list of vector systems which can be used for generation of a genomic library.

Table 1: Part of representative organisms with sequenced genomes (4)

\begin{tabular}{|l|l|l|}
\hline Name of organisms & Genome size & Genes \\
\hline E. coli K-12 & $4,639,221$ & 4,377 \\
\hline Agrobacterium tumefaciens & $4,674,062$ & 5,419 \\
\hline Streptomyces coelicolor & $6,667,507$ & 7,842 \\
\hline Saccharomyces cerevisiae & $12,495,682$ & 5,770 \\
\hline Neurospora crassa & $38,639,769$ & 10,082 \\
\hline Arabidopsis thaliana & $115,409,949$ & $\sim 28,000$ \\
\hline Humans & $3.3 \times 10^{9}$ & $\sim 20,000$ \\
\hline Mouse & $3.4 \times 10^{9}$ & $\sim 23,000$ \\
\hline
\end{tabular}

Table 2: Capable vector systems (5)

\begin{tabular}{|l|l|}
\hline Vector type & Cloned DNA $(\mathrm{kb})^{*}$ \\
\hline Plasmid & 20 \\
\hline lambda phage & 25 \\
\hline Cosmid & 45 \\
\hline P1 phage & 100 \\
\hline BAC (bacterial artificial chromosome) & 300 \\
\hline YAC (yeast artificial chromosome & 1000 \\
\hline * Approximate maximum length of DNA that can be cloned into vectors. \\
\hline
\end{tabular}

The genomic library can be made using each vector according to a requirement after the genome size of an organism (table 1) and the capacity of a vector (table 2). Normally It is efficient to use a vector with a large capacity. For prokaryotes the gene libraries are generated oft using plasmids containing inserts $5 \sim 15 \mathrm{~kb}$, because of their smaller genomes. Only a few thousand recombinants are required for a representative library in 
this case. The eukaryotic organisms hold larger genomes, their genomic libraries required those vectors which should be inserted the larger DNA fragments (Table 2). The genome of Verticillium longisporum is not sequenced. Fungi are eukaryotic microbes with genomes in c. 10 40 Mb. Then a genomic library for $V$. longisporum can use plasmid, lambda phage, cosmid or $\mathrm{P} 1$ phage as a vector.

After an equation of Clarke, L. and Carbon, J. (1979) the exact probability of having any given DNA sequence in the library can be calculated as follows:

$$
N=\ln (1-P) / \ln (1-f)
$$

$\mathbf{P}$ is the desired probability of gene represented in library; $\mathbf{f}$ is the fractional proportion of the genome in one insert; $\mathbf{N}$ is the necessary number of recombinants in a library.

The number of clones required to have a $99 \%$ probability ( $99 \%$ chance of getting the desired gene in the library) of finding a desired sequence (an average insert size of $10 \mathrm{~kb}$ ) represented in a Verticillium library with an approximate $V$. longisporum genome size of 2.5 $x 10^{7}$.

$$
N_{\text {vert }}=\ln (1-0.99) / \ln \left[1-\left(1 \times 10^{4} / 2,5 \times 10^{7}\right)\right]=11510 \text { clones (recombinants) }
$$

\section{Material and methods}

\section{Fungal, bacterial strain and media}

See chapter Reference Gene Selection and Determination of in Planta Gene Expression of V. longisporum by qRT-PCR. Escherichia coli DH5a strain (Hanahan 1983) was used for cloning and grown on LB medium (Sambrook et al., 1989). Electro-competent cells for transformation were stored in the freezer at $-80^{\circ} \mathrm{C}$. LB and SOC medium were used for incubation of bacterial celles (Table 3 and 4). PDB and Czapek Dox were applied for incubation of fungal strain $V$. longisporum VL43.

\section{Preparation of the electroporation competent cells}

1). Preparation of YENB growing media $100 \mathrm{ml}$. [Mix: $0.75 \%$ Yeast Extract $7,5 \mathrm{~g} \mathrm{l}^{-1}$ and $0.8 \%$ Bacto Nutrient Broth (Difco) $8 \mathrm{~g} \mathrm{I}^{-1}$. Filled to volume with distilled water and autoclaved]; 2). Cells were grown overnight in $10 \mathrm{ml}$ of YENB media. 3). Overnight growth 
of $1 \mathrm{~L}$ media with Inoculated $5 \sim 10 \mathrm{ml}$ of culture. 4). Grown at $37^{\circ} \mathrm{C}$ until the $\mathrm{OD}_{600}$ is 0.5 to 0.9 [The optimal $\mathrm{OD}_{600}$ is 0.6 , which takes approximately $3 \mathrm{~h}$ ]. 5). Placed on ice for $30 \mathrm{~min}$ and then centrifuged at $4000 \mathrm{~g}$ for $10 \mathrm{~min}$ at $4^{\circ} \mathrm{C}$. 6 ). The pellet was washed twice with 100 $\mathrm{ml}$ cold water [centrifuged between washes]. 7). Resuspended in $20 \mathrm{ml}$ of $10 \%$ glycerol and centrifuged again. 8). Resuspended to final volume of $2-3 \mathrm{ml}$ in cold $10 \%$ glycerol and aliquoted at $50 \mu \mathrm{l}$ and shot, frozen in liquid nitrogen. [Store at $80^{\circ} \mathrm{C}$ ]. (This protocol was taken from Biotechniques, vol 20 (1): 42-44, Sharme and Schike 1996).

Table 3: Component of LB medium

\begin{tabular}{|l|l|}
\hline Name & Amount \\
\hline Bacto-tryptone & $10 \mathrm{~g}$ \\
\hline Bacto-yeast extract & $5 \mathrm{~g}$ \\
\hline $\mathrm{NaCl}$ & $10 \mathrm{~g}$ \\
\hline $\mathrm{ddH}_{2} \mathrm{O}$ to & $1000 \mathrm{ml}$ \\
\hline Note: adjust pH to 7.0 with $10 \mathrm{~N} \mathrm{NaOH}$, autoclave to sterilize. \\
\hline
\end{tabular}

Table 4: Component of SOC medium

\begin{tabular}{|l|l|}
\hline Name & Amount \\
\hline Bacto-tryptone & $20 \mathrm{~g}$ \\
\hline Bacto-yeast extract & $5 \mathrm{~g}$ \\
\hline $\mathrm{NaCl}$ & $0.5 \mathrm{~g}$ \\
\hline $1 \mathrm{M} \mathrm{KCl}$ & $2.5 \mathrm{ml}$ \\
\hline ddH ${ }_{2} \mathrm{O}$ to & $1000 \mathrm{ml}$ \\
\hline Total volume & $1000 \mathrm{ml}$ \\
\hline $\begin{array}{l}\text { Note: adjust pH to } 7.0 \text { with } 10 \mathrm{~N} \mathrm{NaOH}, \text { autoclave to sterilize, add } 20 \mathrm{ml} \text { of sterile } 1 \mathrm{M} \text { glucose immediately } \\
\text { before use. }\end{array}$ \\
\hline
\end{tabular}

\section{Isolation of fungal genomic DNA}

Extraction of fungal genomic DNA of V. Iongisporum (see chapter "Reference Gene Selection and Determination of in Planta Gene Expression of Verticillium Iongisporum by qRT-PCR “). 


\section{Partial digestion of gDNA with Sau3Al and isolation of target fragments}

A V. longisporum genomic library was generated in following steps: First the $V$. longisporum genomic DNA (gDNA) was isolated, $20 \mu \mathrm{g}$ of gDNA was partially digested for 30 minutes with the restriction enzyme $0.5 \mathrm{U}$ Sau3Al (Fermentas, Germany) in a total volume $900 \mu \mathrm{l}$. Then the digested DNA fragments were size-fractionated on an $0.5 \%$ agarose gel by electrophoresis $(20 \mathrm{~V} / 16 \mathrm{~h})$, and 8-12 kb fragments were cut out and purified with QIAquick Gel Extraction Kit (Figure 1). Then the purified 8-12 kb fragments were inserted into the BamHI site of the pre-cut standard vector pUC57 (GenScript) (Figure 2) by ligation with T4 Ligase (Fermentas, Germany).

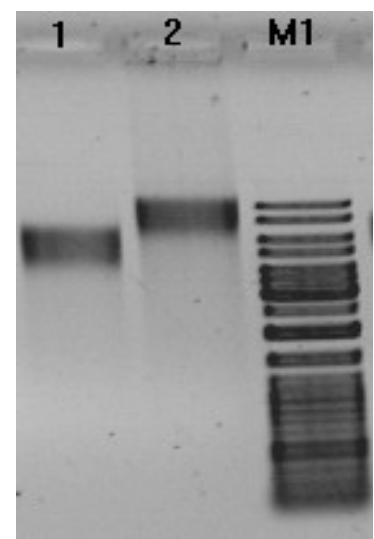

Figure 1: The target 4-8 and 8-12 kb DNA fragments after purification from agarose gel.1:

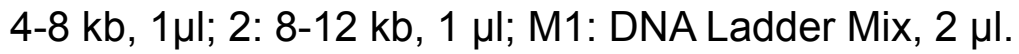

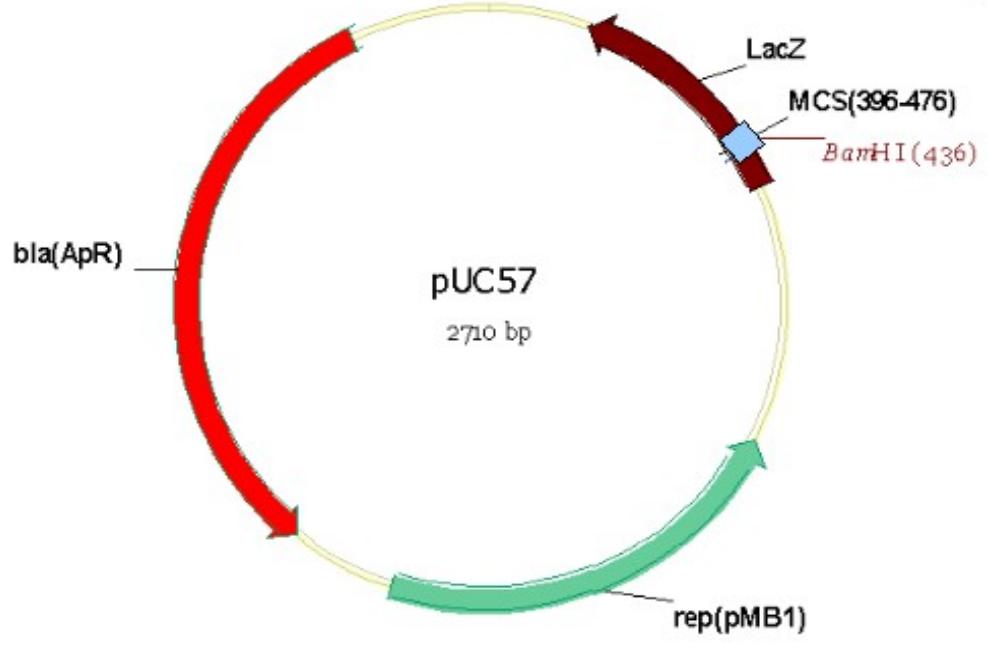

Figure 2: Standard vector pUC57 with BamHI restriction site. 


\section{Preparation of standard plasmid pUC57 as vector}

Plasmid pUC57 was used as a vector for generation of genomic library of $V$. longisporum. pUC57 which is $2710 \mathrm{bp}$ in length, it is a derivative of pUC19. pUC57 MCS contains 6 restriction sites. DNA replication initiates at position $890(+/-1)$ and proceeds in the direction indicated. The bla gene nucleotides 2510-2442 (compl. strand) code for a signal peptide. The restriction site BamHI was used for insertion of DNA fragments from $V$. longisporum genome (Figure 2).

\section{Transformation and monitoring in 96 -well microtiter plate}

The with inserts recirculated plasmids were transformed in competent $E$. coli DH5a cells by electroporation. To obtain the genomic library, 96-well flat-bottomed microtiter plates (Figure 3) were used to grow the transformants in LB medium with 100 ppm ampicillin. Each transformant was cultured in $150 \mu \mathrm{LB}$ per well for two days, and then $100 \mu$ sterile $50 \%$ glycerol was added used multipipeter.

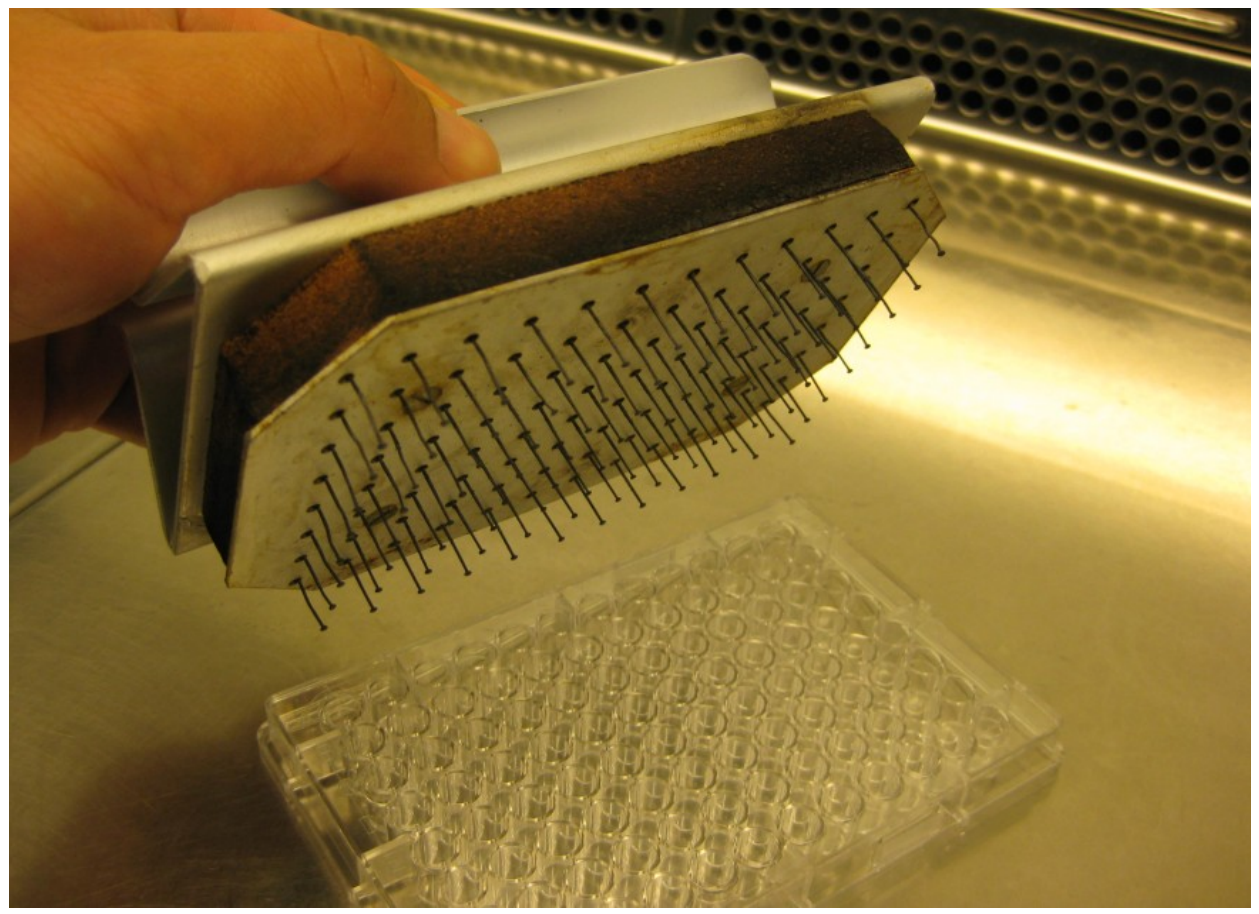

Figure 3: 96-well flat-bottomed microtiter plate for library monitoring and 96-needle inoculating plate for inoculation.

\section{Polymerase chain reaction and designed primers for target genes}

A standard PCR procedure was used in this experiment. PCR amplification was carried out using a 2 min denaturation at $95^{\circ} \mathrm{C}$ as first step, followed by 30 reaction cycles consisting 
of a $30 \mathrm{~s}$ denaturation step at $95^{\circ} \mathrm{C}$, an annealing step for $30 \mathrm{~s}$ at $58^{\circ} \mathrm{C}$ or $59^{\circ} \mathrm{C}$ and a elongation step with a ratio of approximately $1 \mathrm{~min}$ for $1 \mathrm{~kb}$ at $72^{\circ} \mathrm{C}$. An additional final elongation step was performed for $5 \mathrm{~min}$ at $72^{\circ} \mathrm{C}$. The reaction mixture consisted of $\mathrm{NH} 4-$

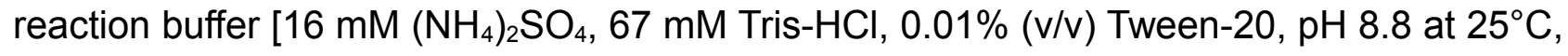
$3 \mathrm{mM} \mathrm{MgCl}_{2}, 0.2 \mathrm{mM}$ of each dATP, dTTP, dCTP and dGTP, $0.3 \mu \mathrm{M}$ of each primer, $0.25 \mathrm{U}$ BioTaq DNA polymerase (Bioline, Luckenwalde, Germany), 1-2 $\mu$ l of template DNA and $\mathrm{ddH}_{2} \mathrm{O}$ up to $25 \mu \mathrm{l}$.

The for detection of target genes from a genomic library used primers were designed from TDFs (Weiberg 2008) (Table 5: Nr. 1-3) or related species (Vercillium group database) (Table 5: Nr. 4-8).

Table 5: Specific primers of putative pathogenicity related candidate genes of VL.

\begin{tabular}{|c|c|c|}
\hline Nr. & Target gene & Primers \\
\hline \multirow{2}{*}{1} & VI_6.2-F & 5'-AATTGGCCAACCAGCTCTACG-3' \\
\hline & VI_6.2-R & 5'-ACGTATTCGCCAGCAGCG-3' \\
\hline \multirow{2}{*}{2} & VI_12.1-F & 5'-AATTCCAGACTCTGTTCGGCAG-3' \\
\hline & VI_12.1-R & 5'-ACGTAAAAGAAACAGGCCATCCC-3' \\
\hline \multirow{2}{*}{3} & VI_12.2-F & 5'-AATTCGTCCTCGGGCCTCAAGGCAGA-3' \\
\hline & VI_12.2-R & 5'-ACGTAATGTCATCACAGGTCAGAGTGG-3' \\
\hline \multirow{2}{*}{4} & VI_NEP1-F & 5'-CGGTGAGGTCAAGTAAGACACGC-3' \\
\hline & VI_NEP1-R & 5'-TGACGACATTCTCCCAGTCG-3' \\
\hline \multirow{2}{*}{5} & VI_NEP2-F(VI_NEPC) & 5'-ACGTAGTCGTCTTCGCACGCGGA-3' \\
\hline & VI_NEP2-R(VI_NEPC) & 5'-CGGGCTCTTGTAGAACGAGCCTG-3' \\
\hline \multirow{2}{*}{6} & VI_NEP3-F(VI_NEPE) & 5'-GCGATTGTCTACCACAAGGACAGCA-3' \\
\hline & VI_NEP3-R(VI_NEPE) & 5'-GCCTAGCCTTGCGAATGTTCTCAG-3' \\
\hline \multirow[t]{2}{*}{7} & VI_NEP4-F(VI_NEPF) & 5'-TGCCGACGAGCGTAGCCATGCA-3' \\
\hline & VI_NEP4-R(VI_NEPF) & 5'-TCCTCATTAGCCCATGCCATGTGA-3' \\
\hline 8 & VI_NEP5-F(VI_NEPG) & 5'-GTACGCTGCTTGGCTGGCACA-3' \\
\hline
\end{tabular}




\section{Procedure of screening and identification}

To obtain a clone containing target gene from complete genomic library, a general screening of the target genes from the library was performed by transferring transformants from microtiter plates as plate-pools inoculated with 96-needle inoculating plates in flasks containing $50 \mathrm{ml} \mathrm{LB}$ medium, overnight incubation shaking at $150 \mathrm{rpm}$ at $37^{\circ} \mathrm{C}$, and plasmids isolation using plasmid extraction kits (Qiagen, Hilden, Germany). $1 \mu \mathrm{g}$ plasmids DNA from each four plate-pool formed a collective pool. Each 96-well microtiter plate contains 8 rows and 12 lines, they were inoculated with multi-pipette and forms 20 pools (each row or line as one pool). The overnight incubated transformant cultures were used directly, or after plasmid extraction, as template for determination of target genes by PCR. Figure 4 shows a scheme for the screening and identification of a target clone.
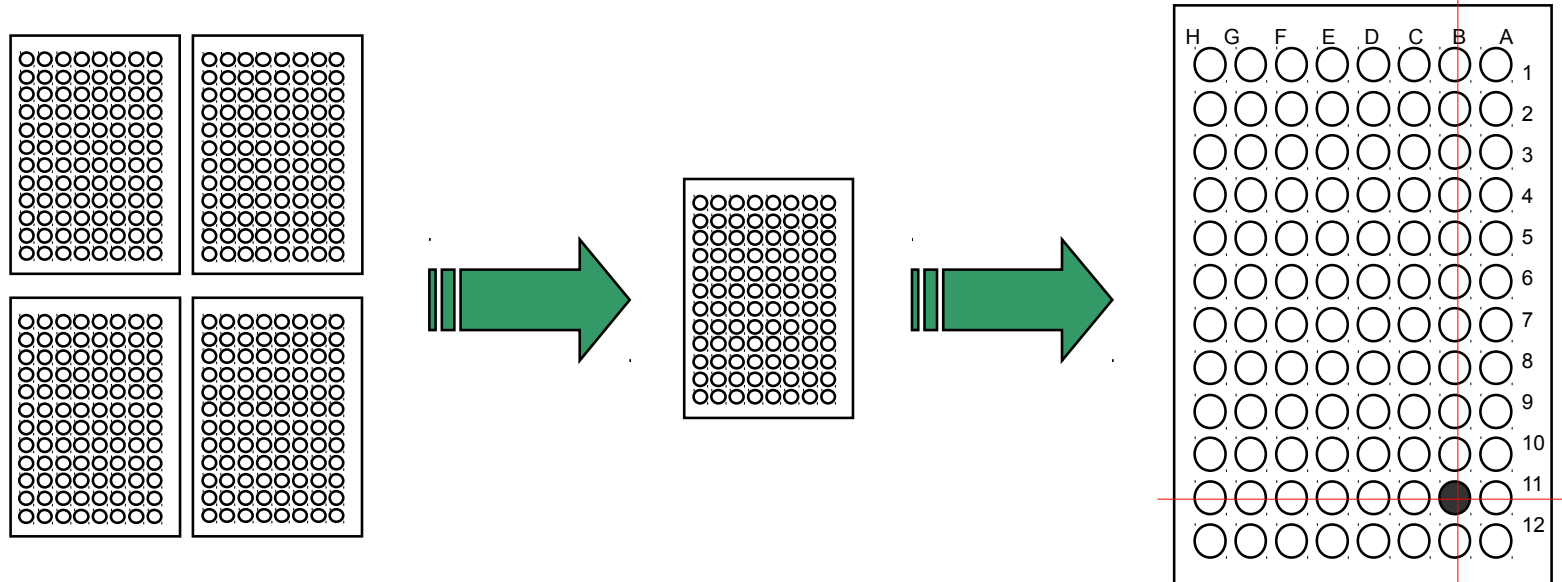

Figure 4: Scheme of the Screening and identification procedure in three steps. First step (left picture): 4 platen form 1 collective pool. Second step (middle picture): 1 plate forms 1 plate-pool. Third step (right picture): Each row or line is 1 pool. If line pool and row pool both were positive by PCR, the target was located on a microtiter plate of genomic library in microtiter plate monitoring..

\section{DNA sequencing}

DNA sequencing of this work was carried out by Europins MWG Operon (Ebersberg, Germany). 


\section{Results}

\section{Plate monitoring and a rapid procedure for colony identification}

A genomic library of $V$. longisporum was generated and contained 9,600 single clones in 100 96-well microtiter flat-bottomed plates. For characterisation of generated genomic library, the transformants of 24 wells each in 3 of 100 microtiter plates were selected randomly, inoculated, plasmids precipitated and inserts checked. About $50 \%$ of the clones were checked using agarose gel electrophoresis to see whether the expected insert was present.

A PCR procedure was developed for rapid screening and identification of a clone containing the target gene from the genomic library on 96-well microtiter plates (Sarstedt, Germany). The procedure was divided into three steps. Figure 5 showed one step for screening.

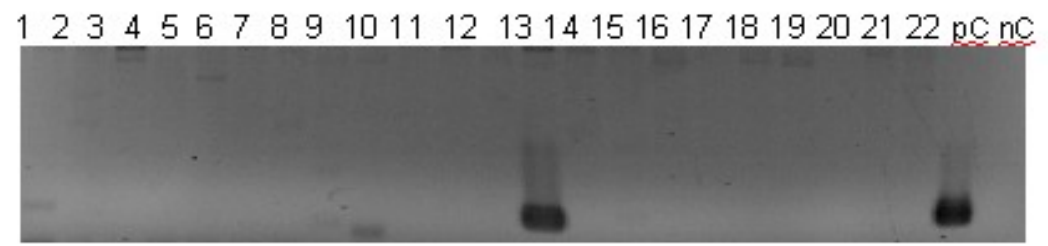

Figure 5: Library screening with plasmids DNA of collective pools as templates by PCR using target gene primers on agarosegel. For $\mathrm{pC}$ : positive control genomic DNA of $V$. longisporum was used. $\mathrm{nC}$ : negative control used $\mathrm{dd}_{2} \mathrm{O}$. 1-22: collective pools of genomic library.

\section{Detection of target genes from the genomic library}

The expected target genes VI_6.2, VI_NEP1, VI_NEP4, VI_NEP5 and VI-12.2 etc. were found in library.

\section{Analysis and characterisation of VI_6.2 gene}

The from the genomic library isolated VI_6.2 gene was sequenced completely. Full-length gene sequence of VI_6.2 with an ORF of 4720 bp nucleotides (supplementary data VI_6.2 sequence), cDNA translated sequence 1534 aa (Figure 8 ), 1 signal peptide with 8 aa, 1 fibronectin type III motif with 119 aa and 4 WSC domains contain 88 aa, 93 aa, 72 aa, and 104 aa respectively. A phylogenetic tree (Figure 7) analysis of VI_6.2-like gene indicates that the relationships and a sense of evolution time among $V$. longisporum VL43, $V$. 
dahliae VdLs.17 and V. albo-atrum VaMs.102 are very close than with other fungi. The phylogenetic tree was constructed using ClustalW2 software (EMBL-EMI). The protein sequence of $V$. longisporum translated using "Transgen" software (EMBL-EMI). The protein sequences of VI_6.2-like gene of related species were blasted using the NCBI database. A protein sequence analysis using the software SMART shows VI_6.2-similar genes in all 11 selected fungal strains containing 3-5 WSC domains. The WSC domain is a putative carbohydrate binding domain which is part of yeast cell wall integrity and a stress response component protein (18). Figure 6 shows a comparison at aminoacid sequence level among four VI_6.2 WSC domains with a WSC domain as consensus sequence in yeast SLG1 protein (21) using software SMART (imple Modular Architecture Research Tool) (22). The WSC domain is a putative carbohydrate binding domain. The domain contains up to eight conserved cysteine residues that may be involved in disulphide bridges. The yeast SLG1 protein contains only one WSC domain.
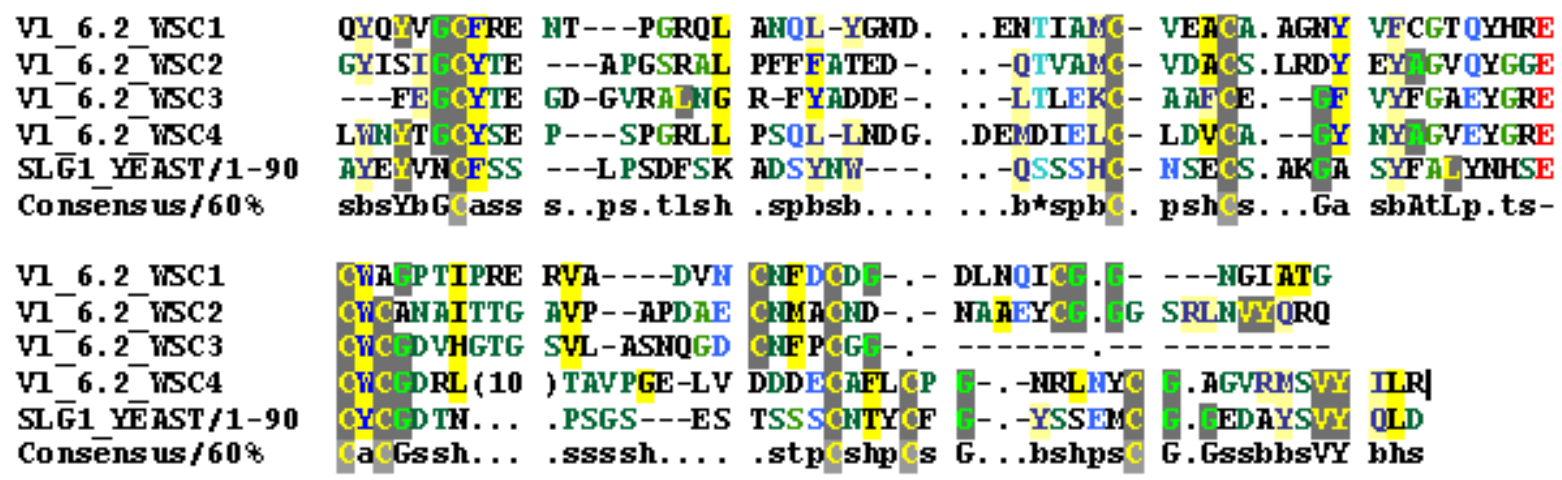

Figure 6: schemetic comparison of aminoacid sequences of four WSC domains with a WSC domain in yeast SLG1 protein (21) as consensus sequence using software SMART. The WSC domain is a putative carbohydrate binding domain. The domain contains up to eight conserved cysteine residues that may be involved in disulphide bridges. The yeast SLG1 protein contains only one WSC domain. 


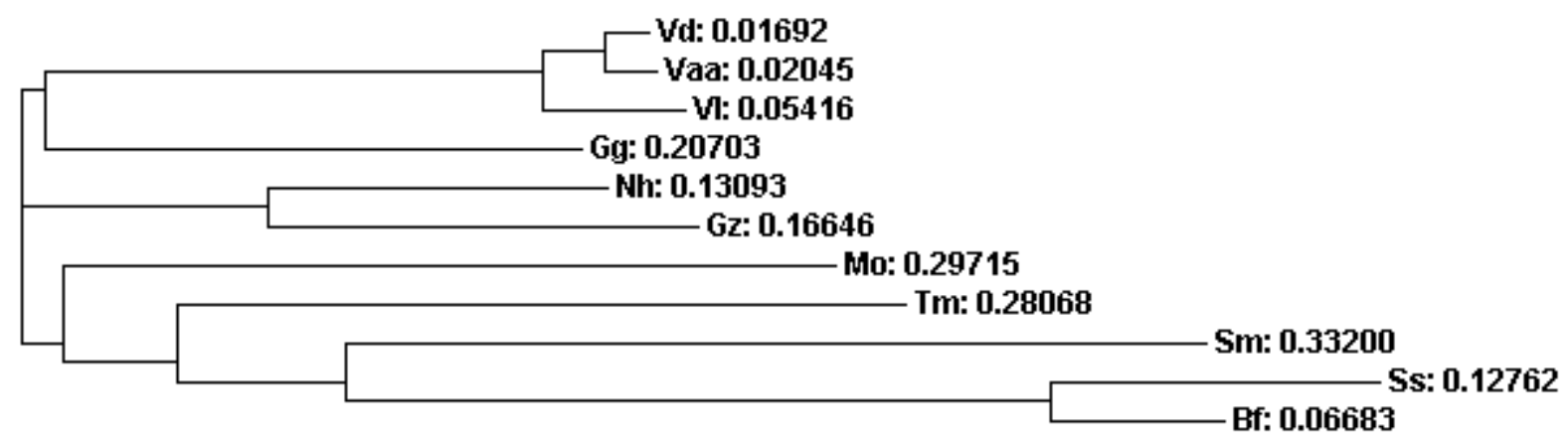

Figure 7: Phylogram of VI_6.2 gene at aminoacid level with related species containing putative WSC domains. The evolutionary relationship shows with distance. Vd: Verticillium dahliae VdLs.17; Vaa: Verticillium albo-atrum VaMs.102; VI: Verticillium longisporum VL43; Gg: Glomerella graminicola M1.001; Nh: Nectria haematococca mpVI 77-13-4; Gz: Gibberella zeae PH-1; Mo: Magnaporthe oryzae 70-15; Tm: Tuber melanosporum Mel28; Sm: Sordaria macrospora; Ss: Sclerotinia sclerotiorum 1980; Bf: Botryotinia fuckeliana B05.10.

MVSFRWLMLAAVAGLANGLADTDTITWGGDNSRAGYQTNHNMDPAVVRSSQFDRIFQTTLPGRYGGRAEQIFSQPLVYTP DDKQYVYLATTQNNVYKLDAQTGEILASRNLH I PELSTDLDGCYDIQPHVGVTGTGVIDPDTGTYYLLAKTYENQELVDV AQGRPAGRYYLHALDVNDLSERPNFPVGLEGTVARNNPDRS FNGGI HLQRPALLHVGQH IYAGLGSHCVKFNFTGWVMGW DKTTGEQVERFATQGEGVPQNTEGGGLWMAGGGLASDDQGS IFFATGNGYAGQLAEI PVNGRNPPTSLEEAAVHMT IQED GSLDLVDFFI PWDKRAMDGDDKDLGSSPLQI LPSEFSCGS IRRIGVVTGKNKKTYF INLDDMGGYRNGEDRFDNI IQTYE HENSVYAGAGVYPGEGGYIYINVVQYPTIVERFSCANGVPS FNKEAETPESNGYTLGVSHGTVTSLNGEPGTAMLWTTDV QNPPGQLRIYDAVPRDGELALLRKWEIAGVTKFSRAVFGDGIMYLGTTTGLFYGFGAPINRPIECTSPLEFGAVSLEASA ETRTLTCTALINTVVNDISLREVTDFS ISGLPTLPLTLAVGATFTIEAVFAPTDLGLLSTDVNIETENSVAGYRTTTSAR LTGTGETDNPRLSVSPREIEFDNVITAGAAPPANNVVLSNQGNSVLTVNEIRYSETINSTLQTWDPASGALVIGPFTIRN IPSTIDANSGATVSVSLSPANGGTFSGHVRFITDGGNTDVTMTAHVGAAPVLLVEFERPDGEGWTTYQEGTAFSFGEVTQ NNVRNLRMRITNTAPAGGVRLSLTVSKPPHGGSGI IRANNAVDLGEGTNLGPGLSETAVLYCAVPKRQWNMEPYQGEATW SLNTNDPKVAYQNIQFECTAVSEQSAPLLENGLSQYQYVGCFRENTPGRQLANQLYGNDENTIAMCVEACAAGNYVFCGT QYHRECWAGPTI PRERVADVNCNFDCDGDLNQ ICGGNGIATGPGGAYISLFADTLRFDGNETNI PEPEEPVEPTDP IVNP GVDGYISIGCYTEAPGSRALPFFFATEDQTVAMCVDACSLRDYEYAGVQYGGECWCANAITTGAVPAPDAECNMACNDNA AEYCGGGSRLNVYQRQSGGSFPSASVSLNGTIPAPTSSLIPASSVPVSSAPI ISSIVTSAAPPVPTPGEDHFIGDWSFEG CYTEGDGVRALNGRFYADDELTLEKCAAFCEGFVYFGAEYGRECWCGDVHGTGSVLASNQGDCNFPCGGDGSQFCGAGNR LQMYRFGGADAPSGAVSSSLVVPTSAVVSSTVALVSSTAAEVSSAVAEVSSQIAIEASTAPASSSVVEESTSVVETSSTV AVESSAVQSSSAQPSSAEASSVIEIMSSAVASSSFVPSSGIPSSTTPTSTPSPSVYPGNDLWNYTGCYSEPSPGRLLPSQ LLNDGDEMDIELCLDVCAGYNYAGVEYGRECWCGDRLNAEGDVPSEGTAVPGELVDDDECAFLCPGNRLNYCGAGVRMSV YILREREEALAEAS

Figure 8: scheme shows from VI_6.2 gene cDNA translated amino acids sequence (1534 aa) containing Signal peptide: green colour; (18 aa); Fibronectin type III (FN3): blue colour (119 aa); Fibronectin is a high-molecular weight ( 440 kDa) extracellular matrix glycoprotein that binds to membrane-spanning receptor proteins called integrins $(19,20)$. Sequence homology analysis revealed the presence of four conserved WSC carbohydrate binding domains (WSC domains) at the C-terminus. WSC domains: red colour (WSC1: 88 aa, WSC2: 93 aa, WSC3: 72 aa, WSC4: 104 aa). 


\section{Characterisation of VI_NEP1}

VI_NEP1 (Necrosis- and ethylene-inducing protein) was isolated from the genomic library and sequenced completely. Full-length gene sequence of VI_NEP1 with an ORF 763 bp nucleotides (Figure 9), cDNA translated sequence 233 aa (Figure 10). A phylogenetic tree (Figure 11) analysis of VI_NEP1(also named NPP1)-like gene indicates the relationships and a time orientation of evolution in the V. longisporum VL43, V. dahliae VdLs.17 and V. albo-atrum VaMs.102 are very close than with other fungi. $V$. longisporum is closer to $V$. albo-atrum than to $V$. dahliae. The phylogenetic tree was created using software "ClustalW" (EMBL-EMI). The protein sequence of $V$. longisporum was translated by software "Transgen" (EMBL-EMI). The protein sequences of VI_NEP1-like gene of related species were blasted from NCBI database. A protein sequence analysis by software SMART in all 15 selected fungal strains shows they are all NNP1-like necrosis inducing proteins. Infiltration of NPP1 into leaves of Arabidopsis thaliana plants result in transcript accumulation of pathogenesis-related (PR) genes, production of HR-like cell death (5).

During sequence analysis of VI_NEP1 we found a conserved hepta-peptide motif GHRHDWE $(6,7)$ essential for necrosis-inducing activity $(8)$ in 5x VI_NEP1-homological genes VI_NEPs (Figure 12), 9x Vd_NEPs (Figure 13) and 7x Vaa_NEPs (Figure 13).

GGATCCTCACAAGCTCGGGGCACAGGATTCAGACAGTGCTTGAAGCTGAGCTGTTCTCAGTTCTCCCTTAGGACACCACA ACAAATGACCGAACGAACCGGCCGGATGATCAGACCAAAACATGGTGCCGTGTTCATCAGCCCTGAATCGCAACCCCACA AGCGCACCAAGTAGATCCTGGTACAGATGCGCGCCTACCGTTGAGTCCCGGACATGTTCTGCTCCCATTGTGGCCATAGA TCCGCACGCCCTATCACCACCGCCTTTCTATCAGCCCCCGCATCACCAGAATGTGCGACAGCCTGGCTTTATTAGTCGTC GGACATGGCTACGCCTTCTTTCTCCGGTATAGCCTCGGTCCGTGCCGACTCAAATCAGTCTCAGGGGTTCGAATCGGGCT TACTCTAATGTGTTGGGGGTCCGGCCTTGCTATCCATGACTCGACATCAACCTCTATGGGCGTGCCACCAGTGCACCCGA ATGGCCCGGGTGGAACAGATGAACCAAAGTATGATAGATGAACCGGCTCCTCTGCCCTTGCCCACCTGCCCAGTCACGAC TCACTCAGCACCGTCCACGGTCACCGTCCTTGCGATCTCGCATGAATGAGTGCCGAGACATGGGTCACTGCCTACACAGC ACTTCGCCAAGGCGAGCTCACTGGGGTGGAGATTTATCGAATTATCGAATATCGTATCTGTCGGCCAAGTTCGGGCTGTC CGGGCCAAGACGACGATTTGATCTTTTGGGATTTGCGCTTAGACGATTGACTGGGCTACTCCAGGGTCTTTGAGCCACGC CCTTTACTGAAAGAGGCAAGGCATTCTCTTCTAGCAGGTGACAGCTGCTATTCAACAGAGCGCTATTCATGTCCACCTCT TGGGGGCGGAGCCGCTCCGCAGCAATGTATTTGCCTGGGTAGAGGATACAGCTAAGCCTACCTTAGCGGCTAGCCTCACG ATGTTCGTGTTCGCATCGTTAACGATGTCCGTCGACCGAGCTCGACATGAGTCGTATGCCTCAAGGACCCCTGGCATCTT GACACTGCAGCAAACATGACAACCACGACAGAATGAAGTAGGAAGCCCGGTGTGTCAACCAGCCGGTCTGTCTGCAGAAG GGTGGTCGATGGAAGGCCAAGGCAACTACATCTCCGGACATGATCAAAGTATATAAGAAGGACGATCACCGCTCCTTGAC TTATTTTGCTTCTCTTCCTCTCATCACCTAGCCTCATTCTCTCTCTCGTCATCTAAACAGCCATCTGCACCTGCTACGAT GCTTCCCTCCACAATCTTCTCGGTCTTTGCCCTCGTCGGCAGCGCCTTGGCTCAGCATCCCCCCAAGGTTAACCACGACA GTATCAACCCCGTCCGCGATACTCTGGGGCCCAACGGCGACATGATCAGGAAGTTCCAGCCTCTGCTTCACATTGCCCAC GGTTGCCAGCCTTACTCCGCTGTCAACACCCGCGGTGAGGTCAAGTAAGACACGCAGCACTCCCTTCAGCTTACACAAAG СтCCACGCTAACACATATTCTGCAGCGCCGGTCTCCAAGACAGCGGTACCACCGCAGGCGGCTGCAAGGAAACCAGCAAG GGCCAGACCTACGCCCGCTCCATGACCCTGAACGGCCAGTTCGGCATCATGTACGCCTGGTACTGGCCCAAGGACCAGCC CGCCGACGGCAACCTCGCCAGCGGCCACCGCCACGACTGGGAGAACGTCGTCATCTGGTTCAACTCGAACAACGCAAACC AGGCCGGCATCCTGCGCGGCGCCGCCTCGGGCCACGGCGACTACAAGAAGGTCAACAACCCCCAGCGCAACAACAACAAC CTCCACGTCGAGTACTTCACCAGCCTCGGCAAGAACCACGAGTTGCAGTTCAAGACGTCGCCCGGCCGCACCTACTGGAT CTGGGACTGGGACAGGATGGACAGCACCGTCCAGGGCGCCCTCAACCGCGCCGACTTTGGCAGCGCCAACTGCCCCTTCA ACAACAACAACTTTGAGAGGAACATGCGCGCCGCGTTTTAAAGGCTCGACGCGCGGCTCGCCAGTCCTGGATTCCATCTG GGCACGCATCTTGGCTCTTTCTCCTCCCGCCTTGGCTTGGCTTCTTGAGGCCAGTCGAGTGCTAGCATAGGTCCTGTACA TAGCTTGTTCTGAATTACATACAACTCTGCCTGTCGAATTTGGTCTTGCATTCTGTGATCGAGTGTGTAAGCTTTTACGC 
AGGTCGATAAATGACCAGTGCGTTGATTAGGTTCTTTCGTTGCTCTATTCATGGGTAGGTTCCCAGGAGCCCTGTCGTGA TCCCGAAAACTCAAATAAACAGCATCATGAACTTTATAAGGCCACCATGCACTGCAGTTGATGTTCCTTTGGAGTGGAAC ACCCCACTACCTTACCTCAAGCAGTGCAGCGGCAAGCAAGCTTGAGTCTCAACTTAATGTCAAGGAAACTGCTGCGGCAT TGAGAAATCAGAGCCAATTCCAATGATTGGGGCACTCCGGAACCCAGCACATATGTCAAAAGACCAGACACTCACAACCA AACACTGCAGATACAGCTCAATTCCAATATGACGATGATCGCATCGACTTGGTATGACATCGGACTGTGATCTCGTTCGA TAGACGAAATCCAAGTTTGCTGACATACACGTTGGGTGCGACAGCTTGGAGAAATGCTCGGCAACTGGTCCTGTGCCAGG ACGTACACAATGACGGGACCCGGCGGGGATGGGGCCGGTGGAGAGCTAGATCGACAGGATGACTTCCGCTGAGGAGACTT CGCGCTCCGGGGAACCGATGCCGCCAGTAATAGTCGAGGTGATCATTAGGGGTGCTAAGCAGTAAAGCAGGAAAGTTTGA ACTGTCCTACAAGTTCTTTGATGGTTTTATGTTTCGGTAAGCAGTGAGGACATCTCCTTATCATCGTAACGCCGCCCATT CTTCGTGCCTCGTCCATACGCTGCCCTGAGGATAATTCACCCAAGTATTACACCAAATAGAGAAATCGAGACAGAATGCT CTACGAAAAAGACGGGCGTCTGGTATGCTCCTATGACGGAGAAAAGCTCTGGATCGAGCCCTGGTCTGCCAATGCTTTCC GCGTCCGAGCCACCAAGCTCTCCACGATGCCGACAGAGAACTGGGCCCTGCAACAGCCTCTTCAGACCGGATCC

Figure 9: Full length sequence of VI_NEP1 gene (763 nt) and untranslated region. Coding sequence including one intron in blue colour, start code in green colour and stop code in red colour.

MLPSTIFSVFALVGSALAQHPPKVNHDSINPVRDTLGPNGDMIRKFQPLLHIAHGCQPYSAVNTRG EVNAGLQDSGTTAGGCKETSKGQTYARSMTLNGQFGIMYAWYWPKDQPADGNLASGHRHDWENVVI WFNSNNANQAGILRGAASGHGDYKKVNNPQRNNNNLHVEYFTSLGKNHELQFKTSPGRTYWIWDWD RMDSTVQGALNRADFGSANCPENNNNFERNMRAAF

Figure 10: Shown from VI_NEP1 gene cDNA translated amino acids sequence (233 aa).

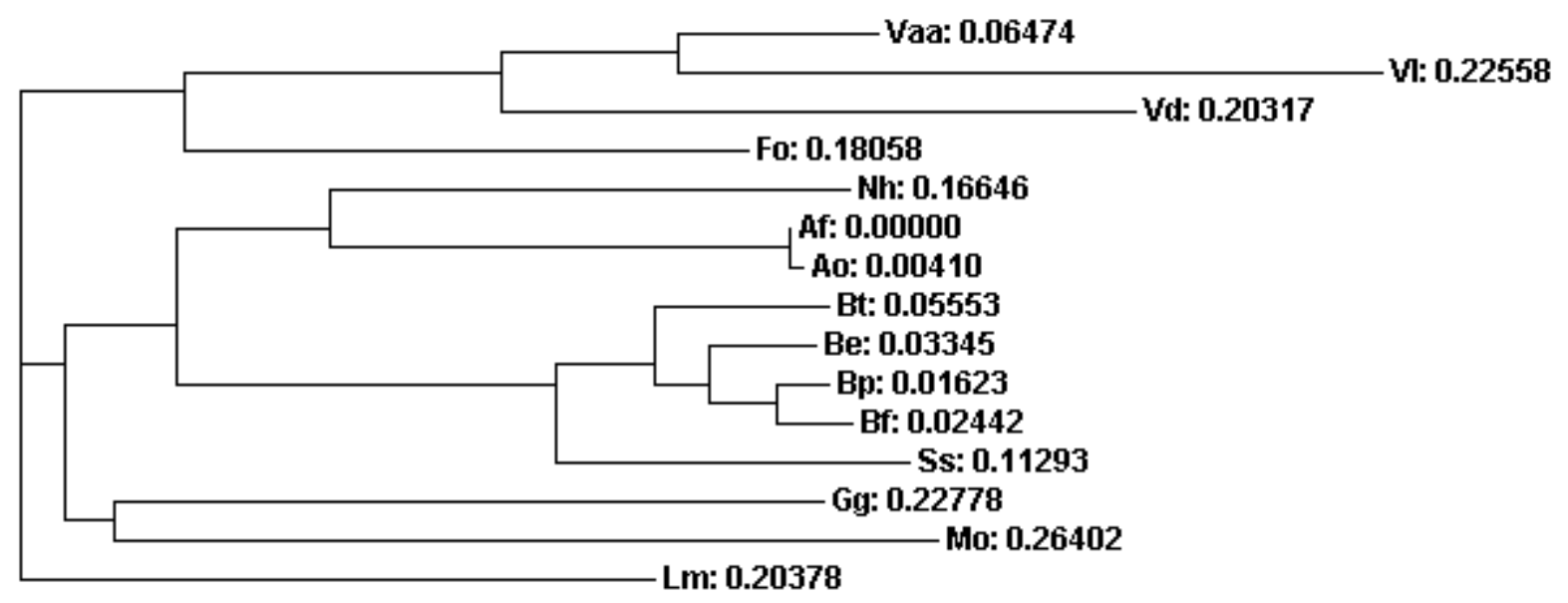

Figure 11: Phylogram of VI_NEP1 gene at aminoacid level with related species containing NEP1-like gene. The relationship shows with distance. Vaa: Verticillium albo-atrum VaMs.102; VI: Verticillium longisporum VL43; Vd: Verticillium dahliae VdLs.17; Fo: Fusarium oxysporum f. sp. erythroxyli; Nh: Nectria haematococca mpVI 77-13-4; Af: Aspergillus flavus NRRL3357; Ao: Aspergillus oryzae RIB40; Bt: Botrytis tulipae; Be: Botrytis elliptica; Bp: Botryotinia pelargonii; Bf: Botrytis fabae; Ss: Sclerotinia sclerotiorum 1980 UF-70; Gg: Glomerella graminicola M1.001; Mo: Magnaporthe oryzae 70-15; Lm: Leptosphaeria maculans. 
VI NEP-1 DQPADGNLASGHRHDWENVVIWFNSNN 138

V1- NEP-2 DQSVSSSFAGGHRHDWENVVVFARGDT 34

VI NEP-3 FQKDTATP IDGHRHDWEHIAVWVRQSD 117

V1 NEP-4 WAWSWPVSSYNHRHDWEHVVWWAKEGK 142

VI $\mathrm{NEP}-5$ AYSIYYKKDSGHKNDWENS TVIWNGDG 112

Figure 12: Alignment of a aminoacid sequence containing hepta-peptide motif GHRHDWE region from VI_NEPs in genome sequence of Verticillium longisporum VL43 using software ClustalW2 (EMBL-EMI). All candidates contain a conserved hepta-peptide motif GHRHDWE. VI_NEP-1, 3, 5 were up-regulated in gene relative expression test in planta by qRT-PCR (The result is not shown) (9).

\begin{tabular}{|c|c|c|}
\hline VDAG_01995.1 & MPKDAPSSGLGHRHDWEGAVWWLSSAA & \\
\hline VDAG_02984.1 & YFEKDHADIG AHKHDWEHIIVWVTDDR & 149 \\
\hline VDAG 03497.1 & YYFEADFGWG AHRHDWEHIAWWVQHGQ & 148 \\
\hline VDAG 04550.1 & DQSVSGSF AGGHRHDWENVVVF ARGDT & 141 \\
\hline VDAG_04701.1 & QP ADGNLASGPP ANDWENVVHL VQLEQ & 139 \\
\hline VDAG 04834.1 & PRRYTQLSIIAHRHDFENTVVFVDDPA & 54 \\
\hline VDAG 06993.1 & DQP IAGN VAGGHRHDWENVV VFVDDPA & 142 \\
\hline VDAG 08022.1 & WAWSWPV SGYNHRHDWEHVVWWAKEGK & 153 \\
\hline VDAG_09117.1 & FQKDT ATP IDGHRHDWEHIAWWVRQSD & 148 \\
\hline VDBG -01240.1 & WAWSWPVSGYNHRHDWEHVVWWAKEGK & 141 \\
\hline VDBG 01559.1 & MPKDAPSSGLGHRHDWEGAVWWLSSAA & 141 \\
\hline $\mathrm{BG}_{-}^{-} 05$ & DQSVSGSF AGGHRHDWENVVVF ARGDT & 142 \\
\hline $\mathrm{VDBG}^{-} 0.5343 .1$ & DQP IAGNV AGGHRHDWEN TVVFVDDPA & 142 \\
\hline VDBG_06347.1 & YYFEADFGWGAHRHDWEHIAVWVQHGQ & 148 \\
\hline $\mathrm{VDBG} 0$ & FQKDT ATP IDGHRHDWEHIAWWVRQSD & 148 \\
\hline 1 & DQP ADGNLVSGHRHDWENVV IWFNSNN & 138 \\
\hline
\end{tabular}

Figure 13: schemetic comparison of aminoacid sequence (in part) in Vd_NEPs (VDAG from genome sequence of Verticillium dahliae VdLs.17) and in Vaa_NEPs (VDBG from genome sequence of Verticillium albo-atrum VaMs.102) using software ClustalW(EMBLEMI). Amino acid sequences derived from Verticillium Group Database. The results show all selected candidates hold a conserved hepta-peptide motif GHRHDWE.

\section{Disscusion}

V. longisporum, V. dahliae and V. Verticillium albo-atrum are closely related species. They are all soilborne fungi causing disease on many economically significant crops $(10,11,12$, 13, 14). Because Verticillium isolates collected from horseradish producing long-spores, they were classified as V. dahliae var. longisporum by Stark in 1961 (15). After detailed 
study in morphological, physiological and molecular nature Karapapa et al. classified them as a separate species (16). Even now the taxonomy of Verticillium is still discussed (17). However, the host range and specificity, special symptoms after infection and other morphological, physiological and molecular descriptions are evidence for the existence of the separate species $V$. longisporum. This study confirms that $V$. longisporum, $V$. dahliae and $V$. albo-atrum are different, but they are very close related species compared with other selected fungal candidates after an analysis with VI_6.2 and VI_NEP1 gene on gene sequence level.

Worldwide access to the genome data gives us great help for sequence analysis which is prerequisite. Especially the successful investment in a genome project for $V$. dahliae and $V$. albo-atrum provides useful sequence information because of the high similarity at sequence level for the $V$. longisporum study. The nucleotide and protein sequence and blast function of Verticillium group database enabled us to design primers and to find a conserved necrosis-inducing active hepta-peptide motif GHRHDWE also in five NPP1-like VI_NEPs.

From a genomic library isolated full-length gene sequences with its UTR is very useful for generating target genes containing long sequences. A normal PCR based amplification of target genes is limited to sequence length, and its correctness is dependant on PCR efficiency and polymerase used.

This genomic library is not large enough to represent all gene sequences because it is limited by the total amount of clones. But this can be improved through a further expansion of the library. A monitoring of a genomic library with microtiter plate combined with a rapid colony-PCR based screening procedure is good for a small genomic library generation.

\section{References}

1. Ouellette, BFF, \& Boguski, M. S. (1997). Database divisions and homology search files: a guide for the perplexed. Genome Res. 7, 952-955.

2. Weld, R. J. \& Ridgway H. J. (2005). Extending AFLP sequences by long template PCR amplification of a fungal genomic library. BioTechniques 38: 372-374.

3. Sambrook, J. \& Russell, D. W. (2001). Molecular Cloning: A Laboratory Manual. $3^{\text {rd }}$ ed. CSH Laboratory Press, Cold Spring Harbor, NY. 
4. http://users.rcn.com/jkimball.ma.ultranet/BiologyPages/G/GenomeSizes.html (Visited on September 2010)

5. Fellbrich, G., Romanski, A., Varet, A., Blume, B., Brunner, F., Engelhardt, S., Felix, G., Kemmerling, B., Krzymowska, M. \& Nurnberger, T. (2002). NPP1, a Phytophthora-associated trigger of plant defence in parsley and Arabidopsis. Plant $\mathrm{J}$ 32: $375-390$

6. Gijzen, M. \& Nürnberger, T. (2006). Nep1-like protein from plant pathogens: Recruitment and diversification of the NPP1 domain across taxa. Phytochemistry 67: $1800-1807$.

7. Crooks, G. E., Hon, G., Chandonia, J. M. \& Brenner, S. E., (2004). WebLogo: a sequence logo generator. Genome Res. 14: 1188-1190.

8. Arenas, Y. C., Kalkman, R.I.C., Schouten, A., Diehoa, M., Vredenbregta, P., Uwumukizaa, B., Osés-Ruiza, M., \& van Kan J.A.L. van Kan. (2010). Functional analysis and mode of action of phytotoxic Nep1-like proteins of Botrytis cinerea. Physiological and Molecular Plant Pathology 74: 376-386.

9. Beinhoff, M., Weiberg, A., Xu, HQ. \& Karlovsky P. (2009). Characterization of NEPlike proteins (NLPs) of Verticillium longisporum according to their relevance for pathogenicity in Brassica napus. $10^{\text {th }}$ international Verticillium Symposium. Greece Corfu Island.

10.Domisch, K. H., Gams, W. \& Anderson, T. H. (1980). Nectria (Fr) 1849, Verticillium Nees ex Link 1824. In: Compendium of Soil Fungi. 1: 829-845. New York: Academic Press.

11. Schnathorst, W. C. (1981). Life cycle and epidemiology of Verticillium. In Mace, M. E., Bell, A.A. \& Beckmann, C. H. (Eds.), Fungal wilt diseases of plants. 81-111. New York: Academic Press.

12.Pegg, G. F. (1984). The impact of Verticillium diseases in agriculture. Phytopathologia Mediterranea. 23: 176-192.

13. Subbarao, K.V., Chassot, A., Gordon, T. R., Hubbard, J.C., Bonello, P., Mulin, R., Okamoto, D., Davis, R.M. \& Koike, S.T. (1995). Host range of Verticillium dahliae 
from cauliflower and genetic relationships and cross pathogenicities of isolates from different crops. Phytopathology. 85: 1105-1112.

14.Bhat, R. G. \& Subbarao, K.V. (1999). Host range specificity in Verticillium dahliae. Phytopathology. 89: 1218-1225.

15. Stark C. (1961). Das Auftreten der Verticillium-Tracheomykosen in Hamburger Gartenbau-Kulturen. Gartenbauwissenschaft 26: 493-528.

16.Karapapa, V.K., Bainbridge, B.W. \& Heale, J.B. (1997). Morphological and molecular characterisation of Verticillium longisporum comb. Nov., pathogenic to oilseed rape. Mycological Research. 101: 1281-1294.

17.Fahleson, J., Lagercrantz, U., Hu, Q., Sreventon, L.A. \& Dixelius, C. (2003). Estimation of genetic variation among Verticillium isolates using AFLP analysis. European Journal of Plant Pathology. 109: 361-371.

18.Lodder, A. L., Lee, T. K. \& Ballester, R. (1999). Characterization of the Wsc1 Protein, a Putative Receptor in the Stress Response of Saccharomyces cerevisiae. Genetics. 152: 1487-1499.

19. Watanabe T., Suzuki K., Oyanagi W., Ohnnishi K. \& Tanaka H. (1990). Its evolutionary relationship to Serratia chitinase and to the type III homology units of fibronectin. J. Biol. Chem. 265: 15659-16665.

20. Pankov, R. \& Yamada, K. M. (2002). Fibronectin at a glance. Journal of cell science 115: 3861-3863.

21.Lodder, A. L., Lee, T. K. \& Ballester, R. (1999). Characterization of the Wsc1 Protein, a Putative Receptor in the Stress Response of Saccharomyces cerevisiae. Genetics. 152: 1487-1499.

22. http://smart.embl-heidelberg.de/ (Visited on September 2010) 


\title{
Chapter 3: Determination of in planta gene expression by qRT-PCR
}

\author{
Haiquan Xu, Arne Weiberg and Petr Karlovsky
}

\section{Abstract}

The in planta determination of relative gene expression of pathogenicity related genes in V. longisporum compared to growth in vitro in a xylem-simulating medium (SXM) by quantitative reverse transcription real-time PCR (qRT-PCR) was applied for description of TDFs after cDNA-AFLP screening and sequence extensions. 10 genes have been characterised after their relative expression levels in planta by qRT-PCR, 6 of them indicated an up-regulated gene expression, 2 of them were down-regulated and further 2 were time-depended. The isolation, purification and transcription procedures of total RNA and mRNA from $V$. longisporum infected Brassica plants were improved and used for the determination of relative gene expression by qRT-PCR. A set of reference genes were tested.

\section{Introduction}

V. Iongisporum (VL) is a pathogen with host specificity on the Brassicas. Verticillium wilt has become a serious problem in northern Europe. After direct penetration of roots tips the mycelia of pathogen entry into xylem vessels of raps and format conidia and systemic colonise in vascular system. The metabolites in xylem vessels of host plant rapes are used as the elicitors for Verticillium cultivation in vitro for a pathogenicity related transcriptome screening using cDNA-Amplified fragment length polymorphism (AFLP) technique (1). The transcript derived fragments (TDFs), which are selected by cDNA-AFLP profiling procedure treated with xylem sap from health plant or infected plant. will be investigated by qRT-PCR.

A qRT-PCR is a variant of the standard PCR technique used for quantification of DNA or messenger RNA (mRNA) abundance developed in 1993 (2). The citations of qPCR have increased dramatically (3). Its on sequence specific primers based specificity and on measurement of fluorescence based high sensitivity allowed qRT-PCR to be a most suited 
method for evaluation of pathogen gene expression during the infection (4). The real-time PCR machine continuously monitor the fluorescence-based increase, which base upon double-stranded DNA combining with for example SYBR Green I or other similar dyes at each stage during the PCR cycle. A identification of relative copy-numbers between a sequence of target gene relative to a sequence of housekeeping gene performs a relative gene expression level of a target gene. The in planta determination of relative gene expression of phytopathogen $V$. longisporum compared to growth in vitro in a xylemsimulating medium by qRT-PCR was applied in this study for description of the putative pathogenicity related genes presented through TDFs.

The quantification of relative gene expression is achieved with analysing $\mathrm{Ct}$ value. The cycle numbers at the threshold level of log-based fluorescence are defined as Ct value (Figure 1). Several data analysis systems have been developed in the last years for relative quantification such as standard curve method for relative quantification, comparative $\mathrm{CT}\left(2^{-\Delta \Delta \mathrm{Ct}}\right)$ method and Pfaffl's model etc. (5). All systems include both target and control samples. Many applications of real-time PCR do not require complex models. The efficiency calibrated model $(6,7)$ and the $\Delta \Delta$ Ct model $(8)$ are widely applied $(3)$.

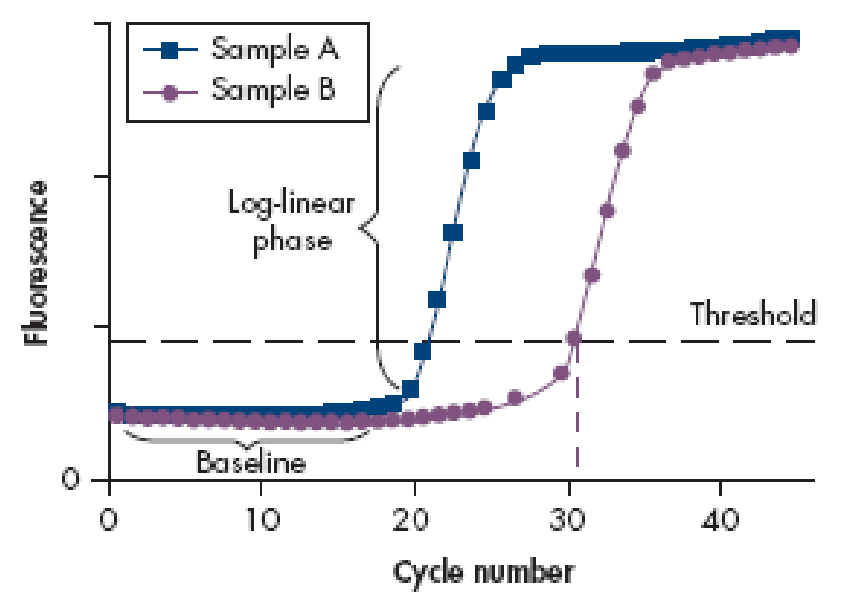

Figure 1: Amplification plots showing increases in fluorescence from 2 samples ( $A$ and $B$ ). Sample A contains a higher amount of starting template than sample B.

\section{Materials and methods}

\section{Fungal isolates and preparing inoculum}

The strain V. longisporum VL43 from Brassica napus grown in northern Germany as 
described was used in this research (Zeise and von Tiedermann) $(10,11)$.

For propagation, the spores were plated onto potato dextrose agar (PDA) and incubated at $23^{\circ} \mathrm{C}$ in the dark. The spore suspensions in a concentration of $1 \times 10^{6}$ spores $\mathrm{ml}^{-1}$ in potato dextrose broth (PDB) with $25 \%$ glycerin were used as fungal stocks at $-80^{\circ} \mathrm{C}$ for long time. Shake cultures were started through adding $500 \mu$ spore suspension $\left(1-3 \times 10^{6}\right.$ conidia ml $^{-}$

$\left.{ }^{1}\right)$ to $300 \mathrm{ml}$ Potato Dextrose or Czapek Dox broth. The inoculated broth was incubated at $23^{\circ} \mathrm{C}$ on a rotary shaker at $100 \mathrm{rpm}$ in the dark. After 7-14 days, the culture was filtered with steril gauze. Spore concentration was determined using microscope and diluted to $1 \mathrm{x}$ $10^{6}$ spores $\mathrm{ml}^{-1}$.

\section{Plant material and inoculation}

Rapid-cycle rape (Brassica napus var. napus, genome Acaacc[12]) was originally provided by P.H. Williams (Department of Plant Biology, University of Wisconsin-Madison, Wl; Crucifer Genetics Cooperative, Stock number 5). Oil-rape seeds were surface sterilised by immersing them in $70 \%$ ethanol for $30 \mathrm{~s}$ and then rinsed in sterilised tap water for $30 \mathrm{~s}$ three times before sowed in sterile silica sand. After 7days the germinated rape seedlings were carefully rinsed from silica substrate, cleaned roots, inoculated in spore suspension ( $1 \times 10^{6}$ spores $\mathrm{ml}^{-1}$ ) of $\mathrm{V}$. longisporum for 30-45 min by dipping, thinned to one plant per pot with an earth/sand mixture (1/1 v/v) and grown in a climatic chamber under constant conditions with a light regime $16 / 8 \mathrm{~h}$ (light/dark) and a temperature $23^{\circ} \mathrm{C} / 20^{\circ} \mathrm{C}$ (day/night). Seedling roots dipped in sterile tap water was as a negative control. Rape plant materials were harvested 14, 21, 28, 35 days post inoculation (dpi) for time-course experiments.

\section{Extraction of fungal genome DNA}

Fungal genomic DNA was extracted from $V$. longisporum mycelium after CTAB protocol (13). Weight lyophilized mycelium, pulverize $200 \mathrm{mg}$ in the mortar. Transfer ground mycelium to $50 \mathrm{ml}$ tube(s) (chloroform resistant) containing $10 \mathrm{ml}$ of TES-Puffer and $4 \mathrm{mg}$ Proteinase $\mathrm{K}(0.2 \mathrm{ml}$ of stock solution $20 \mathrm{mg} / \mathrm{ml})$. Incubate for $45 \mathrm{~min}$ at $45^{\circ} \mathrm{C}$ and then mix by turning the tubes every $10 \mathrm{~min}$. Following add $3.9 \mathrm{ml}$ of $5 \mathrm{M} \mathrm{NaCl}$ and mix well. Next add $1.4 \mathrm{ml}$ of $10 \% \mathrm{CTAB}$ and mix, incubate for $10 \mathrm{~min}$ at $65^{\circ} \mathrm{C}$ and cool tube(s) in ice/water-bath. Add $10 \mathrm{ml}$ Chloroform/Isopentylalcohol, mix throughly and then keep for 30 min in ice/water-bath. Transfer the upper phase and part of the lower phase into another centrifugation tube by pipetting. Spin for $20 \mathrm{~min}$ at $4,500 \mathrm{rpm}, 5^{\circ} \mathrm{C}$ (or $5 \mathrm{~min}$ at 10,000 
rpm). Transfer water phase to new tube(s) containing $10 \mathrm{ml}$ isopropanol (room temperature), mix thoroughly. If DNA precipitates immediately, continue directly with centrifugation (10 $\mathrm{min}$ at $4,500 \mathrm{rpm}$, room temperature). Finally rinse pellet with $70 \%$ ethanol, dry and dissolve in TE buffer.

Mix $4 \mu \mathrm{l}$ DNA solution and $4 \mu \mathrm{l}$ of a 10-times dilution with $2 \mu \mathrm{l}$ loading buffer, load on an $0,8 \%$ agarose gel with 25,50, 100 and 200 ng DNA of bacteriphage lambda. Run at 1 $\mathrm{V} / \mathrm{cm}$ till brompenol blue reaches $3 / 4$ of the length of the gel. Stain with ethidium bromide and visualize under UV light.

\section{Quantification of fungal DNA in planta tissue by qRT-PCR}

For quantification of fungal genomic DNA within the total extracted genomic DNA from Verticillium-infected plant, quantitative real-time PCR with SybrGreen carried out in iCycler (BioRad, Hercules, CA) was used. A 261 bp fragment of ITS region was amplified with the primer OLG70 (5'-CAGCGAAACGCGATATGTAG-3') and OLG71 GGCTTGTAGGGGGTTTAGA-3') in PCR and quantified (14). The amount of fungal DNA in the infected plant was derived from a calibration curve formed with a dilution set of fungal DNA.

\section{Total RNA extraction, mRNA purification and synthase of cDNA}

Total RNA was extracted with a "hot phenol" protocol for quantitative reverse transcription real-time PCR (qRT-PCR). The infected plant material or fungal Mycelium was pulverized under liquid nitrogen in mortars. The powdered material until $500 \mu$ volume was transferred into pre-cooled $2 \mathrm{ml}$ Eppendorf tube. Addition of $500 \mu \mathrm{l}$ of hot extraction buffer (Tris- $\mathrm{HCl}, 0.1$ $\mathrm{M}$; LiCl, 0.1 M; EDTA, $0.01 \mathrm{M}$; SDA, 1\%) (80 $\left.{ }^{\circ} \mathrm{C}\right)$ and vortexed. Addition of $500 \mu \mathrm{l}$ phenol (buffered, $\mathrm{pH} 7.5$ ) and vortexed. The tubes of samples were centrifuged at $13000 \mathrm{rpm}$ for $5 \mathrm{~min}$. and the supernatant was transferred into a new $2 \mathrm{ml}$ Eppendorf tube. Addition of $500 \mu \mathrm{l}$ of chloroform / isoaylalcohol mixture (24:1) and vortexed. The tubes of samples were centrifuged at $13000 \mathrm{rpm}$ for $5 \mathrm{~min}$. And the water phase (top) was transferred in a new 2ml Eppendorf tube. Addition of 1 Vol. of $\mathrm{LiCl}$ solution (4M) and vortexed. The RNA was precipitated at $4^{\circ} \mathrm{C}$ (on ice) for at least $3 \mathrm{hrs}$. After $\mathrm{LiCl}$ precipitation RNA samples were keept on ice. The tubes of samples were centrifuged at $13000 \mathrm{rpm}$ for $15 \mathrm{~min}$. The supernatant was removed at $4^{\circ} \mathrm{C}$. The pellet was dissolved with $15 \mu \mathrm{LEPC}$ water. Addition of $1.5 \mu \mathrm{l} \mathrm{NaOAc}(3 \mathrm{M}$, pH5.2) and $2.5 \mathrm{Vol}$. EtOH (96\%) and vortexed. The samples were 
kept on ice for $25 \mathrm{~min}$. The tubes of samples were centrifuged for $15 \mathrm{~min}$ at $4^{\circ} \mathrm{C}$ and 13000 rpm . The supernatant was removed and the pellet was washed with ice cold EtOH (70\%). The RNA pellet was dried and dissolved in 50-200 $\mu$ DEPC water. The isolated RNA samples were freezed in $-80^{\circ} \mathrm{C}$.

RNA was measured by ultraviolet absorbance at $260 \mathrm{~nm}$ and $280 \mathrm{~nm}$. Calculation of the RNA concentration is based on the absorbance at $260 \mathrm{~nm}$. Diethyl-pyrocarbonate (DEPC)treated water is used to dissolve RNA. Add $1 \mathrm{ml}$ of $0.1 \%$ DEPC to $1000 \mathrm{I}$ of $\mathrm{ddH}_{2} \mathrm{O}$, Mix and leave at room temperature for at least 1 hour. After Autoclave to be cooled to room temperature prior to use.

For increasing of target gene amount in complete template sample, the pure poly $\mathrm{A}^{+} \mathrm{mRNA}$ was purified from total RNA used with Oligotex mRNA Kits (Qiagen, Hilden, Germany). Oligotex resin consists of polystyrene-latex particles and a perfect spherical shape with dC10T30 oligonucleotides which covalently immobilized on the surface. The useful purification of poly A+ mRNA was provided by efficient hybridization. mRNA recoveries were greater than $90 \%$. The Oligotex requires less time and decreased the risk of degradation by RNases.

\section{6. qRT-PCR assay}

Root and hypocotyl of infected plant tissue were harvested on 14, 21, 28, 35 dpi and total RNA was extracted using hot phenol extraction protocol described above. Because of the low quantity of RNA from each plant, each total RNA sample was extracted from a tissue pool of six plants. mRNA was purified from total RNA samples using Oligotex mRNA Purification Kit (Qiagen, Hilden, Germany). About 500 -1000 ng mRNA were used in reverse transcription reactions together with 50pmol oligo-T primer, $1 \mathrm{mM}$ dNTPs, $20 \mathrm{U}$ RiboLock RNAse inhibitor and $200 \cup$ RevertAid reverse transcriptase (Fermentas, St. Leon-Rot, Germany) in a $20 \mu \mathrm{l}$ reaction volume. cDNA synthesized from mRNA was purified by PCR Purification Kit (Qiagen, Hilden, Germany) and quantified using a photospectrometer at $260 \mathrm{~nm}$ (GeneQuant, Cambridge, UK). About $100 \mathrm{ng}$ purified cDNA was used as template in qRT-PCR. SybrGreen system was used in real-time PCR. Housekeeping genes, $\beta$-tubulin and ribosomal protein $S 17(15,16)$. SybrGreen system was used in real-time PCR. Housekeeping genes, ribosomal protein S17, $\beta$-tubulin, GADPH, and Histone H3 $(15,16)$, were used for normalization. $\Delta \Delta C t$ and In efficiency 
calibrated $\Delta \Delta \mathrm{Ct}$ methods were used for quantification of mRNA level between in vitro and in planta samples (6).

\section{Primers used in qRT-PCR}

The primers of candidate internal reference genes (Table 1) and putative pathogenicity related genes of $V$. longisporum (Table 2) used in qRT-PR were designed on basis of TDFs from cDNA-AFLP screening and using different methods extended sequences.

Table 1: Primers of candidate internal reference genes

\begin{tabular}{|c|c|c|c|c|c|}
\hline \multirow[t]{2}{*}{ Nr. } & \multirow[t]{2}{*}{ Primer Name } & \multirow[t]{2}{*}{ Primer Sequences 5'-3' } & \multirow[t]{2}{*}{$\mathrm{Tm}^{\circ} \mathrm{C}$} & \multicolumn{2}{|c|}{ PCR fragment } \\
\hline & & & & gDNA & cDNA \\
\hline \multirow[t]{2}{*}{1} & Vl_GAPDH-f1 & CATGCTCAAGTACGACTCCACC & $57,5^{\circ} \mathrm{C}$ & \multirow[t]{2}{*}{$164 b p$} & \multirow[t]{2}{*}{$164 b p$} \\
\hline & VI_GAPDH-r1 & CAGTGGACTCGACGACGTACT & $57,7^{\circ} \mathrm{C}$ & & \\
\hline \multirow[t]{2}{*}{2} & VI_GAPDH-f2 & TCGCCAAGGTCATCAACGAC & $57,3^{\circ} \mathrm{C}$ & \multirow[t]{2}{*}{ 208bp } & \multirow[t]{2}{*}{$208 b p$} \\
\hline & Vl_GAPDH-r2 & CAGTGGACTCGACGACGTACT & $57,7^{\circ} \mathrm{C}$ & & \\
\hline \multirow[t]{2}{*}{3} & Vl_GAPDH-f3 & GCTCCCATCAAGGTTGGCAT & $57,9^{\circ} \mathrm{C}$ & \multirow[t]{2}{*}{$125 b p$} & \multirow[t]{2}{*}{$125 b p$} \\
\hline & VI_GAPDH-r3 & GCGTACTTGGTCTCAATGAAGGG & $57,8^{\circ} \mathrm{C}$ & & \\
\hline \multirow[t]{2}{*}{4} & VI_GAPDH-f3 & GCTCCCATCAAGGTTGGCAT & $57,9^{\circ} \mathrm{C}$ & \multirow[t]{2}{*}{$497 b p$} & \multirow[t]{2}{*}{$295 b p$} \\
\hline & VI_GAPDH-r1 & CAGTGGACTCGACGACGTACT & $57,7^{\circ} \mathrm{C}$ & & \\
\hline \multirow[t]{2}{*}{5} & VI_GAPDH-f3 & GCTCCCATCAAGGTTGGCAT & $57,9^{\circ} \mathrm{C}$ & \multirow[t]{2}{*}{$374 b p$} & \multirow[t]{2}{*}{$172 b p$} \\
\hline & Vd_GAPDH-R & CACCCTTGAAGACGCCGTG & $58,7^{\circ} \mathrm{C}$ & & \\
\hline \multirow[t]{2}{*}{6} & Histone H3-f & CGCGTGACGAGGAGATGC & $58,2^{\circ} \mathrm{C}$ & \multirow[t]{2}{*}{$163 b p$} & \multirow[t]{2}{*}{$163 b p$} \\
\hline & Histone H3-r & CGTATCCTTCGTGCCAACTG & $55,9^{\circ} \mathrm{C}$ & & \\
\hline \multirow[t]{2}{*}{7} & $\mathrm{Vd}$ _His H3-F & ATGCCACCACGCTCAGGTA & $58,3^{\circ} \mathrm{C}$ & \multirow[t]{2}{*}{$358 b p$} & \multirow[t]{2}{*}{$192 b p$} \\
\hline & Vd_His H3-R & СATCTCCTCGTCACGCGGT & $58,9^{\circ} \mathrm{C}$ & & \\
\hline \multirow[t]{2}{*}{8} & RP-S17-F & GCATCTGCGATGAGATCGCCA & $59,5^{\circ} \mathrm{C}$ & \multirow[t]{2}{*}{$264 b p$} & \multirow[t]{2}{*}{$196 \mathrm{bp}$} \\
\hline & RP-S17-R & TCGGAGTTCTGGGTAAAGTCGAGA & $58,5^{\circ} \mathrm{C}$ & & \\
\hline \multirow[t]{2}{*}{9} & Vd_RP-S17-F & GCATCTGCGATGAGATCGCC & $58,4^{\circ} \mathrm{C}$ & \multirow[t]{2}{*}{$256 b p$} & \multirow[t]{2}{*}{$188 \mathrm{bp}$} \\
\hline & $\mathrm{Vd} \_\mathrm{RP}-\mathrm{S} 17-\mathrm{R}$ & CTGGGTGAAGTCGAGAGCAGA & $58,1^{\circ} \mathrm{C}$ & & \\
\hline \multirow[t]{2}{*}{10} & VI_ $\beta$-tubulin-F & СTACCTGACСTGCTCCGCCATCT & $62,1^{\circ} \mathrm{C}$ & \multirow[t]{2}{*}{$344 b p$} & $278 b p$ \\
\hline & VI_ $\beta$-tubulin-R & GCTGGTACTCCGAAACGAGATCG & $59,2^{\circ} \mathrm{C}$ & & \\
\hline 11 & VI_ß-tubulin-F2 & CATGATGGCCGCCTCTGAC & $58,4^{\circ} \mathrm{C}$ & 192bp & $126 b p$ \\
\hline & VI_ß-tubulin-R2 & CGAAGAGTTCTTGCTCTGGACGT & $58,5^{\circ} \mathrm{C}$ & & \\
\hline
\end{tabular}




\begin{tabular}{|c|c|c|c|c|c|}
\hline \multirow[t]{2}{*}{12} & Vd- $\beta$-Tubulin-F & TCCGTAACGGTCGCTACCTG & $58,3^{\circ} \mathrm{C}$ & \multirow[t]{2}{*}{$261 \mathrm{bp}$} & \multirow[t]{2}{*}{ 193bp } \\
\hline & Vd- $\beta$-Tubulin-R & CCGACGAAGGTGGAGGACAT & $58,6^{\circ} \mathrm{C}$ & & \\
\hline \multirow[t]{2}{*}{13} & $\mathrm{Y}$-Tubulin-F1 & GGAAACCTTGAAGACTTCGC & $54,0^{\circ} \mathrm{C}$ & \multirow[t]{2}{*}{ 288bp } & \multirow[t]{2}{*}{$288 b p$} \\
\hline & Y-Tubulin-R1 & ATCGCTACCATCGGCCTCA & $57,8^{\circ} \mathrm{C}$ & & \\
\hline \multirow[t]{2}{*}{14} & Y-Tubulin-F2 & TGTCTGCGAGCACCACGAC & $59,6^{\circ} \mathrm{C}$ & \multirow[t]{2}{*}{$281 \mathrm{bp}$} & \multirow[t]{2}{*}{$281 b p$} \\
\hline & Y-Tubulin-R1 & GTCGACTTCGCCTTGAATGACG & $58,2^{\circ} \mathrm{C}$ & & \\
\hline
\end{tabular}

Table 2: Designed specific primers of putative pathogenicity related genes of $V$. longisporum after cDNA-AFLP screening

\begin{tabular}{|c|c|c|}
\hline Nr. & cDNA & Primer pair \\
\hline \multirow{2}{*}{1} & TDF2.1(VI_2.1)-XF & 5'-TCCAACATTGAGGCGTCGC-3' \\
\hline & TDF2.1(VI_2.1)-XR & 5'-TGGTGTCGGCGAATGAACC-3' \\
\hline \multirow{2}{*}{2} & TDF6.2(VI_6.2)-XF & 5'-CCTGGAGTCTCAACACCAACG-3' \\
\hline & TDF6.2(VI_6.2)-XR & 5'-TACGTAGTTGCCAGCAGCGC-3' \\
\hline \multirow{2}{*}{3} & TDF10.2(VI_10.2)-F & 5'-AATTTGTTCCGCCCACTTCCATCCG-3' \\
\hline & TDF10.2(VI_10.2)-R & 5'-ACGTGCTGGCTGGCGTAAGAC-3' \\
\hline \multirow{2}{*}{4} & TDF11.1(VI_11.1)-F & 5'-AATTTGCCCCTACCATGCGAG-3' \\
\hline & TDF11.1(VI_11.1)-R & 5'-TCGATTTCTTGTCTGTGTCGCC-3' \\
\hline \multirow{2}{*}{5} & TDF12.1(VI_12.1)-F & 5'-AGCCACAGTATTGCTACGC-3' \\
\hline & TDF12.1(VI_12.1)-R & 5'-GTATGGGTAGGATGTGTCG-3' \\
\hline \multirow{2}{*}{6} & TDF12.2(VI_12.2)-F & 5'-AATTCGTCCTCGGGCCTCAAGGCAGA-3' \\
\hline & TDF12.2(VI_12.2)-R & 5'-ACGTAATGTCATCACAGGTCAGAGTGG-3' \\
\hline \multirow{2}{*}{7} & TDF24.1(VI_24.1)-F & 5'-AATTTGACAAAGCGACCGAAGCTA-3' \\
\hline & TDF24.1(VI_24.1)-R & 5'-AGACTGAAGCCGGGCCAGA-3' \\
\hline \multirow[t]{2}{*}{8} & TDF34.2(VI_34.2)-F & 5'-ATCAGGCGCGCGAGAAGGAGCTG-3' \\
\hline & TDF34.2(VI_34.2)-R & 5'-ACGTGGGTCGGACAAACCTGTC-3' \\
\hline
\end{tabular}




\begin{tabular}{|l|l|l|}
\hline \multirow{3}{*}{9} & VINEP-F & 5'-CGGTGAGGTCAAGTAAGACACGC-3' \\
\cline { 2 - 3 } & VINEP-R & 5'-TGACGACATTCTCCCAGTCG-3' \\
\hline \multirow{2}{*}{10} & VIPKS1-F & 5'-ACATGTCGCCGCGCGAGCCTAC-3' \\
\cline { 2 - 3 } & VIPKS1-R & 5'-CAGGCTGTATCGATGTTCAGACTAGGTCCAC-3' \\
\hline
\end{tabular}

\section{Data analysis of qRT-PCR}

Since qRT-PCR as a powerful tool used for relative quantification of transcriptional level. Several data analysis procedures have been developed. In which $\Delta \Delta \mathrm{Ct}$ model (Livak and Schmittgen, 2001) and the efficiency calibrated model (Pfaffl, 2001) are widely applied. The experimental systems for both models include treatment and control samples. For each sample, the transcriptional level of target gene and reference gene or housekeeping gene were quantified. Amplification efficiency of reaction was performed from serially diluted aliquots by qRT-PCR. Typically, several biological replicates are used for each diluted concentration.

$\Delta \mathrm{Ct}($ Sample $)=\mathrm{Ct}$ target gene in sample $-\mathrm{Ct}$ reference gene in sample

$\Delta \mathrm{Ct}($ Calibrator $)=\mathrm{Ct}$ target gene in calibrator $-\mathrm{Ct}$ reference gene in calibrator

$\Delta \Delta \mathrm{Ct}=\Delta \mathrm{Ct}($ Sample $)-\Delta \mathrm{Ct}($ Calibrator $)$

In efficiency calibrated $\Delta \Delta \mathrm{Ct}$ model the Ct number was first plotted against cDNA input (or logarithm cDNA input), and the slope of the plot was calculated to determine the amplification efficiency. $\Delta \mathrm{Ct}$ for each gene (target or reference) is then calculated by subtracting the Ct number of target sample from that of control sample.

Statistical considerations are not widely discussed for the analysis of the effect of each experimental factor as well as significance testing. In $\Delta \Delta \mathrm{Ct}$ model $\Delta \mathrm{Ct}$ for treatment and control was subject to simple t-test, which will yield the estimation of $\Delta \Delta \mathrm{Ct}$. In efficiency calibrated $\Delta \Delta \mathrm{Ct}$ model a substantial statistical analysis of the REST® program (Pfaffl et al., 2002) was applied. The software based on the efficiency-calibrated model and presented randomization tests to obtain the significance level. 


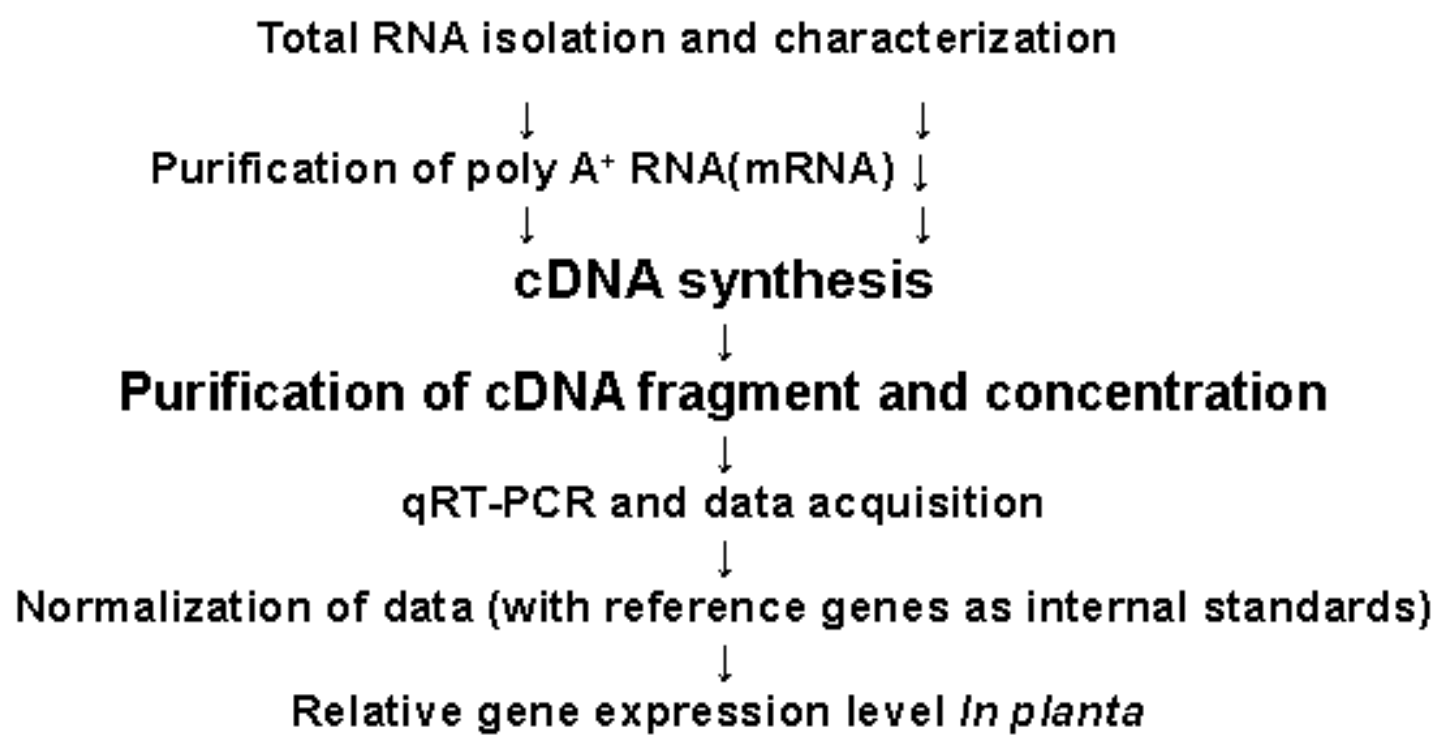

Figure 2: scheme for in planta determination of relative gene expression by qRT-PCR.

\section{Results and discussion}

1. Relative gene expression of putative pathogenicity related genes in planta

For assessment of pathogen $V$. longisporum, oilseed rape plants were inoculated with $V$. longisporum spores via root-dipping. The infection was found in lateral roots, xylem vessels, stems, leaves and pods etc. After 10 dpi the symptoms began to appear in a form of dark-coloured veins, slight chlorosis, a main symptom during the whole infection was clear expanded plant growth stunting (Figure 3). 


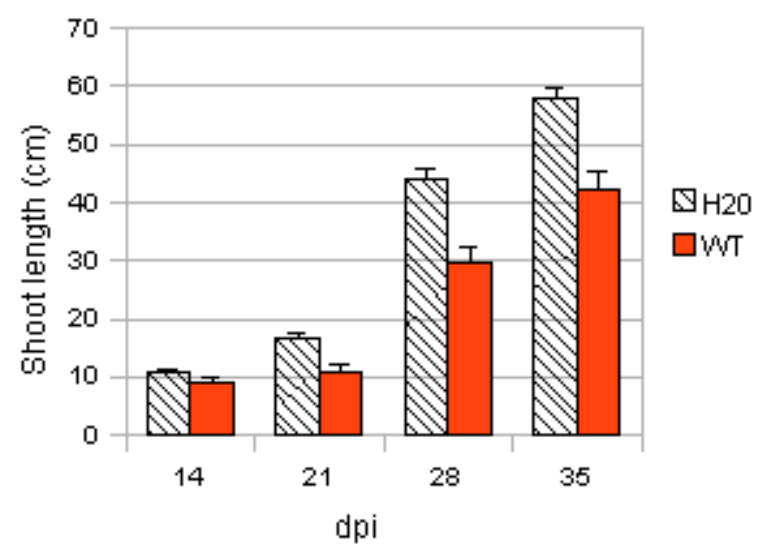

Figure 3: Assessment of disease symptoms on $B$. napus plants inoculated with $V$. longisporum VL43 (concentration $10^{6}$ spores / ml) compared to control (plants treated with water). Error bars indicated the standard deviation of plant growth. significance levels of $p$ $<0.05$ (student's t-test) between treated with wild type of $V$. longisporum and water.

The results of in planta determination of relative gene expression in $V$. longisporum during the infection compared to its growth in vitro in SXM medium by qRT-PCR were performed using different cDNAs transcripted from total RNA and mRNA respectively (Figure 4 and Figure 5). The expression of pathogen transcripts was measured with infected plant root and hypocotyl tissue in time course $14 \mathrm{dpi}, 21 \mathrm{dpi}, 28 \mathrm{dpi}$ and $35 \mathrm{dpi}$. We have not determined the relative gene expression by qRT-PCR using cDNA transcripted from total RNA at $14 \mathrm{dpi}$. We found all TDFs belong to the putative genes and each of them expressed in certain form and degree. The relative gene expressions for TDF6.2, TDF12.2, TDF34.2, and TDF24.1 were up-regulated by determination using qRT-PCR. The relative gene expression for TDF12.1 was suppressed and for TDF2.1 and TDF11.1 demonstrated time-dependent. TDF11.1 shown the different trends by the determination by qRT-PCR using cDNAs from total RNA and cDNAs from mRNA. TDF10.2 and TDF30.2 were down-regulated both using cDNAs from mRNA and total RNA. The extra selected candidate genes VINEP1 (encoding necrosis and ethylene inducing peptides) whose hetero-expression induced necrosis in planta (unpublished) and VIPKS1 (putative encoding polyketide synthase type I) performed a significant up-regulation in all tested time course. Two reference genes, $\beta$-tubulin and ribosomal peptide $S 17$ were used in qRTPCR using CDNAs transcripted with mRNA. In order to increase the statistic validation, we applied three reference genes glyceraldehyde-3-phosphate dehydrogenase (GADPH), 
ribosomal peptide S17 and histone H3 for qRT-PCR using cDNAs transcripted with total RNA.

\section{Establishment of in planta qRT-PCR and selection of primers}

qRT-PCR is a useful tool for determination of relative gene expression. However, in planta determination of pathogen $V$. longisporum gene expression during infection in host plant $B$. napus had to establish because of diversity of biological organisms and the special infection and colonisation form of $V$. longisporum, even qRT-PCR is suitable for pathogen biomass in the host in very low level (17). We have improved two procedures for identification of relative gene expression in planta (Figure 2) including "hot phenol" total RNA extraction protocol. one procedure used isolated mRNA for cDNA synthesis, the another used directly total RNA, both cDNAs were purified and concentrated in about 100 $\mathrm{ng} \mathrm{\mu l}^{-1}$ as template of qRT-PCR.

The specificity, amplification efficiency of all used primers for reference as well as putative pathogenicity related genes were validated respectively. They had no crossing-effect with host plant, the amplification efficiency arriving more than $90 \%$ and kept less difference between reference and target fragments. It is clear, not a single universal reference gene has been found, it exists yet at all (18). However, for this study ribosomal peptide S17, $\beta$ tubulin, GADPH, and histone H3 were selected as stably expressed both in vitro and in planta systems, respectively.

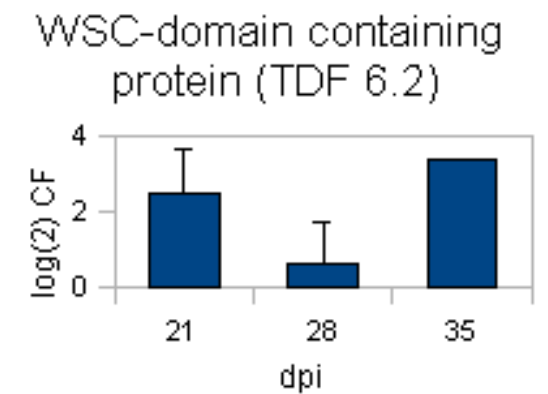

Unknown protein

(TDF 12.2)

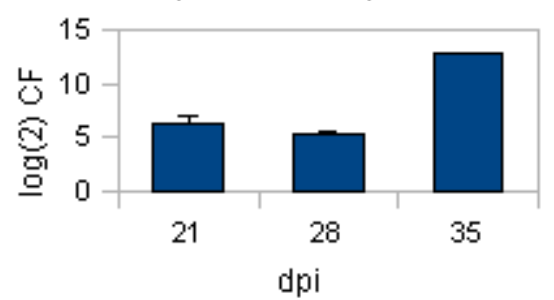

Unknown protein

(TDF 24.1)

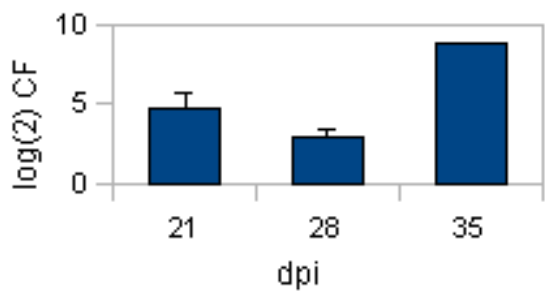

GRIM-19

(TDF 34.2)

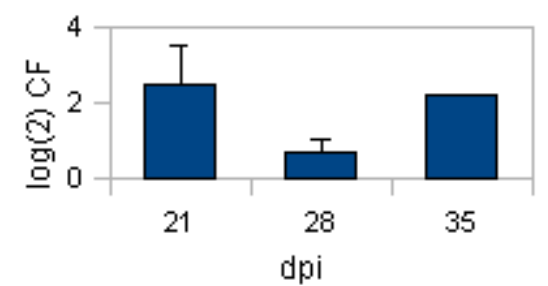

Figure 4a : In planta relative gene expression analasis of selected $V$. longisporum target 
genes VI_6.2 (TDF6.2), VI_24.1 (TDF24.1), VI_12.2(TDF12.2) and VI_34.2(TDF34.2) in time course after infection. The with total RNA transcripted cDNAs were used as templates for qRT-PCR.Transcript levels of selected Verticillium-genes were measured and normalised using three reference genes, GADPH, ribosomal peptide S17 and histone H3. Ratios of relative expression levels between Verticillium in vitro as calibrator and in planta as target were calculated as the $\Delta \Delta \mathrm{Ct}$ values of three biological replicas at each time point. Error bars indicated the standard deviation of calculated $\Delta \Delta \mathrm{Ct}$ values. Significance level was set to $p$ values $<0.05$ and was calculated for three reference genes, respectively. one asterisk indicates significant change in the expression levels regarding to one of the reference genes.

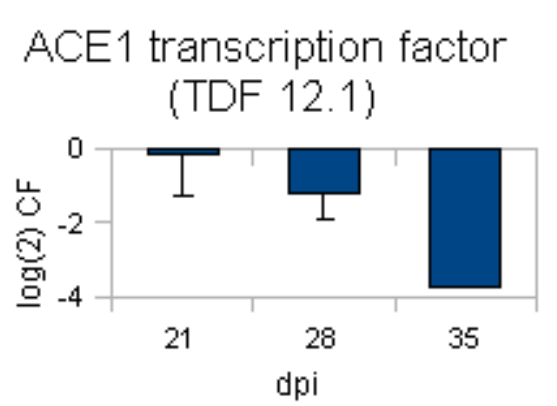

Unknown protein

(TDF 30.2)

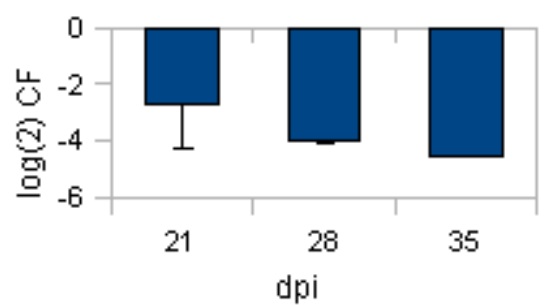

VI PKS1

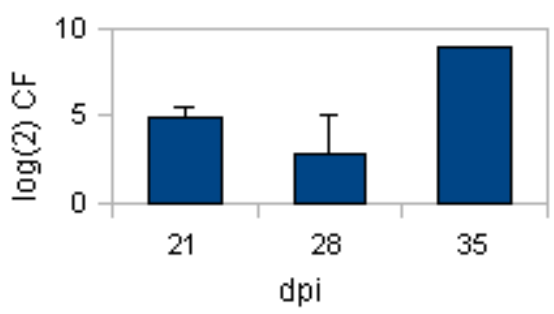

Isochorismate hydrolase

(TDF 2.1)

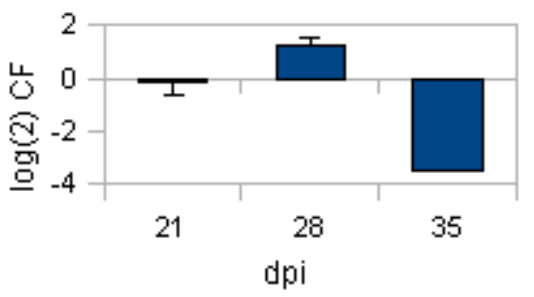

Catalase

(TDF 11.1)

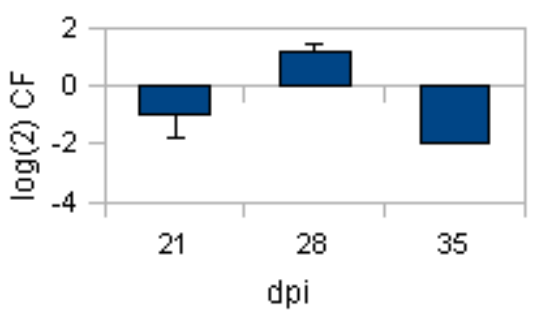

VI NEP

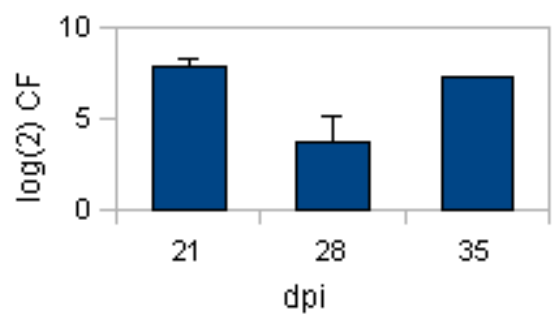

Figure 4b : In planta relative gene expression analasis of selected $V$. longisporum target genes VI_12.1 (TDF12.1), VI_2.1 (TDF2.1), VI_30.2(TDF30.2), VI_11.1(TDF11.1), VI_PKS1 and VI_NEP1 in time course after infection. The with total RNA transcripted cDNAs were used as templates for qRT-PCR. Transcript levels of selected Verticilliumgenes were measured and normalised using three reference genes, GADPH, ribosomal peptide S17 and histone H3. Ratios of relative expression levels between Verticillium in 
vitro as calibrator and in planta as target were calculated as the $\Delta \Delta \mathrm{Ct}$ values of three biological replicas at each time point. Error bars indicated the standard deviation of calculated $\Delta \Delta C$ t values. Significance level was set to $p$ values $<0.05$ and was calculated for three reference genes, respectively.

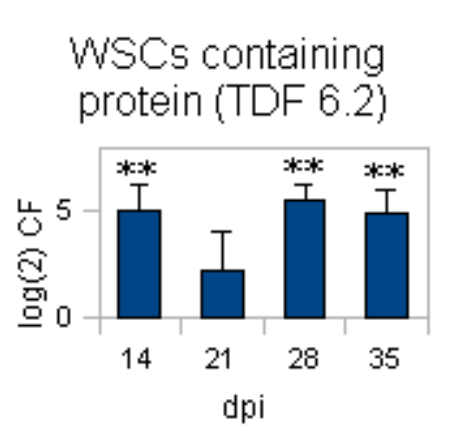

GRIM-19

(TDF 34.2)

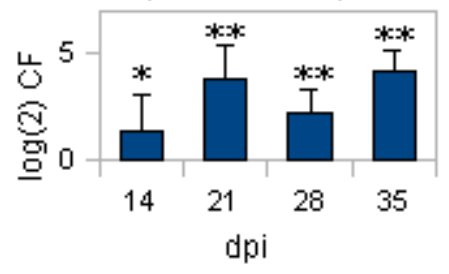

ACE1 tanscription

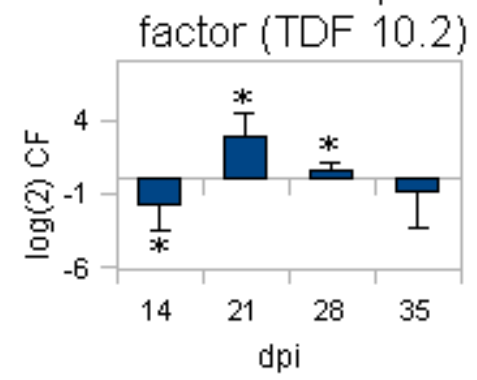

ACE1 transcription factor (TDF 12.1)

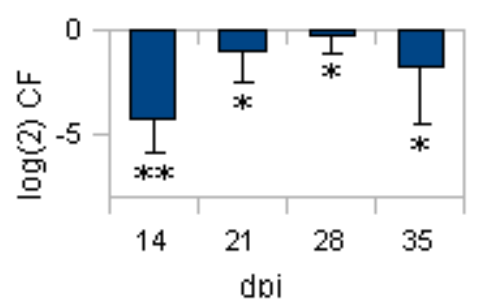

VIPKS1

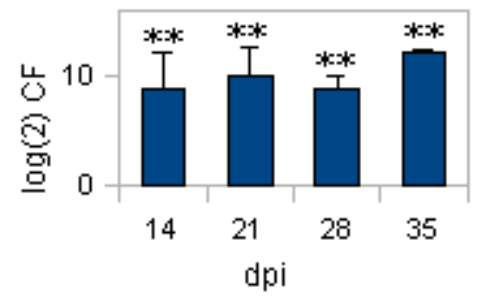

Unknown protein

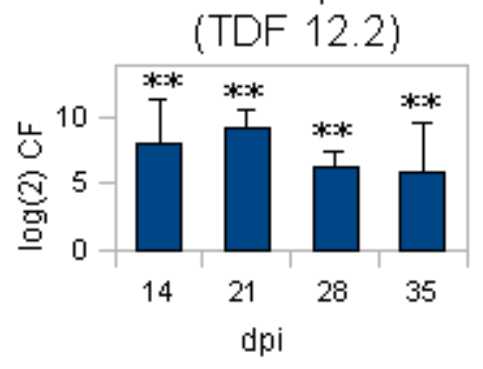

Unknown protein

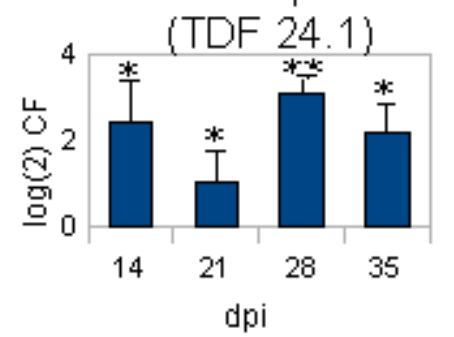

Isochorismate

hydrolase (TDF 2.1)

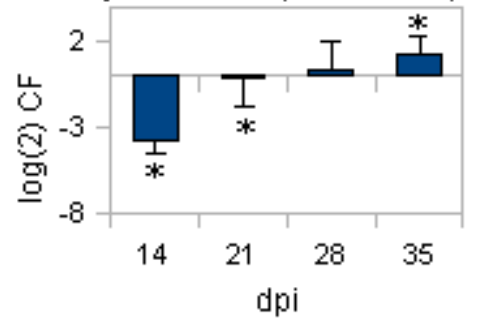

Catalase (TDF 11.1)
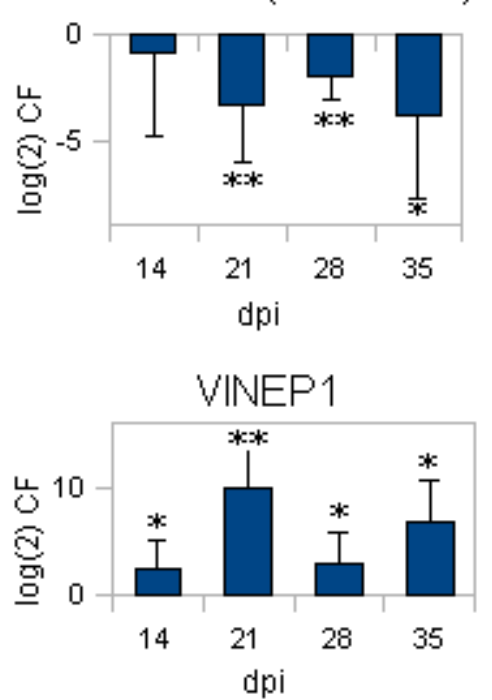

Figure 5: In planta relative gene expression analysis of selected $V$. longisporum target 
genes VI_6.2 (TDF6.2), VI_24.1 (TDF24.1), VI_12.2 (TDF12.2), VI_34.2 (TDF34.2), VI_12.1 (TDF12.1), VI_2.1 (TDF2.1), VI_10.2 (TDF10.2), VI_11.1 (TDF11.1), VI_PKS1 and VI_NEP1 in time course after infection. Transcript levels of selected Verticillium-genes were measured and normalised using two reference genes, $\beta$-tubulin and ribosomal peptide S17. Ratios of relative expression levels between Verticillium in vitro as calibrator and in planta as target were calculated as the $\Delta \Delta \mathrm{Ct}$ values of three biological replicas at each time point. Error bars indicated the standard deviation of calculated $\Delta \Delta \mathrm{Ct}$ values. Significance level was set to $p$ values $<0.05$ and was calculated for two reference genes, respectively. one asterisk indicates significant change in the expression levels regarding to one of the reference genes. The with purified mRNA transcripted cDNAs were used as templates for qRT-PCR. (modified from Weiberg, Xu et al. 2008).

\section{References}

1. Bachem, C. W., van der Hoeven, R. S., Bruijn, S. M., Vreugdenhil, D., Zabeau, M. \& Visser, R. G. (1996). Visualization of differential gene expression using a novel method of RNA fingerprinting based on AFLP: analysis of gene expression during potato tuber development. Plant J. 9: 745-753.

2. Higuchi, R., Fockler, C., Dollinger, G. \& Watson, R. (1993). Kinetic PCR: Real time monitoring of DNA amplification reactions. Biotechnology 11:1026-1030.

3. VanGuilder H. D., Vrana, K. E. \& Freeman, W. M. (2008). Twenty-five years of quantitative PCR for gene expression analysis. BioTechniques. 44: 619-626.

4. Wang, T. \& Brown, M. J. (1999). mRNA quantification by real time TaqMan polymerase chain reaction: validation and comparison with RNase protection. Anal. Biochem. 269: 198-201.

5. Wong, M.L. \& Medrano, J. F. (2005). Real-time PCR for mRNA quantitation. BioTechniques. 39: 1-11.

6. Pfaffl, M. W. (2001). A new mathematical model for relative quantification in realtime RT-PCR. Nucl. Acids Res. 29: 2002-2007.

7. Pfaffl, M. W., Horgan, G. W. \& Dempfle, L. (2002). Relative expression software tool $(\mathrm{REST}(\mathrm{C}))$ for group-wise comparison and statistical analysis of relative expression 
results in real-time PCR. Nucl. Acids Res. 30: e36.

8. Livak, K. J., \& Schmittgen, T. D. (2001). Analysis of relative gene expression data using real-time quantitative PCR and the 2- $\triangle \Delta C T$ method. Methods, 25: $402-408$.

9. Cook, P., Fu, C., Hickey, M., Han, E. S. \& Miller, K. S. (2004). SAS programs for real-time RT-PCR having multiple independent samples. Biotechniques. 37: 990995.

10.Zeise, K. \& von Tiedemann, A. (2001). Morphological and Physiological Differentiation among Vegetative Compatibility Groups of Verticillium dahliae in Relation to V. Iongisporum. J. Phytopathol. 149: 469-475.

11. Zeise, K. \& von Tiedemann, A. (2002). Application of RAPD-PCR for Virulence Type Analysis within Verticillium dahliae and Verticillium longisporum. J. Phytopathol. 150:557-563.

12. Williams P. H. \& Hill C. B. (1986). Rapid-Cycling Populations of Brassica. Science 232: $1385-1389$.

13. Murray, M. G., \& Thompson, W. F. (1980). Rapid isolation of high molecular-weight plant DNA. NAR 8: 4321-4325.

14.Eynck, C., Koopmann, B., Grunewalft-Stocker, G., Karlovsky, P. \& von Tiedemann A. (2007). Differential interactions of Verticillium longisporum and V. dahliae with Brassica napus detected with molecular and histological techniques. Eur. J. Plant Pathol. 118: 259-274.

15. Yan, H. Z. \& Liou, R. F. (2006). Selection of internal control genes for real-time quantitative RT-PCR assays in the oomycete plant pathogen Phytophthora parasitica. Fungal Genetics and Biology. 43 (6): 430-438.

16. Yamamoto, I., Numao, M., Sakaguchi, Y., Tsushima, N. \& Tanaka, M. (2007). Molecular characterization of sequence and expression of chicken GPR39. Gen Comp Endocrinol. 151(1):128-34.

17. Goerke, C., Bayer, M. G. \& Wolz, C. (2001). Quantification of bacterial transcripts during infection using competitive reverse transcription-PCR (RT-PCR) and 
LightCycler RT-PCR. Clin. Disgn. Lab. Immun. 8: 279-282.

18. Andersen, C. L., Jensen, J. L. \& Ørntoft, T. F. (2004). Normalization of real-time quantitative reverse transcrition-pcr data: a model-based variance estimation approach to identify genes suited for normalization, applied to bladder and colon cancer data sets. Cancer Research. 64: 5245-5250.

19. Chandler, D. P., Wagnon, C. A. \& Bolton, H. Jr. (1998) Reverse transcriptase (RT) inhibition of PCR at low concentrations of template and its implications for quantitative RT-PCR. Appl. Environ. Microbiol. 64: 669.

20.Engel, H., Küppers, C. \& Löffert, D. (2003) Highly efficient multiplex PCR using novel reaction chemistry. QIAGEN News 2003, 41.

21. Henegariu, O., Heerema, N.A., Dlouhy, S.R., Vance, G.H., \& Vogt, P.H. (1997) Multiplex PCR: critical parameters and step-by-step protocol. Biotechniques 23, 504.

22. Higuchi, R., Dollinger, G., Walsh, P. S., \& Griffith, R. (1992). Simultaneous amplification and detection of specific DNA sequences. Biotechnology 10:413-417.

23. Logan J, Edwards K, \& Saunders, N. (2009). Real-Time PCR: Current Technology and Applications. Caister Academic Press.ISBN 978-1-904455-39-4.

24. Mackay, I. M. (2007). Real-Time PCR in Microbiology. Caister Academic Press. ISBN 978-1-904455-18-9

25. Multiplex PCR that simply works - the new QIAGEN Multiplex PCR Kit. QIAGEN News 2002, No. 5, 1.

26. Rita S. Cha \& William G. Thilly. (1993). Specificity, Efficiency, and Fidelity of PCR. Genome Res. 3: 18-29. Cold Spring Harbor Laboratory Press.

27. Sambrook, J, Fritsch, E, \& Maniatis, T. (1989). Molecular Cloning: A Laboratory Manual. $2^{\text {nd }}$ ed. New York: Cold Spring Harbor Laboratory Press.

28. Wawrik, B., Paul, J. H., Tabita, F. R. (2002). Real-time PCR quantification of $r b c L$ (ribulose-1,5-bisphosphate carboxylase/oxygenase) mRNA in diatoms and pelagophytes. Appl. Environ. Microbiol. 68: 3771-3779. 


\title{
Chapter 4: A potential pathogenicity related gene VI_6.2 from Verticillium longisporum and its role in cell-wall integrity
}

\author{
Haiquan Xu, Arne Weiberg, Petr Karlovsky
}

\begin{abstract}
A transcript we designated as VI_6.2 was among a set of genes identified by a cDNAAFLP. VI_6.2 showed strong regulation when the effects of xylem sap metabolites of the host plant Brassica napus on the transcriptome of $V$. longisporum were investigated. This find was confirmed by measuring strongly enhanced transcript accumulation in planta during infection of $B$. napus compared to in vitro cultivation of $V$. longisporum.

Full gene sequence analysis of VI_6.2 showed it to comprise of an ORF of 4,722 nucleotides (nt), two introns and translated cDNA is predicted to code for a 1,534 amino acids (aa). Sequence homology analysis (pBLAST, SMART) revealed the presence of four repetitive water soluble carbohydrate (WSC) binding domains at the C-terminus. WSC domains have been reported to influence membrane integrity in different microbes like baker's yeast (Saccharomyces cerevisiae).
\end{abstract}

Through a sequence-specific antisense RNA the gene translation was silenced in $V$. longisporum and transcript accumulation was suppressed to $70 \%$ of its activity in transformants to the non transformed wild type determined by quantitative reverse transcription real-time PCR (qRT-PCR).

Mycelial growth of gene-silenced mutants was inhibited in the presence of membrane disrupting detergent SDS (sodium dodecyl sulfate) in PDA plate with a concentration in 0.2 $\%$. A alkaline stress response related melanistic process of mutants was delayed at $\mathrm{pH} 9$. VI_6.2 gene silenced mutants reduced virulence in B. napus. 


\section{Introduction}

V. Iongisporum is a soil borne plant pathogen on oilseed rape (Brassica napus spp. oleifera) $(29,30,31)$ and has been observed to induce rape's vascular wilt in northern Europe. This disease results in increased economic losses in Sweden and Germany since about 50 years $(32,33,34)$. Phylogenetic analysis of $V$. longisporum shows a very close relation to $V$. dahliae and $V$. albo-atrum (35). The morphology of $V$. longisporum is very similar to other two important phytopathogen $V$. dahliae and $V$. albo-atrum with a small difference in the length of spores $(36,37,38)$.

The fungal cell wall constructs cell form and supports cell integrity to interact with extracellular stress $(14,15)$. PKC1-MPK1 pathway (Protein kinase C - Mitogen-activated protein kinase $)(16,17,18,19,20,21,22)$ was involved in an activation, which produces a major component 1 , 3-beta-D-glucan synthase of cell wall $(23,24,25)$, and reacts to disturb the cell wall (26). WSC (Water-soluble carbohydrate binding) domains are members of a protein family in the yeast Saccharomyces cerevisiae and are putative upstream activators of the PKC1-MPK1 pathway $(15,17)$. A deletion of Wsc1, Wsc2 or Wsc3 induced sensitivity of $S$. cerevisiae cell to extracellular stresses $(16,27,28)$. MPK1 pathway affects also microsclerotia formation and pathogenicity in $\mathrm{V}$. dahliae (26).

Gene silencing with additional antisense RNA in the cell is a classic method discovered by plant scientists in 1988. Flower pigmentation in petunia and tabacco plants was reduced by a constitutive expression of a chalcone synthase gene in antisense direction (1). A few years later this technique was successfully used for the first genetically engineered food tomato "Flavr Savr", The tomato gene polygalacturonase, which is responsible for degradation of cell wall component pectin, was suppressed in this way (2). Antisense RNA gene silencing controls have been applied in many cases of fungi $(3,4,5,6,7)$. This applification is especially useful when the target gene is represented by multiple copies in the fungal genome (8). Antisence RNA-mediated silencing control has also been used in Bacteria (9) and viruses. The short regions of viral RNA sequences, which was uncoded for any viral protein, was carried in plants for increasing of plant resistance against pathogen virus $(10,11)$. These post-transcriptional gene-silencing phenomena may occur via an increased rate of mRNA degradation (12). Antisense RNA technology exhibits is a useful mild genetic tool (13) in gene regulation and has the following advantages compared to other knock-out methods such as low cost, quick and easy to operate. 
Argrobacterium tumefaciens-mediated transformation has been a useful tool for fungal transformation since 1998 (39). An improved protocol has been applied to transform filamentous fungus $V$. longisporum (40).

In this work we characterized a putative WSC domains involved VI_6.2 gene, which found by cDNA-AFLP profiling induced with xylem sap of oilseed rape (Brassica napus spp. oleifera) (41) and silenced with an Antisense RNA method (42).

\section{Materials and Methods}

\section{Bacterial strains}

Escherichia coli strain DH5a and Agrobacterium tumefaciiens strain AGL1 (provided by Dr. Susanne Frick, Leibniz Institute of Plant Biochemistry, Halle/Saale,Germany) were used for plasmid construction and fungal transformation $(43,44,45)$. The strain was stored in a 9 : 1 (water to glycerol) suspension at $-80^{\circ} \mathrm{C}$. Agrobacterium tumefaciens strain AGL1, containing rifampicin and carbenicillin bacterial selection markers.

\section{Fungal isolates and Preparation of fungal inoculum for plant infection}

V. longisporum VL43 isolate from B. Napus (provided by Prof. A. Von Tiedemann, GerogAugust University Göttingen, Göttingen, Germany), was used in the study. For general cultivation, potato dextrose broth (PDB) or Czapek-Dox broth (Difco) media and with agar were used. Fungal stocks were stored at $-80^{\circ} \mathrm{C}$ in $25 \%$ glycerol with about $10^{6}$ conidia $\mathrm{ml}^{-1}$. Shake cultures were begun by adding $500 \mu \mathrm{l}$ spore suspension $\left(1-3 \times 10^{6}\right.$ conidia $\left.\mathrm{ml}^{-1}\right)$ to $300 \mathrm{ml}$ Potato Dextrose or Czapek Dox broth. The inoculated broth was incubated at $23^{\circ} \mathrm{C}$ on a rotary shaker at $100 \mathrm{rpm}$ in the dark. After 7-10 days, the culture was filtered with sterile gauze. Spore concentration was determined using a microscope and diluted to $1 \mathrm{x}$ $10^{6}$ spores $\mathrm{ml}^{-1}$.

For the quantification of transcripts levels of VI_6.2 silenced mutants in vitro by qRT-PCR a liquid simulated xylem fluid medium (SXM) was used $(46,47)$. V. longisporum 6.2 Gene silencing mutants were grown in $100 \mathrm{ml} \mathrm{SXM} \mathrm{liquid} \mathrm{medium} \mathrm{for} 7$ days at $23^{\circ} \mathrm{C}$ on a rotary shaker (150 rpm), inoculated with $100 \mu \mathrm{l}$ of $10^{6}$ spores $\mathrm{ml}^{-1}$ glycerol spore solution. SXM was designed to reflect the nutritional conditions of the vascular fluid, and contains sodium polypectate $\left(2 \mathrm{~g} \mathrm{l}^{-1}\right)$, vitamin-free casamino acids $\left(4 \mathrm{~g} \mathrm{l}^{-1}\right), 1 \mathrm{x}$ trace elements $(48), 1 \mathrm{x}$ potassium salts, and $0.1 \mu \mathrm{M}$ biotin. 


\section{Plant material, inoculation, cultivation and assessment of disease development}

Rapid-cycle rape (Brassica napus var. napus, genome ACaacc[36]) was originally provided by P.H. Williams (Department of Plant Biology, University of Wisconsin-Madison, Wl; Crucifer Genetics Cooperative, Stock number 5).

Rapid-cycling rape seeds were surface sterilised by immersing them in $70 \%$ ethanol for 30 $\mathrm{s}$ and rinsed in sterilised tap water for $30 \mathrm{~s}$ three times. Then the Rapid-cycling rape seeds were germinated in sterile silica sand in climate-controlled chambers (30 kLux, 60\% humidity, $23 / 20^{\circ} \mathrm{C}$ (day/night) temperature and $15 / 9 \mathrm{~h}$ (light/dark) light regime, Philips TL5 HO lamps). Seven-day-old seedling were carefully rinsed from silica sand, the cleaned roots were inoculated in a spore suspension of $V$. longisporum isolate VL43 or its mutants ( $1 \times 106$ spores $\mathrm{ml}-1)$ by root-dipping for 30-45 min. Seedling roots dipped in sterile tap water were used as negative controls. Subsequently, single seedlings were planted into pots with sterile sand-soil mixture $(1: 1)$ and grown under the constant conditions described above. Rape plant material was harvested at 14, 21, 28, 35 days post inoculation (dpi) for time-course experiments.

Plants were scored for disease symptoms using an assessment key according to Zeise (Table 1) (49). For plant stunting plant shoot length was measured.

Table 1: Assessment key for scoring disease symptoms induced by Verticillium sp. on $B$. napus plants in the greenhouse (following Zeise 1992, Eynck 2007)

\begin{tabular}{|l|l|}
\hline Score & Symptom description \\
\hline 1 & no symptoms \\
\hline 2 & slight symptoms on oldest leaf (yellowing, black veins) \\
\hline 3 & slight symptoms on next younger leaves \\
\hline 4 & about $50 \%$ of leaves show symptoms \\
\hline 5 & $>50 \%$ of leaves show symptoms \\
\hline 6 & up to $50 \%$ of leaves dead \\
\hline 7 & $>50 \%$ of leaves dead \\
\hline 8 & only apical meristem still alive \\
\hline 9 & plant dead \\
\hline
\end{tabular}




\section{Genomic DNA extraction and checking the quality and quantity of DNA}

Fungal genomic DNA was extracted from $V$. longisporum mycelium following CTAB protocol (50). Lyophilized mycelium (200 mg), was pulverized in mortars. A small amount of sand was used when necessary. (Mortar and Pestle were washed and dried throughly between samples, there was no need to autoclave). The ground mycelium was transferred to $50 \mathrm{ml}$-tube(s) (chloroform resistant) containing $10 \mathrm{ml}$ of TES-Puffer and $4 \mathrm{mg}$ Proteinase $\mathrm{K}\left(0.2 \mathrm{ml}\right.$ of stock solution $\left.20 \mathrm{mg} \mathrm{ml}^{-1}\right)$. Incubated for $45 \mathrm{~min}$. at $45^{\circ} \mathrm{C}$, mixed by turning the tubes every $10 \mathrm{~min}$. Addition of $3.9 \mathrm{ml}$ of $5 \mathrm{M} \mathrm{NaCl}$, mixed well. Addition of $1.4 \mathrm{ml}$ of $10 \%$ CTAB, mixed, incubated for $10 \mathrm{~min}$ at $65^{\circ} \mathrm{C}$. Cool tube(s) in ice/water-bath, addition of 10 $\mathrm{ml} \mathrm{Chloroform/Isoamylalcohol.} \mathrm{Mixed} \mathrm{throughly,} \mathrm{kept} \mathrm{for} 30 \mathrm{~min}$. in ice/water-bath. Notes: Some perform this incubation at room temperature. The incubation could be prolonged to over night. Processing 8 samples up to this point took $4 \mathrm{~h}$. The upper phase and part of the lower phases were transferred into another centrifugation tube by pipetting (or pouring - avoid sand if reusable tubes are used). Samples were centrifuged for $20 \mathrm{~min}$ at 4,500 $\mathrm{rpm}, 5^{\circ} \mathrm{C}$ (or $5 \mathrm{~min}$ at $10,000 \mathrm{rpm}$ ). Water phase was transferred to new tube(s) containing $10 \mathrm{ml}$ isopropanol (room temperature), and mixed thoroughly. If DNA precipitates, continued with centrifugation (10 $\mathrm{min}$ at $4,500 \mathrm{rpm}$, room temperature). If no precipitate was visible, tubes were kept at room temperature for $1 \mathrm{~h}$ and then centrifuged as above, Pellet was washed with $70 \%$ ethanol, dried and dissolved in TE buffer.

After mixing $4 \mu \mathrm{I}$ DNA solution and $4 \mu \mathrm{l}$ of a 10-times dilution of the DNA with $2 \mu \mathrm{l}$ loading buffer, the DNA was loaded on an 0,8\% agarose gel with 25, 50, 100 and $200 \mathrm{ng}$ DNA of bacteriophage lambda. The gel was run at $1 \mathrm{~V} / \mathrm{cm}$ until brompenol blue reached $3 / 4$ of the length of the gel. Then the gel was stained with ethidium bromide and visualized under UV light.

\section{Total RNA extraction, measurement and mRNA purification}

Total RNA was extracted for quantitative reverse transcription real-time PCR (qRT-PCR) with a "hot phenol" protocol (see chapter 3 )

RNA was measured by ultraviolet absorbance at $260 \mathrm{~nm}$ and $280 \mathrm{~nm}$. Calculation of the RNA concentration is based on the absorbance at $260 \mathrm{~nm}$. Diethyl-pyrocarbonate(DEPC)treated water is used to dissolve RNA. Add $1 \mathrm{ml}$ of $0.1 \%$ DEPC to $1000 \mathrm{I}$ of $\mathrm{ddH}_{2} \mathrm{O}$, Mixed 
and left at room temperature for at least 1 hour. This was cooled to room temperature after autoclaving.

To increase the quantity of target gene in the complete template sample, the pure poly $\mathrm{A}^{+}$ mRNA was purified from total RNA using Oligotex mRNA Kits (Qiagen, Hilden, Germany).

\section{Primers of VI_6.2 gene for quantitative RT-PCR}

Primers of VI_6.2 gene for qRT-PCR (Table 2 and 3) were designed on the basis of the extended sequence from genomic library .

Table 2: Primers for determination of VI_6.2 gene expression by qRT-PCR

\begin{tabular}{|c|c|}
\hline Name of primer & Sequence of primer \\
\hline VI_62-F1 & 5'-AATTGGCCAACCAGCTCTACG-3' \\
\hline VI_62-F(new) & 5'-GTGGCTTACCAGAACATTCA-3' \\
\hline VI_62-F2 & 5'-CCTGGAGTCTCAACACCAACG-3' \\
\hline VI_62-intF2 & 5'-CTGTCTCTTCTGCACCGATCATTTCA-3' \\
\hline VI_62-R1(new) & 5'-GTGGTACTGCGTTCCGCAGA-3' \\
\hline VI_62-R(2r) \{Vl_62-R(new)\} & 5'-TACGTAGTTGCCAGCAGCGC-3' \\
\hline VI_62-R(plus) & 5'-AAGCGTCAACTCGTCGTCGGCGTA-3' \\
\hline
\end{tabular}

Tabele 3: Expected PCR products

\begin{tabular}{|l|l|l|l|}
\hline Primer pair conbination & $\begin{array}{l}\text { PCR } \\
\text { fragment }\end{array}$ & Primer pair conbination & $\begin{array}{l}\text { PCR } \\
\text { fragment }\end{array}$ \\
\hline VI_62-F1+VI_62-R (new) & $79 \mathrm{bp}$ & VI_62-F2+VI_62-R (new) & $232 \mathrm{bp}$ \\
\hline VI_62-F1+VI_62-R1(new) & $101 \mathrm{bp}$ & VI_62-F2+VI_62-R1(new) & $254 \mathrm{bp}$ \\
\hline VI_62-F(new)+VI_62-R (new) & $203 \mathrm{bp}$ & VI_62-intF2+VI_62-R (plus) & $173 \mathrm{bp}$ \\
\hline VI_62-F(new)+VI_62-R1(new) & $225 \mathrm{bp}$ & & \\
\hline
\end{tabular}

\section{Determination of in planta gene expression by qRT-PCR for $V$. longisporum}

Root and hypocotyl of infected plant tissue were harvested on 14, 21, 28, 35 dpi and total RNA was extracted using hot phenol extraction protocol described above. Because of the 
low quantity of RNA from each plant, each total RNA sample was extracted from a tissue pool of six plants. mRNA was purified from total RNA samples using Oligotex mRNA Purification Kit (Qiagen, Hilden, Germany). About 500 -1000 ng mRNA were used in reverse transcription reactions together with 50pmol oligo-T primer, $1 \mathrm{mM}$ dNTPs, $20 \mathrm{U}$ RiboLock RNAse inhibitor and $200 \mathrm{U}$ RevertAid reverse transcriptase (Fermentas, St. Leon-Rot, Germany) in a $20 \mu$ reaction volume. cDNA synthesized from mRNA was purified by PCR Purification Kit (Qiagen, Hilden, Germany) and quantified using a photospectrometer at $260 \mathrm{~nm}$ (GeneQuant, Cambridge, UK). About $100 \mathrm{ng}$ purified cDNA was used as template in qRT-PCR. SybrGreen system was used in real-time PCR. Housekeeping genes, $\beta$-tubulin and ribosomal protein $S 17(51,52)$, were used for normalization. $\Delta \Delta \mathrm{Ct}$ and In efficiency calibrated $\Delta \Delta \mathrm{Ct}$ methods were used for quantification of mRNA level between in vitro and in planta samples (53).

\section{Generation of a genomic library}

A genomic library of $V$. longisporum was generated for sequence extension of TDFs (Transcript derived fragments) after cDNA-AFLP screening. The fungal genomic DNA was isolated and partially digested with the restriction enzyme Sau3AI (Fermentas, Germany) (54). The DNA fragments were size-fractionated on an agarose gel by electrophoresis, and 8-12 kb fragments were cut out and purified using QIAquick Gel Extraction Kit, and then inserted into the BamHI site of the standard vector pUC57 (GenScript). The ligation mix was transformed into competent cells of $E$. coli $\mathrm{DH} 5 \alpha(55)$ by electroporation .

The clones were monitored in 96-well microtiter plates with LB medium containing ampicillin and incubated for 2 days. Clones with target genes were screened from genomic library by PCR and sequenced by Eurofins MWG Operon (Ebersberg, Germany).

\section{Construction of binary Vector with antisense fragment in vitro}

The expression vector pPK2 with hygromycin resistance cassette was used for gene silencing in $V$. longisporum transformation (56). A physical map of the constructed fungal expression vector is shown in Figure 1. The Primers for VI_6.2 fragment were synthesized after design (Table 4) by Invitrogen (Germany). 
Table 4: Primers for construction of a binary vector pPK2-Antisense-VI_6.2

\begin{tabular}{|l|l|}
\hline Name of primer & Sequence of primer \\
\hline AS_6.2_(Ascl)F & 5'-ATCAGTGGCGCGCCATGGACCCAGCTGTCGTCCGTA-3' \\
\hline AS_6.2_(Sbfl)R & 5'-ATCAGTCCTGCAGGGTCCAGCGTATCCGTTGCCTG-3' \\
\hline Blue colour: Restriction sites. \\
\hline
\end{tabular}

Antisense PCR fragments of VI_6.2 were amplified with standard PCR using genomic DNA of $V$. longisporum as a template and under the following conditions: one cycle at $95^{\circ} \mathrm{C}$ for 2 min., followed by 34 cycles of $95^{\circ} \mathrm{C}$ for $30 \mathrm{sec}$., $58^{\circ} \mathrm{C}$ for $30 \mathrm{sec}$., $72^{\circ} \mathrm{C}$ for $1 \mathrm{~min}$. Followed by one cycle of $72^{\circ} \mathrm{C}$ for $5 \mathrm{~min}$. for final extension.

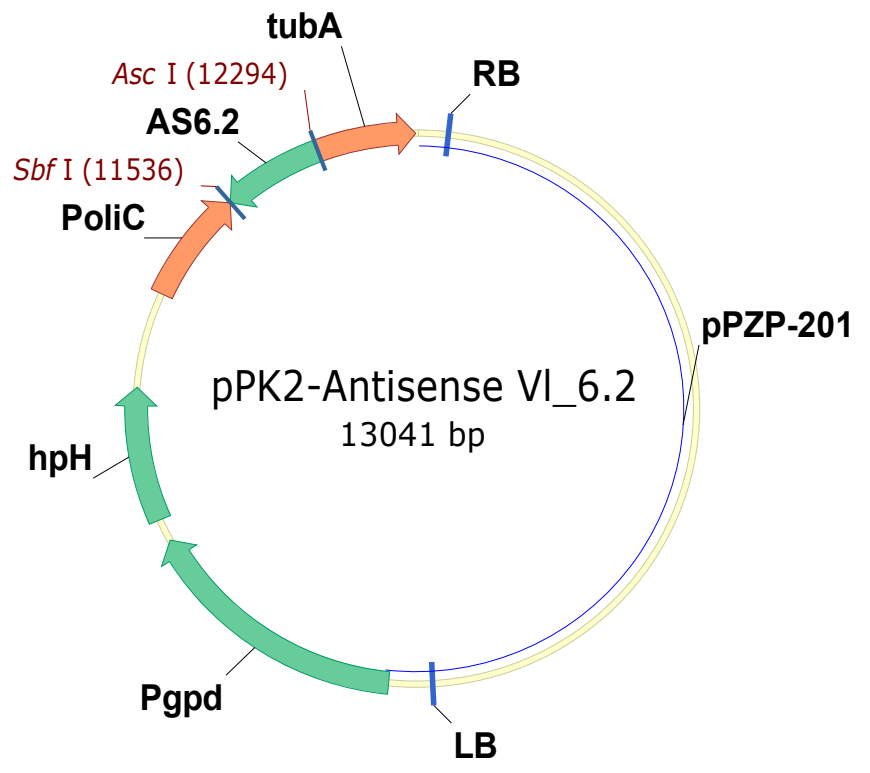

Figure 1: Restriction sites map of the binary vector pPK2-Antisense-VI_6.2 containing a 303 bp large sequence from VI_6.2 gene in antisense direction. PoliC (promoter OliC for a gene encodes subunit 9 of the mitochondrial ATP synthase complex) from Aspergillus nidulans and tubA (terminator for beta-tubulin gene from Botrytis cinerea) were used for control of expression of specific anti-sense RNA-mediated silencing. A Sbfl site (CCTGCAGG) was introduced at 3'-direction of VI_6.2 gene using primer (5'ATCAGTCCTGCAGGGTCCAGCGTATCCGTTGCCTG-3') in combination with another primer (5'-ATCAGTGGCGCGCCATGGACCCAGCTGTCGTCCGTA-3') containing a Ascl site (GGCGCGCC) at 5'-direction of VI_6.2 gene. Pgpd [promoter for glyceraldehyde-3phosphate dehydrogenase (gpd) from Coriolus versicolor] manages $\mathrm{hpH}$ (Hygromycin phosphotransferase resistance gene) and pPZP-201 fragment containing T-DNA region of 
Ti plasmid of Agrobacterium tumefaciens) is from the host binary vector pPZP201.

\section{Agrobaterium-mediated fungal transformation of $V$. longisporum}

A. tumefaciens-mediated transformation following an optimized protocol (57) was used to generate VI_6.2 gene silenced mutants. In vitro generated binary vector pPK2-AntisenseVI_6.2 was first transferred into A. tumefaciens strain AGL1 (58) provided by Dr. Susanne Frick, Leibniz Institute of Plant Biochemistry (Halle/Saale, Germany) for fungal transformation. The strain was stored in a LB medium with appropriate antibiotics and $15 \%$ glycerol at $-80^{\circ} \mathrm{C}$. The fungal $V$. longisporum 43 strain was inoculated onto PDA or Czapek-Dox agar and incubated for $1-2$ weeks at $24^{\circ} \mathrm{C}$. Spores were washed from one Petri dish with 2-3 $\mathrm{ml}$ sterile tap water. A Drigalski spatula was used to release the spores carefully from the mycelium. The spore suspension was collected and the spore concentration was determined, the spore density was adjusted to $10^{7}$ spores $\mathrm{ml}^{-1}$ with sterile tap water. The spore suspension was stored as a recipient for transformation experiments at $4{ }^{\circ} \mathrm{C}$ for no more than 50 hours.

A fresh single colony $(\Phi 1-2 \mathrm{~mm})$ of vector pPK2-Antisense-VI_6.2 held A. tumefaciens AGL1 strain was inoculated in $10 \mathrm{ml}$ of LB medium containing antibiotics kanamycin, rifampicin, and carbenicillin at 50,50 , and $25 \mathrm{\mu g} \mathrm{ml}^{-1}$ respectively. The culture was shaken at $28^{\circ} \mathrm{C}$ and $200 \mathrm{rpm}$ until the $\mathrm{OD}_{600}$ reaches $0.5-0.9 .5 \mathrm{ml}$ of the culture was centrifugated at $4000 \mathrm{xg}$ for $5 \mathrm{~min}$ at room temperature in sterile $15 \mathrm{ml}$ centrifuge tubes. The supernatant was immediately decanted. $1 \mathrm{ml}$ Induction Medium(IM) was added to the cell pellet (59), this contains Acetonsyringone activating vir genes of $A$. tumefaciens, this was mixed gently until cells were resuspended. The mixture was transferred to a $2 \mathrm{ml}$ microcentrifuge tube and centrifuged at $4000 \mathrm{xg}$ for $5 \mathrm{~min}$ at room temperature. The cells were washed briefly by resuspending them. The cell suspension was centrfugated at $4000 \mathrm{xg}$ for $5 \mathrm{~min}$ at room temperature and the bacterial pellet was resuspended in $500 \mu \mathrm{l}$ of IM. After washing and centrifuging the bacterial pellet was resuspended in $150 \mu \mathrm{l}$ of IM. Dilute $\mathrm{OD}_{600}$ of bacterial cells to 0.15 with IM which supplemented with $200 \mu \mathrm{M}$ acetosyringone. The cells were grown for 8-12 hours in a $100 \mathrm{ml}$ Erlenmeyer flask on a shaker at $200 \mathrm{rpm}$ at $28^{\circ} \mathrm{C}$ until cells reach OD600 up to 0.3. A cellophane sheet was placed on each IM plate supplemented with $200 \mu \mathrm{M}$ acetosyringone, $100 \mu \mathrm{l}$ of this induced culture as donor was mixed with $100 \mu \mathrm{l}$ of prepared fungal spore suspension $\left(10^{7}\right.$ spores $\left.\mathrm{ml}^{-1}\right)$ as recipient and spread onto the surface of cellophane sheet. 
The plates were incubated for 60 hours at $23{ }^{\circ} \mathrm{C}$. Then they were transferred to the celluphane membranes onto the selection plates containing $200 \mu \mathrm{M}$ kanamycin, cefotaxime and hygromycin B. After 7-10 days, fungal colonies of transformants were visible. The colonies were transferred onto fresh selection plates. The genomic DNA of transformants were extracted and checked with specific primers by PCR.

\section{In vitro gene expression using qRT-PCR}

Expression level of VI_6.2 gene in vitro with cDNA of $V$. longisporum as template and primer paar VI_62-F2+VI_62-R(2r) was performed by qRT-PCR using a SYBR Green realtime PCR system. qRT-PCR data analysis was conducted with REST@ software and the significance level was set to $p<0.05$ as indicated by asterisk.

\section{In vitro test with detergents}

Detergents Sodium dodecyl sulfate (SDS) $(60,61)$ or Polysorbate 20 (commercially also known as Tween 20) (62) were applied to PDA plates at the following concentrations: SDS, $0.2 \%$ or Tween-20 (0.2\%) (Table 5).

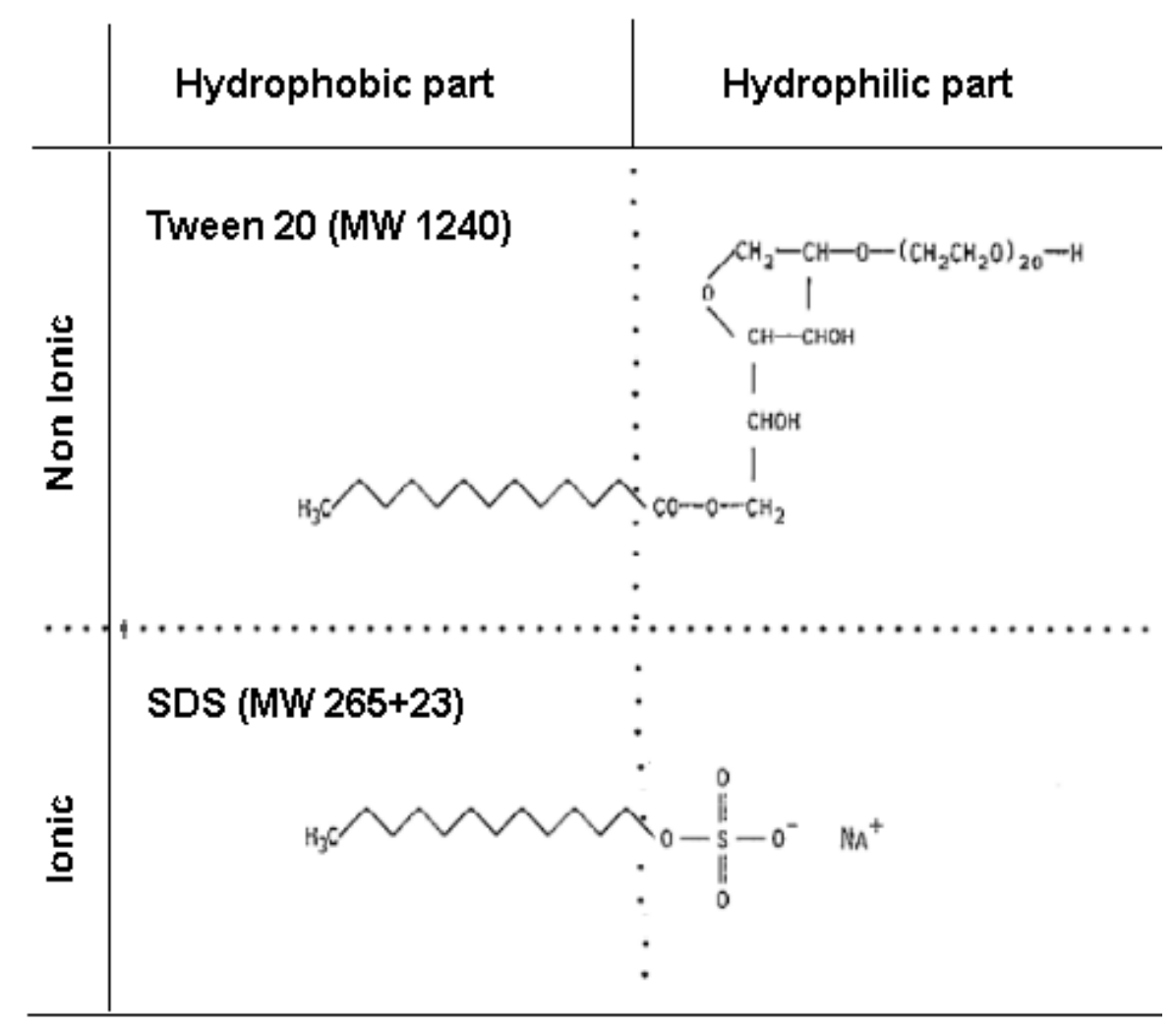

Table 5: Structure formal of Tween 20 and SDS 


\section{Results}

\section{Isolation and characterisation of VI_6.2 gene containing putative WSC domains.}

From the genomic library of $V$. longisporum a full-length gene VI_6.2 with an ORF of 4720 bp nucleotides (nt) and its UTR was isolated, translated cDNA encoded 1536 amino acids (aa) (see Chapter 3). After comparison of genomic DNA and cDNA sequence the VI_6.2 gene included two introns and 56 bp each (Figure 2). SMART (Simple Modular Architecture Research Tool) analysis indicated that VI_6.2 gene contained a signal peptide, a fibronectin type III and four putative WSC (water-soluble carbohydrate binding) domains at the $\mathrm{C}$-terminus (Figure 3 ).

The transcription analysis in V. longisporum by cDNA-AFLP (63), VI_6.2 gene was determined as an activated gene after a treatment with xylem sap which was extracted from mock treated $B$. napus plants. This phenomenon indicated that VI_6.2 gene was related in interaction between phytopathogen $V$. longisporum and host plant $B$. napus. In planta relative gene expression analysis by qRT-PCR exhibited a strong up-regulation of VI_6.2 gene normalised with two housekeeping genes ( $\beta$-tubulin and ribosomal peptide $S 17$ ) in $V$. longisporum during infection at $14,21,28$, and 35 dpi (days post inoculation) compared with gene expression of fungal mycelia in SXM (Figure 4).

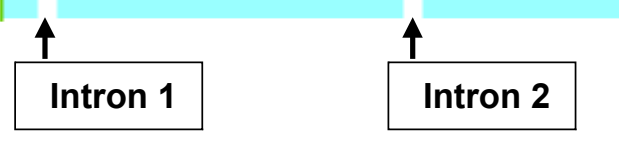

Figure 2: Modular structure shown positions of two introns in VI_6.2 gene. Full-length of VI_6.2 gene sequence was isolated from a genomic library of $V$. longisporum. The ORF contains two introns: Intron 1 (at nucleotide positions 114-169 with a 56 bp length sequence GTGAGCGTCCTCGTTCCGTATCCGGCCCCCTTGAAATGGCACTGACGTGTTTCCAG) and Intron 2 (at nucleotide positions 1324 -1381 with the same length but different sequence GTGCGTTTGGTTCAGGTCTGCGTCTCACCCCCAACATTATTGCTAACTTGCACAA$\mathrm{G})$. Picture of modular structure modified according to the Verticillium group database (64). 


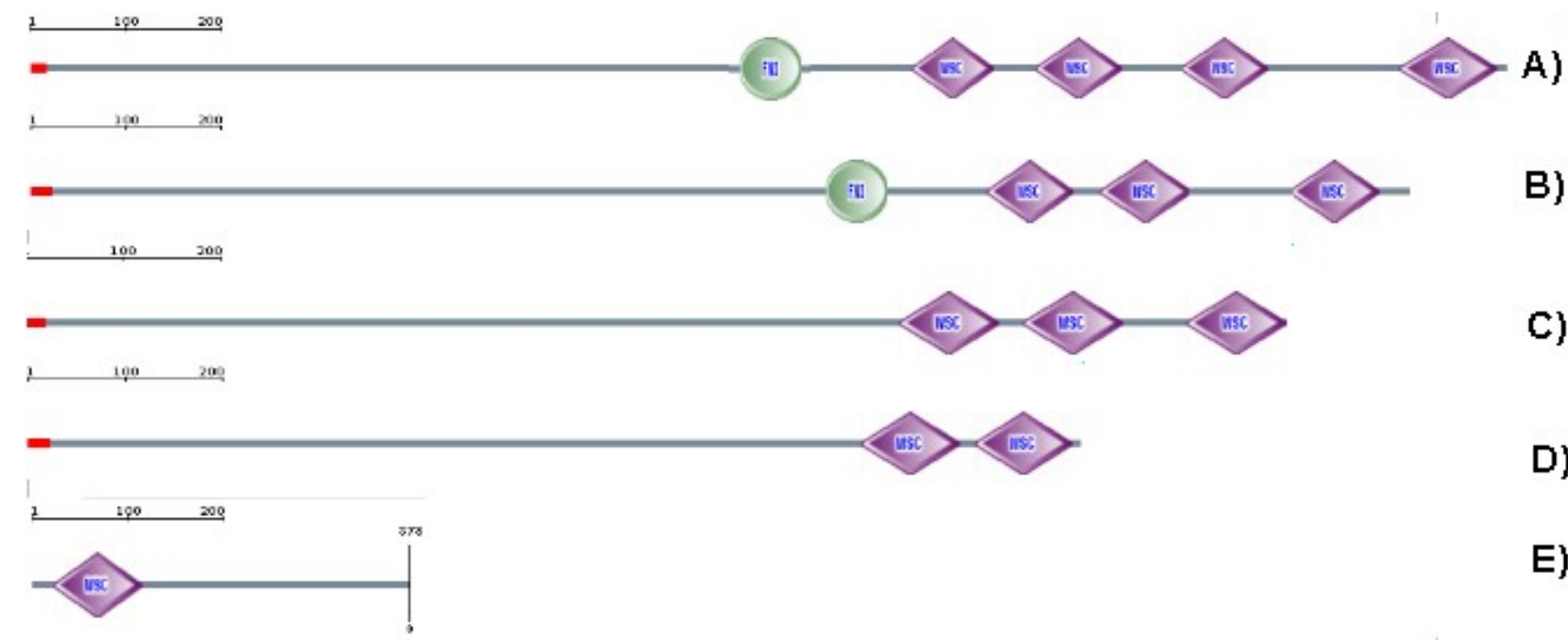

Figure 3: Modular structure shown signal peptide (red), Fibronectin type III (green) and four putative WSC domains (lilac) in amino acids sequences constructed using software SMART (Simple Modular Architecture Research Iool) (65). Sequence homology analysis revealed the presence of four conserved WSC carbohydrate binding domains at the Cterminus for $V$. longisporum, $V$. dahliae and $V$. albu-atrum in A). Fibronectin is a highmolecular weight $(\sim 40 \mathrm{kDa})$ extracellular matrix glycoprotein that binds to membranespanning receptor proteins called integrins (66, 67); B) Magnaporthe oryzae (Sequence Nr. XP_361287.2) with three WSC domains and one Fibronectin type III; C) Botryotinia fuckeliana (Sequence Nr. XP_001556864.1) with three WSC domains; D) Trichoderma asperellum (beta 1, 3 exoglucanase, Sequence Nr. ABY19519.1) with two WSC domains; E). Saccharomyces cerevisiae (SLG1 gene, Sequence Nr. YOR008C) with one WSC domain.

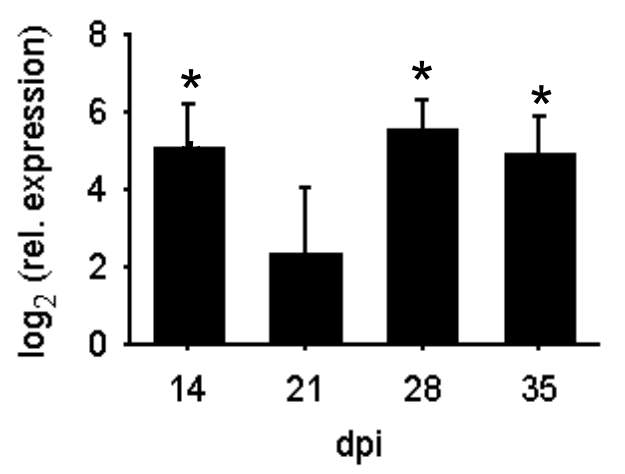

Figure 4: In planta gene expression analysis of VI_6.2 gene of V. longisporum represented in time course. Column charts shown ratios of relative expression levels referred to in vitro grown mycelium in an artificial medium simulating xylem as control and in planta grown 
fungal tissue of $V$. longisporum in infected root/hypocotyl material of $B$. napus plant as target, were calculated as $\Delta \Delta C$ t values from three biological replicas at $14,21,28$, and 35 dpi. Error bars indicated the standard deviation of calculated $\Delta \Delta \mathrm{Ct}$ values. Significance levels were set to $p<0.05$ and were given for both reference genes, double asterisks indicate significant change in the expression levels regarding both reference genes.

\section{Differential silencing effect of VI_6.2 gene in vitro mediated by antisense RNA}

The antisense RNA-mediated post-transcriptional silencing method was used for "knock down" of VI_6.2 gene,, the specific antisense sequence was inserted in genome of $V$. longisporum by $A$. tumefaciens-mediated transformation with a constructed binary vector pPK2. In order to see whether silencing effects occur, we used qRT-PCR to quantify the expression levels of VI_6.2 gene transcripts in vitro. The results were showed in figure 5. The silencing effect of mutants M5, M6, M7 in vitro was suppressed to $70 \%$ of its activity in transformants to the non transformed wild type.

\section{Pathogenicity test of VI_6.2 gene silenced mutants in planta}

The first disease symptoms were visible on $V$. longisporum infected $B$. napus plant after 14 dpi under greenhouse conditions and displayed chlorosis, dark-coloured veins on older leaves and stunting effects on plant growth. At $14 \mathrm{dpi}$ and $21 \mathrm{dpi}$, most of the plants inoculated with VL43 mutants showed less severe symptoms than VL43 wild type (Table 5). General plant growth especially the growth of stem after inoculation with $V$. longisporum isolate 43 or its anti-sense mutants of VI_6.2 gene were inhibited (Figure 6). But after comparison with wild type, the effect of inhibition of plant growth infected by VI_6.2 gene mutants M4, M5, M6, M7 were significant (Figure 6). The picture figure 7 shows $B$. napus plants infected by $\mathrm{VI} 6.2$ silenced mutants compared to mock treated plants (treated with $\mathrm{H}_{2} \mathrm{O}$ ) and $\mathrm{V}$. longisporum isolate 43 wild type. 


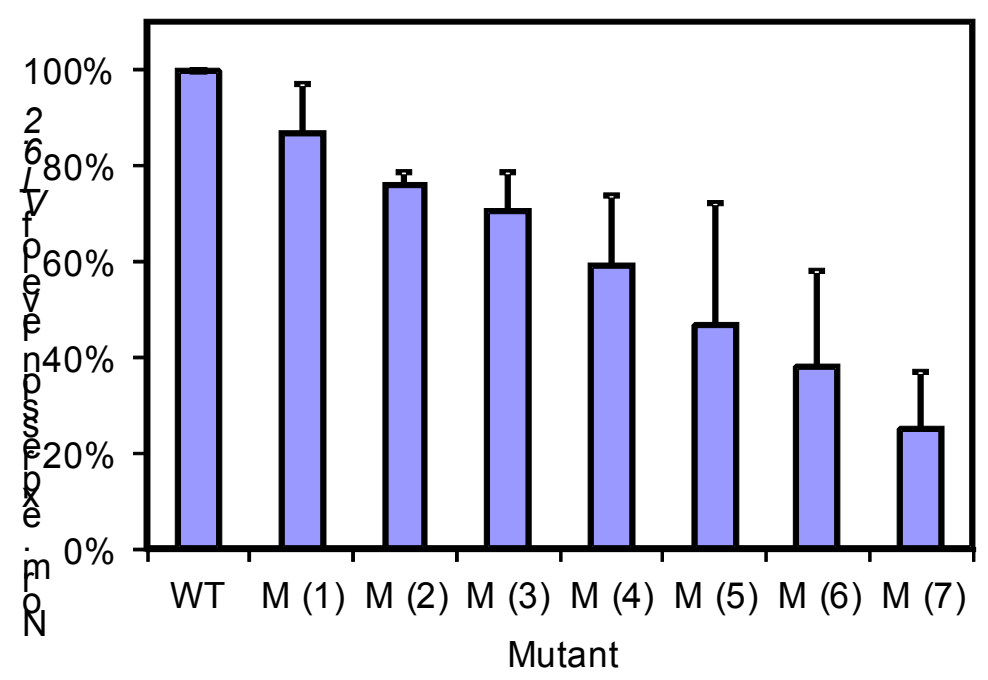

Figure 5: Normalized transcript accumulation of $\mathrm{VI} 66.2$ was reduced in mutants $\mathrm{M}$ (1-7) up to $70 \%$ by introducing anti-sense RNA expression in relation to wild type (WT). Analysis was done applying quantitative RT-PCR.

Table 5: Assessment of disease symptoms on host plant B. napus with disease score

\begin{tabular}{|l|l|l|l|l|l|l|}
\hline dpi & Mock & VL43-WT & VL43-M4 & VL43-M5 & VL43-M6 & VL43-M7 \\
treated with $\mathrm{H}_{2} \mathrm{O}$ & & & & & \\
\hline 14 & $1.33 \pm(0.48)$ & $2.42 \pm(1.41)$ & $2.11 \pm(1.37)$ & $2.00 \pm(1.37)$ & $1.68 \pm(0.82)$ & $2.05 \pm(1.47)$ \\
\hline 21 & $1.35 \pm(0.40)$ & $2.85 \pm(1.30)$ & $2.74 \pm(1.24)$ & $2.68 \pm(1.49)$ & $1.84 \pm(1.21)$ & $2.53 \pm(1.58)$ \\
\hline 28 & $1.38 \pm(0.50)$ & $3.13 \pm(1.45)$ & - & - & - & - \\
\hline
\end{tabular}




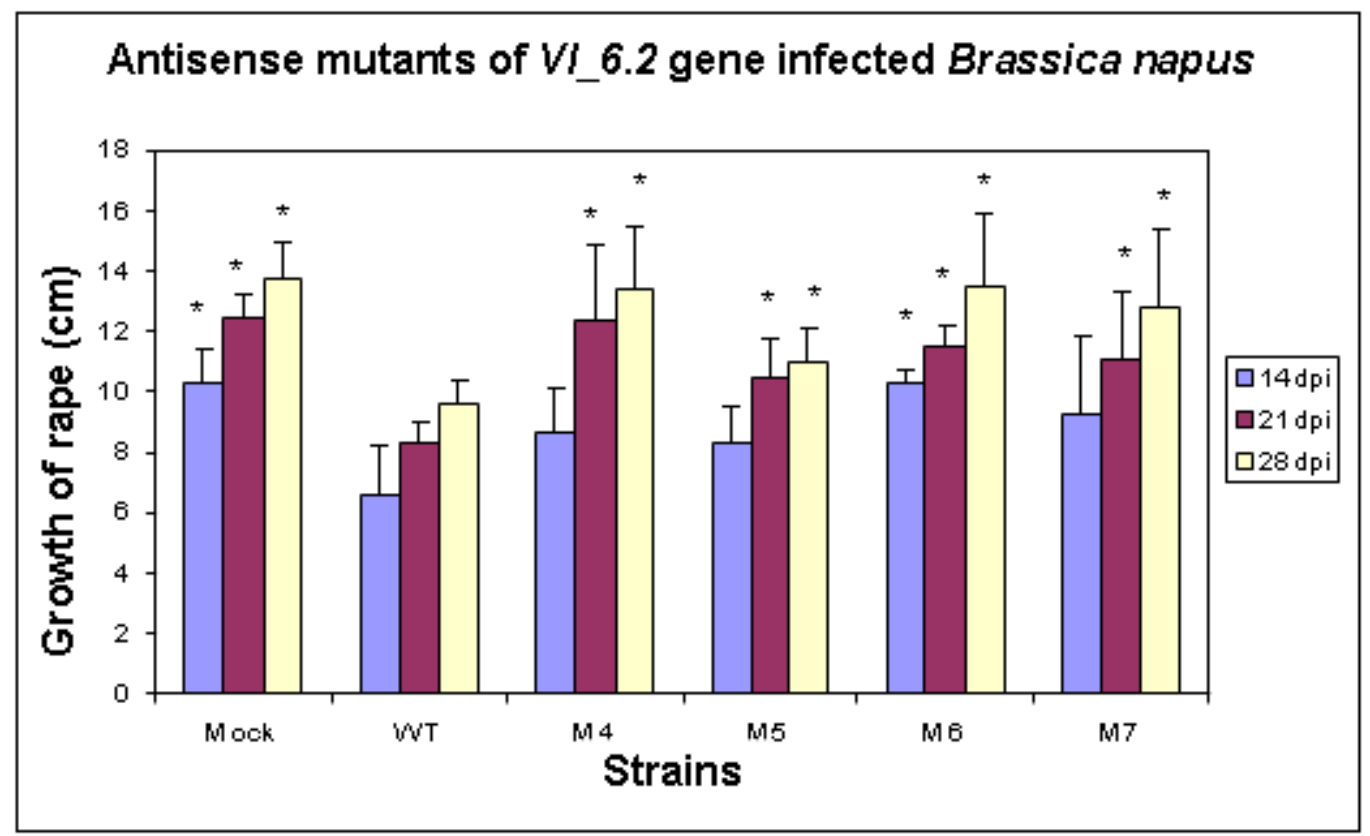

Figure 6: Shoot length of $B$. napus plants was measured in weekly intervals after inoculation. Error bars indicated the standard deviation of calculated average value. Significance level was set to $p<0.05$ (T-test) and was calculated for wild type as a reference.

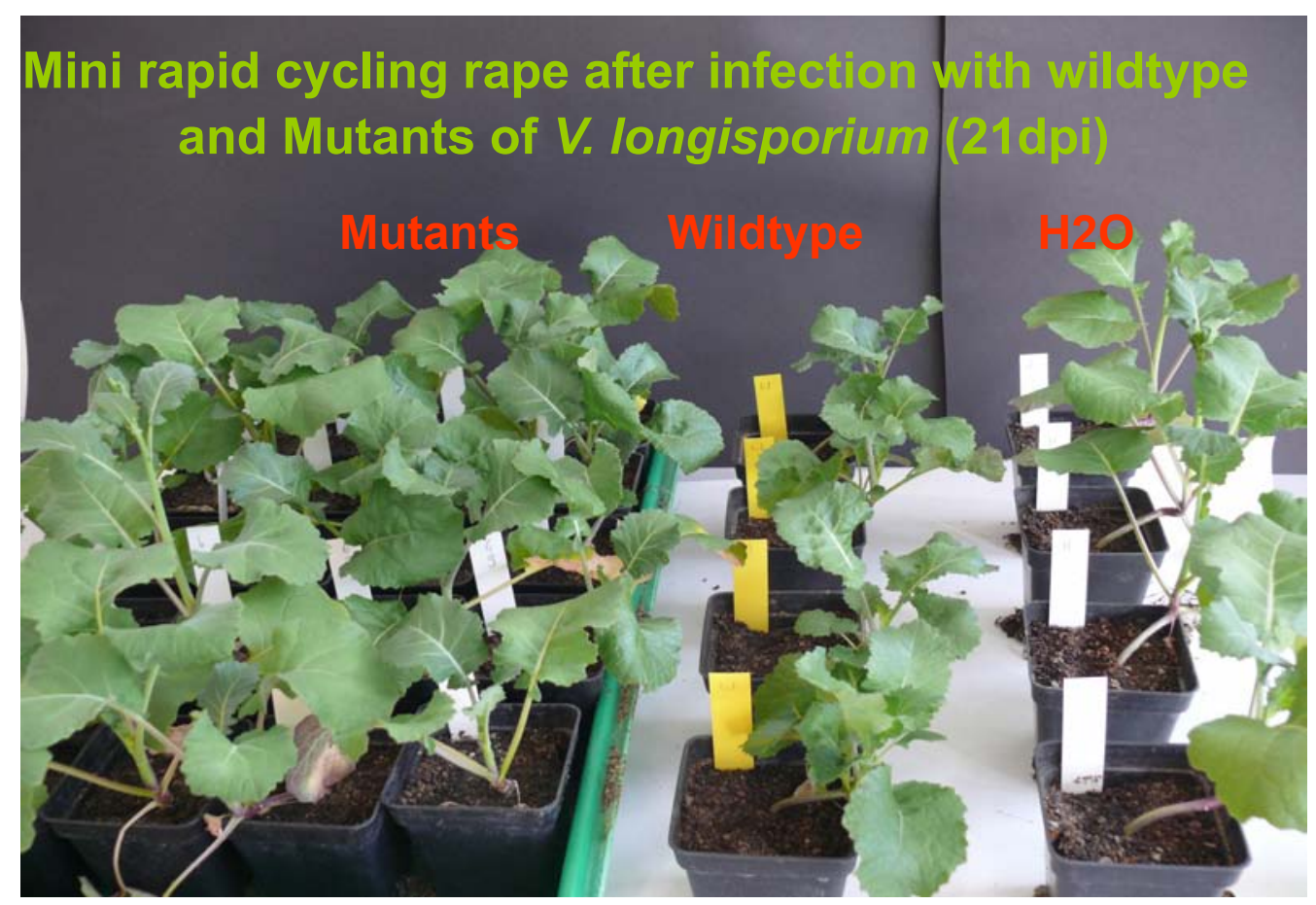

Figure 7: Pathogenicity test of VI_6.2 silencing mutants in planta. Stunting effect as a typical symptom on $B$. napus infected by wild type of $V$. longisporum compared to mock at $21 \mathrm{dpi}$ is visible (Middle and right plants of the picture). The VI_6.2 silencing mutants infected plants showed less stunting effects (left plants of the picture). 


\section{Growth inhibition assay with VI_6.2 gene silenced mutants with detergents}

The silenced gene VI_6.2 comprises conserved WSC domains in its peptide sequence putatively involved in stabilizing the fungal cellular membrane integrity (68). We performed a differential growth inhibition assay on PDA agar plates containing either SDS (sodium dodecyl sulfate) or Tween-20 detergent with mutants $M(6)$ and $M(7)$ exhibited the highest silencing efficiency (Figure 8 and Figure 9). the SDS-containing PDA medium (0.2\%) inhibited fungal growth of VI_6.2 silenced mutants with a larger scope.
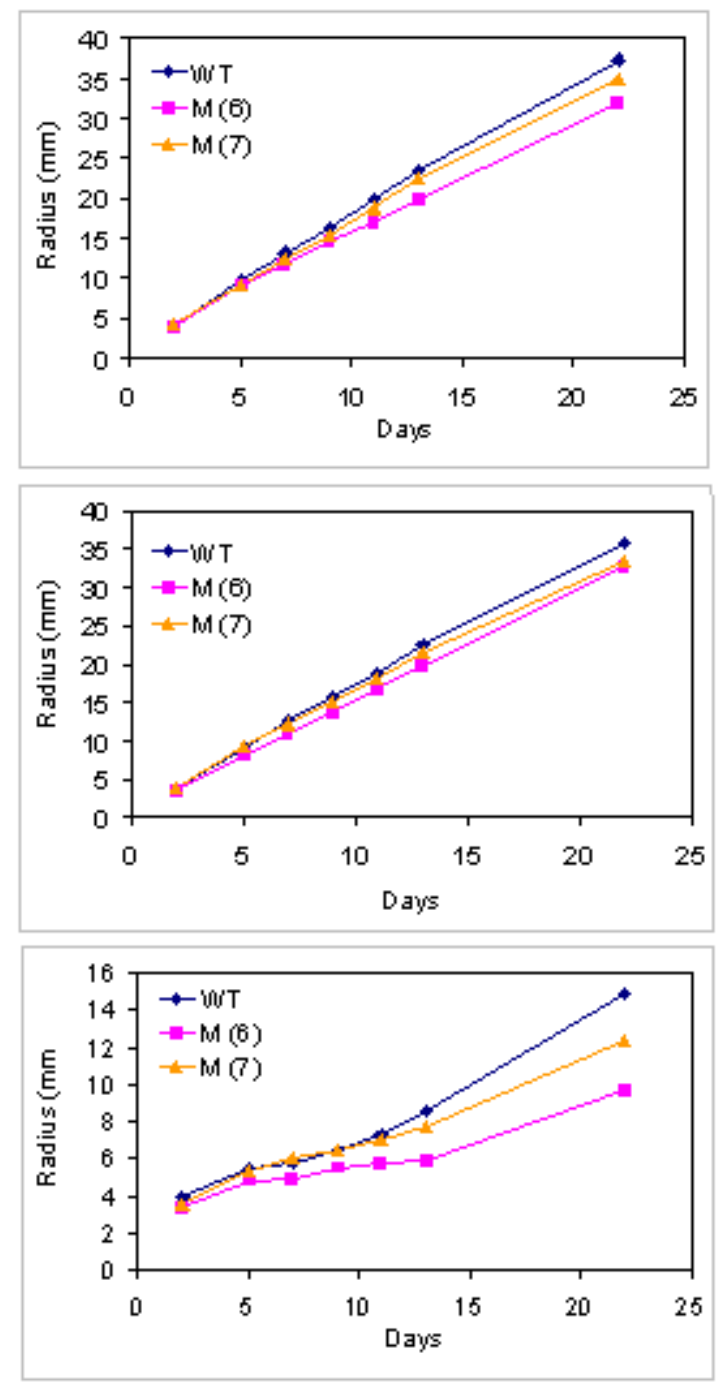

Figure 8: Differential effects of detergents on VI_6.2 gene silencing mutants. The above picture of figure 8 shows the time course of radial mycelial growth of wild type (WT) and the two VI_6.2 gene silenced mutants not treated with detergent. While the SDScontaining medium $(0.2 \%)$ inhibited fungal growth of mutants to a larger extent (below picture in figure 8$)$ than WT. Tween-20 $(0.2 \%)$ exhibited no detectable effect (middle picture in figure 8 ). 


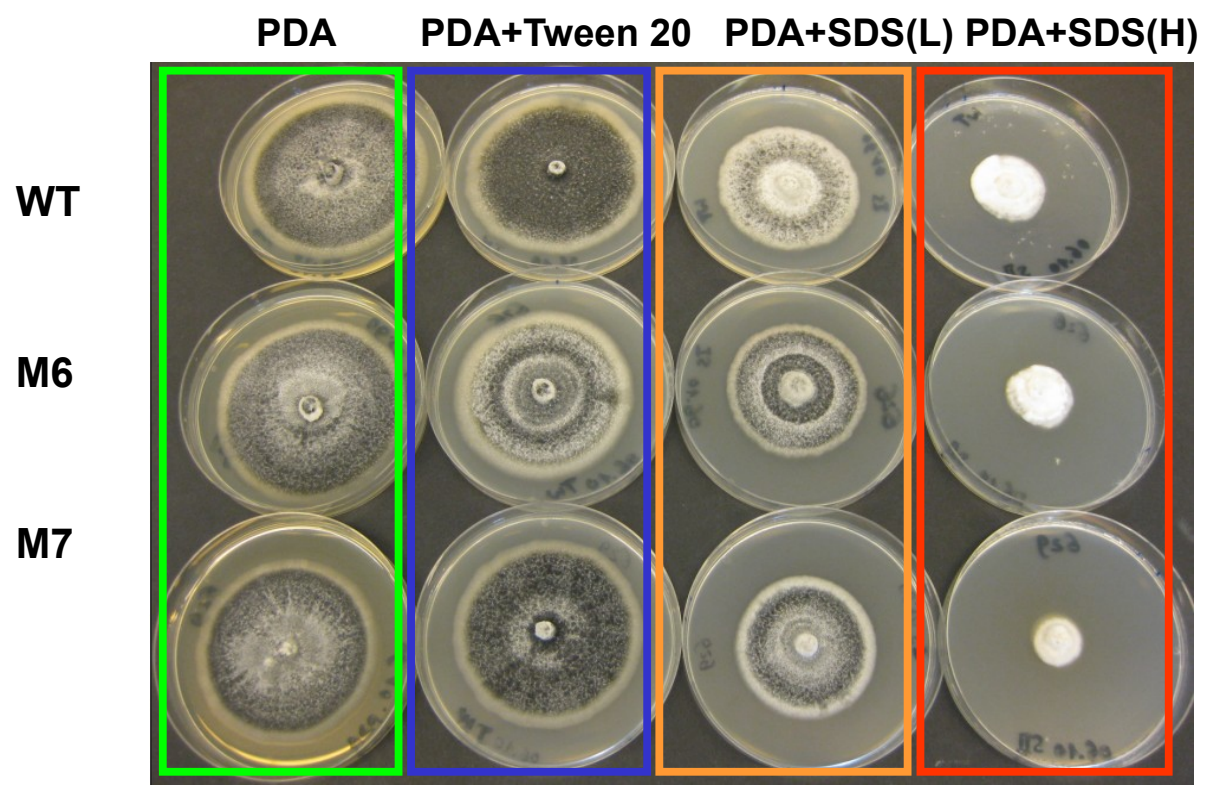

Figure 9: Colony morphology of $V$. longisporum isolate 43 VI_6.2 gene anti-sense mutants on solid media. Line PDA: PDA without detergent. Line PDA+Tween 20: PDA with detergent Tween $20(0.2 \%)$. Line PDA+SDS(L): PDA with detergent SDS $(0.05 \%)$. Line PDA+SDS(H): PDA with detergent SDS $(0.2 \%)$. All PDA plate incubated for 38 days, at $22^{\circ} \mathrm{C}$ in dark). Colony growth of M6 and M7 mutants were inhibited on PDA plate with SDS detergent with a concentration in $0.2 \%$.

\section{Growth inhibition assay with VI_6.2 gene silenced mutants with different $\mathrm{pH}$-value}

The yeast grows better at acidic than at neutral or alkaline $\mathrm{pH}$, Wsc1 participates as an essential cell-surface $\mathrm{pH}$ sensor. Lack of Wsc1, removal of specific extracellular and intracellular domains, or substitution of $\mathrm{Tyr}^{303}$ in this putative membrane stress sensor rendered cells sensitive to alkali and considerably decreased alkali-induced SIt2 activation (69). Therefore, unexpected alkalinization of the environment provided a stress condition for yeast fungus. Here we presented a alkaline stress result with VI_6.2 gene silenced mutants whose cell wall integrity may be disrupted. Mutants M5, M6, M7 showed a delayed melanistic process by a alkaline stress. 


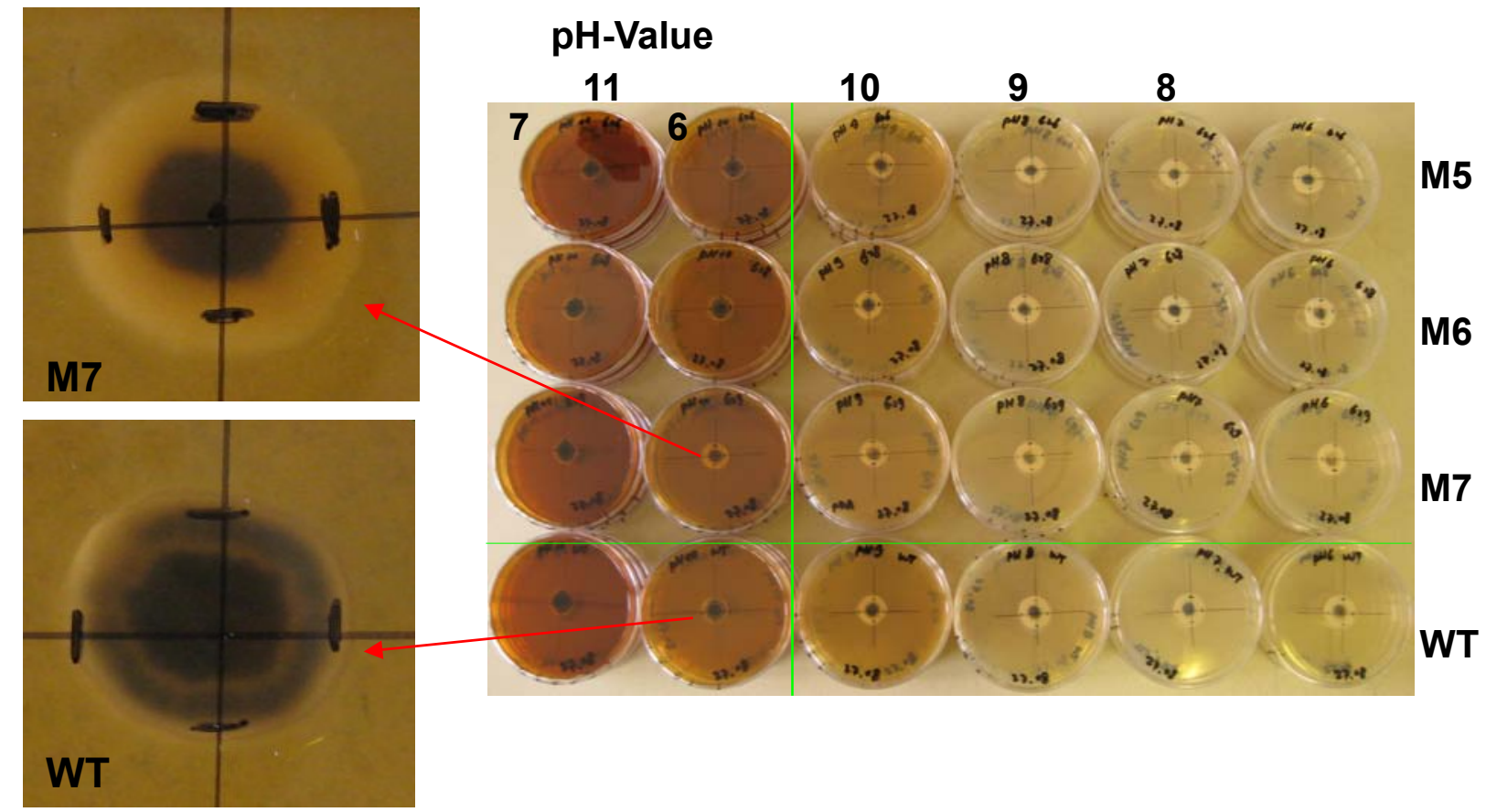

Figure 10: Alkaline stress reflected by delayed melanistic process of VI_6.2 gene mutants compared with wild type decelerated up pH 10 value after 5 days incubation in dark at $23^{\circ} \mathrm{C}$.

\section{Growth assay of VI_6.2 gene silenced mutants with Trichoderma species}

Mycoparasitic fungi Trichoderma species secrete chitinases and glucanases that attack cell wall polymers in other fungi $(70,71,72)$. The strain Trichoderma virens is a wide spread soil saprophyte that has been applied as a biological control agent to protect plants from fungal pathogens. T. virens produces antifungal compounds which assists the killing of its fungal targets (73).
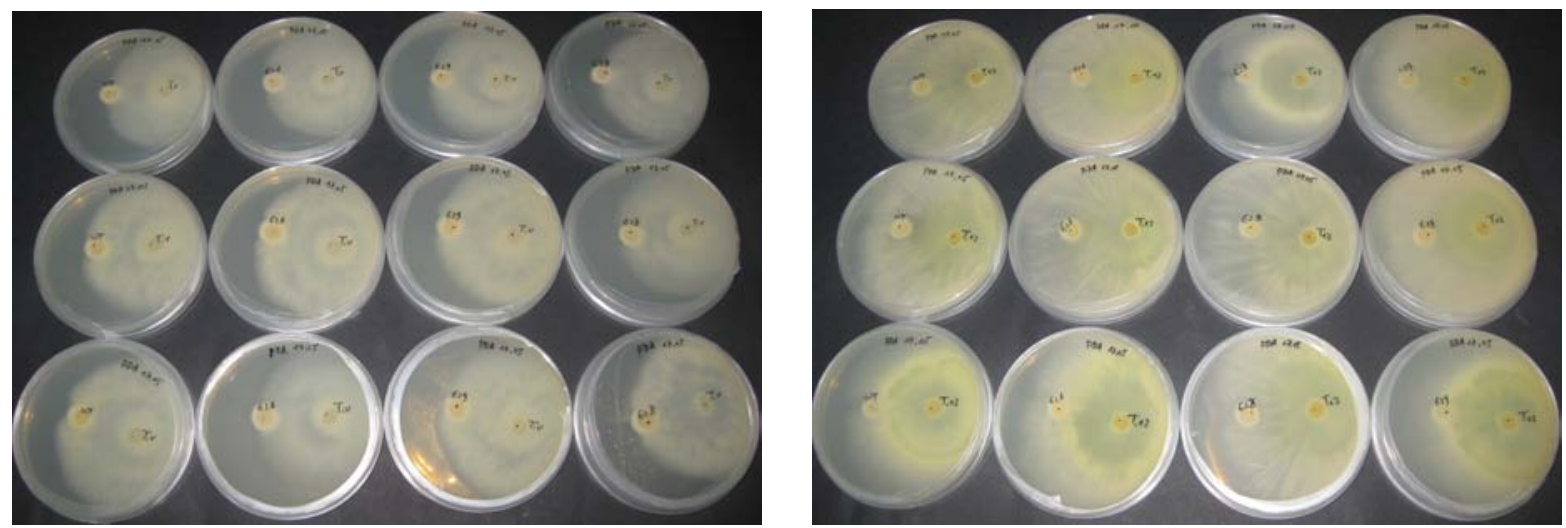

Figure 11: Terichoderma strains were used as mycoparasite for test of cell wall integrity of V. longisporum and its VI_6.2 silenced mutants. Because of large differences in growth 
rates between of Terichoderma and Verticillium strains, the mycoparasitic effect was not visible.

\section{Discussion}

VI_6.2 gene was detected from a signal which responded to the $V$. longisporum transcriptome after treatment with extracts of $B$. napus xylem sap by an cDNA-AFLP profiling method. Sequence analysis was performed on VI_6.2 gene containing four WSC (water-soluble carbohydrate binding) domains at C-terminus. Genetic characterization reports that WSC family are regulators for extracellular stress response and cell wall integrity in the yeast $S$. cerevisiae. A cell wall stress component sensor Wsc1 is a plasma membrane protein that behaves like a linear nano-spring that is capable of resisting high mechanical force and of responding to cell surface stress (74). Our results confirmed antisense RNA methods as a mild gene silencing method in vitro by qRT-PCR. The with antisense RNA methods generated VI_6.2 silenced mutants demonstrated VI_6.2 gene as a stress response regulator activating in growth inhibition assays both with ionic detergent SDS with a concentration of $0.2 \%$ and with alkaline $\mathrm{pH}$ value at 10 . A treatment with SDS in low concentration or a non ionic detergent Tween 20 could not effect the growth of $V$. longisporum, This indicates an elastic role of VI_6.2 gene which behaves in a similar manner to that seen in S. cerevisiae. VI_6.2, Perhaps it also possesses a linear nanospring-like structure in response to extracellular stress under particular conditions.

In this experiment, VI_6.2 gene expression in planta was up-regulated by determination with qRT-PCR. VI_6.2 silenced mutants which resulted in a reduced virulence in planta. Krishna et al. in 2005 reported that MAP(Mitogen-Activated Protein) kinase-mediated signalling pathways are involved in pathogenicity of Verticillium dahliae. Disruption of Verticillum MAP Kinase 1 (VMK1) in V. dahliae severely decreased virulence in diverse host plants (75). Other researchers presented a deletion of WSC genes in $S$. cerevisiae resulting the WSC binding domains as upstream regulators playing a important role in stress response in PKC1-MAPK1 pathway $(15,16)$.

VL_6.2 contains a putative fibronectin type III domain (FN3). Fibronectin as a very common constituent of animal proteins was characterized more than 50 years ago and in studies have been carried out on cell adhesion, self-repair, composition, assembly of extracellular matrix and multi-modular protein structure (76). Normally fibronectin is categorised into two classes: cellular and plasma (77). FN3 modules are the major 
structural units in fibronectin and are also found in a large number of other proteins. The biologically most important activity of fibronectin is its interaction with cells. The ability of fibronectin to serve as a substrate for cell adhesion, spreading, and on the activities of several modules based migration (78). A present FN3-like domain in gene VI_6.2 indicates that VI_6.2 may play a role in cell adhesion and self-repair etc.

In conclusion we postulate that VI_6.2 gene, a putative plasma membrane protein interacting with carbohydrate and related to the PKC1-MAPK1 pathway, has a considerable impact on the effect of infection in planta and external stress response in vitro.

\section{References}

1. Van der Krol, A.R., Lenting, P.J., Veenstra, J.G., van der Meer, I.M., Koes, R.E., Gerats, A.G.M., Mol, J.N.M., \& Stuitje, A.R. (1988). An antisense chalcone synthase gene in transgenic plants inhibits flower pigmentation. Nature. 333, 866-869.

2. Sanders, R.A. \& Hiatt, W. (2005). Tomato transgene structure and silencing. Nat. Biotechnol. Bd. 23: 287-289.

3. Kitamoto, N., Yoshino, S., Ohmiya, K. \& Tsukagoshi, N. (1999). Sequence analysis, overexpression, and antisense inhibition of a $\beta$-xylosidase gene, xylA, from Aspergillus oryzae KBN616. Appl. Environ. Biotechnol. 65: 20-24.

4. Mǿrkeberg, R., Carlsen, M. \& Nielsen, J. (1995). Induction and repression of aamylase production in batch and continuous cultures of Aspergillus oryzae. Microbiology 141: 2449-2454.

5. Nellen, W., \& Lichtenstein, C. (1993). What makes an mRNA anti-sense-itive ? Trends Biochem. Sci. 18: 419-423.

6. Shroff, R., O'Connor, S., Hynes, M.J., Lockington, R.A. \& Kelly, J. (1997). Null alleles of creA, the regulator of carbon catabolite repression in Aspergillus. Fungal Genet. Biol. 22: 28-38.

7. Zheng, X.F., Kobayashi, Y. \& Takeuchi, M. (1998). Construction of a low-serinetype-carboxypeptidase-producing mutant of Aspergillus oryzae by the expression of 
antisense RNA and its use as a host for heterologous protein secretion. Appl. Microbiol. Biotechnol. 49: 39-44.

8. Christensen, T. (1994). Application: Aspergillus oryzae as a host for production of industrial enzymes. In K.A. Powell (ed.), The genus Aspergillus. Plenum Press, New York, N.Y.

9. Gerhart, E. \& Wagner, H. (1994). Antisense RNA Control in Bacteria, Phages, and Plasmids. Annu. Rev. Microbiol. 48: 713-742.

10.Ratcliff, F., MacFarlane, S., \& Baulcombe, D.C., (1999). Gene silencing without DNA: RNA-mediated cross-protection between viruses. Plant Cell. 11: 1207-1215.

11. Waterhouse, P.M., Wang, M.B., \& Lough, T. (2001). Gene Silencing as an adaptive defence against viruses. Nature 411: 834-842.

12. Van Blokland, R., Van der Geest, N., Mol, JNM, \& Kooter, J.M. (1994). Transgenemediated suppression of chalcone synthase expression in Petunia hybrida results from an increase in RNA turnover. Plant J. 6: 861-877.

13.Li, Q., Xu, X., Yang, J.M., Nie, Q.J. \& Xian, M. (2010). Progress of Antisense Technology Applied in Metabolic Regulation of Bacteria. Chinese Journal of Biotechnology. 24(10): 1689-1694.

14.Klis, F.M., Boorsma, A. \& De Groot, P.W. (2006). Cell wall construction in Saccharomyces cerevisiae. Yeast. 23: 185-202.

15. Verna, J., Lodder, A., Lee, K.H., Vagts, A. \& Ballester, R. (1997). A family of enes required for maintenance of cell wall integrity and for the stress response in Saccharomyces cerevisiae. Proc. Natl. Acad. Sci. 94: 13804-13809.

16. Lodder, A.L., Lee, T.K. \& Ballester, R. (1999). Characterization of Wsc1 protein, a putative receptor in the stress response of Saccharomyces cerevisiae. Genetics 152:1487-1499.

17. Gray, J.V., Ogas, J.P., Kamada, Y., Stone, M., Levin, D.E. \& Herskowitz, I. (1997). A role for the Pkc1 MAP kinase pathway of Saccharomyces cerevisiae in bud emergence and identification of a putative upstream regulator. EMBO J. 16: 4924- 
4937.

18.Straede, A. \& Heinisch, J.J. (2007). Functional analysis of the extra- and interacellular domains of the yeast cell wall integrity sensors Mid2 and Wsc1. FEBS Lett. 581: 4495-4500.

19. Costigen, C., Gehrung, S. \& Snyder, M. (1992). A synthetic lethal screen identifies SLK1, anovel protein kinase homolog implicated in yeast cell morphogenesis and cell growth. Mol. Cell. Biol. 12: 1162-1178.

20. Lee, K.S. \& Levin, D.E. (1992). Dominant mutations in a gene encoding a putative protein kinase (BCK1) bypass the requirement for a Saccharomyces cerevisiae protein kinase C homolog. Mol. Cell. Biol. 12: 172-182.

21. Irie, K., Takase, M., Lee, K.S., Levin, D.E., Araki, H., Matsumoto, K. \& Oshima, Y. (1993). MKK1 and MKK2, which encode Saccharomyces cerevisiae mitogenactivated protein kinase-kinase homologs, function in the pathway mediated by protein kinase C. Mol. Cell. Biol. 13: 3076-3083.

22. Lee, K.S., Irie, K. Gotoh, Y., Watanabe, Y., Araki, H., Nishida, E., Matsumoto, K. \& Levin, D.E. (1993). A yeast mitogen-activated protein kinase homolog (Mpk1p) mediates signalling by protein kinase C. Mol. Cell. Biol. 13: 3067-3075.

23. Nonaka, H., Tanaka, K., Hirano, H., Fujiwara, T., Kohno, H., Umikawa, M., Mino, A. \& Takai, Y. (1995). A downstream target of RHO1 small GTP-binding protein is PKC1, a homolog of protein kinase $C$, which leads to activation of the MAP kinase cascade in Saccharomyces cerevisiae. EMBO J. 14: 5931-5938.

24.Drgonová, J., Drgon, T., Tanaka, K., Kollár, R., Chen, G.C., Takai, Y. \& Cabib, E. (1996). Rho1p, a yeast protein at the interface between cell polarization and morphogenesis. Science 272: 277-279.

25. Qadota, H., Python, C.P., Inoue, S.B., Arisawa, M., Anraku, Y., Zheng, Y., Watanabe, T., Levin, D.E. \& Ohya, Y. (1996). Identification of yeast Rho1p GTPase as a regulatory subunit of 1,3- $\beta-$ Glucan synthase. Science 272: 279-281.

26. Bickle, M., Delley, P., Schmidt, A. \& Hall, M.N. (1998). Cell wall integrity modulates RHO1 activity via the exchange factor ROM2. EMBO J. 17: 2235-2245. 
27.Zhu, T., Verna, J., Ballester, R. (2001). Mutations in WSC genes for putative stress receptors result in sensitivity to multiple stress conditions and impairment of RIm1dependent gene expression in Saccharomyces cerevisiae. Mol. Genet. Genomics 266:142-155.

28. Lommel, M., Bagnat, M., \& Strahl, S. (2004) Aberrant processing of the WSC family and Mid2p cell surface sensors results in cell death of Saccharomyces cerevisiae omannosylation mutants. Mol.Cell.Biol. 24: 46-57.

29. Karapapa, V.K., Bainbridge, B.W., Heale, J.B. (1997). Morphological and molecular characterisation of Verticillium longisporum comb. nov., pathogenic to oilseed rape. Mycol. Res. 101:1281-1294.

30.Zeise, K., von Tiedemann, A. (2001). Morphological and Physiological Differentiation among Vegetative Compatibility Groups of Verticillium dahliae in Relation to V. longisporum. J. Phytopathol. 149:469-475.

31.Zeise, K., von Tiedemann, A. (2002). Application of RAPD-PCR for Virulence Type Analysis within Verticillium dahliae and Verticillium longisporum. J. Phytopathol. 150:557-563.

32. Krüger, W. (1989). Untersuchungen zur Verbreitung von Verticillium dahliae Kleb. Und anderen Krankheits- und Schaderregern bei Raps in der Bundesrepublik Deutschland. Nachrichtenblatt des Deutschen Pflanzenschutzdienstes, 41: 49-56.

33. Steventon, L.A., Fahleson, J., Hu, Q. \& Dixelius, C. (2002). Identification of the causal agent of Verticillium wilt of winter oilseed rape in Sweden, V. Iongisporum Mycological Research. 106: 5570-5578.

34.Dixelius, C., Happstadius, I., \& Berg, G. (2005). Verticillium wilt on Brassica oil crops- a Swedish perspective. Journal of the Swedish Seed Association. 115: 3648.

35. Fahleson, F., Hu, Q. \& Dixelius, C. (2004). Phylogenetic analysis of Verticillium species based on nuclear and mitochondrial sequences. Arch Microbiol. 181:435442.

36. Eynck, C., Koopmann, B., Grunewaldt, G., Karlovsky, P. \& von Tiedermann, A. 
(2007). Differential interaction of Verticillium longisporum and $V$. dahliae with Brassica napus detected with molecular and histological techniques. Europ. J. Plant Path. 118: 259-274.

37. Isaac, I. (1957). Verticillium wilt of Brussels sprout. Annals of Applied Biology 45:276-283.

38. Stark, C. (1961). Das Auftreten der Verticillium-Tracheomykosen in Hamburger Gartenbau-Kulturen. Gartenbauwissenschaft 26:493-528.

39. Michielse, C.B., Hooykaas, P.J., van den Hondel, C.A. \& Ram, A.F. (2005). Agrobacterium-mediated transformation as a tool for functional genomics in fungi. Curr. Genet. 48:1-17.

40. Utermark, J. \& Karlosky, P. (2008). Genetic transformation of filamentous fungi by Agrobacterium tumefaciens. Nature Prot. DOI: 10.1038/nprot.2008.83

41. Weiberg, A. (2008). Identification of genes induced in the vascular pathogen Verticillium longisporum by xylem sap metabolites of Brassica napus using an improved genome-wide quantitative cDNA-AFLP. Online.

42. Bautista, L.F., Alenksenko, A., Hentzer, M. Santerre-Henriksen, A. \& Nielsen, J. (2000). Antisense silencing of the creA gene in Aspergillus nidulans Applied and Environmental Microbiology. 66 (10): 4579-4581.

43. Hanahan, D. (1983). Studies on transformation of Escherichia coli with plasmids. J Mol Biol. 166(4): 557-80.

44. Mattanovich, D., Rüker, F., Machado, A.C., Laimer, M., Regner, F., Steinkellner, H., Himmler, G. \& Katinger, H. (1989). Efficient transformation of Agrobacterium spp. by electroporation. Nucleic Acids Res. 17(16): 6747.

45.Lazo, G.R., Stein, P.A., Ludwig, R.A. (1991) A DNA transformation-competent Arabidopsis genomic library in Agrobacterium. Biotechnology (N Y). 9(10): 963-7.

46. Neumann, M.J. \& Dobinson, K.F. (2003). Sequence tag analysis of gene expression during pathogenic growth and microsclerotia development in the vascular wilt pathogen Verticillium dahliae. Fung. Genet. Biol. 38:54-62. 
47. Dixon, G.R., Pegg, G.F. (1972). Changes in the amino acid content of tomato xylem sap following infection with strains of Verticillium albo-atrum. Ann. Bot. 36: 147-154.

48.Zeise K. 1992. Gewächshaustest zur Resistenzprüfung von Winterraps (Brassica napus L. var. oleifera Metzger) gegen den Erreger der Rapswelke Verticillium dahliae Kleb. Nachrichtenblatt Deutscher Pflanzenschutzdienst 44:125-128.

49. Wood, R.K.S., (1961). Verticillium wilt of tomatoes and the role of pectic and cellulolytic enzymes. Ann. Appl. Biol. 49: 120-139.

50. Murray, M.G., \& Thompson, W.F. (1980). Rapid isolation of high molecular-weight plant DNA. NAR 8: 4321-4325.

51.Yan, H.Z. \& Liou, R.F. (2006). Selection of internal control genes for real-time quantitative RT-PCR assays in the oomycete plant pathogen Phytophthora parasitica. Fungal Genetics and Biology. 43 (6): 430-438.

52. Yamamoto, I., Numao, M., Sakaguchi, Y., Tsushima, N. \& Tanaka, M. (2007). Molecular characterization of sequence and expression of chicken GPR39. Gen Comp Endocrinol. 151(1):128-34.

53. Pfaffl, M.W. (2001). A new mathematical model for relative quantification in real-time RT-PCR. Nucleic Acids Res. 29(9): 2002-2007.

54. Meng, J., Yin, Y., Yuan, J., Zhang, X., Huang, Y., Lan, K., Wang, H. \& Tu, Z. (2007). Construction of promoter-trap library screening in vivo-induced gene in Streptococcus pneumoniae. Sheng Wu Yi Xue Gong Cheng Xue Za Zhi. 24(1):14952.

55. Hanahan, J. (1983) Studies on transformation of Escherichia coli with plasmids. Journal of Molecular Biology, 166, 557-580.

56. Covert, S.F., Kapoor, P., Lee, M.H., Briley, A. \& Nairn, C.J. (2001). Agrobacterium tumefaciens-mediated transformation of Fusarium circinatum. Mycological Res. 105: 259-264.

57. Utermark, J., Karlosky, P., 2008. Genetic transformation of filamentous fungi by Agrobacterium tumefaciens. Nature Prot. DOI: 10.1038/nprot.2008.83 
58. Lazo, G.R., Stein, P.A. \& Ludwig, R.A. (1991). A DNA transformation-competent Arabidopsis genomic library in Agrobacterium. Nat. Biotechnol. 9: 963-967.

59. Fortin, C., Nester, E.W. \& Dion, P. (1992). Growth Inhibition and loss of virulence in cultures of Agrobacterium tumefaciens treated with acetosyringone. Journal of bacteriology. 174 (17): 5676-5685.

60.Filip, C., Fletcher, G., Wulff, J.L. \& Earhart, C.F. (1973). Solubilization of the cytoplasmic membrane of Escherichia coli by the ionic detergent Sodium-lauryl Sarcosinate. Journal of bacteriology. 115(3): 717-722.

61. Jukanti, A.K., Bruker, P.L., Habernicht, D.K., Foster, C.R., Martin, J.M. \& Fischer, A.M. (2003). Extraction and activation of wheat polyphenol oxidase by detergents: biochemistry and applications. Cereal Chem. 80(6): 712-716.

62.Schuck, S., Honsho, M., Ekroos, K., Shevchenko, A. \& Simons K. (2003). Resistance of cell membranes to different detergents. PNAS. 100(10): 5795-5800.

63. Weiberg, A. (2008). Identification of genes induced in the vascular pathogen Verticillium longisporum by xylem sap metabolites of Brassica napus using an improved genome-wide quantitative cDNA-AFLP. Online.

\section{4. http://www.broadinstitute.org/annotation/genome/verticilliumdahliae/}

65. http://smart.embl-heidelberg.de/

66. Watanabe T., Suzuki K., Oyanagi W., Ohnnishi K. \& Tanaka H. (1990). Its evolutionary relationship to Serratia chitinase and to the type III homology units of fibronectin. J.Biol.Chem. 265: 15659-16665.

67.Pankov, R. \& Yamada, K.M. (2002). Fibronectin at a glance. Journal of cell science 115: 3861-3863.

68.Lodder, A. L., Lee, T. K. \& Ballester, R. (1999). Characterization of the Wsc1 Protein, a Putative Receptor in the Stress Response of Saccharomyces cerevisiae. Genetics. 152: 1487-1499.

69.Serrano, R., Martín, H., Casamayor, A. \& Ariño, J.J. (2006). Signalling alkaline pH stress in the yeast Saccharomyces cerevisiae through the Wsc1 cell surface sensor 
and the SIt2 MAPK pathway. Biol Chem. 52: 39785-39795.

70.Wiest, A., Grzegorski, D., Xu, B.W., Goulard, C., Rebuffat, S., Ebbole, D.J., Bodo, B. \& Kenerley, C. (2002). Identification of peptaibols from Trichoderma virens and cloning of a peptaibol synthetase. J Biol Chem.

71. Cohen-Kupiec R., Broglie K.E., Friesen D., Broglie R.M. \& Chet I. (1999). Molecular characterization of a novel $\beta-1,3$-exoglucanase related to mycoparasitism of Trichoderma harzianum. Gene 226: 147-154.

72. Saloheimo M., Hakola S., Pere J., Swanson B., Nyyssönen E., Bhatia A., Ward M. \& Penttilä M. (2002). Swollenin, a Trichoderma reesei protein with sequence similarity to the plant expansins, exhibits disruption activity on cellulosic materials. Eur. J.Biochem. 269: 4202-4211.

73. Chet, I. \& Inbar, J. (1994). Biological control of fungal pathogens. Appl Biochem Biotechnol. 48: 37-43.

74. Dupres, V., Alsteens, D., Wilk, S., Hansen, B., Heinisch, J.J. \& Dufrêne Y.F. (2009). The yeast Wsc1 cell surface sensor behaves like a nanospring in vivo. Nature Chemical Biology 5(11):857-862.

75. Rauyaree, P., Ospina-Giraldo, M.D., Kang, S., Bhat, R.G., Subbarao, K.V., Grant S.J. \& Dobinson K.J. 2005. Mutations in VMK1, a mitogen-activated protein kinase gene, affect microsclerotia formation and pathogenicity in Verticillium dahliae. Curr. Genet. 48:109-116.

76. Hynes, R.O. (1990). Fibronectins. (Springer-Verlag, New York.)

77. Mosher, D.F. (2001). A role for fibronectin in self-repair after ischemic injury. Nature Medicine. 7(3): 290-292.

78. Lanza, R., Langer, R. \& Vacanti, J. (2007). Principles of tissue engineering. (Third Edition). 


\title{
Chapter 5: Identification and characterisation of a ACE1-like gene VI_12.1 of Verticillium longisporum
}

\author{
Haiquan Xu, Malte Beinhoff, Arne Weiberg and Petr Karlovsky
}

\section{Abstract}

In a cDNA-AFLP approach investigating the effect of xylem sap metabolites of Brassica napus on the transcriptome of $V$. longisporum, we found a VI_12.1 gene, its gene expression was reduced during infection of $B$. napus in root/hypocotyl tissue in reference to in vitro grown mycelium in a xylem simulating artificial medium, indicating a suppression of this gene during the infection process. The full-length gene sequence of VI_12.1 was isolated from $V$. longisporum. The gene has an ORF of 2,328 nucleotides, one intron and translated cDNA is predicted to code for a 775 amino acids. Sequence analysis of VI_12.1 showed the high homology to the zinc-finger transcription factor ACE1 (1) containing three ZnF_C2H2 domains. ACE1 in saprophytic fungus Trichoderma reseii acts as a regulated transcriptional suppressor of cellulase and xylanase genes. We applied RNAi technology for gene silencing of this ACE1-like VI_12.1 gene in V. longisporum by expressing a genespecific RNA-hairpin. Gene-silenced mutants did not show any visual difference in triggering typical infection symptoms in $B$. napus. A semi-quantitative testing for alterations in cellulase activities on cellulose-containing agar medium showed less difference between the silenced mutants and V. longisporum wild type. Generation of VI_12.1 gene overexpression mutant strains is in processing.

\section{Introduction}

Polysaccharides are polymeric carbohydrates found in plant cell wall and exist in nature. Most filamentous pathogenic or saprophytic fungi can produce polysaccharide-degrading enzymes to degrade different polysaccharides and belong to an important group of microorganism for the global carbon cycle and plant health. They have ability to cause disease of certain plants and bring great economic consequence. V. tricorpus secreted endo and exo-enzymes, capable of degrading cellulosic, hemicellulosic and pectinolytic 
polysaccharides (8). A large number of enzymes and genes from Aspergilli involved in the degradation of plant cell wall polysaccharides. The enzymes covered most of the functions required for the complete degradation of plant cell wall polysaccharides (9). A fungus Ophiostoma ulmi (Buism.) Nannf. causing the first epidemic of the Dutch elm disease (DED) shown a significant correlation between the activity of exoglucanase and $\beta$ glucosidase in vitro and virulence (10). Verticillium species are known to infect many host plants include alfafa, potato, strawberry, tomato, mint, sunflower, eggplant, weeds, cotton, oilseed crops and a range of trees like olive and maple trees $(2,3,4,5,6)$. V. dahliae penetrates the host plant through the root epidermis to xylem elements, spreads in the whole vascular system by rapid colonisation (47) and causes different visible symptoms especial necrosis and wilting as a general result. $V$. dahliae is able to secret cellulases degrading crystalline cellulose (Avicel). The cellulases may play a role in penetration (48). $V$. longisporum causes Verticillium wilt on $B$. napus and induces, leaf chlorosis, curl and especial growth stunting as a typical symptom. In this work we found $V$. longisporum degraded Carboxymethyl (CM) cellulose in vitro on agar plate.

At molecular level the filamentous fungi Arspergillus niger and Trichoderma reesei (Hypocrea jecorina) are two of the best studied organisms for production of cellulase and xynlanase enzymes. XInR (Xylanase regulator, $A$. niger) gene is a transcriptional activator of xylanase and cellulase expression in $A$. niger $(11,12)$ and links a range of intracellular carbon metabolisms $(13,14)$. Xyr1 (Xylanase regulator $1, T$. reesei) gene is a transcriptional regulator of xylanolystic genes in $T$. reesei that activated by different inducers like cellulose, xylan, mixtures of plant polymers $(15,16,17)$. Xyr1 activates generally a hydrolase formation in $T$. reesei $(18,19)$ and interplays with specific transcriptional regulators ACE1 (Activator of cellulases 1, T. reesei) and Ace2 (Activator of cellulases $2, T$. reesei) $(20,21)$. Most zinc finger domains through specific binding to nucleic acids or proteins, play important function for transcription, translation and signalling in cell. ACE1 transcriptional factor contains three Cys2His2-type zinc fingers and is a repressor of cellulase and xylanase expression which was performed by $\Delta$ ace 1 mutants. They grew better than the wild type on medium containing cellulose as sole carbon source $(22,23)$.

Here we report a transcription factor ACE1-like gene of $V$. longisporum related in vitro cellulase activity and involved in pathogenic process in planta as a repressor as compared to mycelium grown in vitro in a xylem-simulating liquid medium (SXM) (33) analysed by 
qRT-PCR.

\section{Materials and Methods}

\section{Plant Material}

Rapid-cycle rape (Brassica napus var. napus, genome ACaacc[26])was originally provided by P.H. Williams (Department of Plant Biology, University of Wisconsin-Madison, Wl; Crucifer Genetics Cooperative, Stock number 5).

Rapid-cycling rape seeds were surface sterilised by immersing them in $70 \%$ ethanol for 30 $s$ and then rinsed in sterilised tap water for $30 \mathrm{~s}$ three times. Then the Rapid-cycling rape seeds were germinated in sterile silica sand in climate-controlled chambers (30kLux, 60\% humidity, $23 / 20^{\circ} \mathrm{C}$ and $15 / 9 \mathrm{~h}$ day/night; Philips TL5 HO lamps). Seven-day-old seedling were carefully rinsed from silica sand, the cleaned roots were inoculated in a spore suspension of $V$. longisporum isolate VL43 or its mutants $\left(1 \times 10^{6}\right.$ spores $\left.\mathrm{ml}^{-1}\right)$ by rootdipping for $30-45 \mathrm{~min}$. Seedling roots dipped in sterile tap water was as a negative control. After inoculation, subsequently, single seedlings were respectively planted into pots with sterile sand-soil mixture $(\mathrm{V}: \mathrm{V}=1: 1)$ and grown under the constant conditions described above. Rape plant materials were harvested 14, 21, 28, 35 days post inoculation (dpi) for time-course experiments. Plants were scored after time course for disease symptoms using an assessment key according to Zeise (see chapter 4). For plant stunting using plant shoot length by measuring.

\section{Fungal strains}

V. longisporum isolate VL43 from Brassica napus was used in this work (Zeise and von Tiedermann 2001) (27). Conidial suspensions in a concentration of about $10^{6} \mathrm{conidia} / \mathrm{ml}$ in Czapek Dox medium mixed with $30 \%$ sterile glycerol were for long term at $-80^{\circ} \mathrm{C}$ stored. For propagation, the stored conidia were spread onto Potato Dextrose Agar (PDA) and incubated for two weeks at $23^{\circ} \mathrm{C}$ in the dark. Spores were gently collected with sterile tapwater. $500 \mu \mathrm{l}$ spores from the stock solution were inoculated in $250 \mathrm{ml}$ Potato Dextrose Broth (PDB) and incubated for one week at $23{ }^{\circ} \mathrm{C}$ by rotary shaking. The resulting suspension was filtered using sterile gauze. Inoculum for root immersing inoculation was concentrated to $1 \times 10^{6} \mathrm{spores} / \mathrm{ml}$ after counting with a haemocytometer. 


\section{Bacterial strains}

Escherichia coli strain $\mathrm{DH} 5 \mathrm{\alpha}$ was used for construction of plasmids. Agrobacterium tumefaciens strain AGL-1 (28) (provided by Dr. Susanna Frick, Leibniz Institute of Plant Biochemistry, Halle/Saale) was applied for the transformation of fungi. This strain is rifampicin and carbenicilin resistant and contains the hyper-virulent Ti plasmid pEHA105 (pTiBo542 $\triangle$ TDT-DNA) (29). Cells were stored for long term in the freezer at $-80^{\circ} \mathrm{C}$.

\section{Determination of gene expression in vitro and in planta by qRT-PCR}

For quantification of transcripts level of VI_12.1 silenced mutants in planta, according to time course, root and hypocotyl of infected plant tissue were harvested on 14, 21, 28, 35 dpi and applied for total RNA extraction after a above described "hot phenol" extraction protocol. Because of less amount of RNA from each plant, each total RNA sample was extracted from a tissue pool of six plants. mRNA was purified from total RNA sample by Oligotex mRNA Purification Kit (Qiagen, Hilden, Germany). About 500-1000 ng mRNA was used in reverse transcription reaction together with 50 pmol oligo-T primer, $1 \mathrm{mM}$ dNTPs, $20 \mathrm{U}$ RiboLock RNAse inhibitor and $200 \mathrm{U}$ RevertAid reverse transcriptase (Fermentas, St. Leon-Rot, Germany) in a $20 \mu \mathrm{l}$ reaction volume. From mRNA synthesized cDNA was purified by PCR Purification Kit (Qiagen, Hilden, Germany) and quantified with photospectrometer by $260 \mathrm{~nm}$ (GeneQuant, Cambridge, UK). About 100ng purified cDNA was used in qRT-PCR as template. SybrGreen system was used in real-time PCR. Housekeeping genes, $\beta$-tubulin and ribosomal protein $S 17(30,31)$, were used for normalization. $\Delta \Delta \mathrm{Ct}$ method and Pfaffl's method were used for quantification of mRNA level between in vitro and in planta samples (32).

For quantification of transcripts level of VI_12.1 silenced mutants in vitro by qRT-PCR a SXM medium was used. VI_12.1 Gene silenced mutants were grown in $100 \mathrm{ml}$ SXM medium for 7 days at $23^{\circ} \mathrm{C}$ on a rotary shaker $(150 \mathrm{rpm})$, inoculated with $100 \mu \mathrm{l}$ of $10^{6}$ spores $/ \mathrm{ml}$ glycerol spore solution. SXM was designed to reflect the nutritional conditions of the vascular fluid, and contains sodium polypectate $\left(2 \mathrm{~g} \mathrm{l}^{-1}\right)$, vitamin-free casamino acids $\left(4 \mathrm{~g} \mathrm{l}^{-1}\right), 1 \mathrm{x}$ trace elements (34), $1 \mathrm{x}$ potassium salts, and $0.1 \mu \mathrm{M}$ biotin. 
Table 1: Designed primers for VI_12.1 gene expression by qRT-PCR

\begin{tabular}{|l|l|l|}
\hline Name of primer & Sequence of primer & PCR fragment \\
\hline C12-RT-f (VI_12.1-RT-F) & 5'-AGCCACAGTATTGCTACGC-3' & $219 \mathrm{bp}$ \\
\hline C12-RT-r (VI_12.1-RT-R) & 5'-GTATGGGTAGGATGTGTCG-3' & \\
\hline
\end{tabular}

\section{Construction of the binary vector PPK2-RNAi-Hairpin-VI_12.1}

For a knock-down of ACE1-like gene VI_12.1 we applied a hairpin cassette-based RNAi technique (55). The backbone of pPK2 (35) was used for construction of binary vector pPK2-RNAi-Hairpin-VI_12.1 (36) (Figure 1). The construction was divided in two steps: At first an antisense sequence of $\mathrm{VI}$ _12.1 and a intron sequence of the putative Hydrophobin from $V$. longisporum as the space were assembled and inserted in vector pPK2. The antsense and the intron sequence were amplified by PCR respectively using genomic DNA extracted from $V$. Iongisporum mycelium. The amplificons were digested with enzymes Ndel (Fermentas) and ligated with T4-ligase (Fermentas). The result of ligation was used as a template for amplification of antisense-space fragment. As second step, the sense sequence of $\mathrm{VI} 12.1$ gene was inserted in the vector pPK2 containing antisense-space fragment. All PCRs used bioline polymerase and standard procedure. The for construction of binary vector pPK2-RNAi-Hairpin-VI_12.1 used primers are listed in Table 2.

Table 2: Primers for construction and detection of target binary vector

\begin{tabular}{|l|l|}
\hline Name of primer & Sequence of primer \\
\hline VI_12.1_RNAiFas_Sdal_F & 5'-TAGTGACCTGCAGGTCACAACATCACTCTACTGCT-3' \\
\hline VI_12.1_RNAiFas_Ndel_R & 5'-GATATGCATATGAATTCCAGACTCTGTTCGGCAG-3' \\
\hline VI_12.1_RNAiFs_BgllI_F & 5'-GATATGAGATCTAATTCCAGACTCTGTTCGGCAG-3' \\
\hline VI_12.1_RNAiFs_Ascl_R & 5'-GAGCTCGGCGCGCCTCACAACATCACTCTACTGCT-3' \\
\hline Vlh_Intron_Ndel_F & 5'-GATATGCATATGTGACTGCTCTACCCGTACGT-3' \\
\hline VIh_Intron_BglII_R & 5'-GATATGAGATCTCTCCTGGCACTCTTTGCTAT-3' \\
\hline pPK2-PoliC-F & 5'-ATTAAGCGGGAGACGTAT-3' \\
\hline pPK2-TtubA-R & 5'-CCTCGATGAACTCACGCTCA-3' \\
\hline Blue colour: Restriction sites. & \\
\hline
\end{tabular}


The restriction sites map of binary vector pPK2-RNAi-Hairpin-VI_12.1 is following in Figure 1. The constructed vector pPK2-RNAi-Hairpin-VI_12.1 was transferred into $A$. tumefaciens by electroporation (37) at $2.0 \mathrm{kV}, 200$ ohms and $25 \mu \mathrm{F}$ using a cuvette with 1 mm gap between the electrodes.

\section{Agrobacterium-mediated transformation for knock-down of ACE1-like VI_12.1}

Agrobacterium-mediated transformation was applied for fungal transformation (39). The $A$. tumefaciens strain AGL1 containing the binary vector pPK2-RNAi-Hairpin-VI_12.1, was incubated in LB medium completed with rifampicin $\left(25 \mathrm{\mu g} \mathrm{ml}^{-1}\right)$, carbenicillin $\left(25 \mathrm{\mu g} \mathrm{ml}^{-1}\right)$ and kanamycin $\left(50 \mathrm{\mu g} \mathrm{ml}^{-1}\right)$ on a rotary shaker with $200 \mathrm{rpm}$ at $28^{\circ} \mathrm{C}$ for $48 \mathrm{~h}$ until $\mathrm{OD}_{600}$ of AGL1-cells reaching 0.5-0.9, The bacteria were harvested and washed $2 x$ with IM-solution (induction medium) and resuspended in IM supplemented with $200 \mu \mathrm{M}$ AS (acetosyringone). Grow cells for 8-12 $\mathrm{h}$ under same conditions like before until the cells reach $\mathrm{OD}_{600}=0.3$. The prepared fresh fungal spores were mixed with pre-induced AGL1 cells and co-cultivated at $23^{\circ} \mathrm{C}$ in dark for $60 \mathrm{~h}$ on a cellophane sheet placed IM agar plate supplemented $200 \mu \mathrm{M}$ acetosyringone. After co-cultivation, use sterile forceps to transfer the cellophane membranes onto selection plates containing $200 \mu \mathrm{M}$ cefotaxime and hygromycin $\mathrm{B}$. The plates were incubated at $23^{\circ} \mathrm{C}$ and after $8-10$ days the developed colonies of transformants were visible. To check their stability, all transformants were incubated on PDA plate for at least three generations. To control transformation each colony was checked with specific primers of VI_12.1 gene (Table 1) combined with pPK2PoliC primer or pPK2-TtubA primer (Table 2) by PCR. 


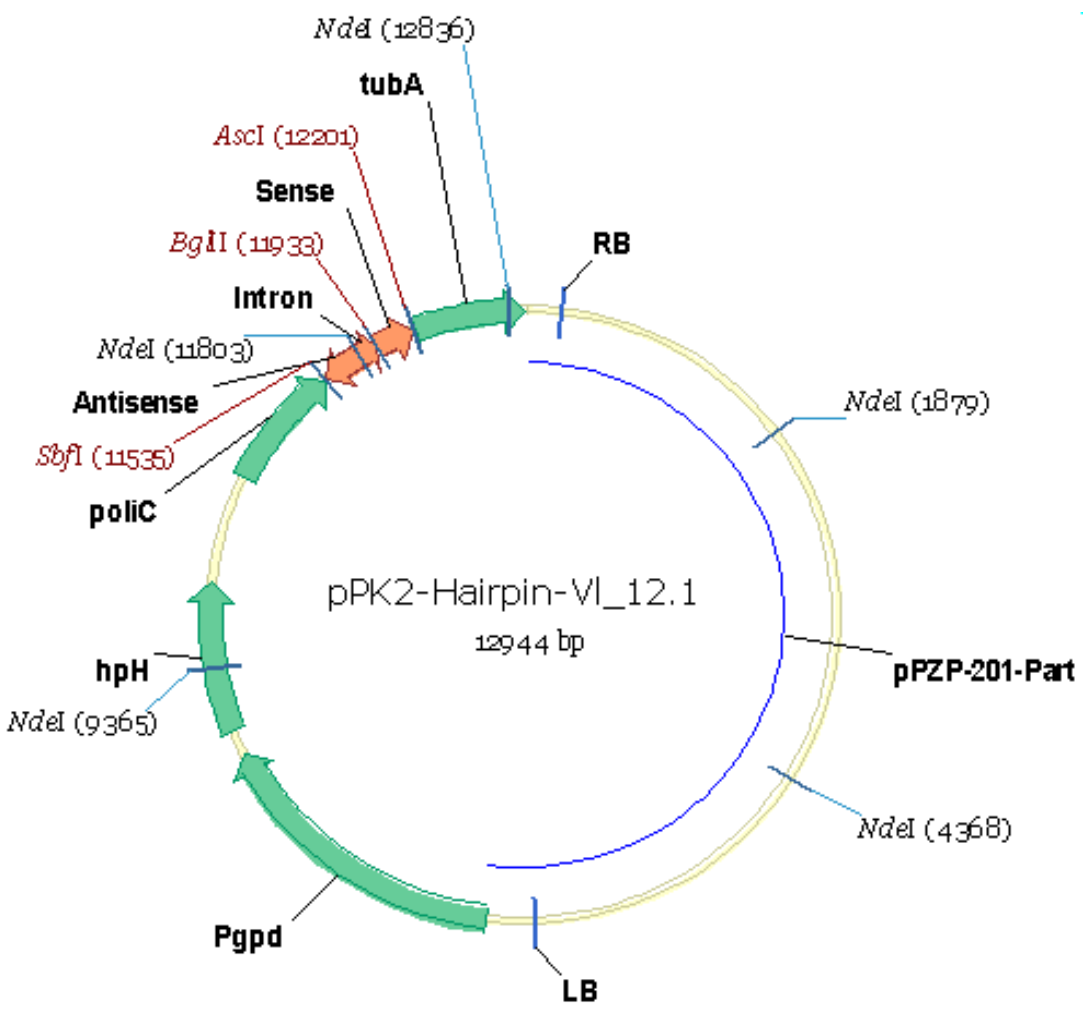

Figure 1: Restriction sites map of pPK2-RNAi-Hairpin-VI_12.1. For construction of RNAiHairpin cassette, a 159 bp large sequence of VI_12.1 gene was used in both antisense (with primer pair VI_12.1-RNAiFas_Sdal_F and VI_12.1_RNAiFas_Ndel_R) (Table 2) and antisense direction (with primer pair VI_12.1_RNAiFs_BgllIF and VI_12.1RNAiFs_Ascl_R) (Table 2), a native $V$. longisporum putative Hydrophobin intron sequence 129 bp was incorporated as spacer (with primer pair Vlh-Intron_Ndel_F and VlhIntron_BgllI_R) between the antisense and the sense sequence. The binary vector contained PoliC (promoter OliC for a gene encoding subunit 9 of the mitochondrial ATP synthase complex from Aspergillus nidulans) and TtubA (terminator for beta-tubulin gene from Botrytis cinerea) for control of RNAi-Hairpin cassette. Pgpd (promoter for glyceraldehyde-3-phosphate dehydrogenase [gpd] from Coriolus versicolor) controlled $\mathrm{hpH}$ (Hygromycin B phosphotransferase) resistance gene and the PPZP-201 fragment cut out from host binary vector pPZP201 contained T-DNA region including the LB (left-boarder) and RB (right-boarder) from Ti plasmid of Agrobacterium tumefaciens) (38).

\section{Colorimetric assay of cellulase activity}

Water-soluble carboxymethyl-substituted cellulose, labelled covalently with a dye Remazol Brilliant Blue R (RBB) to CM-cellulose-RBB complex was used as substrate for assay of endo-acting cellulase activity (40). Enzyme assay was performed on modified basic 
Czepek Dox (CD) agar plate after diffusion effect.

\section{Results}

\section{Isolation and Characterisation of V. Iongisporum gene VI_12.1}

We found a putative zinc-finger transcription factor ACE1 (activator of cellulase 1 characterized in $T$. reesei) in $V$. longisporum according to sequence analysis. The fulllength ACE1-like gene VI_12.1 with an ORF of 2,328 nucleotides (nt) containing one intron (Figure 2) was isolated from $V$. longisporum by the PCR technique based cloning and direct sequencing. Its translated CDNA is predicted to code for a 775 amino acids (aa) (Figure 5). It has three $\mathrm{ZnF}_{\text {C2}} \mathrm{CH} 2$-like motifs (41) respectively containing 25, 29, 26 amino acid residues (Figure 3) (ZnF_C2H2-motif 1: KKCREPGCNKEFKRPCDLTKHEKTH; ZnF_C2H2-motif 2: WKCPVKTCKYHEYGWPTEKGMDRHHNDKH; ZnF_C2H2-motif 3: YECLFKPCPYKSKRES-SCKQHMEKAH) and including paired cysteines and histidines for zinc coordinating and stable fold (Figure 3 and 4). A multiple alignment of putative VI_12.1 from $V$. longisporum with conserved amino acid sequences of other fungi is partial shown in Figure 4. The nucleotide sequence identity within this gene between $V$. longisporum and $V$. dahliae was determined at a level of 95\% (data not shown). VI_12.1 gene keeps a high similarity like $V$. dahliae on the protein level and contains a close revolutionary relationship with ACE1 in T. reesei (Figure 6). In a cDNA-AFLP profiling, the $V I$ 12.1 gene was investigated as a induced candidate gene in transcriptome from $V$. longisporum after a treatment with xylem sap metabolites of $B$. napus. ACE1-like VI_12.1 in planta relative gene expression was determined as suppressed in time course experiment by qRT-PCR compared with the mycelium grown in vitro in a xylem-simulating liquid medium (Figure 5). After sequence extension and transcription analysis an ACE1like gene VI_12.1 was identified.

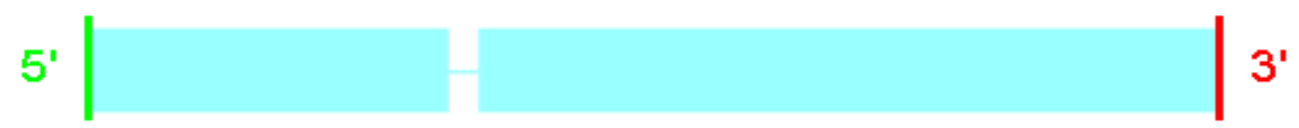

Figure 2: Modular structure shown position of one Intron in VI_12.1 gene. The 2,328 nucleotides ORF contains one intron at nucleotide positions 745-804 and with a 60 bp length sequence GTAAGTCAACTCTTGTATCAACGCAGCGTTTGGGGAGATACTTATCGGTCGTTGATGAAG. Modified after modular structure in Verticillium group database. 


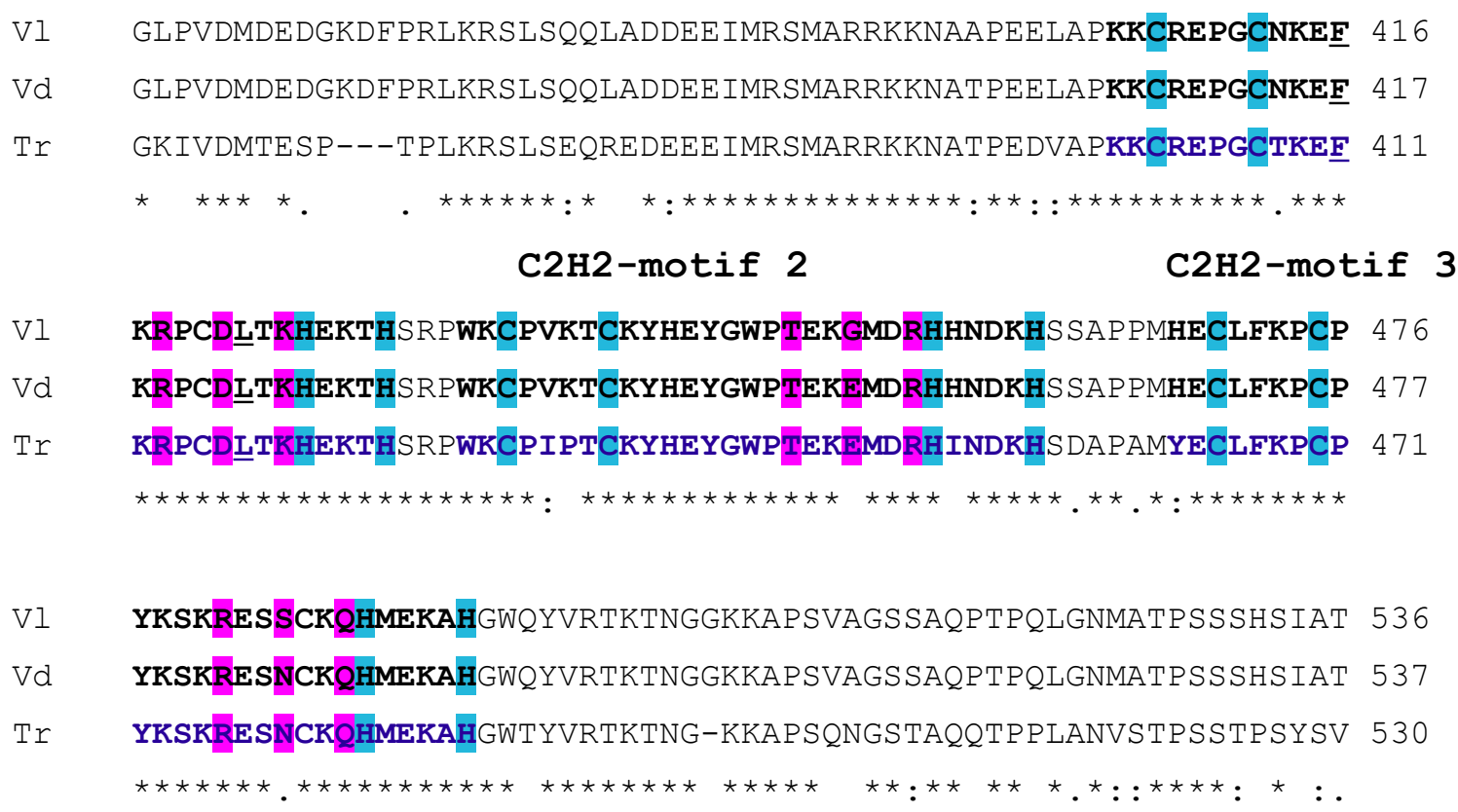

Figure 3: Alignment of three putative $\mathrm{ZnF}-\mathrm{C}_{2} \mathrm{H}_{2}$ Motifs (Nr. 1, Nr. 2 and Nr. 3) in ACE1 from T. reesei $(\mathbf{T r})$ and the homologous residues from $V$. dahliae $(\mathbf{V d})$ and $V$. longisporum $(\mathbf{V I})$. $\mathrm{ZnF}-\mathrm{C}_{2} \mathrm{H}_{2}$ Motifs positioned after Saloheimo's work in 2000 (22) and results of analysis with NCBI database (http://www.ncbi.nlm.nih.gov/), simple modular architecture research tool (SMART) (http://smart.embl.de/) and CLUSTAL 2.0.12 multiple sequence alignment. The amino acid sequence of $T$. reesei $(\mathrm{Tr})$ appears in NCBI database with the Accession $\mathrm{Nr}$. Q9P8W3. The amino acid sequence of $V$. dahliae is from Verticillium group database. ZnF$\mathrm{C}_{2} \mathrm{H}_{2}$ Motifs marked with red colour. Blue colour shows the conserved cysteines $(\mathrm{C})$ and histidines $(H)$. Green colour signals the possible primarily responsible binding site for recognition of an extended sequence after Ganss in 2004 (46). 
(A)

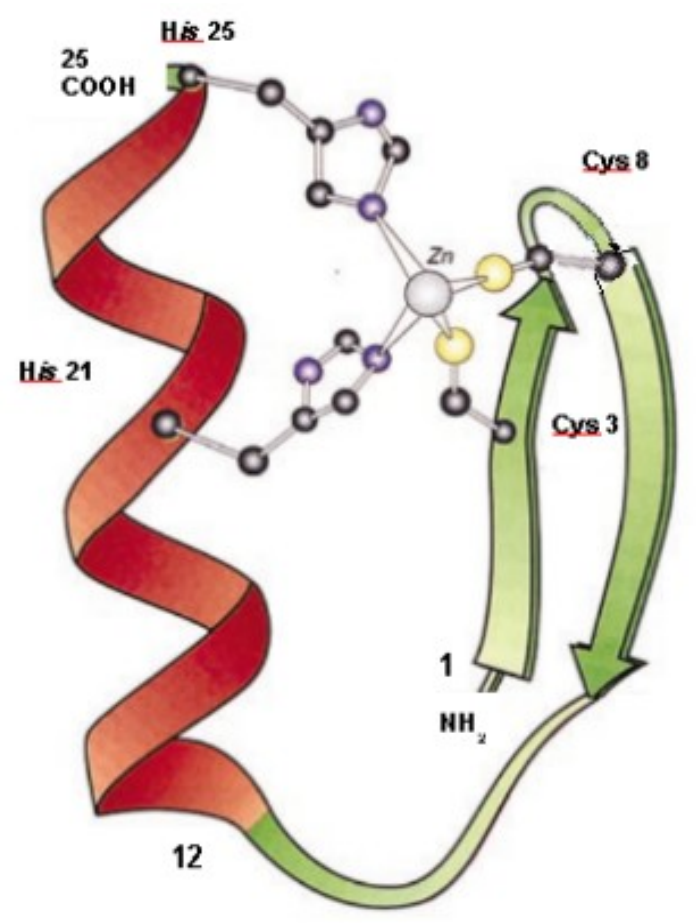

(B)

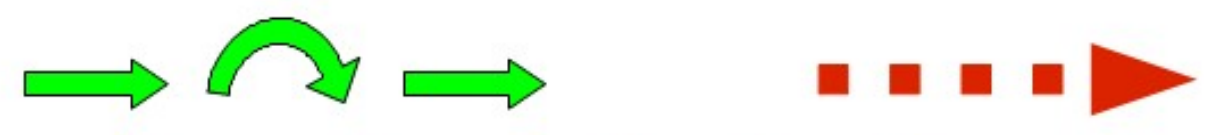

C2H 2 motif: $F / Y-X-\bar{C}-\mathrm{X}-\mathrm{X}-\mathrm{X}-\mathrm{X}-\overline{\mathrm{C}}-\mathrm{X}-\mathrm{X}-\mathrm{X}-\underline{\mathrm{F}}-\mathrm{X}-\mathrm{X}-\mathrm{X}-\mathrm{X}-\mathrm{X}-\overline{\mathrm{X}}-\underline{\mathrm{L}}-\mathrm{X}-\overline{\mathrm{X}}-\overline{\mathrm{H}}-\mathrm{X}-\mathrm{X}-\mathrm{X}-\mathrm{H}-\mathrm{X}-\mathrm{X}-\mathrm{X}-\mathrm{X}-\mathrm{X}$

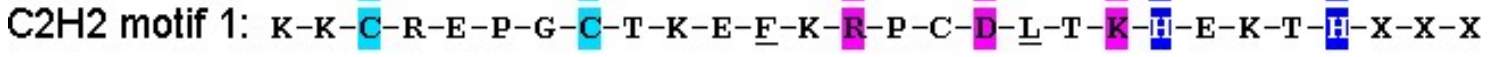

Figure 4: $\mathrm{C} 2 \mathrm{H} 2$ zinc finger motif 1 . (A) The $\mathrm{C} 2 \mathrm{H} 2$ zinc finger motif 1 consists of two cysteins and two histeins residues to form with a $\mathrm{Zn}$ ion to a stable fold (modified after Ganss 2004). A short antiparallel $\beta$-sheet constructed with two $\beta$-strands and a hairpin turn, connected with an $\alpha$-helix. (B) $\mathrm{C} 2 \mathrm{H} 2$ motif 1 is compared with $\mathrm{C} 2 \mathrm{H} 2$ motif (consensus): Both have two $\beta$-strands (green arrows) containing two cysteins (letters with hell blue background) residues and a hairpin turn (curved green arrow) connected with an a-helix (red dashed arrow) containing two histeins (letters with dark blue background) residues, Conserved amino acids are underlined (46).

MSCQNPRRRSPVTRVGDASSNGLTSLKTNMTLRKGATFHSPTSLDSSS IDAFIPPALGRISDQS*RRVGAHVR
RMEMIVSGIETSLNLNDTPRPASKPSRDECLPRTNGFLGRPTVDPAMAKDTKTSGERRVLRPRHRRSSEQHAS
DSGLGTSLASSVEKQAPS ITSKTSKASAITRSAAAPSNTMTKVSGLSSKAVSRVHEHVLRPLRAKPELKDFEP
IVLDIPRRIRDKEI ICLRDLEKTLIFMAPVSQLLYQRSVWGDTYRSLMKERAKTAALYLDFCLTSIRCIQATV
EYLSDREQIRPADRPYTNGYFIDLVEQIRQYAGQLATAKEAGVEGREMDVDPTDEVKLFGGISQNGRPAELVR
VRKDGQAISMATGLPVDMDEDGKDFPRLKRSLSQQLADDEEIMRSMARRKKNAAPEELAPKKCREPGCNKEFK
RPCDLTKHEKTHSRPWKCPVKTCKYHEYGWPTEKGMDRHHNDKHSSAPPMHECLFKPCPYKSKRESSCKQHME
KAHGWQYVRTKTNGGKKAPSVAGSSAQPTPQLGNMATPSSSHSIATPPEESTSLFPPFNHDDFPHYVPAEEFA
DTCLGPMGQPPMTLEGIDFNDLGVSPTDYNTPSTDTSYPYTSYQDGPEFVINNDDIYGARVQIPTPAWPEKMM
AGMQNYAPVSACQPQMMPEPLAPHISPIGQGNAMLFTPNSLAEVDEGFDDFGGCGDDFTLFPVNGLDKDAQFQ
TLFGSEMPSSGLGLSQGASQDFFGNGMDWSSMEYHTYSQQPQHQQ

Figure 5: Amino acids sequence of Vl_12.1 gene translated by software Transeq. 


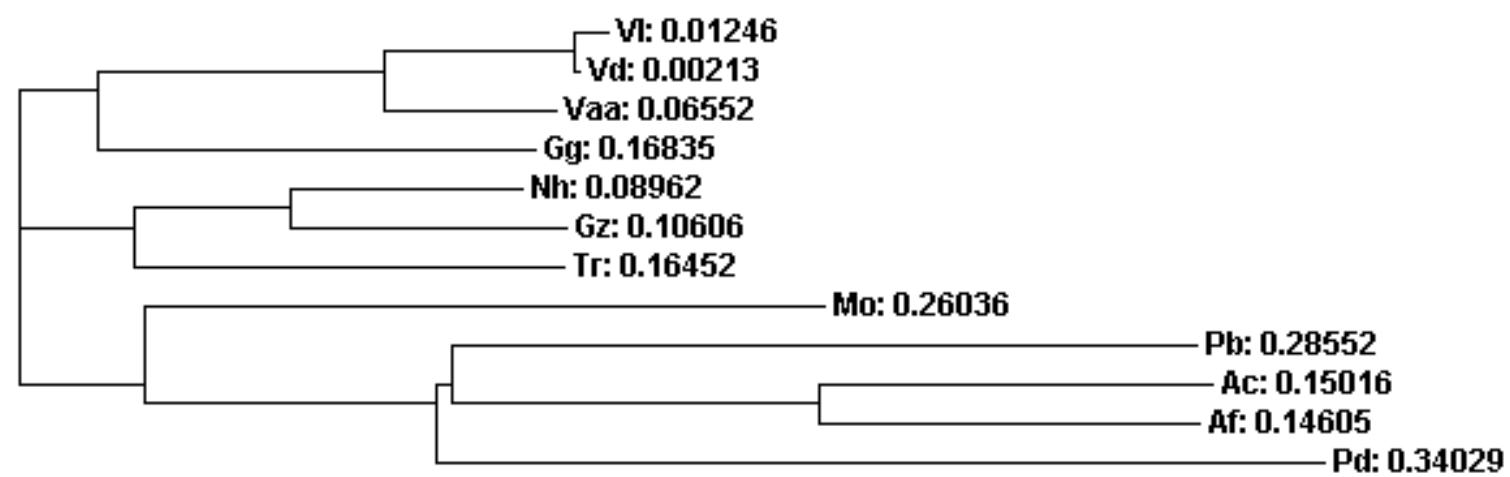

Figure 6: Phylogeny tree showing revolutionary relationship was formed from an alignment of VI_12.1 protein sequences from $V$. longisporum and related species using alignment program ClustelW2. VI: Verticillium longisporum; Vaa: Verticillium albo-atrum VaMs.102; Vd: Verticillium dahliae VdLs.17; Gg: Glomerella graminicola M1.001; Nh: Nectria haematococca mpVI 77-13-4; Gz: Gibberella zeae PH-1; Tr: Trichoderma reesei; Mo: Magnaporthe oryzae 70-15; Pb: Paracoccidioides brasiliensis Pb01; Ac: Aspergillus clavatus NRRL 1; Af: Aspergillus fumigatus Af293; Pd: Penicillium decumbens.

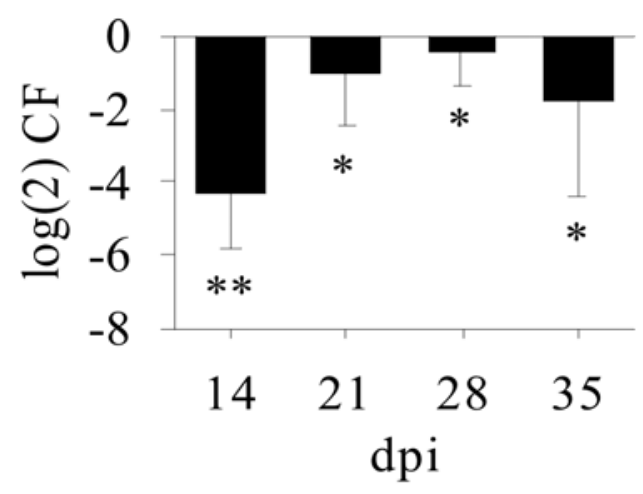

Figure 7: ACE1-like gene VI_12.1 was identified using root and hypocotyl tissue of VLinfected Brassica plants at 14, 21, 28, 35 dpi im comparison to in vitro grown mycelium by the treatment with xylem sap metabolites. Gene expression analysis was done by qRTPCR. All qRT-PCR data were analysed by REST ${ }^{\circ}$ software (Relative Expression Software Tool) available at http://www.wzw.tum.de/gene quantification. ${ }^{*} \mathrm{p}$-value $<0.05$.

\section{Generation and characterisation of $\mathrm{VI}$ _12.1 silenced mutants}

The V. longisporum ACE1-like gene VI_12.1 was silenced using a RNAi-mediated posttranscriptional gene "knock-down" method with a hairpin construction using intron sequence from the putative Hydrophobin in V. longisporum as a space. The expression of 
ACE1-like gene VI_12.1 after gene silencing was suppressed up to $96 \%$ in $V$. longisporum quantified by qRT-PCR (Figure 7). Growth rates of transformants were slightly enhanced on PDA agar plates (Figure 8). Gene-silenced mutants did not perform any visual difference in triggering typical infection symptoms in B. napus. Figure 7 showed the growth of plants from pathogenicity test.

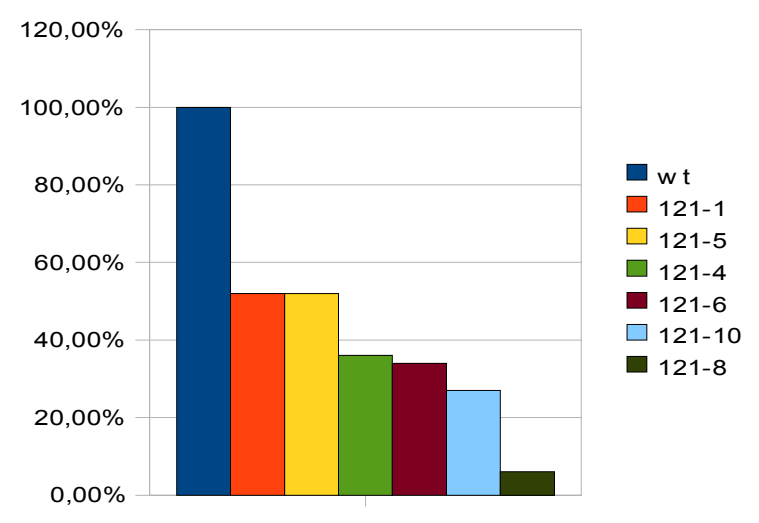

Figure 7: Gene expression levels of ACE1-like gene VI_12.1 silenced mutants in vitro were determined by qRT-PCR and compared with wild type strain. The normalized level of Acel-like gene expression of wild type in vitro (calibrator) is always $100 \%$.

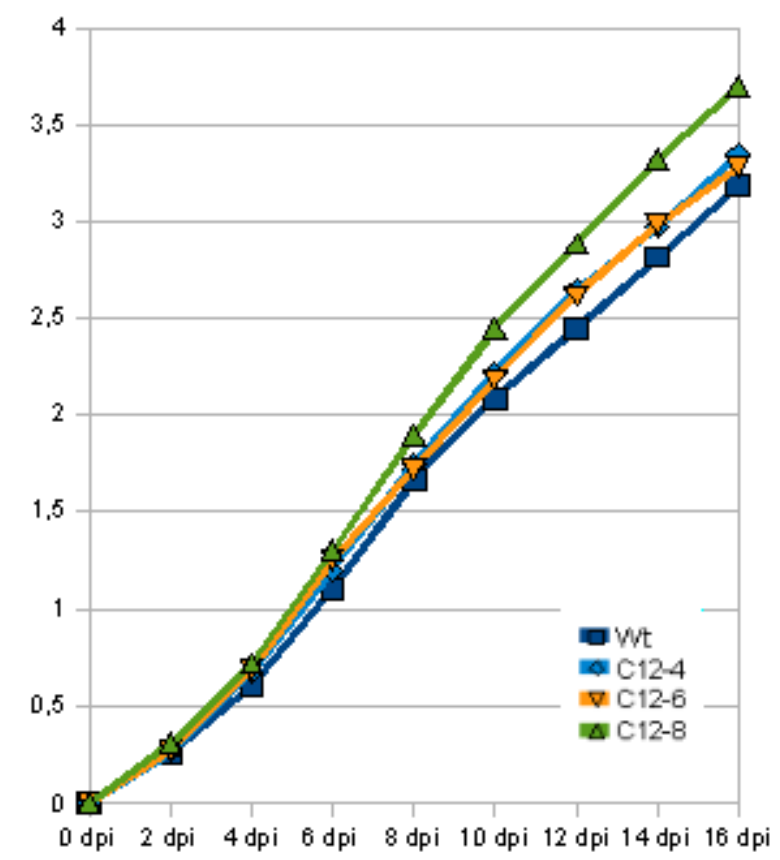

Figure 8: Growth rate of wild type and Acel-like gene mutant strains on PDA plate. The VI_12.1 mutant strains C12-4, C12-6, C12-8 and wild type VL43 were tested. 


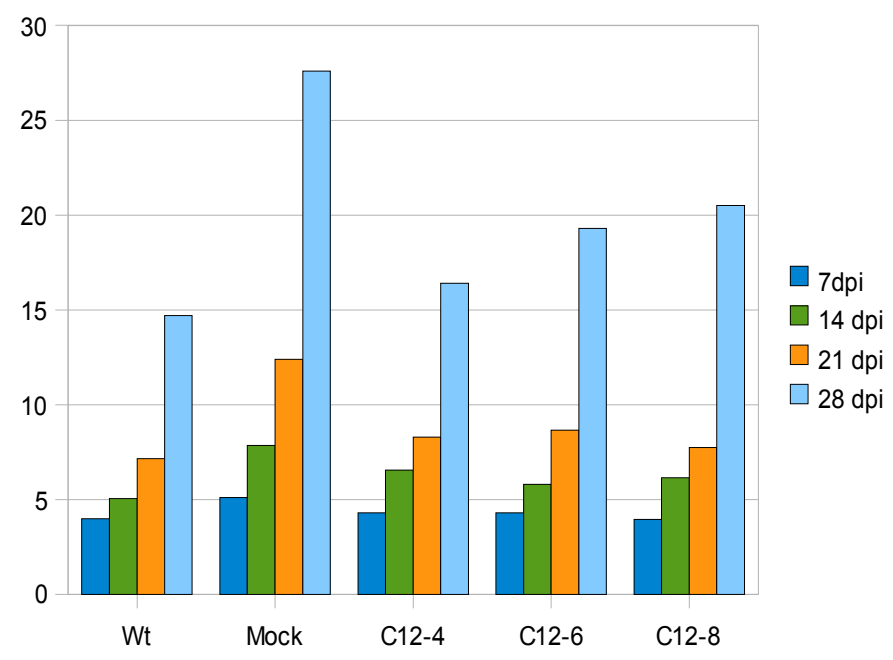

Figure 9: Pathogenicity tests of Acel-like gene silenced mutants in planta were determined in time course experiment in green house. The VI_12.1 mutant strains C12_4, C12_6, C12_8 and wild type VL43 were used. The used Brassica plant was "rapid -rolling cycle".

\section{Colorimetric assay of cellulase activity}

A colorimetric assay for the determination of cellulase activity was demonstrated on agar plate . A semi-quantitative comparison of cellulase activity on cellulose as a single carbon source showed that Acel-like gene silenced strains grown better than wild type (Figure 10). The mutant strains C12-4, C12-6 and C12-8 showed the bright yard with similar size created by diffusion effect after incubation at $23^{\circ} \mathrm{C}$ in dark for 3-5 days. The Samples of $V$. longisporum wild type hold similar diffusion effect with 2-3x more biomass of conidia.

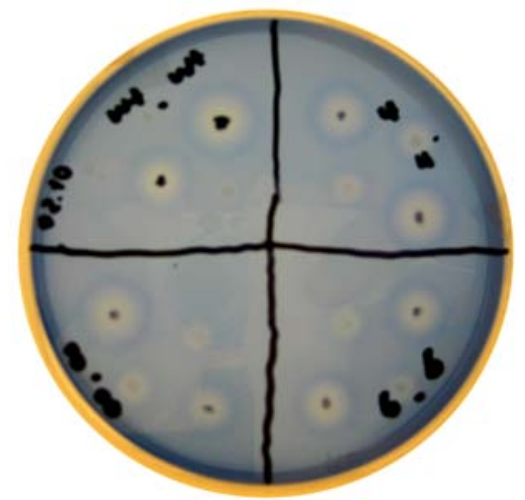

Figure 10: With modified Czapek Dox medium containing Remazol Brilliant Blue and CMcellulose as a single carbon source. The ACE1-like mutant $V$. longisporum strains C12-4 (above right), C12-6 (below right) and C12-8 (below left) compared with wild type (above 
left) were be characterised on agar plate. The bright yard created after incubation at $23^{\circ} \mathrm{C}$ in dark for 3-5 days by diffusion effect.

\section{Discussion}

\section{1. $\mathrm{C} 2 \mathrm{H} 2-\mathrm{Zinc}$ finger as a interaction modular for ACE1 and its homologue in VL}

Zinc fingers are small protein domains contained in the most common eukaryotic DNAbinding proteins in which zinc ion plays a important role for the stability of structure. First one of zinc fingers was discovered in the Xenopus transcription factor IIIA (TFIIIA) $(49,50)$. Zinc fingers perform a widely functions in cell, such as transcription, translation, replication, repair, signalling, proliferation, differentiation, metabolism and apoptosis etc. The typically function of zinc fingers is regulation via their interaction modules by binding to variable compounds like small molecules, proteins and nucleic acids. After the functional properties of different zinc fingers they are divided into three groups, $\mathrm{C} 2 \mathrm{H} 2$-like finger, gag knuckle and treble clef finger. $\mathrm{C} 2 \mathrm{H} 2$ zinc fingers are the most studied $(51,52)$ and can be divided into two classes after the number of zinc finger motifs in protein sequence (53). The proteins containing fewer than five $\mathrm{C} 2 \mathrm{H} 2$ motifs belong to one class which are identified as transcriptional activators or repressors involved in gene regulation. The another class has five or more zinc finger motifs (54). The VI_12.1 was found during a cDNA_AFLP screening. This gene contained three $\mathrm{C} 2 \mathrm{H} 2$-like zinc fingers, each consists of two cysteine, two histeine and the conserved residues in $\mathrm{C} 2 \mathrm{H} 2$ type 1 after comparison with ACE1 which contains three $\mathrm{C} 2 \mathrm{H} 2$-type motifs (22). The gene expression of VI_12.1 was suppressed during infection of $B$. napus in root/hypocotyl tissue compared with in vitro grown mycelium in a xylem simulating artificial medium. This result confirmed the group of $\mathrm{C} 2 \mathrm{H} 2$ zinc finger motifs which functions as regulator in gene expression.

The fungus $T$. reesei produces effective cellulase. It is well-known in addition to inducers such as pophorose, cellubios, lactose and $\beta$-cellobiono-1,5-lactone $(42,43)$ that cellulases in $T$. reesei were regulated also by its carbon source cellulose. The cellulase gene expression regulated by transcriptional factors ACE1 and ACEII $(20,44)$. Aro and her colleague reported that ACE1 acted on transcriptional level as a repressor and regulated the cbh1 (cellulase gene in $T$. reesei) promoter by binding to AGGCA element (45) which was found also in the upstream region of a putative cellulase of $V$. albo-atrum. Therefore, we speculate that ACE1-like VI_12.1 gene possibly via the specific recognition sites of 
$\mathrm{C} 2 \mathrm{H} 2$ zinc fingers binds to the AGGCA element in cellulase promoter fragment in $V$. longisporum because of high identity between these two species. Thus we recommend that the cellulase regulation mechanism in $T$. reesei could be used as a basic model for $V$. longisporum gene Vl_12.1 study.

After a semi-quantitative colorimetric cellulase activity assay, the visual inspection revealed Acel-like VI_12.1 mutant strains indicated no significant difference to $V$. longisporum wild type on Czapek Dox agar plate containing CM-cellulose as solo carbon source. Even sometimes the wild type affected weaker than mutants. Hence, generating of overexpression mutant for VI_12.1 gene and the assay using polysaccharides as inducers under quantitative condition for furthermore investigation of VI_12.1 are crucial step for successful gene function analysis.

\section{ACE1-like gene VI_12.1 related with pathogenesis}

Transcription factor genes encoding regulatory protein exist in all eucaryote. They interplay with promoter in genome and regulate gene expression to control cell cycle and adapt environmental changing. Some transcriptional factor genes were identified in the last years. To delete a gene encoding zinc-finger protein called FOW2 in Fusarium oxysporum f.sp. Melonis by mutagenesis, induced to loss pathogenicity of fungus for penetration of host plant roots (24). In another vascular wilt pathogen $F$. oxysporum, a inducible zincfinger protein XInR was demonstrated to regulate the expression of xylanase (25).

Pathogenicity test in this work performed two results. One side the VI_12.1 gene was suppressed during infection of $B$. napus in root/hypocotyl tissue in reference to in vitro grown mycelium in a xylem simulating artificial medium; another side the VI_12.1 gene silenced mutants did not affect the infection on Brassica plants. These indicated that VI_12.1 possibly not direct correlated with pathogenicity, This suggestion confirmed also by similar result with ACE1 expression in fungal pathogen Magnaporthe grisea. During infection on rice, the expression of $M$. grisea gene ACE1 connected to the onset of appressorium-mediated penetration without host plant signals (56). ACE1 in T. reesei affected as a repressor of cellulase and xylanase expression. $V$. dahliae was able to secrete cellulases, and showed its aggressive isolates degrading crystalline cellulose quickly than the less aggressive isolates (48). Thus we speculated that VI_12.1 might regulate the production of polysaccharide-degrading enzymes to activate for penetration 
through the host cell wall, adaptation to xylem environment and indirectly related with pathogenesis.

\section{Refereneces}

1. Stricker, A.R., Mach, R.L. \& De Graaff, L.H. (2008). Regulation of transcription of cellulases- and hemicellulasese-encoding genes in Aspergillus niger and Hypocrea jecorina (Trichoderma reesei). Appl Microbiol Biotechnol. 78: 211-220.

2. Domisch, K.H., Gams, W. \& Anderson, T. -H. (1980). Nectria (Fr) 1849, Verticillium Nees ex Link 1824. In: Compendium of Soil Fungi. 1: 829-845. New York: Academic Press.

3. Schnathorst, W.C. (1981). Life cycle and epidemiology of Verticillium. In M.E. Mace, A.A. Bell \& C.H. Beckmann (Eds.), Fungal wilt diseases of plants. 81-111. New York: Academic Press.

4. Pegg, G.F. (1984). The impact of Verticillium diseases in agriculture. Phytopathologia Mediterranea. 23: 176-192.

5. Subbarao, K.V., Chassot, A., Gordon, T. R., Hubbard, J.C., Bonello, P., Mulin, R., Okamoto, D., Davis, R.M. \& Koike, S.T. (1995). Host range of Verticillium dahliae from cauliflower and genetic relationships and cross pathogenicities of isolates from different crops. Phytopathology. 85: 1105-1112.

6. Bhat, R. G. \& Subbarao, K.V. (1999). Host range specificity in Verticillium dahliae. Phytopathology. 89: 1218-1225.

7. Eynck, C., Koopmann, B., Grunewaldt-Stoecker, G., Karlovsky, P. \& von Tiedermann, A. (2007). Differential interaction of Verticillium longisporum and $V$. dahliae with Brassica napus detected with molecular and histological techniques. Eur J Plant Pathol. 118: 259-274.

8. Bahkali, A.H. (1999). Cell wall degrading enzymes produced by the phytopathogenic fungus Verticillium tricorpus. Saudi J Bio Sci. 6(2): 133-146.

9. Vries, R.P. \& Visser, J. (2001). Aspergillus enzymes involved in degradation of Plant Cell Wall Polysaccharides. Microbiol. Mol. Biol. Rev. 65:497-522. 
10.Przybył, K., Dahm, H., Ciesielska, A. \& Moliński, K. (2006). Cellulolytic activity and virulence of Ophiostoma ulmi and O. novo-ulmi isolates. For. Path. 36: 58-67.

11. De Graaff, L.H., van den Broeck, H.C., van Ooijen, A.J., Visser, J. (1994). Regulation of the xylanase-encoding xInA gene of Aspergillus tubigensis. Mol Microbiol. 12(3):479-490.

12. Van Peij, N.N., Visser, J., de Graaff, L.H.I (1998). Isolation and analysis of xInR, encoding a transcriptional activator co-ordinating xylanolytic expression in Aspergillus niger. Mol Microbiol. 27(1):131-142.

13. Hasper, A.A., Visser, J., de Graaff, L.H. (2000). The Aspergillus niger transcriptional activator $\mathrm{XInR}$, which is involved in the degradation of the polysaccharides xylan and cellulose, also regulates D-xylose reductase gene expression. Mol Microbiol. 36(1):193-200. Erratum in: Mol Microbiol 2000 Jun;36(6):1506.

14.Pel HJ, et al. Nat Biotechnol. (2007). Genome sequencing and analysis of the versatile cell factory Aspergillus niger CBS 513.88. 25(2):221-231. DSM Food Specialities, PO Box 1, 2600 MA Delft, The Netherlands.

15. Bisaria, V.S. \& Mishra, S. (1989). Regulatory aspects of cellulase biosynthesis and secretion. Crit Rev Biotechnol. 9(2):61-103.

16. Kubicek, C.P. (1993). From cellulose to cellulase inducers: facts and fiction. In: Suominen, P., Reinkainen, T. (eds) Proceedings of the $2^{\text {nd }}$ Tricel Symposium on Trichoderma reesei Cellulases and Other hydrolases, Espoo, Finland. Foundation for Biotechnical and Industrial Fermentation Research, Helsinki, pp 181-188.

17.Zeilinger, S. \& Mach, R.L. (1998). Xylanolytic enzymes of Trichoderma reesei: properties and regulation of expression. Curr Topics Cer Chem 1: 27-35.

18.Stricker, A.R., Grosstessner-Hain, K., Würleitner, E. \& Mach, R.L. (2006). Xyr1 (Xylanase regulator 1 ) regulates both the hydrolic enzyme system and D-xylose metabolism in Hypocrea jecorina. Eukaryot Cell. 5: 2128-2137.

19.Stricker, A.R., Steiger, M.G. \& Mach, R. L. (2007). Xyr1 receives the lactose induction signal and regulates lactose metabolism in Hypocrea jecorina. FEBS Lett 581: 3915-3920. 
20. Aro N., IImén M., Saloheimo A.,N., IImen M. \& Penttilä M. (2001). Acell, a novel transcritional activator involved in regulation of cellulase and xylanase genes of Trichoderma reesei. The Journal of Biological Chemistry. 276(26): 24309-24314.

21. Aro N., Ilmén M., Saloheimo A. \& Penttilä M. (2003). Acel of Trichoderma reesei is a repressor of cellulase and xylanase expression. Appl. Environm. Microbiol. 69: 5665.

22. Saloheimo A., Aro N., IImen M. \& Penttilä M. (2000). Isolation of the ACE1 gene encoding a $\mathrm{Cys}_{2}-\mathrm{His}_{2}$ transcription factor involved in regulation of activity of the cellulose promoter cbh1 of Trichoderma reesei. J. Biol. Chem. 275:5817-5825.

23. Aro N., Pakula T. \& Penttilae M. (2005). Transcriptional regulation of plant cell wall degradation by filamentous fungi. FEMS 29: 719-739.

24.Imazaki I., Kurahashi M., lida Y., Tsuge T. (2007). Fow2, a Zn(II)2Cys6-type transcription regulator, controls plant infection of the vascular wilt fungus Fusarium oxysporum. Mol. Microbiol. 63: 737-753.

25. Calero-Nieto F., Hera C., Di Pietro A., Orejas M., Roncero M.I.G. (2007). Regulatory elements mediating expression of xylanase genes in Fusarium oxysporum. Fung. Genet. Biol. 45: 28-34.

26.Williams P.H., Hill C.B. (1986). Rapid-Cycling Populations of Brassica. Science 232:1385-1389.

27.Zeise K., von Tiedemann A. 2001. Morphological and Physiological Differentiation among Vegetative Compatibility Groups of Verticillium dahliae in Relation to $\mathrm{V}$. longisporum. J. Phytopathol. 149:469-475.

28. Lazo, G.R., Stein, P.A. \& Ludwig, R.A. (1991). A DNA transformation-competent Arabidopsis genomic library in Agrobacterium. Biotechnology 9: 963-967.

29.Kim, M.J., Baek, K. \& Park, C-M. (2009). Optimization of conditions for transient Agrobacterium-mediated gene expression assays in Arabidopsis. Plant Cell Rep. 28: 1159-1167.

30. Yan, H.Z. \& Liou, R.F. (2006). Selection of internal control genes for real-time quantitative RT-PCR assays in the oomycete plant pathogen Phytophthora 
parasitica. Fungal Genetics and Biology. 43 (6): 430-438.

31. Yamamoto, I., Numao, M., Sakaguchi, Y., Tsushima, N. \& Tanaka, M. (2007). Molecular characterization of sequence and expression of chicken GPR39. Gen Comp Endocrinol. 151(1):128-34.

32. Pfaffl, M.W. (2001). A new mathematical model for relative quantification in real-time RT-PCR. Nucleic Acids Res. 29(9): 2002-2007.

33. Neumann, M.J. \& Dobinson, K.F. (2003). Sequence tag analysis of gene expression during pathogenic growth and microsclerotia development in the vascular wilt pathogen Verticillium dahliae. Fungal Genetics and Biology. 38: 54-62.

34.Bennett, J.W. \& Lasure, L.L. (1991). Growth media. In: Bennett, J.W., Lasure, L.L (Eds.), More gene manipulation in Fungi. Academic Press, San Diego, pp. 441-458.

35. Covert, S.F., Kapoor, P., Lee, M., Briley, A. \& Nairin, C.J. (2001). Agrobacterium tumefaciens-mediated transformation of Fusarium cirtinatum. Mycological Research. 105: 259-264.

36. Goldoni, M., Azzalin, G., Macino, G. \& Cogonl. (2004). Efficient gene silencing by expression of double stranded RNA in Neurospora crassa. Fungal Genet Biol. 41: 1016-1024.

37. Wen-Jun, S. \& Forde, B.G. (1989). Efficient transformation of Agrobacterium spp. by high voltage electrotroporation. Nucleic Acid Research. 17: 8385.

38. Fua, D.L., St. Amanda, P.C., Xiao, Y.M., Muthukrishnanc, N. \& Lianga, G.H. (2006). Characterization of T-DNA integration in creeping bentgrass. Plant sciece. 170(2): 225-237.

39. Utermark, J.\& Karlosky, P.: (2008). Nature Prot. DOI: 10.1038/nprot.2008.83.

40.Wirth S. J. and Wolf G. A. (1992). Micro-plate colorimetric assay for endo-acting cellulase, xylanase, chitinase, 1,3-ß-glucanase and amylase extracted from forest soil horizons. Soil Biol. Biochem. 24: 511-519.

41. Saloheimo, A., Aro, N., IImen, M. \& Penttila,M. (2000). Isolation of the ACE1 gene encoding a Cys(2)-His(2) transcription factor involved in regulation of activity of the 
cellulase promoter cbh1 of Trichoderma reesei. J Biol Chem 275 (8): 5817-5825.

42. Morikawa, Y., Ohashi, T., Mantani, O. (1995). Cellulase induction by lactose in Trichoderma reesei PC-37. Appl Microbiol Biotechnol 44: 106-111.

43. Ilmén, M., Saloheimo, A., Onnela, M. \& Penttila, M.E. (1997). Regulation of cellulase gene expression in the filamentous fungus Trichoderma reesei. Appl Environ Microbiol. 63: 1298-1306.

44. Saloheimo, A., Aro, N., Ilmén, M. Et al. (2000). Isolation of the ace1 gene encoding a Cys2-His2 transcription factor involved in regulation of activity of the cellulase promoter cbh1 of Trichoderma reesei. J Biol Chem. 275: 5817-5825.

45. Ling, M., Qin, Y.L., Li, N. \& Liang, Z.Q. (2009). Binding of two transcriptional factors, Xyr1 and ACE1, in the promoter region of cellulase cbh1 gene, biotechnol Lett. 31: 227-231.

46. Ganss, B. \& Jheon, A. (2004). Zinc finger transcription factors in skeletal development. Crit Rev Oral Biol Med. 15(5): 282-297.

47. Heinz, R., Lee, S., Saparno, A., Nazar, R.N. \& Robb, J. (1998). Cyclical systemic colonization in Verticillium-infected tomato. Physiol Mol Plant Pathol. 52: 385-396.

48. Novo, M., Pomar, F., Gayaso, C. And Merino, F. (2006). Cellulase activity in isolates of Verticillium dahliae differing in aggressiveness. Plant Disease. 90: 155-160.

49. Miller, J., McLachlan, A.D. \& Klug, A. (1985). Repetitive zinc-binding domains in the protein transcription factor IIIA from Xenopus oocytes. EMBO J. 4: 1609-1614.

50. Brown, R.S., Sander, C. \& Argos, P. (1985). The primary structure of transcription factor TFIIIA has 12 consecutive repeats. FEBS Lett. 186: 271-274.

51.Wolfe, S.A., Grant, R.A., Elrod-Erickson, M. \& Pabo, C.O. (2001). Beyond the 'recognition code': structures of two Cys2His2 zinc finger/TATA box complexes. structure (Camb.). 9: 717-723.

52. luchi, S. (2001). Three classes of $\mathrm{C} 2 \mathrm{H} 2$ zinc finger proteins. Cell Mol Life Sci. 58: 625-635. 
53. Pieler, T. \& Bellefroid, E. (1994). perspectives on zinc finger protein function and evolution-an update. Mol Biol Rep. 20: 1-8.

54. Sri Krishna, S., Majumdar, I. \& Grishin, N.V. (2003). Structural classification of zinc fingers. Nucleic Acids Research. 31(2): 532-550.

55. Nakayashiki, H., Hanada, S., Quoc, N.B., Kadotani, N. Tosa, Y. \& Mayama, S. (2005). RNA silencing as a tool for exploring gene function in ascomycete fungi. Fungal Genetics and Biology. 42: 275-283.

56. Fudal, I., Collemare, H., Böhnert, H.U., Melayah, D. \& Lebrun M-H. (2006). Expression of Magnaporthe grisea avirulence gene ACE1 is connected to the initiation of appressorium-mediated penetration. Eukaryotic Cell. 6(3): 546-554. 


\section{Chapter 6: A putative VI_PKS1 gene involved in melanistic process}

\section{Introduction}

Polyketides are large group of secondary metabolites which exist in bacteria, fungi, plants etc. $(1,2,3,4)$. Because of their biosynthetic complexity $(5,6)$ and special application in pharmaceutical industry were Polyketides intensive researched. These natural resources include numerous toxins [fumonisins (7), aflatoxin (8), zearalenones $(9,10)$ ], antibiotics, and therapeutic compounds (11, 12), fungal melanins (13), and other pigments (14). Microbial polyketides are generally assembled through three types of polyketide synthase (PKS) (15). Fungal PKSs belong to Type I which is large multifunctional polypeptides that consist of a lot of modular units (modulars) determining the length of the carbon backbones of polyketides. Fungal secondary metabolites such as mycotoxins, fungal melanins and pigments are main groups of PKS type I (PKS1). In phytopathogenic fungi they are known often to play a role during the host-pathogen interaction as phytotoxins, pathogenicity or virulence factors.

\section{Results and Discussion}

We found a putative PKS1 in V. longisporum according to sequence analysis compared to sequences in V. dahliae and Bipolaris oryzae. A fragment 1936 nt (DNA sequence intern from Hanno Wolf et al.) in the gene VI_PKS1 containing a putative catalytic modules $\beta$ ketoacyl synthase (KS) and an acyl transferase (AT) motif (Figure 4) was isolated from $V$. longisporum using the PCR technique based direct sequencing. Its translated CDNA is predicted to code for 656 aa (Figure 4). A multiple alignment of diese fragment in VI_PKS1 from $V$. longisporum with the amino acid sequences of $V$. dahliae and Bipolaris oryzae was shown in Figure 4. VI_PKS1 gene keeps a high similarity like V. dahliae (similarity 100 $\%$ ) and Bipolaris oryzae (similarity $85,8 \%$ ) on the protein level. Moriwaki et. al demonstrated that PKS1 gene is involved in the melanin biosynthesis pathway of Bipolaris oryzae by a disrupting the PKS1 gene (16). 
VI_PKS1 gene was determined in planta relative gene expression by qRT-PCR in this study as a up-regulated gene, which was compared with housekeeping genes in $V$. longisporum during infection. This phenomenon indicated that VI_PKS1 gene may play a role in interaction between pathogen $V$. longisporum and host plant $B$. napus.

The $V$. longisporum PKS1 gene silenced mutant strains were generated using the antisense RNA- and RNAi-mediated methods. The binary vectors containing specific target fragments for VI_PKS1 gene silencing were constructed using procedures as generating VI_6.2 gene silenced mutant strains described in chapter 4 and VI_12.1 gene silencing mutant strains presented in chapter 5 , respectively. The for both silencing strategys used target fragments placed at $\beta$-ketoacyl synthase motif and Acyl transferase motif in VI_PKS1 (Figure 3 and Table 1 see primers for construction of binary vectors pPK2-antisense-PKS1-I and pPK2-antisense-PKS1-II). In vitro silencing effects of mutant strains were determined by qRT-PCR and resulted in vitro until $60 \%$ for the specific antisense RNA gene expression regulation and until 90\% (This result was reported by Malte Beinhoff in 2009) for the RNAi-mediated gene silencing. The pathogenicity assays in planta performed all tested VI_pKS1 silenced mutant strains which did not affect the growth of the host plant $B$. napus, but a morphological phenomenon of fungal colony with reduced melanistic accumulation was observed on solid medium compared with wild type. They were incubated at $23^{\circ} \mathrm{C}$ in dark for $4-5$ weeks (Figure 1). This Phenomenon was also observed in a competitive assay with Gliocladium roseum on solid medium. The $V$. longisporum isolate 43 performed oft a melanistic process in SXM medium or on SXM agar plate during an incubation at $23^{\circ} \mathrm{C}$ in dark after 3-4 weeks (Figure 2). In vitro determination of VI_PKS1 relative gene expression level by qRT_PCR demonstrated a dramatic enhance of VI_PKS1 gene expression in comparison with the VI_PKS1 relative gene expression level at 5 days (Figure 3 ). 

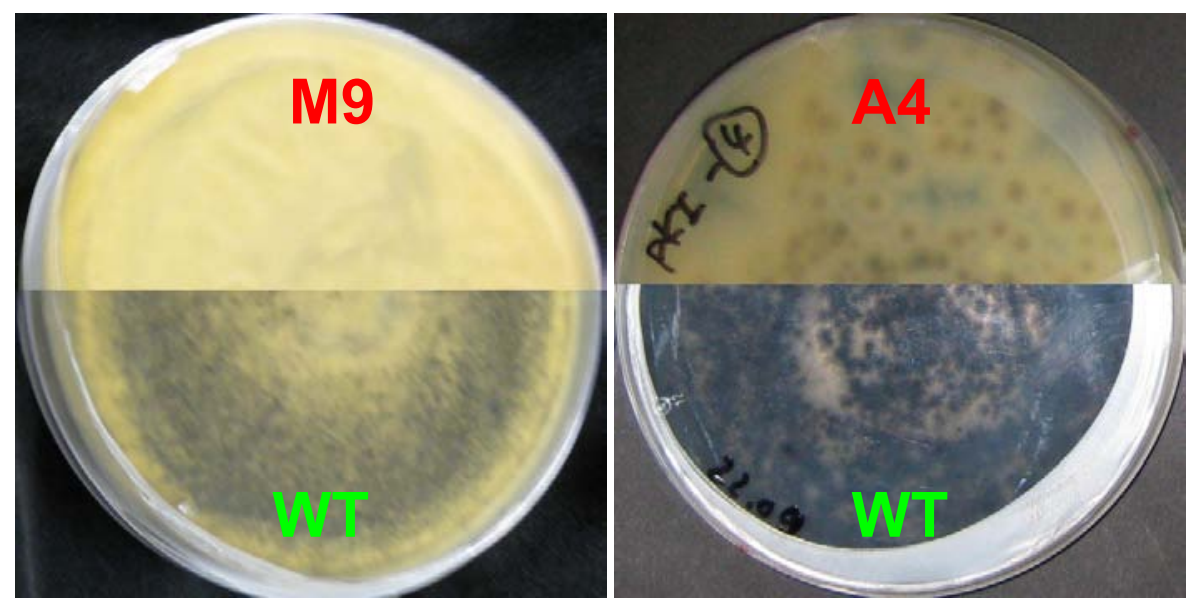

Figure 1: Morphological phenomenon of VI_PKS1 gene silenced mutant strains. A reduced melanistic accumulation of the colonies was observed after comparison with wild type on PDA and Czapek-Dox plates. Letters in green colour: Wild type strain VI_43; Letters in red colour: Mutant strains, M9 and A4.

Table 1: Primers for construction of binary vectors pPK2-antisense-PKS1-I and pPK2antisense-PKS1-II

\begin{tabular}{|l|l|l|}
\hline Name of Primers & Sequence of primers & Length \\
\hline AS-VI_PKS1_I_F & 5'-ATCAGTGGCGCGCCCATGTCGCCGCGCGAAGCCTA-3' & 939 bp \\
\hline AS-VI_PKS1_I_R & 5'-ATCAGTCCTGCAGGTTTTATGCCGACGTGAGGAGGGA-3' & 620 bp \\
\hline AS_VI_PKS1_II_F & 5'-ATCAGTGGCGCGCCCTTCATCTTCACAGGCCAAGG-3' & \\
\hline AS_VI_PKS1_IIR & 5'-ATCAGTCCTGCAGGGGAGTGGAAGGCATAGGGAAC-3' & \\
\hline \multicolumn{2}{|l|}{ Blue colour: Restriction sites. }
\end{tabular}




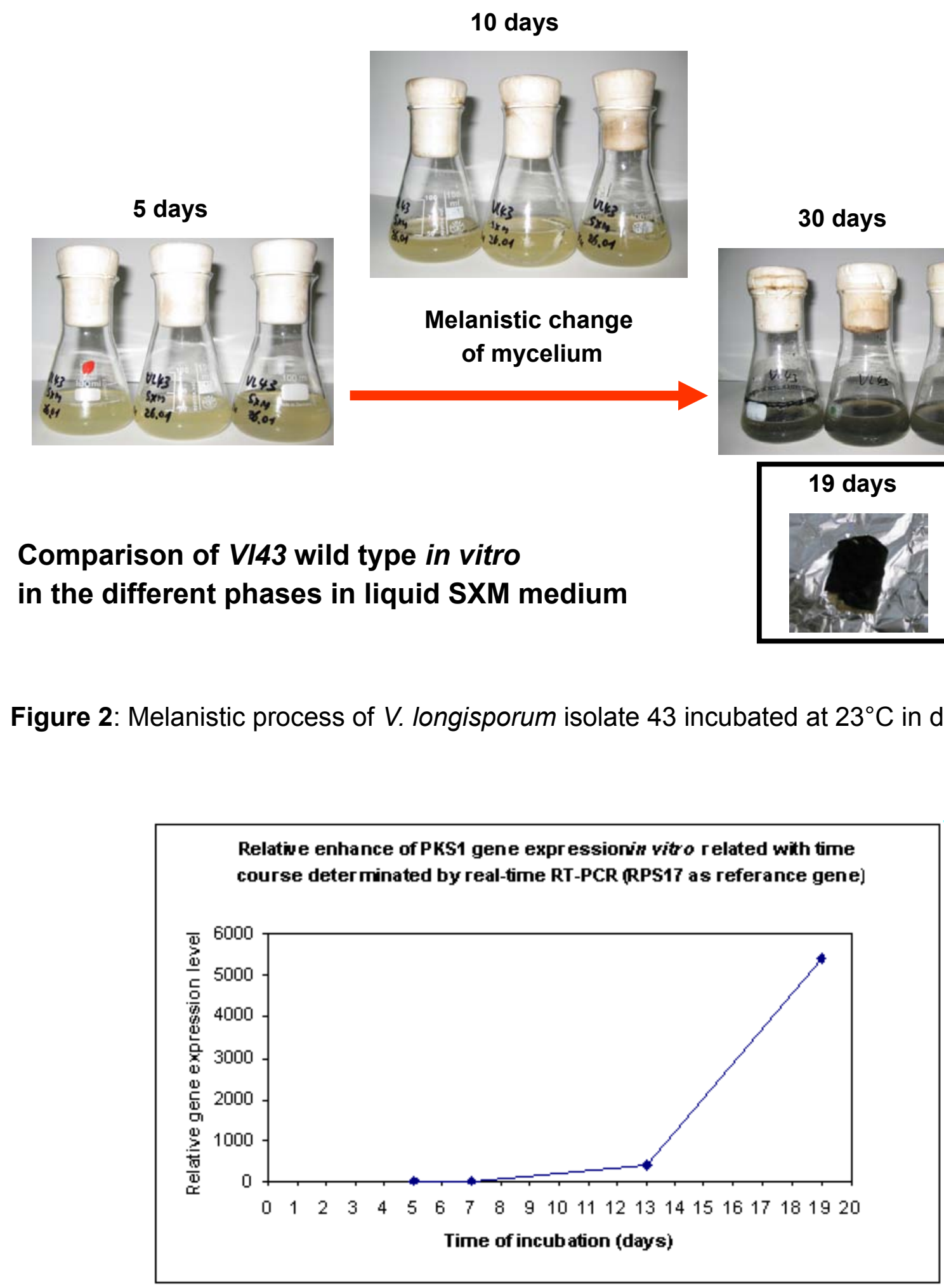

Figure 3: In vitro VI_PKS1 relative gene expressions in time course 5d, 7d, 14d and 19d determined by qRT-PCR. The ribosomal protein S17 (RPS17) was used as a reference gene, VI_PKS1 relative gene expression level at 5 days was set as a calibrator and a normalisation of qRT-PCR data used $\triangle \triangle C T$ method (see chapter 3). 

RFNIDTHYDITGKAINTSHTQYGCWIENPGLFDPRFFNMSPREAYQTDPMQRMALTTAYE 478 RFDAKAHCDPSGKGKNKSHTPYGCFIDEPGLFDPRFFNMSPREAAQTDPMGRLALTTAYE 468

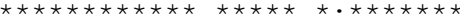

ALEMSGYVPNRTASTRLDRIGTFYGQTSDDWREINAAQEVDTYFITGGVRAFGPGRINYH 88 ALEMSGYVPNRTASTRLDRIGTFYGQTSDDWREINAAQEVDTYFITGGVRAFGPGRINYH 538 ALEMSGYVPNRTPSTKLERIGTFYGQTSDDWREINAAENIDTYFITGGVRAFAPGRINYY 528

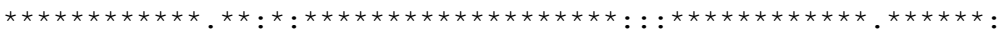

$\beta$-ketoacyl synthase motif FGFSGPSLNIDTACSSSAAALOIACTSLWAKDCDTAVVGGLSCMTNPDIFSGLSRGOFLS 148 FGFSGPSLNIDTACSSSAAALQIACTSLWAKDCDTAVVGGLSCMTNPDIFSGLSRGQFLS 598 FRFSGPSYSVDTACSSSLAAIQLACTSLWAGDCDTACAGGLNVLTNPDIFSGLSKGQFLS 588

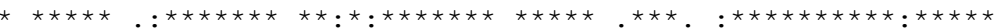

KTGPCATFDNGADGYCRADGCASVIVKRLDDAIADKDNVLAVILGTATNHSADAISITHP 208 KTGPCATFDNGADGYCRADGCASVIVKRLDDAIADKDNVLAVILGTATNHSADAISITHP 658 KTGSCKTYDNDADGYCRGDGCGSVVLKRYEDAIADKDNILGCILGAATNHSAEAVSITHP 648

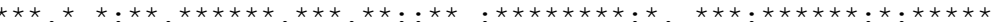

HGPTQSILSSAILDEAGVDPLDVDYVEMHGTGTQAGDGTEMVSVTDVFAPANRKRPANRP 268 HGPTQSILSSAILDEAGVDPLDVDYVEMHGTGTQAGDGTEMVSVTDVFAPANRKRPADRP 718 HAGAQEYLYNKVLSNAGVDAHEISYVEMHGTGTQAGDGIEMTSVTNAFAPRHRQRTPEQT 708

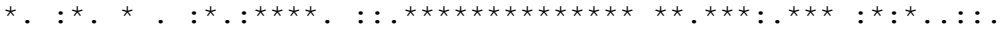

LYLGAVKSNIGHGEAASGVTALCKVLMMLQKNAIPPHVGIKKDINKTFPKDLAERNVNIA 328 LYLGAVKSNI GHGEAASGVTALCKVLMMMQKNAI PPHVGIKKDINKTFPKDLAERNVNIA 778 LHLGAIKANIGHGEAASGINSLVKVLMMMKKNAI PANVGIKGVMNKTFPKDLAQRNVHIE 768

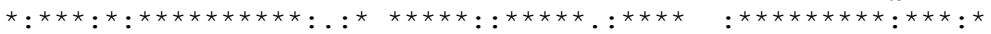

FHMTPLKRHDGKPRRIFINNFSAAGGNTGLLLEDGPS-QTPTQADPRSAQVITITAKSKT 387 FHMTPLKRHDGKPRRIFINNFSAAGGNTGLLLEDGPS-OTPTQADPRSVQVITITAKSKT 837 TTQVAWPRKGAEKRKIFLNNFSAAGGNTAVILEDGPLPEEPKGVDPRTMHMVTVSARSIT 828

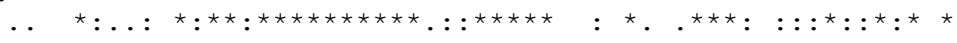

AMIKNAEQLVTWMEKNPETPLADVAYTTTARRMQHYWRLNVAASTLSEAMSAIKERLTQN 447 AMIKNAEQLVTWMEKNPETPLADVAYTTTARRMQHYWRLNVAASTLSEAMSAIKERLTQN 897 SLKKNINNLIDFIDENPSVTLPSLAYTTTARRIQHNYRVAFSVSEMSKVKDGLRAQLKDT 888

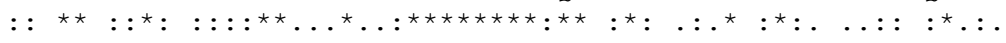

FVPISTEQPKVAFIFTGQGSHYAGLGKDLYAHYAVFRDSINEFNHIAEVHGFPSFVPLID 507 FVPISTEQPKVAFLFTGQGSHYAGLGKDLYAHYSVFRDS INEFNHIAEVHGFPSFVPLID 957 YSPLPMVPTKTAFTFTGQGSQYTGLGQKLYEDLETFKTDIDQLDKLARLHSLPSILPLLT 948

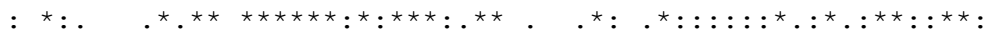

Acyl transferase motif GSEPDVSKLSPVVVQLGLCCFEMALARLWAAWGIRPAVVLGHSLGEYAALNAAGVLSASD 567 GSEPDVSKLSPVVVQLGLCCFEMALARLWAAWGIRPAVVLGHSLGEYAALNVAGVLSASD 1017 G--ADVATLSPVVVQLGMACIQVALARMWGAWGVRPIAVIGHSLGEYAALHVAGVISASD 1006

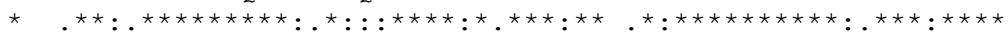

TIYLVGSRAQLLVDRCTAGTHAMLAVQGPVGTVNEALGSEFASVNIACINGPRETVLSGE 627 TIYLVGSRAQLLVDRCTAGTHAMLAVQGPVGTVNEALGSEFASVNIACINGPRETVLSGE 1077 MVLLVGRIRAOLEEECTANTHGMLAVKGSVEAIKAALGDKMT--EIACMNGPEETVLCGT 1064

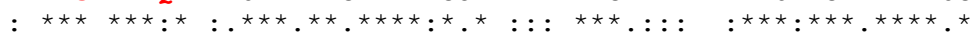

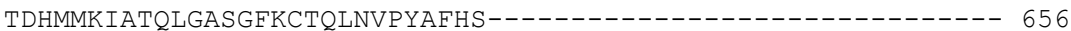
ADHMMKIATQLGASGFKCTELKVPYAFHSAQVEPI LDEFEHLARFTRFMPAQVPIISPLL 1137 VDVVNSTNELLASKGFKSTKLNVPFAFHSAQVEPILEKFKAAAASVTFNKPVVPVMSPLN 1124

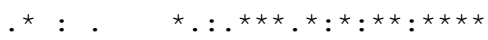

Figure 4: Alignments of the amino acid sequences among VI_PKS1 of V. longisporum and its homologous of $V$. dahliae and Bipolaris oryzae from Verticillium group database and NCBI GenBank. The putative catalytic modules $\beta$-ketoacyl synthase (KS) and acyl transferase (AT) motif are found in VI_PKS1 sequence. KS motif includes an active site cysteine; AT motif includes an active site serine. 


\section{References}

1. Metsä-Ketelä, M., Salo, V., Halo, L., Hautala, A., Hakala, J., Mäntsälä, P. \& Ylihonko, K. (1999). An efficient approach for screening minimal PKS genes from Streptomyces. FEMS Microbiol. Lett. 180:1-6.

2. Ridley, C. P., H. Y. Lee, \& C. Khosla. (2008). Evolution of polyketide synthases in bacteria. Proceedings of the National Academy of Sciences of the United States of America. 105: 4595-4600

3. Wawrik, B., Kutliev, D., Kerkhof, L., Zylstra, G. J. \& Kukor, J. J. (2007). Biogeography of Actinomycete Communities and Type II Polyketide Synthase Genes in Soils Collected in New Jersey and Central Asia. Applied and Environmental Microbiology, 73(9): 2982-2989.

4. Castoe, T. A., Stephens, T. Noonan, B. P. \& Calestani, C. (2007). A novel group of type I polyketide synthases (PKS) in animals and the complex phylogenomics of PKSs. Gene 392:47-58

5. Khosla, C., Gokhale, R. S., Jacobsen, J. R. \& Cane, D. E. (1999). Tolerance and specificity of polyketide synthases. Annu. Rev. Biochem. 68: 219-253.

6. Jenke-Kodama, H., A. Sandmann, Muller, R. \& Dittmann, E. (2005). Evolutionary implications of bacterial polyketide synthases. Molecular Biology and Evolution. 22: 2027-2039.

7. Koehn, F. E. \& Carter, G. T. (2005). The evolving role of natural products in drug discovery. Nat Rev Drug Discov. 4(3): 206-220.

8. Proctor, R. H., Desjardins, A. E., Plattner, R. D. \& Hohn, T. M. (1999). A polyketide synthase gene required for biosynthesis of fumonisin mycotoxins in Gibberella fujikuroi mating population. A. Fung. Genet. Biol. 27:100-112.

9. Watanabe, C. M., Wilson, D., Linz, J. E. \& Townsend, C. A. (1996). Demonstration of the catalytic roles and evidence for the physical association of type I fatty acid synthases and a polyketide synthase in the biosynthesis of aflatoxin B1. Chem. Biol. 3:463-469. 
10.Kim, Y. T., Lee, Y. R., Jin, J., Han, K. H., Kim, H., Kim, J. C., Lee, T., Yun, S. H. \& Lee, Y. W. (2005). Two different polyketide synthase genes are required for zearalenone in Gibberella zeae. Mol. Microbiol. 58: 1102-1113.

11. Utermark, J. \& Karlovsky, P. (2007). Role of zearalenone lactonase in protection of Gliocladium roseum from fungitoxic effects of the mycotoxin zearalenone. Appl. Environm. Microbiol. 73: 637-642.

12. Wawrik, B., Zylstra, G., Kerkhof, L. \& Kukor, J. (2005). Identification of Unique Type II Polyketide Synthase Genes in Soil. Applied and Environmental Microbiology. 71: 2232-2238

13.Tsai, H. F., Fujii, I., Watanabe, A., Wheeler, M.H., Chang, Y. C., Yasuoka, Y., Ebizuka, Y. \& Kwon-Chung, K. J. (2001). Pentaketide melanin biosynthesis in Aspergillus fumigatus requires chain-length shortening of a heptaketide precursor. $J$ Biol Chem. 276(31): 29292-29298.

14. Mapari, S. A., Thrane, U. \& Meyer, A. S. (2010). Fungal polyketide azaphilone pigments as future natural food colorants? Trends Biotechnol. 28(6): 300-307.

15. Hutchison, C. R. \& Fujii, I. (1995). Annu. Rev. Microbiol. 49: 201-238.

16. Moriwaki, A., Kihara, J., Kobayashi, T., Tokunaga, T., Arase, S. \& Honda, Y. (2004). Insertional mutagenesis and characterization of a polyketide synthase gene (PKS1) required for melanin biosynthesis in Bipolaris oryzae. FEMS Microbiol Lett. 238(1): 1-8. 


\section{Chapter 7: Labeling V. longisporum with GFP and its derivatives}

\section{Introduction}

The green fluorescent protein (GFP) was extracted from the small, mouse-sized umbrellashaped glowing Pacific Northwest jellyfish Aequorea victoria, and identified as a protein first by Osamu Shimomura in 1962 (1). This jellyfish produces green bioluminescence (2) from small photoorgans located on its umbrella. In order for bioluminescence to occur, Aequorea releases calcium ions to bind a photoprotein called aequorin, which released blue light (Figure 1). The blue light in vivo $(3,4)$ or ultraviolet light in vitro was absorbed by green fluorescent protein, which in turn emitted the green light $(5,6,7)$. This made an advantage for GFP than luciferases which glow under the special conditions such as calcium ions and coelenterazine required for aequrin $(8,9,10)$, ATP and magnesium required for luciferase $(11,12,13)$ etc. Wild-type GFP had a major excitation peak at 395 $\mathrm{nm}$ and a minor peak at $475 \mathrm{~nm}$, gave off bright green light with an emission peak at 509 $\mathrm{nm}$ with a shoulder at $540 \mathrm{~nm}$. The GFP research attracted Douglas Prasher, a scientist of biochemistry. He got an revolutionary idea about expression of GFP as tracer molecule in bacteria in 1987 (14). He and co-worker had cloned and sequenced the gene for GFP from jellyfish Aequorea victoria in 1992 (6). The result interpreted that GFP was a small protein with 238 amino acids. Its small size allowed it was easy as a to be fused protein. The expression of GFP in Escherichia coli and Caenorhabditis elegans succeeded in Laboratory of Marty Chalfie in 1994 (15). The crystal structures of wt-GFP (16) and enhanced GFP S65T mutant (17) elucidated both that GFP protein kept a stabil can shape structure constructed with 1 central located $\alpha$-helix and $1 \beta$-barrel consisted of 11 surrounded tightly packed $\beta$-sheets and the chromophore was located in the middle of the $\beta$-barrel.

The chromophore of GFP was responsible for its fluorescence as the "light in the can". Osamu Shimomura described a chemical structure of chromophore in Aequorea green fluorescent protein first in 1979 (18). Cody and co-workers confirmed the hexapeptide structure of chromophore in 1993. The chromophore formation was a stepwise procedure, which changed a sequence of three amino acids (Ser65, Tyr66 and Gly67) into a single 
conjugated system that extended from the side chain of Tyr66 to a heterocycle (19). The surrounding residues forced upon chromophore to influence the fluorescence properties. This structure basis made an artificial engineering of GFP molecule possible (7). Roger Tsien's laboratory developed GFP mutants which started fluorescing faster than wild type, They were brighter and had different colours. First new derivative of GFP with blue colour and oxygen dependence was reported in 1994 (20). A yellow fluorescent T203Y mutant was designed based on crystal structure of S65T GFP mutant in 1996 (17). Cormark and co-workers have successful generated a popular green fluorescent variant EGFP (enhanced GFP) (21). Red fluorescent proteins (DsRed) was discovered in anthozoan corals by Lukyanov' laboratory in 1999 (22) and led to discovery of many new fluorescent proteins and chromoproteins. The biggest difference between green fluorescent protein and its red analogue DsRed, was the chromophore of DsRed, which had an extra double bond extending the chromophores conjugation and causing the red-shift (23). Although the original Y66W mutant of Aequorea wild-type GFP was weakly fluorescent, the from it improved variant ECFP was widely used (24).

GFP was used in a range of research areas. In filamentous fungi the GFP was permit to be used in biochemical assays, cell screening and as marker for monitoring of different fungal infection and to follow the development of fungal-plant interaction. GFP and its derivatives as reporter genes were especially used to study the activity of target genes and their transcriptional promoters.

\section{Methods and Results}

For in vitro construction of transcriptional and translational fusion we applied the binary vector pPK2 as backbone, EGFP and ECFP as reporter gene (Figure 2) and used Agrobacterium-mediated transformation to generate respectively EGFP and ECFP marked $V$. longisporum mutants. The high level expression and bright fluorescence were obtained in with EGFP and ECFP marked V. longisporum strains (Figure 3 and Figure 4). A Leica TCS SPII Confocal Laser Scanning Microscope (CLSM) was equipped for performance of fluorescent fungal strains. A Melles Griot Argon $488 \mathrm{~nm}$ laser was used for excitation for scanning, and 520-560 emission filters to capture the fluorescence of eGFP tagged cultures. A Melles Griot Argon 436 nm laser was used for excitation for scanning, and 440480 emission filters to capture the fluorescence of eCFP tagged strains. Pictures were viewed using the Leica LAS AF Imaging software. 
The binary vector pPK2-eGFP15 was also successfully transferred and expressed in other fungal species Fusarium graminearum, Trichoderma reesei and Gliocladium roseum (Data unpublished).
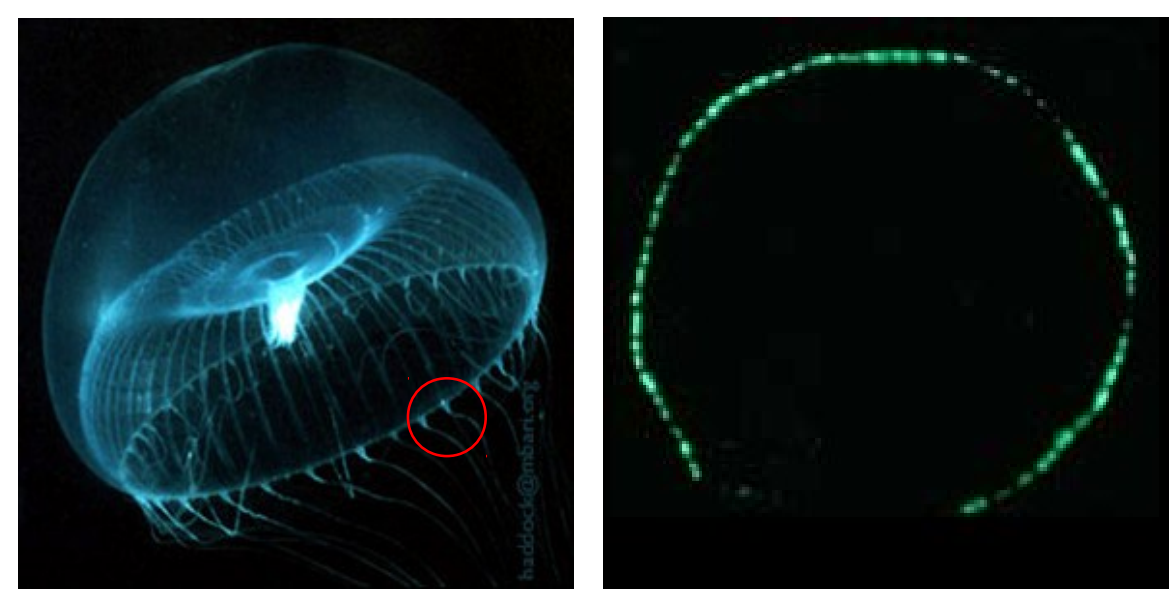

Figure 1: Aequorea victoria (left picture). Photo from the bioluminescence web page of Steve Haddock, Monterey Bay Aquarium Research Institute. Photoreceptors on umbrella of Aequorea victoria bioluminescing (right picture). Photo of Osamu Shimomura) [Modified according to GFP web page of Marc Zimmer (http://www.conncoll.edu/ccacad/zimmer/ GFP-ww/shimomura.html)]
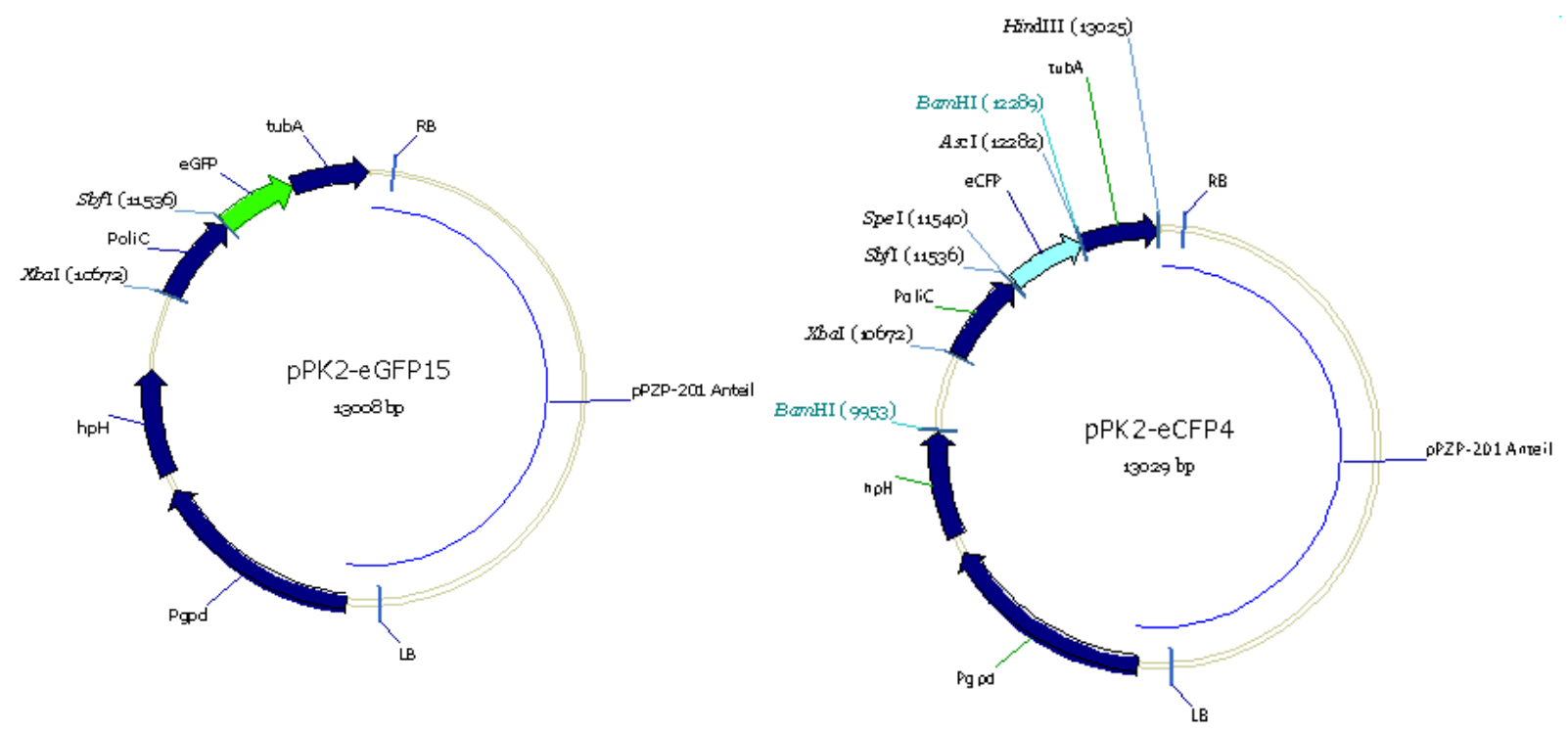

Figure 2: Maps of binary vectors pPK2-eGFP15 and pPK2-eCFP4 for transcriptional and translational reporter in fungi. Promoter OliC for a gene encodes subunit 9 of the mitochondrial ATP synthase complex from Aspergillus nidulans and terminator for betatubulin gene from Botrytis cinerea were used for control of expression of EGFP or ECFP. A Sbfl site (CCTGCAGG) was introduced at 3'-direction of VI_6.2 gene using primer (5'- 
ATCAGTCCTGCAGGGTCCAGCGTATCCGTTGCCTG-3') in combination with another primer (5'-ATCAGTGGCGCGCCATGGACCCAGCTGTCGTCCGTA-3') containing a Ascl site (GGCGCGCC) at 5'-direction of VI_6.2 gene. Pgpd [promoter for glyceraldehyde-3phosphate dehydrogenase (gpd) from Coriolus versicolor] manages $\mathrm{hpH}$ (Hygromycin phosphotransferase resistance gene) and pPZP-201 fragment containing T-DNA region of Ti plasmid of Agrobacterium tumefaciens is from the host binary vector pPZP201.
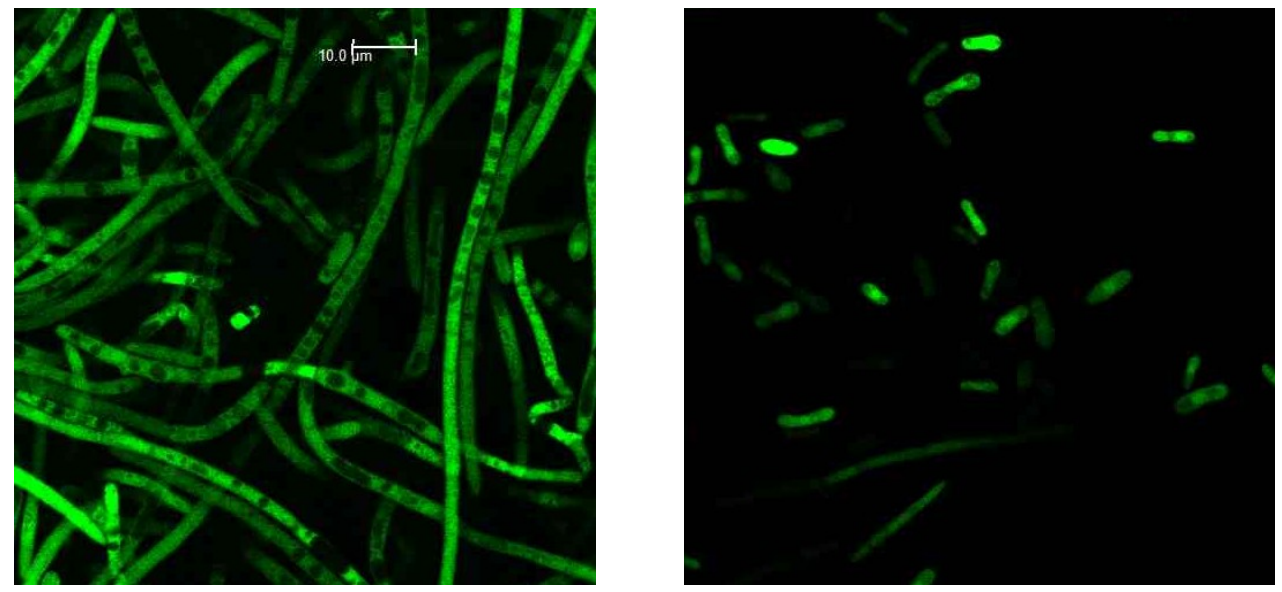

Figure 3: Mycelium and spores of $V$. longisporum isolate 43 expressing eGFP. Fluorescence scanning microscopy of fungal cultures: $488 \mathrm{~nm}$ laser was used for excitation for scanning, 520-560 emission filters to capture the fluorescence of eGFP tagged strain.
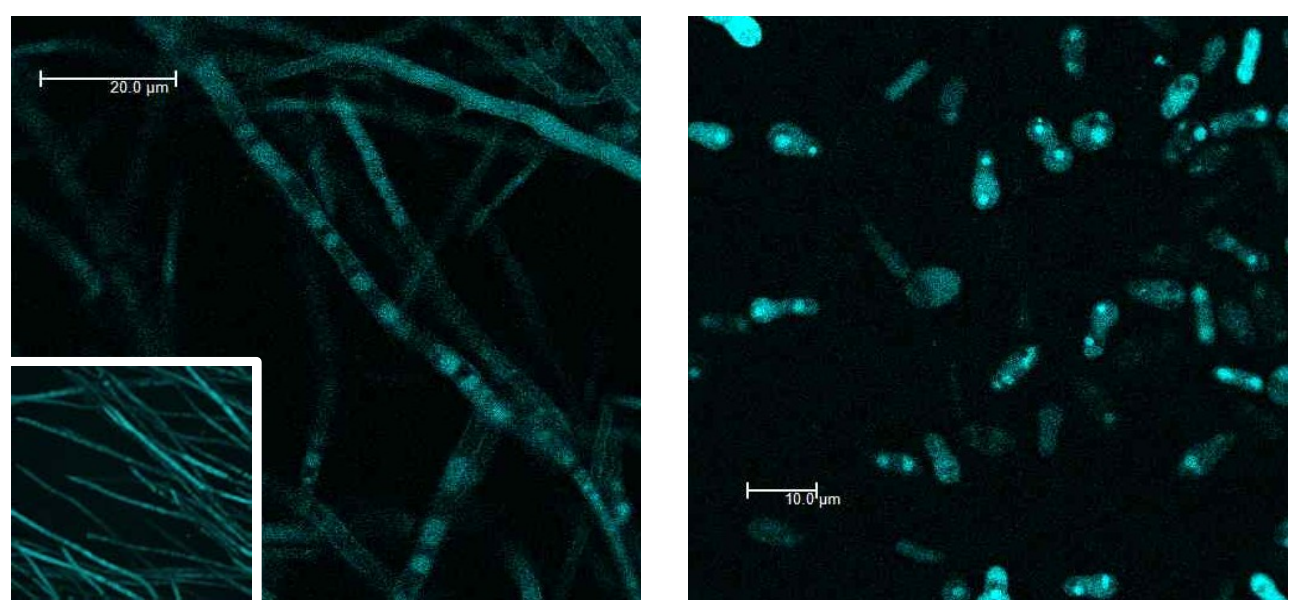

Figure 4: Mycelium and spores of $V$. longisporum isolate 43 expressing eCFP. Fluorescence scanning microscopy of fungal cultures: $436 \mathrm{~nm}$ laser was used for excitation for scanning, $440-480 \mathrm{~nm}$ emission filters to capture the fluorescence of eCFP tagged strain. 


\section{References}

1. Shimomura, O., Johnson, F. H. \& Saiga, Y. (1962). Extraction, purification and properties of aequorin, a bioluminescent protein from the luminous hydromedusan, Aequorea. J. Cell. Comp. Physiol. 59: 223-229.

2. Davenport, D. \& Nicol, JAC. (1955). Luminescence of hydromedusae. Proc. R. Soc. London. 144: 399-411.

3. Morise, H., Shimomura, O., Johnson, F.H. \& Winant, J. (1974). Intermolecular Energy Transfer in Bioluminescent systems of Aequorea. Biochemistry 13: 26562662.

4. Shimomura, O. (1979). Structure of the chromophore of Aequorea green fluorescent protein. FEBS Letters 104: 220-222.

5. Prendergast, F. \& Mann, K. (1978). Chemical and physical properties of aequorin and the green fluorescent protein isolated from Aequorea forskålea. Biochemistry 17 (17): 3448-3453.

6. Prasher, D.C., Eckenrode, V.K., Ward, W.W., Pendergast, F.G. \& Cormier, M.J. (1992). Primary structure of the Aequorea victorea green fluorescent protein. Gene 111: 229-233.

7. Tsien, R. (1998). The green fluorescent protein . Annu Rev Biochem 67: 509-544.

8. Cormier, M.J., Hori, K. \& Anderson, J.M. (1974). Bioluminescence in coelenterates. Biochim. Biophys. Acta 346: 137-164.

9. Hori, K., Anderson, J.M., Ward, W.W. \& Cormier, M.J. (1975). Renilla luciferin as the substrate for calcium induced photoprotein bioluminescence. Assignment of luciferin tautomers in aequorin and mnemiopsin. Biochemistry 14: 2371-2376.

10. Shimomura, O. \& Johnson, F.H. (1975). Chemical nature of bioluminescence systems in coelenterates. Proc. Natl. Acad. Sci. USA 72: 1546-1549.

11. Charbonneau, H. \& Cormier, M.J. (1979). Ca2+-induced bioluminescence in Renilla reniformis. Purification and characterization of a calcium-triggered luciferin-binding protein. J. Biol. Chem. 254 769-780. 
12. Anderson, J.M., Charbonneau, H. \& Cormier, M.J. (1974). Mechanism of calcium induction of Renilla bioluminescence. Involvement of a calcium-triggered luciferin binding protein. Biochemistry 13 1195-1200.

13.Lorenz, W.W., McCann, R.O., Longiaru, M. \& Cormier, M.J. (1991). Isolation and expression of a cDNA encoding Renilla reniformis luciferase. Proc. Natl. Acad. Sci. USA 88: 4438-4442.

14.Zimmer, M. (http://www.conncoll.edu/ccacad/zimmer/GFP-ww/shimomura.html)

15. Chalfie, M., Tu, Y., Euskirchen, G., Ward, W.W. \& Prasher, D.C. (1994). Green fluorescent protein as a marker for gene expression. Science 263: 802-05.

16. Yang, F., Moss, L.G. \& Phillips, G. N. (1996). The molecular structure of green fluorescent protein. Nature Biotechnology. 14: 1246-1251.

17. Ormo, M., Cubitt, A.B., Kallio, K., Gross, L. A., Tsien, R. Y. \& Remington, S. J. (1996). Crystal structure of the Aequorea victoria green fluorescent protein. Science 273: 1392-1395.

18. Shimomura, O. (1979). Structure of the chromophore of Aequorea green fluorescent protein. FEBS Letters. 104: 220-22.

19. Cody, C. W., Prasher, D. C., Westler, W. M., Prendergast, F. G. \& ward, W. W. (1993). Chemical structure of the hexapeptide chromphore of the Aequorea greenfluorescent protein. Biochemistry. 32: 1212-1218.

20. Heim, R., Prasher, D. C. \& Tsien, R. Y. (1994) Wavelength mutations and posttranslational autoxidation of green fluorescent protein. Proc. Natl. Acad. Sci. USA 91: 12501-12504.

21. Cormark, B. P., Valdivia, R. H. \& Falkow, S. (1996). FACS-optimized mutants of the green fluorescent protein (GFP). Gene. 173: 33-38.

22. Matz, M. V., Fradkov, A. F., Labas, Y. A., Savitisky, A. P., Zaraisky, A. G., Markelov, M. L . \& Lukyanov, S. A. (1999). Fluorescent proteins from nonbioluminescent Anthozoa species. Nature Biotech. 17: 969-973.

23. Gross, L. A., Baird, G. S., Hoffman, R. C., Baldridge, K. K. \& Tsien, R. Y. (2000). 
The structure of the chromophore within DsRed, a red fluorescent protein from coral. Proceedings of the National Academy of Sciences of the United States of America. 97: 11990-11995.

24. Ai, H-W., Henderson, J. N., Remington, S. J. \& Campbell, R. E. (2006). Directed evolution of a monomeric, bright and photostable version of Clavularia cyan fluorescent protein: structural characterization and applications in fluorescence imaging. Biochem J. 400(3): 531-540. 


\section{Chapter 8: General discussion}

\section{Research methods}

Plant fungal pathogens as plant parasites, cause the most significant plant diseases and hods the largest proportion of organisms. An improved understanding of fungal pathogenesis may lead to improve the plant disease resistance through breeding using genetic engineering. Research using modern tools at morphological, cellular, physiological, biochemical and especially molecular level have developed rapidly in recent years. The advent of electron-, fluorescent-, and confocal-microscopy provided the possibilities to make cytological observation of the ultra structure and interaction between pathogen fungus and host plant. The molecular biological techniques such as PCR, cloning, transformation, sequencing, silencing, over expression, molecular marker and other related disciplines were widely applied to study fungal genetic, metabolic, pathogenic mechanisms and functional analysis. In our work the whole $V$. longisporum transcripts after a treatment with extracts of $B$. napus xylem sap were screened by cDNA-AFLP and compared to water treated controls. The signal results of comparison required genetic identification and primary characterisation. They were completed for TDFs analysis using different functional methods of sequence extension and in planta relative gene expression by qRT-PCR to identify the target genes and to see how they related to pathogenicity of $V$. longisporum on $B$. napus. Further gene functional analysis followed with mutant strain generation using other strategies such as gene over expression, post-transcriptional silencing and fusing with green fluorescent protein as a marker etc..

The fluorescence-based qRT-PCR method used in this study provided on the whole an efficient alternative for our experiments with advantages such as sensitivity, simplicity and relative low-costs for the determination of gene expression. The high sensitivity of qRTPCR limited its usage as an absolute measurement of low expression of target genes because of a frequent occurrence of the variable PCR efficiency. Thus, we used a procedure to determine relative target gene expression using qRT-PCR, which correlated with the reference gene expression levels. The choice of reference genes was based on literature search and a control test of the cross reaction with the host plant and the primer efficiency were tested. Slight changes of quality and quantity of the initial templates, different amplification efficiencies and possibly inhibitors present at low levels can lead to 
increased variability of dataanaylsis after $\mathrm{qRT}-\mathrm{PCR}$ and produce false relative gene expression levels. Total RNA was used for quantification of gene transcripts $(1,2)$. We conclude that an isolation of mRNA and an additional purification of cDNA of samples are effective for the samples containing low fungal biomass or for candidates tested with low genes expression. A sequence comparison among $V$. longisporum, V. dahliae and V. alboatrum with reference genes at nucleotide and amino acid levels may provide further evidence for their evolutionary relationships.

The gene regulation in fungal cells controlled at post-transcriptional level depends on two important aspects, antisense-RNA regulation and RNA interference. These two aspects have been developed as efficient tools for gene silencing in biotechnology. Although the progress of antisense-RNA regulation at the molecular level is not fully described. The recent trend is towards antisense-RNA regulation in eukaryotes using an RNAi-like mechanism in final phase $(3,4,5)$. Both RNAi- and antisense RNA-mediated gene silencing were used for functional analysis of candidate genes. The RNAi method demonstrated a relatively strong silencing effect (up to 90\%) compared to the antisenseRNA regulated gene expression (up to 70\%) and determined in vitro by qRT-PCR. Thus we recommend the use of the RNAi method for a gene silencing applification. Antisense RNA-mediated regulation is more suitable when a mild gene knock-down is required.

Green fluorescent protein (GFP) has been widely used in fungal research areas such as in biochemical assays, cell screening and as marker for monitoring pathogen infection and to follow the pathogen-host interaction etc.. Eynck et al in 2007 (6) have used the GFP marked Verticillium strains to demonstrate the fungal infection process on host plant Brassica napus. Utermark and Karlovsky in 2006 (7) used GFP to fuse with the zearalenone-sensing promoter-element of the zearalenone lactonase gene zes 2 to exploit zearalenone sensing ability of Gliocladium roseum. We have successfully constructed two binary vectors fused with enhanced derivatives of GFP for fungal transcriptional and translational fusion. However, GFP expression related to physiological state of fungal mycelium, and the fluorescence reduction in old hyphae (6). A another alternative is to use bioluminescent luciferase, which functions as an enzyme to cut the costly substrates and lead to imaging. Recently these two methods both were used for fusion with target genes or promoters as reporters for functional analysis or for tracing the behaviour of the microorganisms. 


\section{Molecular mechanisms of pathogenicity}

Functional analysis of fungal pathogenicity-related genes has attracted more attention in recent years. The xylem sap inducible pathogenicity related genes expressed by $V$. longisporum during the infection process on $B$. napus are involved in a set of molecular mechanisms which related with pathogen activities of aggression and defence. They are host determination, signaltransduction, stress response, biosynthesis of secondary metabolites and activation of the plant cell wall degrading enzymes etc..

Pathogenicity means that an organism is able to cause disease. This ability represents a genetic resources of the pathogen and a established relationship based on the hostpathogen interactions. The pathogen organism cause the damage to the host. However, this disease is not an inevitable result of the host-pathogen interaction. Virulence suggests the degree of pathology caused by the pathogen. A term often used interchangeably with pathogenicity, pathogens can exhibit a wide range of virulence at different levels. Virulence can be extended under a correlation with the ability of the pathogen to multiply within the host and may be affected by other internal factors and external conditions.

Pathogenicity related genes enable the pathogen and host to establish compatible interaction and affect the normal gene function. They can relate with the structure of genes involved in infection. For example, the rice blast fungus disease gene (mpg1) $(8,9)$ encodies a protein with a small molecule, which is typically hydrophobic, it may function by binding to hydrophobic cuticle on the leaves. VirA and VirG are two virulence genes in Agrobacterium (10), they regulate the transformation on plants or other organisms through a two-component regulatory system to sense particular phenolic compounds synthesized by wounded plant tissues. Under the certain conditions, other vir genes are activated, the T-DNA is processed from the Ti-plasmid and transferred into host cells. many plants and non-plant species can not provide enough and correct phenolic compounds, then VirA and VirG can not start regulation (10). Melanins are polymers for dark-pigment and belong to one type of the fungal secondary metabolites. Fungal melanins have been shown on the one side to be important virulence factors in interaction between pathogenic fungal species and host plants. Performing a key role in appressoria-mediated infection (11). Several fungal phytopathogens Bipolaris oryzae, Pyricularia oryzae, Colletotrichum orbiclare, Verticillium dahliae etc. were observed which were important for a successful infection on host plant under a melanin accumulation of appressorium (12, 13). The 
dihydoxynaphthalene (DHN) plays a very important role (12) for a large accumulation of melanin deposits in the appressorium cell wall of the inner layer, before the invasion of the spores. Bipolaris oryzae (Breda de Haan) causes rice brown leaf spot disease, produces 1,8-dihydroxynaphthalene (DHN)-melanin (12), It is similar to Colletotrichum lagenarium, Magnapothe grisea, and Alternaria alterata $(13,14,15)$. DHN-melanin biosynthesis was speculated to be started by PKS. Moriwaki et. al demonstrated that PKS1 gene is involved in the melanin biosynthesis pathway of Bipolaris oryzae by a disrupting the PKS1 gene. On the other side, an accumulation of pigments displayed melanins as an important tolerance factor in stress response of fungal organisms to radical environmental change such as UV radiation (15) and protection against antifungal drugs (16).

In this study, 10 genes from $V$. longisporum were isolated using different methods, they were identified by sequence analysis and characterized. Eight of them were profiled from a cDNA-AFLP screening. After in planta relative gene expression analysis by qRT-PCR, they were grouped in three types. up-regulated, suppressed and time-dependent. For further functional analysis, four of them, VI_6.2, VI_12.1, VI_PKS1 and VI_NEP1 were investigated as the candidates. According to the outcome of these results we proposed their tentative roles in pathogensis by measuring of the putative function of candidate genes. Here we divide them into two types, namely genes function for secondary metabolites and genes function for cell-wall degradation and integrity.

The determination of VI_PKS1 relative gene expression by qRT-PCR demonstrated that VI_PKS1 was up-regulated in planta and gene silenced mutant strains reduced VI_PKS1 gene expression in vitro. VI_PKS1 relative gene expression in V. Iongisporum liquid culture presented a huge increase after 3 week incubation and perhaps acted as a factor related stress-response of fungus to nutrient and other conditions. The VI_PKS1 silenced mutants reduced melanine production compared to wild type and this was displayed very clearly in a competitive assay with Gliocladium roseum where a strong decrease of melanine accumulation was observed. Thus we suggest that the VI_PKS gene expression is involved in aggression and defence mechanisms and its function as a pathogenicity related factor is reduced.

In sequence analysis and in planta relative gene expression determination we identified and characterized a small peptide gene encoding necrosis- and ethylene inducing peptide with its homologue with high similarity. We identified a conserved hepta-peptide motif 
GHRHDWE which is essential for necrosis-inducing activity $(30,31)$. This hepta-peptide motif exists in 5 NEP1-homological genes in V. longisporum, 7 NEP1-homological genes in V. albo-atrum and 9 NEP1-homological genes in V. dahliae. Vd_NEP1 was shown to elicit wilt and chlorosis symptoms on leaves of several host plant species (17). A hetero VI_NEP1 gene expression assay showed VI_NEP1 gene to be able to induce chlorosis on leaves of oilseed rape and tabaco (intern results). NEP-encoding genes are found in other fungal pathogens Pythium aphanidermatum and Phytophthora parasitica but with different numbers of copies: 1,2 , and 4 . respectively $(18,19)$. Plant pathogenic species of $V$. longisporum, has two copies of NEP1 gene because of its near-diploid status. A phylogenic analysis showed that the sequence similarity at nucleotide level between $\mathrm{V}$. longisporum and $V$. dahliae for NEP1 is decreased, compared with results of other genes. We propose that the number of NEP-like homologues and the change of gene sequences at DNA level as the evidence that for $V$. longisporum uses a another means of aggression for infection than $V$. dahliae.

It is well-known that the cell-wall degrading enzymes cellulases, hemicellulases and pectinases play important roles in the penetration of host plant roots by fungal pathogen. In this study we found that $V$. longisporum degraded Carboxymethyl (CM) cellulose in vitro. ACE1 functions as a repressor of cellulase and xylanase expression in T. reesei. V. dahliae, which were able to secrete cellulases, and showed its aggressive isolates degrading crystalline cellulose quicker than the less aggressive isolates (20). A deletion of FOW2 gene encoding zinc-finger protein in Fusarium oxysporum f.sp. Melonis induced to loss pathogenicity to penetrate roots of host plant (21). A XInR gene encoding inducible zinc-finger protein in vascular wilt F. oxysporum, regulated the expression of xylanase (22). During infection on rice, the expression of $M$. grisea gene ACE1 connected to the aggression of appressorium-mediated penetration without host plant signals (23). Pathogenicity tests in this work two results: first the VI_12.1 gene was suppressed during infection of $B$. napus in root/hypocotyl tissue in reference to in vitro grown mycelium in a xylem simulating artificial medium; second the VI_12.1 gene silenced mutants did not affect the infection on Brassica plants. These indicate that VI_12.1 functions as a regulator for the cell-wall degradation may only be possible with a decrease of its expression products, but this is minimal.

Wsc1 is a a cell wall stress component sensor protein in plasma membrane that behaves like a linear nano-spring that is capable of resisting high mechanical force and responds to 
cell surface stress (24). WSC domains play a role in membrane integrity in different microbes like baker's yeast (Saccharomyces cerevisiae). The with antisense RNA methods generated VI_6.2 silenced mutants demonstrated VI_6.2 gene as a stress response protein activating in growth inhibition assays both with ionic detergent SDS and with alkaline $\mathrm{pH}$ value at 10. A treatment with SDS in low concentration or a non ionic detergent Tween 20 could not effect the growth of $V$. longisporum, This indicates an elastic role of VI_6.2 gene which behaves in a similar manner to that seen in S. cerevisiae. It is possible that VI_6.2 possesses a linear nano-spring-like structure in response to extracellular stress under particular conditions. Disruption of Verticillum MAP Kinase 1 in $V$. dahliae severely reduced virulence in host plants (25). Other researchers presented a deletion of WSC genes in S. cerevisiae resulting the WSC binding domains as upstream regulators playing a important role in stress response in PKC1-MAPK1 pathway $(26,27)$. Rauyaree et al. presented that MAP (Mitogen-Activated Protein) kinase-mediated signalling pathways are involved in pathogenicity of Verticillium dahliae in 2005 (28). VI_6.2 was investigated as being up-regulated in planta by qRT-PCR compared to in vitro cultivation of $V$. longisporum in a xylem-simulating artificial medium. VI_6.2 silenced mutants which resulted in a reduced virulence in planta. thus we propose that VI_6.2 gene was actively involved in cell-wall integrity related both to the aggression and the defence process of $V$. longisporum.

V. longiporum is a "near-diploid" and host-specific fungal phytopathogen causing wilt disease in oilseed rape and induces, leaf chlorosis, curl and especial growth stunting as typical symptoms. $V$. dahliae is non-pathogenic on $B$. napus (6). The morphology of $V$. longisporum is very similar to two other phytopathogen $V$. dahliae and $V$. albo-atrum with a small difference in the length of the spores (28). The high similarity and identity of the sequences at nucleotide and amino acid levels were confirmed according to the results of comparisons among these three species in this study. We suggest that an infection ability based on the specific pathogenicity related factors of $V$. longisporum on $B$. napus could be a model mechanism for description of a successful balance between heredity and variation of Verticillium species along with evolutionary selection under the special environmental dilemma and the internal genetic possibility. The genes variate in the evolution process and cause the changed biological phenotypes. At the same time, the identical kind in order to adapt to the circumstances it is frequently necessary to be able to have a change in phenotype, sometimes even a change of a complete gene. We speculate that some 
Verticillium isolates successfully developed this variation. Until today we can find $V$. longiporum only in several regions in northern Europe.

\section{References}

1. Bachem, C. W., van der Hoeven, R. S., Bruijn, S. M., Vreugdenhil, D., Zabeau, M. \& Visser, R. G. (1996). Visualization of differential gene expression using a novel method of RNA fingerprinting based on AFLP: analysis of gene expression during potato tuber development. Plant J. 9: 745-753.

2. Higuchi, R., Fockler, C., Dollinger, G. \& Watson, R. (1993). Kinetic PCR: Real time monitoring of DNA amplification reactions. Biotechnology 11: 1026-1030.

3. Nakayashiki, H., Hanada, S., Nguyen, B. Q., Kadotani, N., Tosa, Y. \& Mayama, S. (2005). RNA silencing as a tool for exploring gene function in ascomycete fungi. Fungal Genet Biol. 42: 274-283.

4. Sanders, R. A. \& Hiatt, W. (2005). Tomato transgene structure and silencing. Nat. Biotechnol. Bd. 23: 287-289.

5. Koehn, F. E. \& Carter, G. T. (2005). The evolving role of natural products in drug discovery. Nat Rev Drug Discov. 4(3): 206-220.

6. Eynck, C., Koopmann, B., Grunewalft-Stocker, G., Karlovsky, P. \& von Tiedemann, A. (2007). Differential interactions of Verticillium longisporum and V. dahliae with Brassica napus detected with molecular and histological techniques. Eur. J. Plant Pathol. 118: 259-274.

7. Utermark J., Karlovsky P. (2007). Role of zearalenone lactonase in protection of Gliocladium roseum from fungitoxic effects of the mycotoxin zearalenone. Appl. Environm. Microbiol. 73:637-642.

8. Talbot, N. J., Ebbole, D. J. \& Hamer, J. E. (1993). Identification and Characterization of MPG1, a Gene Involved in Pathogenicity from the Rice Blast Fungus Magnaporthe grisea. THE PLANT CELL. 5(11): 1575-1590,

9. Talbot, N. J., Kershaw, M. J., Wakley, G. E., De Vries, O.M.H., Wessels, J.G.H. \& 
Hamer, J. E. (1996). MPG1 Encodes a Fungal Hydrophobin Involved in Surface Interactions during Infection-Related Development of Magnaporthe grisea. THE PLANT CELL. 8(6 ): 985-999

10. Gelvin, S. B. (2006). Agrobacterium Virulence Gene Induction. Methods in Molecular Biology. 343(I): 77-85.

11. Metsä-Ketelä, M., Salo, V., Halo,L., Hautala, A., Hakala, J., Mäntsälä, P. \& Ylihonko, K. (1999). An efficient approach for screening minimal PKS genes from Streptomyces. FEMS Microbiol. Lett. 180:1-6.

12. Howard, R. J., Ferrari, M. A., Roach, D.H. \& Money, N. P. (1991). Penetration of hard substrates by a fungus employing enormous tugor pressures. PNAS 88 : 11281-11284.

13. Gómez, B. L. \& Nosanchuuk, J. D. (2003). Melanin and fungi. Curr. Opin. Infect. Dis. 16: 91-96.

14. Yasuyuki, K., Tsuda, M., Furusawa, I. \& Shishiyama, J. (1989). Genetic analysis of genes involved in melanin biosynthesis of Cochliobolus miyabeanus. Experimental Mycology. 13(1): 77-84.

15. Moriwaki, A., Kihara, J., Kobayashi, T., Tokunaga, T., Arase, S. \& Honda, Y. (2004). Insertional mutagenesis and characterization of a polyketide synthase gene (PKS1) required for melanin biosynthesis in Bipolaris oryzae. FEMS Microbiol Lett. 238(1): 1-8.

16. Ridley, C. P., Lee, H. Y. \& Khosla, C. (2008). Evolution of polyketide synthases in bacteria. Proceedings of the National Academy of Sciences of the United States of America 105: 4595-4600.

17. Wang, J., Cai, Y., Gou, J., Mao, Y., Xu, Y., Jiang, W. \& Chen, X. (2004). VdNEP, an elicitor from Verticillium dahliae, induces cotton plant wilting. Appl. Environ. Microbiol. 70: 4989-4995.

18. Fellbrich, G., Romanski, A., Varet, A., Blume, B., Brunner, F., Engelhardt, S., Felix, G., Kemmerling, B., Krzymowska, M., \& Nürnberger, T. (2002). NPP1, a Phytophthora-associated trigger of plant defense in parsley and Arabidopsis. Plant 
J. 32: $375-390$.

19. Qutob, D., Kemmerling, B., Brunner, F., Küfner, I., Engelhardt, S., Gust, A. A., Luberacki, B., Seitz, H.,U., Stahl, D., Rauhut, T., Glawischnig, E., Schween, G., Lacombe, B., Watanabe, N., Lam, E., Schlichting, R., Scheel, D., Nau, K., Dodt, G., Hubert, D., Gijzen, M. \& Nürnberger T. (2002). Phytotoxicity and innate immune responses induced by Nep1-like proteins. Plant Cell 18: 3721-3744.

20. Novo, M., Pomar, F., Gayaso, C. \& Merino, F. (2006). Cellulase activity in isolates of Verticillium dahliae differing in aggressiveness. Plant Disease. 90: 155-160.

21. Imazaki, I., Kurahashi, M., lida, Y., Tsuge, T. (2007). Fow2, a Zn(II)2Cys6-type transcription regulator, controls plant infection of the vascular wilt fungus Fusarium oxysporum. Mol. Microbiol. 63: 737-753.

22. Calero-Nieto, F., Hera, C., Di Pietro, A., Orejas, M., Roncero, M.I.G. (2007). Regulatory elements mediating expression of xylanase genes in Fusarium oxysporum. Fung. Genet. Biol. 45: 28-34.

23. Fudal, I., Collemare, H., Böhnert, H. U., Melayah, D. \& Lebrun M-H. (2006). Expression of Magnaporthe grisea avirulence gene ACE1 is connected to the initiation of appressorium-mediated penetration. Eukaryotic Cell. 6(3): 546-554.

24. Dupres, V., Alsteens, D., Wilk, S., Hansen, B., Heinisch, J.J. \& Dufrêne Y.F. (2009). The yeast Wsc1 cell surface sensor behaves like a nanospring in vivo. Nature Chemical Biology 5(11):857-862.

25. Rauyaree, P., Ospina-Giraldo, M. D., Kang, S., Bhat, R. G., Subbarao, K. V., Grant S. J. \& Dobinson K. J. 2005. Mutations in VMK1, a mitogen-activated protein kinase gene, affect microsclerotia formation and pathogenicity in Verticillium dahliae. Curr. Genet. 48:109-116.

26. Verna, J., Lodder, A., Lee, K. H., Vagts, A. \& Ballester, R. (1997). A family of enes required for maintenance of cell wall integrity and for the stress response in Saccharomyces cerevisiae. Proc. Natl. Acad. Sci. 94: 13804-13809.

27. Lodder, A. L., Lee, T. K. \& Ballester, R. (1999). Characterization of Wsc1 protein, a putative receptor in the stress response of Saccharomyces cerevisiae. Genetics 
152:1487-1499.

28. Karapapa, V. K., Bainbridge, B. W., \& Heale, J. B. (1997). Morphological and molecular characterisation of Verticillium longisporum comb. nov., pathogenic to oilseed rape. Mycol. Res. 101:1281-1294.

29. Rauyaree, P., Ospina-Giraldo, M. D., Kang, S., Bhat, R. G., Subbarao, K. V., Grant S. J. \& Dobinson K. J. (2005). Mutations in VMK1, a mitogen-activated protein kinase gene, affect microsclerotia formation and pathogenicity in Verticillium dahliae. Curr. Genet. 48: 109-116.

30.Gijzen, M. \& Nürnberger, T. (2006). Nep1-like protein from plant pathogens: Recruitment and diversification of the NPP1 domain across taxa. Phytochemistry 67: 1800-1807.

31. Crooks, G. E., Hon, G., Chandonia, J. M. \& Brenner, S. E., (2004). WebLogo: a sequence logo generator. Genome Res. 14: 1188-1190. 


\section{Chapter 9: Supplementary data}

\section{Extended DNA and amino acid sequences of genes and proteins of $V$. longisporum}

(Note: Green colour: Start code; Red colour: Stop code; Bright blue colour: Intron)

\section{1). VI_6.2 gene (Hypothetical protein including 4 WSC binding domains)}

Coding sequence (including introns):4722 nt

GTTTGATTTGGGCACGATGAGGGTGTTTATGAATCACAGATATCTCGACATGTTTTGTTTGATTATAGTCGTTGTCGTTA TCTTTTCCTCGGATGGGCGTCCTGTTGTGAAGGATTTGGGGATCACAGAGTTTAGAGGGCACACAGCGCCGCCATGGATA TCTTGTTTTCTCTCTTCTCGAGAATCCGTCTGTTCGGAGTTTCAGGACCCTGGGCAACTTTACGCTTCGGAATATATTAT AGTCCTGGAGTATATTACATGGTACTTTACTTGTGGAACTAATTGACTTGACTTTACCGAAGTTAGATGGTCGTGCTTGG TGGACATGTCACATCTCATATGTTCCAGCAGCCAGGTTGAGATGCATTGAGTTGGAACGCTGAAAATATGTCTCTGTGGT ATATGTAAACCTCCGGGAGACCCTCACTTCAGGGCTTAGCGCCTCTACGGCTTCCTTGGGCGAACGGACAGACGCAAACG CTAACAACGGCTGATCATTACGGCAGAGGGCGGCGGGGCATCGGCCGCAAGCCCTAGCGGCGGGGCGTCTCGGGCTAAAA GTCAGGTAGCTGTAGGGCAGGTTATTGCCATGGGTCGCAAAAGTCTGGGACAGCATGATTTGGGACCAACGAGGAGCGTA AATCAGACGCCTTTCGGTCGTTGAGGTGAGCTCTCGCCAGACGCCTTTCGGTCGTTGAGGTGAGCTCTCGCCAAGCACTG AAAGGTGCTTGTGCATGAGTTCCAGTGCTCTGGGACTGAAAAGCGAGGGACCAACTTGTTCGAACATGCCAATGAATGCC ACCCACTACTGTAGCGGCATTCAAGGTCGACTCGTGCTAGGGTAGGTGGGAATCCTACCCCTGGCAGTTTGGTGGAGGTG CATGACGCAAGACGACCGTGAGCTCTGCTGAGTTCGTTTACGCACAGAAGGCAGATGTGCTGGAGGTAAGCTAGGTAAAC ACTGTTACATACTTGTTGATCAAGATGGAGTCGAAATAAATGAATGCTGTAGATGCTCGCCCAAATTGAGGGAGAGCACA TCGTTAAGGCCCACCTGATCTCAGGTCTTACTTGTAGAAGCTGTAATACTCCGAGCATACATGTACTGCTCCGGGCAGCA AGAATCAAGTCCCAAATTAAGAAAAAACCAGGACTCTGACACGTTCTGCAGGTGATTGGGATAAAGACCAAAGCGGCGTG ACTTGGCAGCGGTACTTGATCATGAAAGTCTGTTGAGCTGATGCCGCGGACGCAGCTCCGCCACAACGGTCGGTCGCGTC GTTATTCGCGCTGGTGGGGGTCGACCTTGTACATGTACATGTATCCTTTAAGCTCGTCACTGCCACTGGCGGTCGGGCCA AGgGTAGGGTTGAATCATCCAACACCACAATCTTTCAAGCCAAAGATGGGCTTCAACATGGATGAAATGTAATGTCGAAG ATGCGATTGTCGGCGACCAGTCAGATATAGAGAGACTCGACGAATCCTTTGGGGCACTCACCTTTGAACAGACGCAGACT GCTGCCACCCCGGTTGGAGGACATTGTCCTGCTACTGTGAAGGGGGAGAGGATCGCGATGCTGGTGGGCGATACGAGGCC AAGAATTGACAAGACCCGCTAAATCTGTCGGGGCAGTCGGAGGGCCTGCGTGGCTTGCGTTAGCGCCACACGGCCACCTG CATTTTCCGCGCCGATTCTCTCGACAGCCTGCAACTGCCCCTTGAACCGCCCCCGCTTCTGGAAATTGGATGAAGGAATG CATCCTCGCCTTCGCCAGAACACCTGACGAACTGTCGAATTGACGCAACCATGAGCTGGCTTCTTCACCAGGGAGAAATT GTGTGTGAACAAAACGAGGGCAAAATATCTGTCGCCTCAATGGCTACACCTCCCGATGCGAAGCCCCTCCATCGCCATGG CATACTCACCAGGCATCTGCCAACCTTGTGGCCTCGTTGGCGGCAAAGGAGAGCCACTGGTCACCCATCACATCTCACAC GTGTCCGCGAAAGATAAACAGCAACGTGTGCCTGGAGTATGGATCTCTGCAGCAGCCCGCCAAGGAGAACGGTCCAGCAC TCGACAAAGACTCGGCCGGCGACCTGGCACCGCCACTGCCCAGCATCTTCGTCTATTCGTGCATGGGAACCAGGCCCAAA CTGGTGGGATCGTCAGGAACCTACTCCCCCGTCGCAACTGTTCGGCACCCCGGCCGCTGGAGGAATCGAGAAGAGGGCAA GGAGGGGCACCAACTGCCTCCTACAGAAATTAATCGGACGGTGGAGGGGGTCCTTTTTTTTCCAGACGCCTTGGCACCAG CGACACAAGCGACAATATTTCCCATCGGCCTGCCTGTTACATCCAAGATTGACTACGTCCCCACTGTTGCCCAGTCGCCT CGTCAAACCAGGCGGGCGTGCGGTCATGAGCCATCCATCATCTGGCAGGCGCCGACTGGCGGAGCCCATCCGCAAGTCCA GAGTCCGGGGCCTTACTATCTTTATGTACTACTCGTCCGAGGAAGCAATGCAGACAAGGCACCGCGCGGCGCGGCATGAC ACCCGAAAATCTAGGGGACCCATCAGGAACAGAACAAGGATGCCGTATGATCGACGAATATTACCAGCGGCCCGCCCGCC TGGCTTTGCCGGGCGGGTTTCTCGATCGTTCATCCGCTTTCCCATCCTTTCTTGACTCACTCGTTCGTCAAGCTTAGGTT CGCGGCCATGGTTTCTTTTCGCTGGCTGATGCTGGCAGCGGTCGCCGGCCTTGCCAATGGCCTGGCCGACACCGACACCA TCACCTGGGGTGGCGATAACTCGCGCGCCGGCTACCAGACGTGAGCGTCCTCGTTCCGTATCCGGCCCCCTTGAAATGGC ACTGACGTGTTTCCAGTAACCATAACATGGACCCAGCTGTCGTCCGTAGTTCTCAATTCGATCGGATCTTCCAAACCACA CTTCCCGGTCGATACGGCGGCCGTGCCGAGCAGATCTTCTCTCAGCCCCTCGTTTACACTCCCGACGACAAGCAGTACGT CTATCTTGCGACCACGCAGAATAATGTCTACAAACTCGATGCGCAGACGGGCGAAATCCTTGCCTCACGCAATCTCCACA TTCCTTTCCTCTCGACAGACCTCGACGGATGCTACGATATTCAACCCCACGTCGGTGTCACTGGTACTGGTGTCATCGAT CCTGACACCGGCACCTACTACCTCTTGGCCAAAACCTACGAGAACCAGGAGCTTGTCGACGTCGCCCAAGGTCGCCCTGC CGGACGCTACTACCTGCACGCTCTTGATGTGAACGATTTGAGCGAGCGTCCCAACTTCCCTGTCGGCCTCGAGGGTACCG TCGCCAGGAATAACCCCGATCGAAGCTTCAATGGCGGCATCCATCTTCAACGCCCTGCGCTGCTGCATGTGGGCCAGCAT ATTTACGCCGGCCTCGGCTCCCATTGCGTCAAATTCAACTTCACCGGCTGGGTCATGGGCTGGGATAAAACTACCGGAGA ACAGGTCGAGCGCTTTGCGACGCAGGGCGAGGGCGTACCCCAGAACACCGAGGGCGGCGGCCTGTGGATGGCCGGTGGTG GCCTTGCTTCCGATGACCAGGGCTCCATCTTCTTCGCGACAGGCAACGGATACGCTGGACAGCTTGCTGAGATTCCTGTT 
AACGGCCGCAACCCCCCGACTTCGCTTGAGGAGGCTGCTGTTCACATGACGATCCAAGAAGACGGAAGCTTAGATCTGGT CGACTTCTTCATACCATGGGATAAGCGCGCTATGGATGGAGACGACAAGGATCTTGGATCAAGCCCTCTTCAAATTCTAC CCAGCGAATTTTCTTGCGGCAGCATCAGGCGTATCGGAGTCGTGACGGGCAAGAACAAGAAGACCTACTTCATCAATCTT GATGACATGGGTGGCTACCGCAACGGCGAGGATCGCTTCGACAATATCATCCAGACTTATGAACACGAGAACTCGGTTTA TGCTGGTGCTGGCGTCTACCCTGGAGAGGGCGGTTACATTTACATCAACGGTGCGTTTGGTTCAGGTCTGCGTCTCACCC CCAACATTATTGCTAACTTGCACAAGTCGTACAATATCCTACCATCGTCTTCCGCTTCTCTTGCGCCAACGGTGTGCCTT CGTTCAATAAAGAGGCCGAGACCCCAGAGTCCAACGGCTACACCCTTGGCGTGAGCCACGGCACTGTCACCTCTCTCAAC GGAGAGCCTGGCACTGCCATGCTCTGGACCACTGACGTACAGAACCCGCCCGGCCAGCTTCGCATCTACGATGCAGTCCC TCGCGACGGCGAGCTTGCCCTCCTCCGAAAGTGGGAGATTGCCGGCGTTACCAAATTCAGCCGCGCTGTATTCGGCGACG GTATTATGTACCTGGGCACGACTACTGGCTTGTTCTACGGATTCGGCGCTCCCATCAACCGCCCCATCGAGTGCACTTCG CCTCTCGAATTCGGCGCCGTCAGTCTCGAAGCCAGCGCAGAGACCCGTACTTTGACTTGCACTGCTCTGATCAACACTGT TGTGAATGACATTTCTCTCCGCGAGGTAACCGATTTCAGCATTTCAGGACTGCCAACACTGCCCTTGACACTGGCTGTGG GCGCCACATTCACAATCGAGGCTGTCTTCGCGCCTACCGACCTCGGCCTTCTCTCCACCGATGTCAACATTGAGACGGAG AACAGCGTCGCCGGATACCGTACCACCACATCTGCCCGACTCACCGGCACCGGCGAGACAGACAACCCAAGACTTTCTGT CAGCCCCAGAGAAATCGAATTCGACAACGTCATCACAGCTGGCGCAGCGCCACCTGCTAACAATGTCGTGCTGTCGAACC AGGGCAACTCTGTTCTGACAGTCAACGAGATCCGATACTCTGAGACGATCAACAGCACTCTGCAAACCTGGGATCCAGCC AGCGGCGCCCTAGTCATTGGGCCTTTCACAATCAGGAACATTCCTTCCACCATTGATGCCAATTCGGGCGCCACGGTCTC CGTATCCCTGAGCCCCGCGAATGGAGGCACATTCAGCGGGCACGTTCGATTCATTACTGATGGTGGTAATACCGATGTGA CCATGACCGCTCACGTAGGTGCGGCTCCTGTGCTCCTCGTCGAGTTCGAGCGCCCTGACGGCGAGGGATGGACCACATAT CAAGAAGGGACCGCATTCTCGTTTGGCGAGGTCACCCAGAACAACGTGAGAAACCTCAGGATGCGCATCACCAACACCGC CCCTGCTGGTGGTGTCAGACTATCTCTTACGGTCTCCAAACCTCCTCATGGCGGCTCCGGAATCATCAGGGCCAACAATG CTGTCGATCTTGGTGAGGGTACAAACCTGGGTCCTGGCCTGAGTGAAACTGCCGTGCTTTACTGTGCTGTTCCTAAGAGG CAGTGGAACATGGAGCCCTACCAAGGCGAGGCTACCTGGAGTCTCAACACCAACGATCCCAAGGTGGCTTACCAGAACAT TCAATTTGAGTGTACTGCTGTCTCTGAACAGTCTGCTCCTCTCCTGGAGAATGGGCTGTCGCAGTATCAGTATGTCGGTT GCTTCAGGGAAAACACCCCTGGCCGGCAATTGGCCAACCAGCTCTACGGAAACGACGAGAACACCATTGCCATGTGCGTG GAGGCATGCGCTGCTGGCAACTACGTATTCTGCGGAACGCAGTACCACCGAGAGTGTTGGGCCGGCCCGACCATCCCTAG GGAGCGTGTTGCGGACGTCAACTGCAACTTTGACTGTGATGGGGATCTCAATCAGATCTGCGGTGGCAACGGTATTGCGA CTGGACCTGGTGGCGCTTACATTTCTCTCTTCGCCGATACTCTGCGATTCGATGGCAACGAGACCAACATCCCTGAGCCT GAGGAGCCAGTGGAACCTACTGATCCCATTGTTAACCCAGGCGTTGATGGATACATAAGCATTGGCTGCTACACCGAAGC ACCGGGGAGCCGCGCGCTGCCTTTCTTCTTCGCCACCGAGGATCAAACTGTCGCCATGTGCGTGGACGCCTGCTCGCTTC GTGACTACGAGTACGCTGGTGTCCAATATGGCGGAGAGTGCTGGTGCGCCAACGCTATCACGACGGGTGCCGTTCCGGCG CCTGACGCGGAATGCAACATGGCCTGCAATGACAACGCTGCCGAGTACTGCGGTGGCGGCTCTCGGCTCAACGTCTACCA ACGCCAATCTGGAGGTTCTTTCCCTTCTGCTAGTGTCTCTTTGAATGGCACTATCCCGGCGCCGACTTCGTCTTTGATCC CCGCCTCTTCCGTGCCTGTCTCTTCTGCACCGATCATTTCAAGCATCGTGACGTCCGCCGCCCCGCCAGTGCCGACACCA GGAGAGGATCACTTTATTGGCGACTGGTCGTTCGAAGGCTGCTACACCGAAGGCGATGGCGTGCGGGCCTTGAACGGTCG CTTCTACGCCGACGACGAGTTGACGCTTGAAAAGTGTGCCGCCTTCTGCGAGGGTTTCGTTTACTTCGGTGCCGAATACG GGCGCGAGTGTGGTGCGGCGACGTTCATGGCACTGGCAGCGTGTTGGCGTCCAATCAAGGCGACTGCAACTTTCCTTGTG GCGGCGACGGCTCACAGTTTTGTGGTGCGGGCAACAGGCTTCAGATGTATCGCTTCGGTGGTGCGGACGCGCCTTCGGGG GCTGTGAGCAGCTCTCTTGTGGTGCCCACGTCTGCGGTCGTCAGTTCTACTGTTGCTCTTGTTAGTTCAACTGCCGCAGA AGTCAGCTCTGCCGTTGCGGAGGTTAGCTCTCAGATAGCCATCGAGGCTAGCACTGCCCCTGCTTCCAGCTCCGTCGTTG AAGAATCCAGCACATCAGTCGTCGAGACCAGCTCGACGGTTGCTGTGGAGTCAAGCGCTGTTCAGTCCCAGTTCTGCCCA ACCCAGCTCCGCAGAGGCCAGCTCGGTCATCGAGATTATGTCTTCCGCCGTTGCATCTTCGAGCTTTGTTCCTAGCTCTG GGATCCCATCATCCACGACCCCGACCTCGACGCCGTCACCCTCGGTCTATCCAGGCAACGATCTCTGGAACTACACGGGC TGCTACTCTGAGCCCTCCCCTGGACGCCTTCTCCCCAGTCAGCTCCTGAACGACGGCGATGAGATGGACATTGAGCTCTG TCTCGACGTCTGCGCTGGGTACAACTATGCAGGTGTCGAGTATGGTCGTGAGTGCTGGTGCGGTGACCGCCTCAACGCCG AGGGTGACGTCCCCAGCGAGGGCACAGCAGTGCCTGGCGAGCTGGTGGACGACGATGAGTGTGCCTTCCTGTGCCCTGGC AACAGGCTGAATTACTGCGGTGCAGGTGTCAGAATGAGCGTGTATATCCTGAGAGAGCGCGAGGAGGCGCTGGCTGAGGC GTCCTGAGACAGATAAAGTGGCATGATAGATGGTAAATTGCATGATTGGTTCAGCCCGGCAGGCTCTGCCTTCCAATAGG CACTTTTTGTATTTTCTTGTGATAATGAACCTCACGCTGGGGCTTCGTATATAAATTATAAGCAACATATTGCTATTGC TTGCCGACTCAACTCGCGTGATGGGTAACTTGAAGTCCGCCCACCAGCGGGCTTTTGTAAGGCTCCCATCTCGATACTGA TAGAACATTCATGGAGTTCAAACTTCCCCTGCTTCAGCTGCTCGTACCTTGAAAACAGGTGTGACGATACCCGTCTCTAC TCCCCACGTGTTCTTCCGCTTCAGTCGATGATATTTGAGCAGCTCCTCGCGGCCGGGAGACATCTCGATTCCCAGCTGCA AGAGAATCTCGACGACAGCCGTGTATAAGATCC

\section{Aminoacid sequence: 1534 aa}

MVSFRWLMLAAVAGLANGLADTDTITWGGDNSRAGYQTNHNMDPAVVRSSQFDRIFQTTLPGRYGGRAEQIFSQPLVYTP DDKQYVYLATTQNNVYKLDAQTGEILASRNLHIPFLSTDLDGCYDIQPHVGVTGTGVIDPDTGTYYLLAKTYENQELVDV AQGRPAGRYYLHALDVNDLSERPNFPVGLEGTVARNNPDRS FNGGI HLQRPALLHVGQHIYAGLGSHCVKFNFTGWVMGW DKTTGEQVERFATQGEGVPQNTEGGGLWMAGGGLASDDQGS IFFATGNGYAGQLAE I PVNGRNPPTSLEEAAVHMT IQED GSLDLVDFFI PWDKRAMDGDDKDLGSSPLQILPSEFSCGS IRRIGVVTGKNKKTYFINLDDMGGYRNGEDRFDNI IQTYE HENSVYAGAGVYPGEGGYIYINVVQYPTIVFRFSCANGVPSFNKEAETPESNGYTLGVSHGTVTSLNGEPGTAMLWTTDV 
QNPPGQLRIYDAVPRDGELALLRKWEIAGVTKFSRAVFGDGIMYLGTTTGLFYGFGAPINRPIECTSPLEFGAVSLEASA ETRTLTCTALINTVVNDISLREVTDFS ISGLPTLPLTLAVGATFTIEAVFAPTDLGLLSTDVNIETENSVAGYRTTTSAR LTGTGETDNPRLSVSPREIEFDNVITAGAAPPANNVVLSNQGNSVLTVNEIRYSETINSTLQTWDPASGALVIGPFTIRN IPSTIDANSGATVSVSLSPANGGTFSGHVRFITDGGNTDVTMTAHVGAAPVLLVEFERPDGEGWTTYQEGTAFSFGEVTQ NNVRNLRMRITNTAPAGGVRLSLTVSKPPHGGSGI IRANNAVDLGEGTNLGPGLSETAVLYCAVPKRQWNMEPYQGEATW SLNTNDPKVAYQNIQFECTAVSEQSAPLLENGLSQYQYVGCFRENTPGRQLANQLYGNDENTIAMCVEACAAGNYVFCGT QYHRECWAGPTI PRERVADVNCNEDCDGDLNQ ICGGNGIATGPGGAYISLFADTLRFDGNETNI PEPEEPVEPTDP IVNP GVDGYIS IGCYTEAPGSRALPFFFATEDQTVAMCVDACSLRDYEYAGVQYGGECWCANAITTGAVPAPDAECNMACNDNA AEYCGGGSRLNVYQRQSGGSFPSASVSLNGTIPAPTSSLIPASSVPVSSAPI ISS IVTSAAPPVPTPGEDHFIGDWSFEG CYTEGDGVRALNGRFYADDELTLEKCAAFCEGFVYFGAEYGRECWCGDVHGTGSVLASNQGDCNFPCGGDGSQFCGAGNR LQMYRFGGADAPSGAVSSSLVVPTSAVVSSTVALVSSTAAEVSSAVAEVSSQIAIEASTAPASSSVVEESTSVVETSSTV AVESSAVQSSSAQPSSAEASSVIEIMSSAVASSSFVPSSGIPSSTTPTSTPSPSVYPGNDLWNYTGCYSEPSPGRLLPSQ LLNDGDEMDIELCLDVCAGYNYAGVEYGRECWCGDRLNAEGDVPSEGTAVPGELVDDDECAFLCPGNRLNYCGAGVRMSV YILREREEALAEAS

\section{2). VI_2.1 gene (Isochorismate hydrolase)}

\section{Coding sequence (including introns): $629 \mathrm{nt}$}

GACTCCTGTTCATCAAATAACACACAATCAAGGATTGCCTGTGCCAGATCAGCAACGTTCACCATGTCCTCATTCCGCTC CATGCTCGGCGTGCCGCCGTCCACGGCCTCCACCAGGACAGTGTCCTCGTCATCATCGACGCCCAGGGCGAATACGCCGA GGGCAAGCTCAAGATTTCCAACATTGAGGCGTCGCGCCCCAACATCTCTTCCCTGCTGGAGAAGTACCGCGCCGCCAACG CGCCCATCGTCCACGTCGTCCACGAGACGCCCGCCGGCGCCCCTCTCTTCACGCAGGGCACGAAGCTCGCTGAGATCTTC GACGAGCTCACGCCCGAGGAAGGCGAGGCTGTCGTGACGAAGCACCACCCCGGTTCATTCGCCGACACCAACCTTCAGGA GATCCTGGAGAAGTCCGGCAAGAAGAAGATTGTGCTCGTCGGGTACATGGTGAGTCTTATCAACGAGATGGAAAGCTCGT CGTGGAACGTTGCTGACACATTGCAGGCTCACGTCTGCGTCTCGACGACGGCCAGGCAGGGCGCGCAGAGGGGGTGGGAT GTCATCGTTGCCGAGGACGCTGTCGGTGACAGGGACATTCCCGGCGTGGATGCTGCGCAGCTTGTGAAGGTTGCTCTGGC TGAGATTGCTGATGTCTTTGGCACTCTTGTCTCGAGCAAGGATATCAACTAGGACGTCACGTGAATGCTACCGTTATGAT CAAT

\section{Aminoacid sequence: 190 aa}

MSSFRSMLGVPPSTASTQDSVLVI I DAQGEYAEGKLKISNIEASRPNISSLLEKYRAANAPIVHVVHETPAGAPLFTQGT KLAEIFDELTPEEGEAVVTKHHPGSFADTNLQEILEKSGKKKIVLVGYMVHVCVSTTARQGAQRGWDVIVAEDAVGDRDI PGVDAAQLVKVALAEIADVFGTLVSSKDIN

\section{3). VI_11.1 gene (Peroxidase/Catalase)}

\section{Coding sequence (including introns): 2289 nt}

TCGCCATACCTCGTCCTGCCACGCCGACCAGGTATCACCGAGTACACCCCCAATCACACTTTATCAACCGCAGACACAAC CACACCGACTCACCCAACATGGCCGAGTCGGAGAGCAAGTGCCCCGTCCACCAACTCAACAACGTCGGCGGCGGCGGCAC CCGCAACCGTGACTGGTGGCCCAATGCTCTGAAGCTCAACATTCTCCGTCAGCACACAGATGTCACGAACCCCCTCGGCA ACGACTTTGACTACGCTGCTGCCTTCAACAGCCTCGACTACAATGCCGTCAAGAAGGACCTCAAGGACCTCATGACCGAC TCTCAGGACTGGTGGCCCGCCGACTTTGGTCACTACGGAGGTCTCTTCGTTCGCATGGCGTGGCACAGCGCCGGTACCTA CCGCGTCTTCGACGGCCGCGGTGGTGGCGGTCAGGGCCAGCAGCGTTTTGCTCCCCTGAACAGCTGGCCCGACAATGTCT CGCTCGACAAGGCTCGTCGCCTGTTGTGGCCCATCAAGCAGAAGTACGGCAACAAGATCTCCTGGGCTGATCTGCTGCTC CTCACCGGCAACGTCGCCCTCGAGTCGATGGACTTCAAGACCTTTGGCTTCGCCGGTGGTCGGGCCGACGTCTGGGAGGC CGACGAGTCGGTCTACTGGGGTGGCGAGACCACTTGGCTCGGCAACGACGTCCGCTACTCTGGTGGCAACAAGGGCGACA AGGGTCCGGGCAGCCTCGTCACCGACGAGGGTCATGATAAGAGCACCCACACCCGTGGCTTGCAGAAGCCTCTCGGTGCT GCCCATATGGGTCTGATCTACGTCAACCCCGAGGGCCCCGATGGCAACCCCGACCCTGTTGCTGCTGCCCACGACATCCG CACCACCTTTGGCCGCATGGCCATGAACGACGAGGAGACCGTCGCTCTTATTGCTGGTGGCCACTCCTTCGGCAAGACCC ACGGCGCCGGCCCCAACGACAAGATCGGTGCCGAGCCCGAAGGTGCCCCTCTTGAGGCTCAGGGTTTCGGCTGGCAGAAC GGATACAAGTCTGGCAAGGGTCCCGACACCATCACCAGCGGTCTCGAGGTCACCTGGACCGCGACCCCGACCAAGTGGAG TAACAAGTACTTCGAGTACCTCTTCAAGTACGAGTGGGAGCTCACCAAGAGCCCTGCTGGCGCCAACCAGTGGGTGGCCA AGACCGACGACGAGATCATCCCCGATGCCTACGACTCGTCCAAGAAGCACCGCCCTACAATGCTCACCACCGATCTGTCC ATGCGCTTCGATCCCGAGTACGAGAAGATCTCTCGCCGTTTCCTCGAGAACCCAGACCAGTTTGCCGATGTTTTCGCTCG CGCCTGGTTCAAGCTCCTTCACCGTGACCTTGGCCCCAAGGCTCGCTACCTCGGCCCTGAAATCCCTGCCGAAGACCTCC TGTGGCAGGACCCCATCCCCGCTGTTGACCACCCTCTGATCGACGAGAGCGACATTGCCGCTCTCAAGAAGGAGATCCTC TCCTCCGGACCTGAGCCCTCGCAGTTCATCTCCGTTGCCTGGGGAGCGTCTTCTTCCTTCCGTGGCAGCGACAAGCGCGG TGGTGCCAACGGCGCCCGTATCCGCCTCGCCCCCCAGAAGGACTGGGAGGTCAACAACCCCGCCCAGCTGGCCAAGGTTC TGCAGGCCCTTGAGGGTGTGCAGAAGAGCTTCAACGATGCTCAGCAGGGTGGCAAGAAGGTCTCTCTCGCCGACTTGATC GTCCTGGCCGGTAACGCCGCTGTTGGGAAGGCCGCGTCGGCCGCCGGCCACAGCGTCACCGTCCCCTTCACTCCTGGCCG 
TGGCGACGCCACTCACGAGCAGACCGACATTGAGTCCGTCAGCCACCTCGAGCCTTTTGCCGACGGCTTCCGCAACTACG GCCACTCGACCGACCGCGTCAAGACGGAGCAGTTCCTTGTTGACCGTGCTCACCTTCTGACGCTGTCGGCGCCTGAGCTG ACCGTCCTCGTTGGCGGCCTCCGCGTTCTGAACGCCAACTACGACGGATCCCAGCATGGTGTCCTGACCAAGCGCCCCGG CCAGCTGTCCAACGACTTCTTTGTCAACCTGCTCGACATCAGCACGGCATGGAAGGCTACCGGCAGCGACGAGGAGCTCT TTGAGGGTAGCGACCGCAAGACTGGCGACAAGAGGTGGACTGCCACGCGTGCGGATCTCGTTTTCGGATCCCACGCCGAG CTGCGCGCCCTTGCCGAAGTGTATGGCAGCGCCGACGGCGAGAAGAAGTTTGTCAACGACTTTGTCGCGGCGTGGACCAA GGTCTCGAACCTCGACCGTTTCGATCTCAAGAAGGCATCTGCCGTCAAGACGTCGAGCCGCCTGTAAACGCCTCTAAGAA GTCAATGACGAAATGTTGAGTGTTATAGTAATGAAACCACACTTCATCTCCACTTCACTGGACCAGTATTC

\begin{abstract}
Aminoacid sequence: 762 aa
MAESESKCPVHQLNNVGGGGTRNRDWWPNALKLNI LRQHTDVTNPLGNDFDYAAAFNSLDYNAVKKDLKDLMTDSQDWWP ADFGHYGGLFVRMAWHSAGTYRVFDGRGGGGQGQQRFAPLNSWPDNVSLDKARRLLWPIKQKYGNKISWADLLLLTGNVA LESMDFKTFGFAGGRADVWEADESVYWGGETTWLGNDVRYSGGNKGDKGPGSLVTDEGHDKSTHTRGLQKPLGAAHMGLI YVNPEGPDGNPDPVAAAHDIRTTFGRMAMNDEETVALIAGGHSFGKTHGAGPNDKIGAEPEGAPLEAQGFGWQNGYKSGK GPDTITSGLEVTWTATPTKWSNKYFEYLFKYEWELTKSPAGANQWVAKTDDEI I PDAYDSSKKHRPTMLTTDLSMRFDPE YEKI SRRFLENPDQFADVFARAWFKLLHRDLGPKARYLGPEI PAEDLLWQDP I PAVDHPLIDESDIAALKKEILSSGPEP SQFISVAWGASSSFRGSDKRGGANGARIRLAPQKDWEVNNPAQLAKVLQALEGVQKSFNDAQQGGKKVSLADLIVLAGNA AVGKAASAAGHSVTVPFTPGRGDATHEQTDIESVSHLEPFADGFRNYGHSTDRVKTEQFLVDRAHLLTLSAPELTVLVGG LRVLNANYDGSQHGVLTKRPGQLSNDFFVNLLDISTAWKATGSDEELFEGSDRKTGDKRWTATRADLVFGSHAELRALAE VYGSADGEKKFVNDFVAAWTKVSNLDRFDLKKASAVKTSSRL
\end{abstract}

\title{
4). VI_12.1 (VI_10.2) gene (Zinc-finger transcription factor ace1)
}

\section{Coding sequence (including introns): $2328 \mathrm{nt}$}

AGAGCTGGCCATCGCCCGCCAGTACCCACTCCCCCTTCCGACACTTTCGTCATGTCGTGCCAGAACCCTCGCCGCAGGTC CCCTGTGACCCGCGTCGGCGACGCTTCCAGCAATGGCCTCACCAGCCTTAAGACCAACATGACCCTGCGCAAGGGGGCCA СCTTCCACTCGCCCACCTCTCTCGACTCTTCATCCATCGACGCCTTCATCCCCCCAGCTCTTGGTCGTATCTCAGACCAA TCTTGAAGACGTGTCGGCGCTCACGTCCGCCGCATGGAGATGATCGTCAGCGGCATCGAGACATCACTCAATCTGAATGA TACCCCAAGGCCGGCCTCCAAGCCTTCGCGTGACGAGTGCCTGCCTCGCACAAACGGCTTCCTCGGCCGCCCTACTGTCG ACCCCGCCATGGCAAAAGACACCAAGACCAGCGGGGAGCGCCGCGTTTTGCGCCCAAGACATCGTCGCTCATCGGAGCAG CACGCTTCGGACAGCGGTCTCGGCACCTCTCTGGCCTCTTCCGTCGAGAAGCAAGCCCCCAGCATCACCTCCAAGACCAG CAAGGCATCCGCCATTACACGCTCTGCCGCCGCTCCTTCCAACACCATGACCAAGGTCTCTGGCCTGAGCTCCAAGGCGG TCAGCCGTGTTCACGAACACGTTCTTCGCCCCCTTCGTGCCAAGCCTGAGTTGAAGGACTTCGAGCCCATCGTCCTGGAC ATTCCCAGGCGAATCCGTGACAAGGAAATCATCTGCCTCAGGGATCTTGAGAAGACTTTGATCTTCATGGCACCGGTAAG TCAACTCTTGTATCAACGCAGCGTTTGGGGAGATACTTATCGGTCGTTGATGAAGGAGAGGGCCAAGACCGCCGCCTTGT ACCTCGATTTCTGCCTGACGTCCATTCGATGCATTCAAGCCACCGTCGAATACCTCAGCGACCGCGAACAAATTAGACCG GCCGACCGACCATACACTAACGGATACTTCATTGATCTCGTCGAACAGATTCGCCAATACGCCGGACAACTGGCCACTGC CAAGGAAGCCGGAGTCGAGGGGCGTGAGATGGACGTCGACCCCACCGACGAGGTTAAGCTGTTCGGTGGCATCTCGCAGA ACGGCCGCCCCGCCGAGCTTGTCCGCGTCAGAAAGGACGGTCAAGCCATCTCCATGGCCACTGGCCTCCCCGTTGACATG GATGAGGACGGCAAGGATTTCCCCAGACTGAAGCGCTCCCTGAGCCAGCAGCTGGCAGACGACGAGGAGATCATGCGGTC CATGGCTCGCAGGAAGAAGAACGCTGCGCCGGAGGAGCTCGCGCCCAAGAAATGCCGCGAGCCTGGCTGCAACAAGGAGT TCAAGCGTCCCTGTGACCTGACCAAGCACGAGAAGACTCACTCTCGTCCCTGGAAGTGCCCTGTCAAGACGTGCAAGTAC CACGAGTACGGCTGGCCCACCGAGAAGGGGATGGACCGCCATCACAACGACAAGCACTCCTCAGCGCCCCCCATGCACGA GTGCCTGTTTAAGCCTTGCCCTTACAAGTCGAAGCGCGAGTCAAGCTGCAAGCAGCACATGGAGAAGGCCCACGGATGGC AGTACGTCCGCACCAAGACCAACGGCGGCAAGAAGGCGCCCAGCGTTGCTGGAAGCTCGGCACAGCCGACCCCTCAGCTT GGCAACATGGCAACGCCCTCGAGCAGCCACAGTATTGCTACGCCGCCCGAGGAGAGCACCAGCCTCTTCCCGCCTTTTAA CCACGATGACTTCCCTCACTACGTCCCGGCCGAGGAGTTTGCTGACACCTGCCTCGGGCCCATGGGACAGCCGCCCATGA CGCTCGAGGGTATCGACTTTAACGACCTTGGCGTGTCTCCCACTGATTACAACACCCCTTCTACCGACACATCCTACCCA TACACCTCTTACCAGGATGGACCCGAGTTTGTCATCAACAACGATGACATTTACGGCGCCCGTGTCCAGATCCCGACACC GGCGTGGCCCGAAAAGATGATGGCTGGCATGCAGAACTACGCCCCAGTGTCTGCATGCCAACCTCAGATGATGCCCGAGC CGCTCGCCCCACACATCTCCCCGATAGGTCAGGGGAACGCCATGCTCTTCACGCCCAACTCGTTGGCCGAGGTTGACGAA GGCTTTGATGATTTCGGCGGCTGTGGTGATGATTTCACCTTGTTCCCCGTCAACGGGCTCGACAAGGACGCACAATTCCA GACTCTGTTCGGCAGCGAGATGCCCAGCAGCGGCCTCGGCTTGTCTCAGGGCGCCTCCCAGGACTTCTTTGGGAACGGCA TGGACTGGTCCAGCATGGAATACCACACCTACTCCCAGCAGCCCCAGCACCAGCAGTAGAGTGATGTTGTGAGACTTCAC TTACTGGTTGCTTTGGGATGGCCTGTTTCTTTTACGT

\section{Amino acid sequence: 754 aa}

MSCQNPRRRS PVTRVGDASSNGLTSLKTNMTLRKGATFHSPTSLDSSS I DAF I P PALGRISDQSRRVGAHVRRMEMIVSG IETSLNLNDTPRPASKPSRDECLPRTNGFLGRPTVDPAMAKDTKTSGERRVLRPRHRRSSEQHASDSGLGTSLASSVEKQ APSITSKTSKASAITRSAAAPSNTMTKVSGLSSKAVSRVHEHVLRPLRAKPELKDFEPIVLDIPRRIRDKEI ICLRDLEK TLIFMAPERAKTAALYLDFCLTS IRCIQATVEYLSDREQIRPADRPYTNGYF I DLVEQIRQYAGQLATAKEAGVEGREMD 
VDPTDEVKLFGGISQNGRPAELVRVRKDGQAISMATGLPVDMDEDGKDFPRLKRSLSQQLADDEEIMRSMARRKKNAAPE ELAPKKCREPGCNKEFKRPCDLTKHEKTHSRPWKCPVKTCKYHEYGWPTEKGMDRHHNDKHSSAPPMHECLFKPCPYKSK RESSCKQHMEKAHGWQYVRTKTNGGKKAPSVAGSSAQPTPQLGNMATPSSSHSIATPPEESTSLFPPFNHDDFPHYVPAE EFADTCLGPMGQP PMTLEGIDFNDLGVSPTDYNTPSTDTSYPYTSYQDGPEFVINNDDIYGARVQIPTPAWPEKMMAGMQ NYAPVSACQPQMMPEPLAPHISPIGQGNAMLFTPNSLAEVDEGFDDFGGCGDDFTLFPVNGLDKDAQFQTLFGSEMPSSG LGLSQGASQDFFGNGMDWSSMEYHTYSQQPQHQQ

\title{
5). VI_24.1 gene (Hypothetical protein)
}

\section{Coding sequence (including introns): 1402 nt (incomplete)}

CGATTCGTCCTGGCCCCTCCATTTCCATTTCATACCCTTCCGACACGACTGGATAGACCCTTCTTCCAGGACATGATCGC AGCCATCTCCGATGGCTGCCTCACAGCTCGACCTTCCCCTTCCCGGTGCCTCCTTCTTCGATATTCACCATGATGGAACG ACCACCCGCAGTCCTGTCCCGTTGCCCGATGGGGGCTGCAACTTTGTCGACCTGACGCCCGGTGCCAACGGAGCCAAGTG TGGATGTCGCCGCTTCTGGAGTCGCACTGTTTCCGGGAGAGGATTCGCAGATACCGTAGGATCGGACCACACGGCCTGGT GCATGTGCACTCACCACGCTTGTTACCACGACCACACCCGCGACGCAGAAGCCGCCACCCCCGTAATAGGATTCGTTCCC GGACAGGAGAATACAAAACTCAAGGGACATCGTGGGCCCCTAAGCCCCGTCGTTCAGGATGCTTCGTTCCGCCTGCCTTC TGGATTCTCTACTTCATTGGATCTTATGAATCTGGACGCCGCGATGCTGCTGCCCATGAGCAAGCCCGAGGATGCCAGGA ACCCGCGCGCTGGACCCCTCAGCCAGCAGCTCGAATCTACACTACAGGATACGTTAAGTTGGGGCGAGTTTGTCCAGTCT CAGTCAGCCAACACGACCACACTGCCCCCGATCCCCCCTCAATGCCTTATGCCCTCTCAACCCAGTTCCACCACATCATC TAGCCAAGCTCGTTACTTGCGCCCTTTTGCCGGGAAAGGATTAAACACGCTCAGTGGTGTGCACCAGCCCGACCCTCGTT CTCCTCGCCAGGAAAAGCCGCACGACCTGGAGCCCATGGACATTCAGCCCACAAGATCTGGAATGGAAGTCGTTACCGCG GGTGCCGCATCTGCTGTTGGAAATGGTCAGACACTCCGAAAGCTCGACGATCTCCTGTCCTTACGGTCCAGGCTCCCGC AGCAATATTGGGTCACCTTCACGTGATACGTTTCGACACATGTCAGACACAGTCCAAGGACACGAGCAACGGATCGATC GTTTGGAGAATGTTTCCTTCTCCGCAGGAGGTAATGACGAATGCCATGAAAAGCATGATGCCATGGATCTTCGCGTTACG GACCTAGAAGGCCGGGTAGAAGAGGTTGAAAAACTCATGAATGATAATACCAGCCACGGAACTGCCCGCCATCTCCGCCA ACCTGCCATCGATGAGTCGATGAGCAGCGCCGTCTCTGTTTCTACCAGCCCAACTGCTCGTATCTCCGACGCGAGCGAGG TTTACAACCACATACAGTCCCTTCAGTCTCAACTTCGGCACCTCCAGTCTTTTGTGCCATCTTGTATGCATGCCTGGGAA GTGGAGGTGGTGTTTCTCCCGTTCGCTCTCCGGCGCATCTGGCAAGAAAGGCACGACTTCAAGCTGGAACCAACATCTAG CATGGACGAATGGACTCAGCTCCCCAACACCAACAGTACTGCCAGGTCAGGCA

\begin{abstract}
Amino acid sequence: 421 aa (incomplete)
MAASQLDLPLPGASFFDIHHDGTTTRSPVPLPDGGCNFVDLTPGANGAKCGCRRFWSRTVSGRGFADTVGSDHTAWCMCT HHACYHDHTRDAEAATPVIGFVPGQENTKLKGHRGPLSPVVQDASFRLPSGFSTSLDLMNLDAAMLLPMSKPEDARNPRA GPLSQQLESTLQDTLSWGEFVQSQSANTTTLPP I P PQCLMP SQPSSTTSSSQARYLRPFAGKGLNTLSGVHQPDPRSPRQ EKPHDLEPMDIQPTRSGMEVVTAGAASAVGNGSDTPKARRSPVLTVQAPAAIFGSPSRDTFRHMSDTVQGHEQRIDRLEN VSFSAGGNDECHEKHDAMDLRVTDLEGRVEEVEKLMNDNTSHGTARHLRQPAIDESMSSAVSVSTSPTARISDASEVYNH IQSLQSQLRHLQSFVPSCMHA
\end{abstract}

\section{6). VI_25.8 gene (IBR finger domain- containing protein)}

TACAATTACGAGATGGCATGGCGCGGCTGCACCAGTCCAAGATCAATGTTTTGCGCGACCGGCAGGCCAAGCGCATGGA AGAGCTGCTCGAACGACAGGCAAACGAGATGGAGAAGCTGGCGGACCGGAAGGAACAGGAACTCGAGGCTCTCGCAAGCG ACTTTGCTCAAGAAGAAGACGAGCTCGCCCAGGTCTTCAGTGAACGCAAGCGCATGATGCTTCGTGTTTGGTCTCTGCGC CTCGAGGTTCTGAGAAACGAGCTCGAAGACAAAGACGGCCTTGCCTATGTTGCTGTTGGGTTTCCGCCTTGGAACGGCGA CTACAGCATTCGGGACGACGCAGCGCACCTAGTGGCAATCGCCGCTTCTTGTTCTTGATCGGCGAACTCTTTCACTCGCC GAACTGCAAACGGAGTCTTTCTTTGGACACCAATCCTTACAATGCTCATGAAAAAGGATCACTTGGACATAACGTACCTC GGCTGAGGACCGACGGAGTTAATCATTTCTGGGGTCTGGAGTCCTGGAGGAAGGGGCTGAATCTTATACCACGGATGAGC GCCGAGCGGCCGCCACCGCGGTGGAGCTCCAGCTTTTGTTCCCTTTAGTGAGGGTTAATTGCGCGCTTGGCGTAATCATG GTCATAGCTGTTTCCTGTGTGAAATTGTTATCCGCTCACAATTCCACACAACATACGAGCCGGAAGCATAAAGTGTAAAG CCTGGGGTGCCTAATGAGTGAGCTAACTCACATTAATTGCGTTGCGCTCACTGCCCGCTTTCCAGTCGGGAAACCTGTCG TGCCAGCTGCATTAATGAATCGGCCAACGCGCGGGGAGAGGCGGTTTGCGTATTGGGCGCTCTTCCGCTTCCTCGCTCAC TGACTCGCTGCGCTCGGTCGTTCGGCTGCGGCGAGCGG

\section{Amino acid sequence: 167 aa (incomplete)}

YNLRDGMARLHQSKINVLRDRQAKRMEELLERQANEMEKLADRKEQELEALASDFAQEEDELAQVFSERKRMMLRVWSLR LEVLRNELEDKDGLAYVAVGFP PWNGDYSIRDDAAHLVAIAASCS * RRTLSLAELQTESFFGHQSLQCS * KRITWT * RTS AEDRRS * 


\title{
7). VI_33.3 gene (DOA4-independent degradation protein)
}

\section{Coding sequence (including introns): $910 \mathrm{nt}$}

TCCTAGTTCCATCGCCAGGCTTCAGGCATACACAACAACCCATCTCGGCCGCGCCTCGTGGATACTCGACCTTTGTATTC GTGTTGCCAGTCACTTCACCGCCACGATGAATGTAGGACACTCGGCCCGCGTCGCGGACCCTCAAAGGCACAGAGTCGGC TTGTTGCTAACGTGGGCTGTATAGATCCTGGAATACATGTTCGGGAAGCGTATGACGCCAGCGGAGCGCCTGCGCAAGAA CCAACGCATGCTCGACAAGGCGATTCGCGAGCTCGACCAAATCCGAGTCAAGCTGGAGAAGCAGGAGAAGACGCTGGTTA CGCAGATTAAACAGAGTGCGCAAAAGGGACAAATGGGCGCTTGCAAGATCCAGGCCAAGGATCTCGTGCGTACGCGAAGG TGGGTTCTCTCGGTATCAAGGCCAGACAGGATTGGGCTAACATTATTCAGATATATTGAGAAGTTCTATTCGATGCGCAG CCAGCTGCAAAAGATCTCTCTCCGCCTACAGGCATGATAACCCCGCCAATCTACCGTGCGCGTGTCAGCTAACCTACGTA TCAGACCTACCGCACAAATGAGCAGATGATGCAGGCGATGAAGGGAGCTACGACTGCTCTTGGCAGCATGAACCGTTCGA TGAACTTGCCGGCACTCCAACGAATTGCCATGGAGTTTGAGCGGGAGAACGATGTCATGGAGCAGAGGCAAGAGATGATG GACGATGCGATCGATGATGCCATGGATGTGGGTGAGGAGGAGGAGGGGGAAGAGGTGGTTGAGCAAGTGTTGGAGGAGAT TGGCATTGATCTCAACTCCGCGGTACGTCAACTTGATCGAATGGAGACTCACTACGAAACTGACCAGCGTGGCAGCTCGG CGAGACCCCCACGGGCGTGCAGTCAAGCGCAGTACCGGAACAACGAGTTGCGCAAGCCATTGGCGGCGAAGGCGGCATGG GCGGAGGCGGGGCGGACGATGATCTACAGGCACGACTTGACAGTCTCAGGCGGTGAGGGCTCTCTATGCATTGGTGGAGC TAGCCAGCAGAGAGTGAACGGTAGTCATGAACTTGCGGGCGGTGTTTTGGAGTACGAGGATTGTGCCAGGTTGCATTTCA GCTGGCGTTTTGCCTGTTGTGCTTGCGCCGAACGAACTGATATTCAGTTGTCTTTTTGCCTCGCATCGTCGGGAATATTT AAGATCGCTTCCGGAATAGTGGTTGCGCAGTCTTCAGTGATACCACACCGCGTCTTGAGTCGCCGGGTTTACCGCTGGAC GGCACCCATGATGTGAACTGTGTCGGCCTTGCCTGGAACATCTTGAGGGGTGTCGCGGGGGGGAGCAGGAGACCACACAG GGCTGAGATTTTTTCACATATTTCGGCCAGGGACAGACGGCCGAGGATAACGCCTGAATTGCGCCTTGAG

\begin{abstract}
Amino acid sequence: 201 aa
MNI LEYMFGKRMT PAERLRKNQRMLDKA IRELDQIRVKLEKQEKTLVTQIKQSAQKGQMGACKIQAKDLTYRTNEQMMQA MKGATTALGSMNRSMNLPALQRIAMEFERENDVMEQRQEMMDDA IDDAMDVGEEEEGEEVVEQVLEEIGIDLNSALGETP TGVQSSAVPEQRVAQAIGGEGGMGGGGADDDLQARLDSLRR
\end{abstract}

\section{8). VI_34.2 gene (NADH:ubiquinone oxidoreductase 14kD subunit)}

\section{Coding sequence (including introns): $684 \mathrm{nt}$}

AGCAAGCTCAACCTCCATCATCGACCACTACTACAATCATATCACGACCTCCCCTCCACGCCAATTGCCTGCTCCGACTG CGCTGCTTCGAACGCGGCGACCTTGGCCCCCGAAGACCGACCGAATCCCGAGAGACGCGCGACAGCGACATACCGCCATC ATGCCCCAGGACATGCCGCCCGTGGGCGGCTATAATGCCGTTCAATACAAGGTGGGTTTACCGATCGATCCCGTCGTGGC CGACAGCTAGGCCAATTGGGCTCAATACAGTGCATCAATGCCTCTTCAGCACCGATAAACTTCAACGAGACTCCGCATCA GGCCCCAGGCGCCCATACAGACTTCTCCCCGAGCAACGCCGGCTAACGCTTCTCCTAGCGTAACCTCCCCGCCCGCGGCT TCCGCCCTGGAATCCTCCTTCTCGGAATGGGCGCCGTCATGGGCTACGGCTGGTACAAACTGATCAAGGGCATCCGCGAG GCCAAGTACGTCCTCGTTCCCCCCTCCCGCTTTGTCTCGTCTTGCTTCGGCTGCGTAGCTTGGAGCCGTTGACCAATCCT CCCTCGAACAAAGAACTGACCACCATGCCAGCGAGCTTGCCCGTGAGAAGATGTGGGCGCGCATCCACCTCATTCCTCTC CTCCAGGCCGAGGAGGACCGCGACCAGATCCGCCGATGGTACGCCGATCAGGCGCGCGAGAAGGAGCTGCTGGGCGAGAA CACGCGTGTGTACCACACGGACAGGTAGGACTGACTGGACGGCTTGCTGTAGAGGGCCGTTTGCTAACGAGGTGCAGGGT TTGTCCGACCCACGTTCGCTGTTGCGCCGGAGAAGACGAAATAGGCGGGAGGCCGGGTCGGGACAGGAGACTTGGGGGAA CAGGAAAGAAGAAGAGCCATACCGGGCACGAAGCCGTTGAAGAAG

\section{Amino acid sequence: 118 aa}

MPQDMPPVGGYNAVQYKRNLPARGFRPGILLLGMGAVMGYGWYKLIKGIREANELAREKMWARIHLI PLLQAEEDRDQIR RWYADQAREKELLGENTRVYHTDRFVRPTFAVAPEKTK

\section{9). VI_NEP1 (Necrosis- and êthylene-inducing protein)}

\section{Coding sequence (including introns): $763 \mathrm{nt}$}

GGATCCTCACAAGCTCGGGGCACAGGATTCAGACAGTGCTTGAAGCTGAGCTGTTCTCAGTTCTCCCTTAGGACACCACA ACAAATGACCGAACGAACCGGCCGGATGATCAGACCAAAACATGGTGCCGTGTTCATCAGCCCTGAATCGCAACCCCACA AGCGCACCAAGTAGATCCTGGTACAGATGCGCGCCTACCGTTGAGTCCCGGACATGTTCTGCTCCCATTGTGGCCATAGA TCCGCACGCCCTATCACCACCGCCTTTCTATCAGCCCCCGCATCACCAGAATGTGCGACAGCCTGGCTTTATTAGTCGTC GGACATGGCTACGCCTTCTTTCTCCGGTATAGCCTCGGTCCGTGCCGACTCAAATCAGTCTCAGGGGTTCGAATCGGGCT TACTCTAATGTGTTGGGGGTCCGGCCTTGCTATCCATGACTCGACATCAACCTCTATGGGCGTGCCACCAGTGCACCCGA ATGGCCCGGGTGGAACAGATGAACCAAAGTATGATAGATGAACCGGCTCCTCTGCCCTTGCCCACCTGCCCAGTCACGAC TCACTCAGCACCGTCCACGGTCACCGTCCTTGCGATCTCGCATGAATGAGTGCCGAGACATGGGTCACTGCCTACACAGC ACTTCGCCAAGGCGAGCTCACTGGGGTGGAGATTTATCGAATTATCGAATATCGTATCTGTCGGCCAAGTTCGGGCTGTC CGGGCCAAGACGACGATTTGATCTTTTGGGATTTGCGCTTAGACGATTGACTGGGCTACTCCAGGGTCTTTGAGCCACGC 
CСTTTACTGAAAGAGGCAAGGCATTCTCTTCTAGCAGGTGACAGCTGCTATTCAACAGAGCGCTATTCATGTCCACCTCT TGGGGGCGGAGCCGCTCCGCAGCAATGTATTTGCCTGGGTAGAGGATACAGCTAAGCCTACCTTAGCGGCTAGCCTCACG ATGTTCGTGTTCGCATCGTTAACGATGTCCGTCGACCGAGCTCGACATGAGTCGTATGCCTCAAGGACCCCTGGCATCTT GACACTGCAGCAAACATGACAACCACGACAGAATGAAGTAGGAAGCCCGGTGTGTCAACCAGCCGGTCTGTCTGCAGAAG GGTGGTCGATGGAAGGCCAAGGCAACTACATCTCCGGACATGATCAAAGTATATAAGAAGGACGATCACCGCTCCTTGAC TTATTTTGCTTCTCTTCCTCTCATCACCTAGCCTCATTCTCTCTCTCGTCATCTAAACAGCCATCTGCACCTGCTACGAT GCTTCCCTCCACAATCTTCTCGGTCTTTGCCCTCGTCGGCAGCGCCTTGGCTCAGCATCCCCCCAAGGTTAACCACGACA GTATCAACCCCGTCCGCGATACTCTGGGGCCCAACGGCGACATGATCAGGAAGTTCCAGCCTCTGCTTCACATTGCCCAC GGTTGCCAGCCTTACTCCGCTGTCAACACCCGCGGTGAGGTCAAGTAAGACACGCAGCACTCCCTTCAGCTTACACAAAG СTCCACGCTAACACATATTCTGCAGCGCCGGTCTCCAAGACAGCGGTACCACCGCAGGCGGCTGCAAGGAAACCAGCAAG GGCCAGACCTACGCCCGCTCCATGACCCTGAACGGCCAGTTCGGCATCATGTACGCCTGGTACTGGCCCAAGGACCAGCC CGCCGACGGCAACCTCGCCAGCGGCCACCGCCACGACTGGGAGAACGTCGTCATCTGGTTCAACTCGAACAACGCAAACC AGGCCGGCATCCTGCGCGGCGCCGCCTCGGGCCACGGCGACTACAAGAAGGTCAACAACCCCCAGCGCAACAACAACAAC CTCCACGTCGAGTACTTCACCAGCCTCGGCAAGAACCACGAGTTGCAGTTCAAGACGTCGCCCGGCCGCACCTACTGGAT CTGGGACTGGGACAGGATGGACAGCACCGTCCAGGGCGCCCTCAACCGCGCCGACTTTGGCAGCGCCAACTGCCCCTTCA ACAACAACAACTTTGAGAGGAACATGCGCGCCGCGTTTTAAAGGCTCGACGCGCGGCTCGCCAGTCCTGGATTCCATCTG GGCACGCATCTTGGCTCTTTCTCCTCCCGCCTTGGCTTGGCTTCTTGAGGCCAGTCGAGTGCTAGCATAGGTCCTGTACA TAGCTTGTTCTGAATTACATACAACTCTGCCTGTCGAATTTGGTCTTGCATTCTGTGATCGAGTGTGTAAGCTTTTACGC AGGTCGATAAATGACCAGTGCGTTGATTAGGTTCTTTCGTTGCTCTATTCATGGGTAGGTTCCCAGGAGCCCTGTCGTGA TCCCGAAAACTCAAATAAACAGCATCATGAACTTTATAAGGCCACCATGCACTGCAGTTGATGTTCCTTTGGAGTGGAAC ACCCCACTACCTTACCTCAAGCAGTGCAGCGGCAAGCAAGCTTGAGTCTCAACTTAATGTCAAGGAAACTGCTGCGGCAT TGAGAAATCAGAGCCAATTCCAATGATTGGGGCACTCCGGAACCCAGCACATATGTCAAAAGACCAGACACTCACAACCA AACACTGCAGATACAGCTCAATTCCAATATGACGATGATCGCATCGACTTGGTATGACATCGGACTGTGATCTCGTTCGA TAGACGAAATCCAAGTTTGCTGACATACACGTTGGGTGCGACAGCTTGGAGAAATGCTCGGCAACTGGTCCTGTGCCAGG ACGTACACAATGACGGGACCCGGCGGGGATGGGGCCGGTGGAGAGCTAGATCGACAGGATGACTTCCGCTGAGGAGACTT CGCGCTCCGGGGAACCGATGCCGCCAGTAATAGTCGAGGTGATCATTAGGGGTGCTAAGCAGTAAAGCAGGAAAGTTTGA ACTGTCCTACAAGTTCTTTGATGGTTTTATGTTTCGGTAAGCAGTGAGGACATCTCCTTATCATCGTAACGCCGCCCATT CTTCGTGCCTCGTCCATACGCTGCCCTGAGGATAATTCACCCAAGTATTACACCAAATAGAGAAATCGAGACAGAATGCT CTACGAAAAAGACGGGCGTCTGGTATGCTCCTATGACGGAGAAAAGCTCTGGATCGAGCCCTGGTCTGCCAATGCTTTCC GCGTCCGAGCCACCAAGCTCTCCACGATGCCGACAGAGAACTGGGCCCTGCAACAGCCTCTTCAGACCGGATCC

\section{Amino acid sequence: 118 aa}

MLPSTIFSVFALVGSALAQHPPKVNHDS INPVRDTLGPNGDMIRKFQPLLHIAHGCQPYSAVNTRGEVNAGLQDSGTTAG GCKETSKGQTYARSMTLNGQFGIMYAWYWPKDQPADGNLASGHRHDWENVVIWFNSNNANQAGILRGAASGHGDYKKVNN PQRNNNNLHVEYFTSLGKNHELQFKTSPGRTYWIWDWDRMDSTVQGALNRADFGSANCPFNNNNFERNMRAAF

\section{0). VI_PKS1 (Polyketide synthase) \\ Coding sequence (including introns): 1968 nt (incomplete)}

GATCCGAGGTTTTTTAACATGTCGCCGCGCGAAGCCTACCAGACCGACCCCATGCAACGCATGGCCCTGACCACGGCTTA TGAAGCCTTGGAAATGTCTGGGTATGTCCCGAATAGGACAGCCTCTACCAGGCTTGACCGGATTGGTACATTTTACGGTC AGACCTCCGATGATTGGCGAGAGATCAATGCCGCACAGGAAGTCGACACATACTTCATCACCGGGGGAGTACGCGCCTTT GGCCCTGGCAGAATCAACTACCACTTCGGTTTCAGTGGACCTAGTCTGAACATCGATACAGCCTGTTCTTCCAGTGCCGC AGCTCTGCAAATCGCATGCACCTCGCTCTGGGCCAAGGACTGTGACACGGCAGTCGTTGGCGGCTTGTCTTGCATGACCA ACCCCGATATTTTCTCAGGACTCAGCCGTGGCCAGTTCTTGTCCAAGACTGGTCCCTGTGCTACGTTTGACAATGGAGCT GATGGTTACTGCCGAGCTGATGGCTGCGCCTCCGTCATTGTGAAGCGTCTGGATGATGCCATTGCCGACAAGGACAATGT CCTGGCGGTCATCCTGGGCACGGCTACCAACCATTCTGCCGACGCCATATCGATTACCCATCCTCATGGACCTACGCAGT CGATCCTATCATCAGCCATTCTCGATGAGGCTGGCGTCGATCCTCTCGATGTTGACTACGTCGAGATGCATGGGACAGGC ACTCAGGCCGGTGATGGCACGGAAATGGTCTCTGTCACAGACGTATTCGCACCTGCCAACCGCAAGCGTCCTGCAAACAG ACCTCTGTATCTCGGCGCTGTGAAATCTAACATCGGCCACGGTGAGGCTGCTTCAGGCGTGACAGCTCTCTGCAAGGTTC TCATGATGTTGCAAAAAAACGCCATCCCTCCTCACGTCGGCATAAAAAAGGATATCAACAAGACCTTTCCTAAGGATCTT GCGGAGCGAAACGTCAACATCGCTTTCCACATGACACCTCTCAAAAGGCATGATGGGAAACCCAGGAGAATCTTCATCAA CAACTTCAGCGCCGCCGGTGGTAATACCGGTCTCCTCCTTGAGGATGGTCCCAGCCAGACGCCCACACAGGCGGACCCTC GCAGTGCTCAAGTCATTACTATCACGGCCAAGTCCAAGACGGCCATGATTAAGAATGCTGAACAATTGGTGACGTGGATG GAGAAGAATCCCGAAACCCCGCTTGCTGATGTTGCTTACACCACAACGGCCCGTCGCATGCAACACTACTGGCGCCTGAA TGTCGCCGCCTCCACCTTGTCTGAAGCCATGTCAGCCATCAAGGAGAGGCTCACTCAAAACTTTGTGCCCATCTCGACTG AGCAGCCAAAGGTGGCCTTCATCTTCACAGGCCAAGGCTCTCACTATGCTGGTCTTGGCAAGGACCTCTACGCCCACTAC GCTGTCTTCAGAGACAGCATCAATGAGTTCAATCATATCGCCGAAGTCCATGGCTTCCCGTCTTTTGTGCCATTGATTGA TGGCAGCGAACCTGACGTCTCCAAGCTATCACCCGTGGTTGTGCAGCTTGGCCTCTGCTGCTTCGAGATGGCTCTAGCCA GACTGTGGGCTGCATGGGGTATCAGGCCCGCTGTGGTTCTGGGGCACTCTCTCGGAGAATATGCTGCTCTGAACGCCGCC GGCGTACTGTCCGCAAGCGACACCATCTATCTCGTCGGCAGTCGCGCTCAGCTTCTCGTCGACAGGTGCACTGCTGGTAC 
CCATGCCATGCTTGCTGTGCAGGGCCCGGTTGGGACTGTCAACGAGGCTCTCGGATCCGAATTCGCCTCAGTCAACATCG CCTGCATCAACGGGCCTCGTGAGACCGTTCTCAGTGGTGAAACTGACCACATGATGAAGATTGCCACGCAATTGGGCGCG TCTGGATTCAAGTGCACCCAGCTGAATGTTCCCTATGCCTTCCACTCC

\section{Amino acid sequence: 656 aa (incomplete)}

DPRFFNMSPREAYQTDPMQRMALTTAYEALEMSGYVPNRTASTRLDRIGTFYGQTSDDWRE INAAQEVDTYFITGGVRAF GPGRINYHFGFSGPSLNIDTACSSSAAALQIACTSLWAKDCDTAVVGGLSCMTNPDIFSGLSRGQFLSKTGPCATFDNGA DGYCRADGCASVIVKRLDDAIADKDNVLAVILGTATNHSADAIS ITHPHGPTQS I LSSAILDEAGVDPLDVDYVEMHGTG TQAGDGTEMVSVTDVFAPANRKRPANRPLYLGAVKSNIGHGEAASGVTALCKVLMMLQKNAIPPHVGIKKDINKTFPKDL AERNVNIAFHMTPLKRHDGKPRRIFINNFSAAGGNTGLLLEDGPSQTPTQADPRSAQVITITAKSKTAMIKNAEQLVTWM EKNPETPLADVAYTTTARRMQHYWRLNVAASTLSEAMSA IKERLTQNFVPISTEQPKVAFIFTGQGSHYAGLGKDLYAHY AVFRDS INEFNHIAEVHGFPSFVPLIDGSEPDVSKLS PVVVQLGLCCFEMALARLWAAWGIRPAVVLGHSLGEYAALNAA GVLSASDTIYLVGSRAQLLVDRCTAGTHAMLAVQGPVGTVNEALGSEFASVNIACINGPRETVLSGETDHMMKIATQLGA SGFKCTQLNVPYAFHS

\section{1). VI_12.2 gene (Hypothetical protein) \\ Coding sequence: 172 nt (incomplete)}

AATTCGTCCTCGGGCCTCAAGGCAGAGTGTTGGGAGGCACTTGAGATGGACAAGTACATCAACGACTGGATGGCAACCAA CAGCGCCGCTGCCGGGTGTGACACTCTTGGTTTTGCCCAGTGCTACCTCCAGTTCAACGGCCTGACCACTCTGACCTGTG ATGACATTACGT

\section{Sequence of the UTR: $681 \mathrm{nt}$ (incomplete)}

CTTCGGTATCGGTATAGGGGGGGAGTATCTATTGTTGATGAAAGGAGGAAGAGCAATAATCAACGCGCTTCATTCAGCCT GATGACGCCCGTGAGTCGGTCATTATCCAGGGTGCTCGTATCCTCCTCGCACCCTCGAGACACCCAGCGTAGCATCCAGT GGGGGCCAAGGAGAAGGGAACCCCGAGACGATTGTGGGGTGCTGCGACTTGCAGGGTATCACCAAGAAGCCCGCTGCTGG GAGCCGCACGGGGCTGCCGGCGCATGACGTGCCAAGCACTTTATCGCCCAAGCCATCGTTTCAGCGTTGAGCAGATCGGG AGCTGTCGTCTTCCATCGTGCAGCTATCATCTCAACTTTGGAATGGTTCGTGGCTCTCAGTGACATTCGTACATACCAAT GCTCTGTCTGGGCTGAACGAAATCTTGTCGCTCGACCATATGTTAAGCGGGTTGAGGACCTAGCCTACCAGCTACTAACT ACGTCTTGGTGCTGGTGGCCTTCAACTCAGTCAAATTACCACATTAGAGTGAGCTTGAGCCAAGCGACAGGTTTAGTTGT CCTTGCTGTCAGGTAGGGCTGTGCAACCATGCTGTGAGCCATAGGGACATGAGTCGCCCAAATGAAGCCAAGGGGCCATG AATCGCCAAAAGCCTGCCGTGCTGCCCGCTCAATACCCCAT 


\section{Presentations at national and international conferences}

Xu H.Q., Löfke C., Weiberg A., Karlovsky P. 2007. Identification and Characterization of a gene coding for a putative necrotic peptide VI-NEP of Verticillium longisporum. 8. VAAM Symposium „Molecular Biology of Fungi“ Hamburg, Germany, September 23-26 2007.

Xu H. Q., Weiberg A. \& Karlovsky P. (2009) Characterisation of potential pathogenicity related gene VI_6.2 of Verticillium longisporum. $10^{\text {th }}$ International Verticillium Symposium Corfu Island, Greece. November 16-20 2009.

Xu H. Q., Beinhoff M., Weiberg A. \& Karlovsky P. (2009). Identification and characterisation Verticillium longisporum gene encoding a transcription factor similar to repressor of polysaccharide hydrolases Acel of Trichoderma reesei. $10^{\text {th }}$ International Verticillium Symposium Corfu Island, Greece. November 16-20 2009.

\section{Publication of this Work}

Weiberg A., Xu H.Q., Riediger N., von Tiedemann A. \& Karlovsky P. (2008) Adaptation of Verticillium longisporum to xylem sap enviroment as revealed by cDNA-AFLP analysis. Dissertation online. 


\section{Eidesstattliche Erklärung}

Hiermit erkläre ich eidesstattlich, dass diese Dissertation selbständig und ohne unerlaubte Hilfe angefertigt wurde.

Göttingen, im Dezember 2010 


\section{Danksagung}

An dieser Stelle möchte ich mich ganz besonders bei Herrn Prof. Dr. Petr Karlovsky für die Bereitstellung des Themas, die Diskussionen und Hilfsbereitschaft sowie für die gewählte Freiheit und die Unterstützung bei der Durchführung dieser Arbeit und schließlich für die Durchsicht der Manuskripte bedanken.

Bei Herrn Prof. Dr. Andreas von Tiedemann bedanke ich mich für die bereitwillige Übernahme des Korreferats.

Bei Prof. Dr. G. A. Wolf bedanke ich mich für die Bereitstellung des Substrates für die Cellulase Aktivität Test.

Bei Ruth Pilot bedanke ich mich für die Durchsicht der Dissertationsschrift.

Bei Arne Weiberg, Malte Beinhoff, Mona Querbusch, Nadine Riediger und Haidy Yin bedanke ich mich für die Mitarbeit am Verticillium-Projekt.

Allen anderen Doktoranden, Master-Studenten und anderen Mitarbeitern der Arbeitsgruppe Molekulare Pflanzenpathologie danke ich für die herzliche und freundliche Atmosphäre und die große Hilfsbereitschaft während meiner gesamten Promotionszeit.

Heike Rollwage, Ruth Pilot, Patricia Bartoschek, Monika Bossmann, Petra Romanczuk and Evelin Vorbeck, danke ich für die Unterstützung meiner praktischen Arbeiten im Labor.

Dem Gewächshaus-Team Eugen Hodyl und Frank Gremmes danke ich für die stete Hilfsbereitschaft bei mechanischen Problemen und der Pflanzenflege.

Bei Frau Evelin Kistner und Frau Matina Bode bedanke ich mich ganz herzlich für die Hilfe und Unterstützung bei allen administrativen Problemen.

Der DFG danke ich für die finanzielle Unterstützung und der DFG Forschergruppe FOR546 für die gute Zusammenarbeit und rege Diskussionen.

Am Ende gilt mein Dank meiner Familie und meinen Freunden. 


\section{Curriculum Vitae}

\section{Personal data}

Name:

Place of birth:

Family status:

Place of residence:

e-mail:

Secondary education

09/1970 until 07/1975

08/1975 until 06/1980

Graduation:

Tertiary education

1980-1984

1984

10/1997-04/2000

$04 / 2000$

05/2000-/2004

03/2007-02/2011
Haiquan Xu

Jiangsu, China

married

Iltisweg 11, 37081 Göttingen

xhaiqua@yahoo.de

primary school, Jiangsu, P.R.China

grammar school Jiangsu, P.R.China

high school diploma

Bachlor student at Nanjing Agricultural University

Bachlor in Phytomedicine

Master student at the Institut Plant Pathology, Georgy-August University Göttingen

Master in Phytomedicine

PhD student at the Institut Microbiology, Georgy-August University Göttingen

PhD student at the Department of Crop Science, Molecular Plant Pathology and Mycotoxin Research Unit, Georgy-August University Göttingen 